\title{
Moving teams forward : effects of feedback and team reflexivity on team performance
}

Citation for published version (APA):

Gabelica, C. R. (2014). Moving teams forward : effects of feedback and team reflexivity on team performance. [Doctoral Thesis, Maastricht University]. Datawyse / Universitaire Pers Maastricht. https://doi.org/10.26481/dis.20141204cg

Document status and date:

Published: 01/01/2014

DOI:

$10.26481 /$ dis.20141204cg

Document Version:

Publisher's PDF, also known as Version of record

\section{Please check the document version of this publication:}

- A submitted manuscript is the version of the article upon submission and before peer-review. There can be important differences between the submitted version and the official published version of record.

People interested in the research are advised to contact the author for the final version of the publication, or visit the DOI to the publisher's website.

- The final author version and the galley proof are versions of the publication after peer review.

- The final published version features the final layout of the paper including the volume, issue and page numbers.

Link to publication

\footnotetext{
General rights rights.

- You may freely distribute the URL identifying the publication in the public portal. please follow below link for the End User Agreement:

www.umlib.nl/taverne-license

Take down policy

If you believe that this document breaches copyright please contact us at:

repository@maastrichtuniversity.nl

providing details and we will investigate your claim.
}

Copyright and moral rights for the publications made accessible in the public portal are retained by the authors and/or other copyright owners and it is a condition of accessing publications that users recognise and abide by the legal requirements associated with these

- Users may download and print one copy of any publication from the public portal for the purpose of private study or research.

- You may not further distribute the material or use it for any profit-making activity or commercial gain

If the publication is distributed under the terms of Article $25 \mathrm{fa}$ of the Dutch Copyright Act, indicated by the "Taverne" license above, 


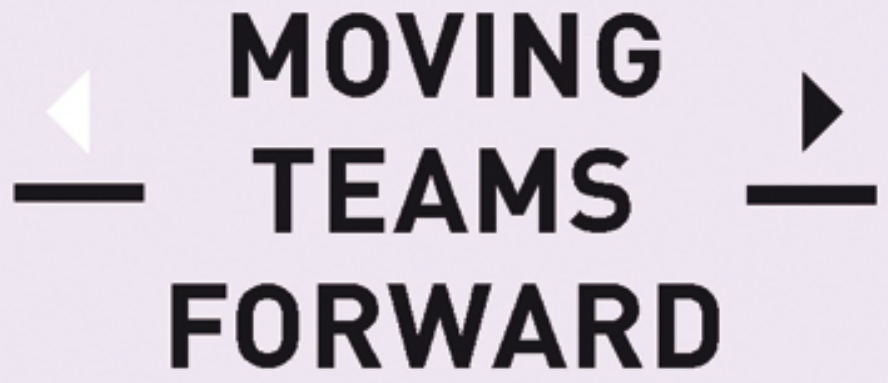

EFFECTS OF FEEDBACK AND TEAM REFLEXIVITY ON TEAM PERFORMANCE

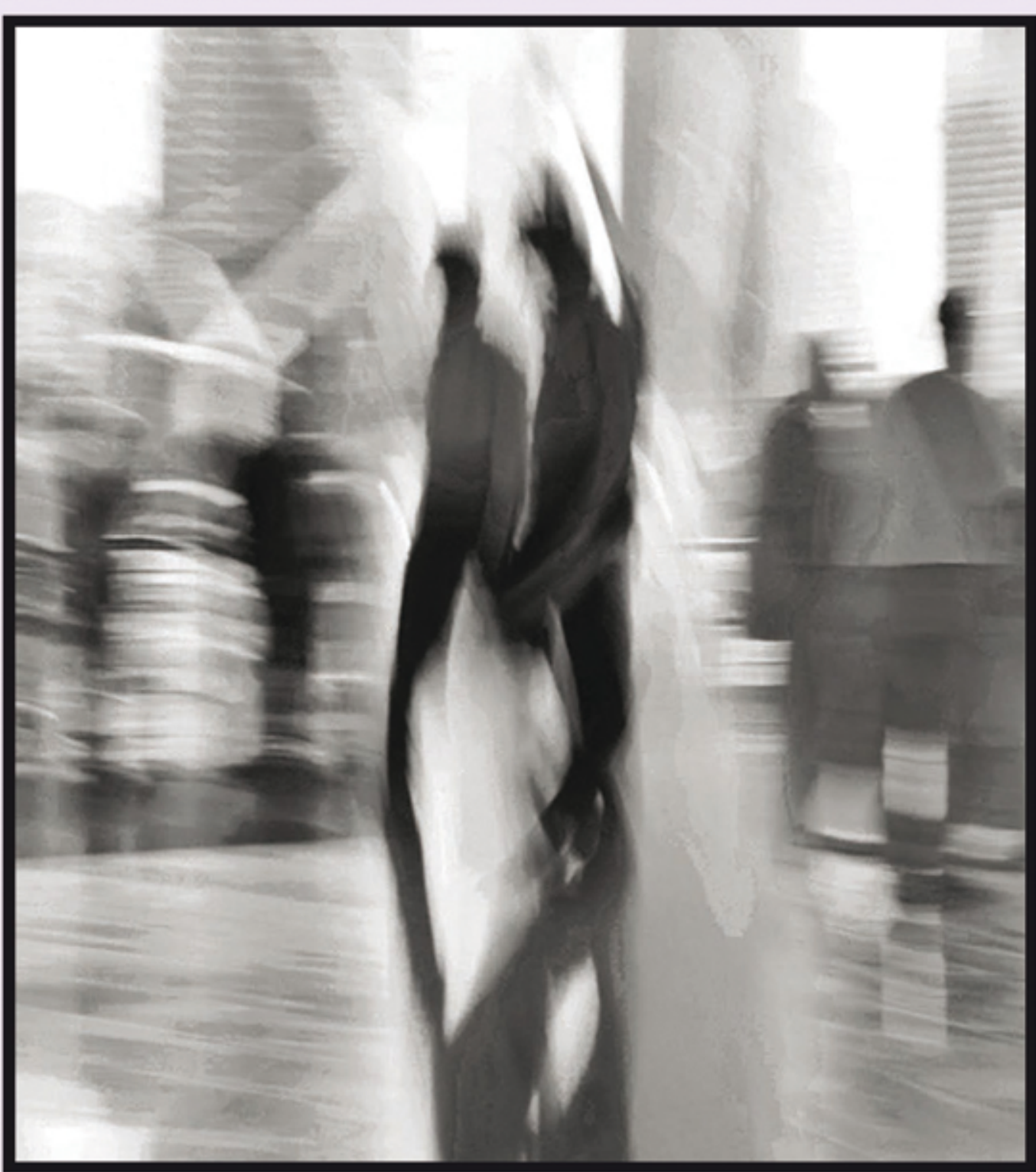




\section{Maastricht University}

In the context of the research school

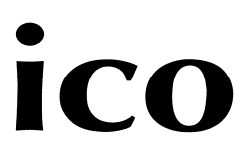

Cover design: Marcos Schmitz

Print: Datawyse

ISBN 9789461593818

Copyright (c) 2014 Catherine Gabelica, Maastricht, The Netherlands

All rights reserved. No part of this publication may be reproduced, stored in a retrieval system, or transmitted, in any form, or by any means, electronic, mechanical, photocopying, recording or otherwise, without the prior permission in writing from the author. 


\section{MOVING TEAMS FORWARD}

Effects of feedback and team reflexivity on team performance

\section{DISSERTATION}

to obtain the degree of Doctor at Maastricht University,

on the authority of the Rector Magnificus, Prof. dr. L.L.G. Soete

in accordance with the decision of the Board of Deans,

to be defended in public

on Thursday 4 December 2014, at 12.00 hours

by

Catherine Gabelica

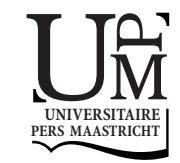




\section{Supervisors}

Prof. dr. W. H. Gijselaers

Prof. dr. M. S. R. Segers

Co-supervisor

Dr. P. Van den Bossche, Maastricht University / University of Antwerp, Belgium

\section{Assessment Committee}

Prof. dr. J. G. A. M. Lemmink (chair)

Prof. dr. A. C. Edmondson, Harvard Business School, United States

Prof. dr. M. Euwema, KU Leuven, Belgium

Dr. H. G. Guenter

Prof. dr. M. G. Heijltjes 


\section{Acknowledgements}

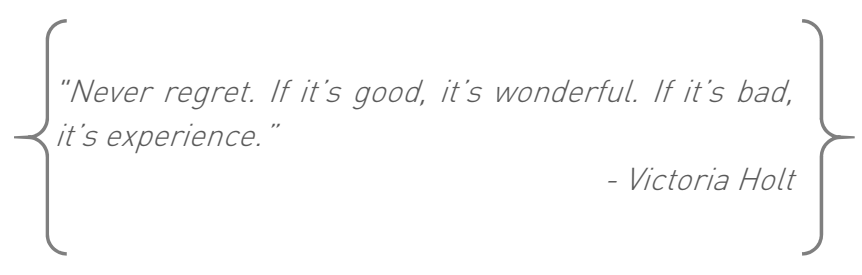

Happiness can be found, even in the darkest of times, if one only remembers to turn on the light (Steve Kloves). It is a matter of mindset. It can be achieved by selectively choosing thoughts that bring enjoyment, passion, energy, and authentic meaning. I have learned to that to be able to truly enjoy new experiences, one must open his eyes and look forward to the excitement of possibilities. What if life was more about getting out of your comfort zone and creating opportunities? Something so stimulating that it carries you along with it like a low tide. Routines are comfortable. They bring peacefulness. You just need to install yourself in there and the sound of it will lull you. Yet behind the challenge that we timidly try to take up with all the uncertainties that we carry along the way, there is something else. Openness to other ideas, perspectives, and cultures. Boldness feels great. The euphoria of having accomplished something a bit crazy, uncomfortable, but stimulating.

But learning hurts, my supervisor said. Well, literally. I am probably a survivor, but this experience has also been an eye opener on my fallibility, my capacity to move forward, to sit on the driver's seat and look back at difficult experiences with pragmatism and philosophy. There were so many struggles but one only truth: without struggles, no matter how painful they are, there is no deep learning. And right now is one of those moments when we can learn how to influence our future.

As my words fill this book, a phase of my life is closing and a new one is opening. I feel a mixture of hope, excitement, and fear of the unknown. I was thrilled to be off on a journey I had looked forward to. Almost six years ago, on my first day as a fresh PhD in an almost foreign country I thought "this sounds terribly complex, I think I am going to have a nervous breakdown." And I was right. I now realize how much I have changed. I have learned that research is a tough world, a top sport that takes a lot of patience, commitment, devotion, sacrifices, self-transcendence, but also a lot of humility, when receiving painful feedback, creativity when facing problems, such as data loss or nonchalant study participants, rigor and persistence (more than effort), and basically most 
of your physical and mental energy you have probably discovered on the way. But why would you do that to yourself?

Because at the end of the tunnel, the light is bright, warm, and inspiring. Because it also gives, in turn, self-rewarding and energizing moments, proudness, and a priceless magic power: being better able to understand this world and make human behaviors slightly more understandable. Probably I am secretly looking for a way to make the world a bit better. This is a great challenge, to which I can probably contribute, even to a very small extent. This is what gives me sparkles in my eyes and motivates me to get out of bed every morning. This is what should work mean for me, a practice of my deepest interests, a real-life concern about real life matters, problems for which I still need the right keys to solve, and a close relation to these fascinating social entities.

Because without others, nothing has real meaning. The same applies to this endeavor. It is time to pour my heart out to those without whom there would be no success story.

My thanks go first to my supervisors who made this adventure possible and an enjoyable collaboration. This manuscript has benefited enormously from their collegial participation to the manuscript but also to the process of improving my research skills.

Wim, thank you for recognizing my passion and giving me this wonderful opportunity. You helped me keep the bigger picture, "stretch" my mind, focus and structure my thoughts, and provided me with valuable and constructive suggestions during the planning and development of this research work. Your idea of using a flight simulation drove me crazy due to my apparent inability of flying a plane. I had fun learning from your experience and I will NEVER feel the same during a take-off and landing. My fascination for air crashes will stick with me.

Mien, you provided your perspective from your experience in learning and development of professionals and your deep knowledge of how to instigate learning. You have in several occasions helped me "polish the diamond" like you said. Your comments always proved to be both positive and reinforcing and you always courteously suggested how to sharpen my thoughts and writing.

Piet, you are an amazing daily (literally) supervisor and mentor. I definitely became a groupie of your wisdom and pragma. Your helped me in multiple ways. You provided advice and encouragement when it was most needed, wisdom, unconditional support, and a sharp critical eye. We've spent time discussing many details of this research, from conceptual thinking, practical implementations, to little daily problems, panic attacks, nervous breakdowns 
and of course during my sick leaves. In the final stage of a long journey, I owe you my inspiration and love for research.

Steve Fiore deserves special recognition. Steve, you are an exceptional mentor and friend. Thank you for sharing your extended knowledge and expertise, your network, and your love for crossing boundaries. I am particularly grateful for the fun discussions we had about so many diverse topics, the warm welcome in Orlando at the IST, the opportunity to conduct research and meet inspiring people.

I also give my thanks to my past and present colleagues who supported me, participated to (and crashed in) my pilot study and with whom I shared fun times and common struggles. I will never forget the PhD parties, the travel to Sweden, and the sushi evenings. Janine, Alexandra, Anna, Maike, Jeannette, Simon, Jan, Rinske, Katherina, Gwen, Therese, Bas, Bart, Mieke, Aida, Selma, Zane, Janina, Paul, Tamerius, Elena, and of course my unforgettable roomie Diana. Literally, much of my every day would not be possible without our supernatural secretaryaka second mum, Henny. Many thanks.

I would like to express my very great appreciation to Sven De Mayer for your time, patience and great insights into the $\mathrm{R}$ and LGM worlds.

Additionally I had the indispensable help of student-assistants, Mira, Claudia, Zane, and Caroline.

Thanks to Elena for her help with this layout.

Practical advice given by Jos van Erp has been a great help in challenging my thinking at the beginning of this thesis.

My special thanks are extended to my friends who do not always get the point of working 7 days/7 but contributed to my mental stability and with whom I spent countless fun and relaxing times.

Last but not least, where I come from, "family" means unconditional love, mutual support, and sacrifices for the ones we love. How can I possibly thank my parents and my sister? You were truly a gift to me. My abundant thanks and sincere gratitude for always being there to share, support, take care of me, and literally help me get back on my feet. Hvala vam od srca! Of course, my thoughts go to my shining nieces and their positive energy and anti-stress power.

My priceless daily companion was invaluable in supporting my efforts to make this. Your love, steady support, wisdom and endless patience made me a better and stronger person.

Finally, my thoughts go to the ones who left too early. 



\section{Table of content}

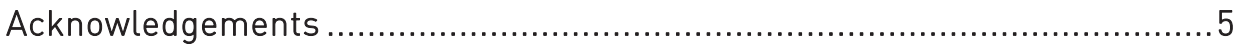

Chapter 1

Introduction.

Chapter 2

Establishing Team Knowledge Coordination from a Learning Perspective .33

Chapter 3

Feedback, a powerful lever in teams

Chapter 4

Dynamics of Team Reflexivity after Feedback

Chapter 5

The Effect of Team Feedback and Guided reflexivity on Team Performance

Change

Chapter 6

General Conclusions

Summary.

Valorization addendum

About the author 



\section{Chapter 1 \\ Introduction}


12 | CHAPTER 1 


\section{INTRODUCTION}

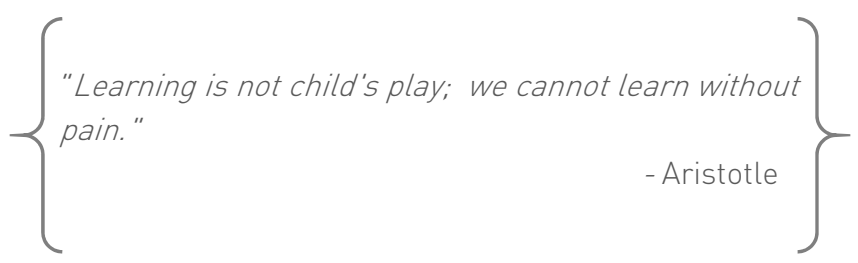

Everyone experienced unsuccessful stories with teams. Some people might pessimistically claim that, in practice, people are not able to work with others nor learn from each other, and that in some cases it is not going to work, no matter how much effort they make. However, this belief is misguided. It ignores the fact that humans have an amazing capacity to learn and are not static but dynamic. Undoubtedly, effective collaboration can be learned. We can learn to work with others and together as a team, step back from situations, scrutinize what surely needs improvement, and act on insights we gain. Considering what we do and what we have done so far as a team can act as an eye-opener that reveals that our team should step out of its comfort zone and self-centeredness, hurl itself in the unknown, face it, and challenge it. The problem is that not all teams spontaneously learn nor have a clear idea of how they perform to truly learn from past experiences and derive consequences for future actions. They need adequate support and guidance to make the most of their experience and achieve successful work. It does not only mean guiding teams through their collaborative effort but also helping them learn how to learn themselves and thus proactively look for improvement opportunities. Learning is thus not only situated within individuals and teams but also in the conditions we create to make this learning happen. This seems self-evident but in practice, many cases exist in which teams, seemingly well-trained to cope with highly complex tasks, do not exhibit the excellent coordination and communication the situation requires. We invite you to read the following team scenario and highlight, as an external observer, what could be done differently in terms of communication between team members and how we could create the conditions under which this team would be better prepared to act as a team.

"June the 1st 2009, Air France flight 447 is on route from Rio to Paris. Captain Marc Dubois, age 58, is in charge of the plane, with almost 11000 flying hours under his belt. The second pilot is 37-year-old-David Robert scoring 6500 flight hours. The third one, Pierre-Cedric Bonin, 32, is the least experienced member of the crew with less than 3000 flying hours. As they approach the Equator, they 
enter an area called the intertropical convergent zone. It is generating some severe areas of weather. But Captain Dubois seems unconcerned. Flight 447 stays on the course, while several other flights do decide to divert around the storm that night.

Captain Dubois: We are not going to let a bunch of cumulous bug us.

Co-pilot Bonin: It looks like we're entering the cloud cover.

1h51. Now the dimmed cockpit is suddenly lit up.

Captain Dubois: Ha well, that's all we needed.

Co-pilot Bonin: Ha, what is it?

Captain Dubois: Mister St Elmo.

Captain Dubois recognizes the flashes of St. Elmo's fire, an electrical phenomenon common in the tropics.

Co-pilot Bonin: I did not have the impression that there was going to be much of a storm.

Captain Dubois: It is going to be turbulent when I'll go for my rest.

David Robert Who was having a break will shortly swap places with Captain Dubois. Before Robert arrives, Captain Dubois wants to establish who is going to fly the plane while he is on his break.

Captain Dubois: Who is going to land this plane? You? Good. Robert is going to take my seat.

This means that Bonin will pilot the plane until the Captain returns. But as soon as Captain Dubois leaves the flight deck, the weather deteriorates.

Co-pilot Bonin: Thank god we are in a A330 right?

Co-pilot Robert: Clearly!

Co-pilot Bonin: Minus forty-two degrees.

Robert suggests changing course to avoid the storm clouds.

Co-pilot Robert: Don't you maybe want to steer to the left a bit?

Co-pilot Bonin: Sorry? 
Co-pilot Robert: Could you go a bit to the left?

2:10. A loud sound is heard in the cockpit. Then an alarm is triggered. The alarm warns the crew that the auto-pilot disengaged and handed control back to them.

Co-pilot Bonin: I've got the controls.

Co-pilot Robert: Alright.

Bonin takes manual control of the plane with a side stick. Robert is now co-pilot. What the crew does not realize is that the temperature has caused ice to block three vital sensors. These sensors detect the speed of the air against the aircraft. With these being frozen up, the crew loses all speed and altitude indication as the instrument display gives them false reading. In theory, when the ice melts the indicators start working again.

Bonin pulls back on the control stick, which causes the aircraft to climb. The aircraft instruments supposedly show a loss of altitude.

Co-pilot Bonin: It is not displaying the right speed.

Co-pilot Robert: We've lost the speed so...

Bonin still decides to trust the instruments and keeps on pulling back on the stick. The aircraft goes up quite rapidly and as a result, it starts slowing down.

Now another alarm brings out. The "stall" warning. Stall happens when the aircraft is going too slowly for the wings to produce sufficient lift and therefore, the aircraft starts to drop. To prevent the plane from falling. Bonin needs to act quickly. The way to recover is to get the speed back and this has to be done by going downhill. But Bonin keeps the stick back. As a result, the aircraft gains even more altitude while continuing to lose speed.

Co-pilot Robert: Watch your speed. Watch your speed.

Co-pilot Bonin: Ok, ok, ok, I'm descending.

Co-pilot Robert: Stabilize!

Co-pilot Bonin: Yeah.

Robert wants to get Captain Dubois back from his break. But there is no answer. Air France 447 is now seven miles above the sea and is still climbing. The plane starts to drop. 
Co-pilot Robert: We've put the thrust on-What is going on? Do you understand what is going on or not?

Co-pilot Bonin: Hell, I'm not controlling the aircraft! I'm not controlling the aircraft at all!

Co-pilot Robert: Shit, where are we? What's that there?

Co-pilot Bonin: / think we are flying too fast.

Captain Dubois returns to the cockpit, taking the jump seat behind the young officer.

Captain Dubois: What is going on? What are you doing?

Co-pilot Robert: What's happening? I do not know. I don't know what is going on. We're losing control of the aircraft. We've totally lost control of the aircraft. We don't understand anything. We've tried everything.

Captain Dubois: Take that, take that!

Co-pilot Bonin: The problem is that I do not have vario.

Captain Dubois: Ok.

The vario meter, the instrument that measures the vertical speed of the aircraft has stopped working.

Co-pilot Bonin: I have no more displays.

Co-pilot Robert: We have no single valid indication.

Co-pilot Bonin: I have the impression that we are flying at a crazy speed, what do you think?

He moves to put out the airbrakes. David Robert rapidly overrules the man flying the plane.

Co-pilot Robert: No no! Do not put the airbrakes on!

Co-pilot Bonin: No? OK!

Co-pilot Robert: Don't extend!

The aircraft now falls to below 30000 feet but they still have time to recover the situation. Robert now takes over control of the plane without the customary verbal acknowledgment. He does not realize that Bonin is still pulling back on his stick. The crew concentrates on getting the wings straight rather than getting the plane downwards out of the storm. 
Co-pilot Bonin: There we are. The wings are back to their level aren't they?

Captain Dubois: Level the wings, the horizon, the standby horizon.

Co-pilot Robert: The horizon.

Co-pilot Robert: We're pulling. What do you think? What do you think? What should we do?

Captain Dubois: Well, I don't know, it is going down.

Captain Dubois: Now, you are climbing.

Co-pilot Bonin: Ok, I am climbing up there? Ok, so we're going down.

Co-pilot Robert: You're climbing.

Captain Dubois: Shit it is not possible.

The stall alarm having run 58 times now cuts out. The computer has switched up. The ocean is just 20000 feet below. The rate of descent is now 10000 feet a minute. The noise is terrific. Robert thinks he is flying the plane but does not seem to realize that Bonin is still keeping the nose of the plane... up.

Co-pilot Robert: Wait, I've got the controls. I've got the controls, haven't I? Eh?

[Breakdown of communication]

Co-pilot Bonin: We're there, we are reaching level 100.

The aircraft is not flying. It is falling. With its nose pointed up.

Co-pilot Robert: Climb, climb, climb!

Co-pilot Bonin: But I've had the nose up for a while!

Captain Dubois now gets the vital information. He realizes Bonin has been pushing the nose up and stalling the aircraft.

Captain Dubois: No, no, no, no, Do NOT go up! NO, NO, NO, NO! Co-pilot Robert: Go down!

Robert knows that to get out of the storm, he has to get the plane pointing downwards.

Co-pilot Robert: Go down. Give me the controls. The controls to me, controls to me!

Co-pilot Bonin: Go ahead. You've got the commands. 
Captain Dubois: Watch out. You are pitching up there.

Co-pilot Robert: / am pitching up?

Captain Dubois: You're pitching up.

The aircraft detects the ocean below (at 200 feet).

There is a new warning sign. [PULL UP MESSAGE]

Captain Dubois: Come on. Pull up!

Co-pilot Bonin: Let's go, pull up, pull up, pull up.

Co-pilot Robert: We are going to crash. This cannot be happening.

[PULL UP MESSAGE]

Bonin: What is happening?

Captain Dubois: 10 degrees pitch attitude

The recording stops at $2 \mathrm{~h} 4 \mathrm{O}^{1} . "$

On June the 6th, five days after flight 447 disappeared, fragments of the aircraft were found. In April 2011, the black boxes were finally discovered and unraveled the exact sequence of events that led to the loss of the aircraft. The data indicated that the plane had fallen because of the combination of a technical problem-the icing up of air-speed sensors-with severe weather and most importantly, a complex human "error chain" that ended in a crash and the loss of 228 lives.

The above-described sequence of events raises many questions. How was it that the three pilots trained by a safe and well-known airline could so tragically lose control? Is this disastrous outcome mostly due to one individual, Bonin, who made the fatal and sustained mistake of keeping the nose of the plane up, or to the crew as a whole since no one has corrected the errors made by their least experienced colleague? Concerning communication between team members, it is clear that crew members were confused and did not know who was doing what in this cockpit nor did they ever seem to question it. No clear responsibilities were defined; leading to a low synergy. They failed to spot the problem, or rather too late. Crucially, communication broke down many times.

1 This discussion is an adaption from the technical report of the crash: Bureau d'enquêtes et d'analyses pour la sécurité de l'aviation civile (2012). Rapport final de l'Accident survenu le 1er juin 2009 à l'Airbus A330-203 immatriculé F-GZCP exploité par Air France vol AF 447 Rio de Janeiro Paris, retrieved from http://www.bea.aero/docspa/2009/f-cp090601/pdf/f-cp090601.pdf. 
On the one hand, Bonin pulled back on the stick without telling anything. The more he pushed, the more the aircraft fell and the more it fell, the more he pulled back on the stick in an endless vicious circle. On the other hand, Captain Robert was strangely passive and stayed behind his colleagues. When he came back after his break, he did not inquire about the emergency situation and it looks like he did not formulate two important questions: what happened and how this happened? There was no collective reflection about possible reasons for the warnings and alternatives to correct previous errors. As far as Robert is concerned, he proposed the most plausible evaluation of the situation and solution but very timidly. In the final technical report of the crash from the Bureau d'Enquêtes et d'Analyses pour la sécurité de l'aviation civile (BEA), aviation experts concluded that a lack of diagnosis of the stall situation by the crew and, as a consequence, a lack of actions to recover the situation led to the degradation of communication quality and coordination between the pilots, and ultimately to the total loss of the cognitive control of the situation.

The extreme example described above echoes a series of cases that illustrate the nature of typical human errors in aviation: poor communication and coordination, leadership issues, and misinterpretation of the task environment (Hagen, 2012). By contrast, human history is also replete with examples of successful teams that achieved far more than individuals working alone. For example, flight controllers, engineers and spacewalkers aboard the International Space Station worked around the clock to devise a creative solution -with a toothbrush- to fix a key power system and as a result, saved their space station (Garber, 2012, September 6). These examples show how in some cases teamwork allows people to attain high-quality results while in other settings a team does not seem to reach its potential performance. They remind us that human behaviors, of course, are never displayed in a vacuum. Pilots but also many individuals in working situations in all types of contexts are part of a complex system that can either augment or decrease the probability that they will make a mistake (Sharit, 2012).

As part of this system, teams composed of interdependent members with complementary knowledge and expertise have been adopted by contemporary organizations. They are expected to effectively handle complex tasks because of their capability to perform and adapt to changing circumstances and to bring multiple perspectives to a given problem (Ilgen, Hollenbeck, Johnson, \& Jundt, 2005; Kozlowski \& Illgen, 2006). This configuration of people is considered as a team when the following conditions are met. Firstly, team members depend on the others to get relevant information necessary for team success (i.e., interdependence). Thus, they interdependently make decisions, recognize 
relevant cues, plan, gain knowledge, and develop solutions. Secondly, they share a common goal and outcome. Finally, they have clear differentiated responsibilities and roles (Cannon-Bowers, Salas, \& Converse, 1993).

However, the availability of complementary expertise is not enough to deal successfully with complex tasks (Salas, Stagl, \& Burke, 2004). In addition to individuals' abilities and expertise, a key determinant of a team's performance is the quality of its process for working together (Kernaghan \& Cooke, 1986). Yet, teamwork is not some magic happening by simply being co-located. Team members also need to engage in specific key team behaviors to achieve wellcoordinated, effective work.

In the first part of this introduction, we have explored practice and set the stage for the present research on learning behaviors that allow team members to combine their resources to resolve task demands and, in doing so, be effective. The present thesis examines key team learning processes and how certain interventions can improve these processes. This research was conducted in the form of four studies, among which a review of the literature and three empirical studies. The theoretical and conceptual basis for these studies follows.

\section{THE PRESENT THESIS}

In this thesis, we take a learning perspective on collaborative work. First, we seek to answer the question of which (socio-cognitive) learning processes on a team level are powerful predictors of subsequent team coordination and performance, and second whether feedback interventions (i.e., provision of performance feedback at the team level) with guided reflexivity (i.e., prompts to guide reflection at the team levell impact performance change. This section is structured around key questions we address in each chapter.

\section{Defining the antecedents of team coordination: what are the factors predicting coordination success?}

In the examples outlined above, the management and synchronization of knowledge and expertise available in the teams played a crucial role in laying the basis for effective or ineffective performance of collaborative partners. This synchronization of knowledge and skills has been referred to as knowledge coordination in the team literature (Wittenbaum, Vaughan, \& Stasser, 1998). So far, a large body of research in different domains has shown that teams 
synchronizing and integrating members' knowledge effectively perform better than teams coordinating poorly le.g., Fiore \& Salas, 2004; Gibson, 2001; Marks, Sabella, Burke, \& Zaccaro, 2002; LePine, Piccolo, Jackson, Mathieu, \& Saul, 2008; Mathieu, Heffner, Goodwin, Salas, \& Cannon-Bowers, 2000; Rico, Sanchez-Manzanarez, Gil, \& Gibson, 2008). Whereas team coordination has been shown to predict team performance, there has been little discussion about factors explaining this team coordination le.g., Fiore \& Salas, 2004; Gibson, 2001). This thesis seeks to fill this gap by proposing that team coordination is a function of a dynamic process of interaction and exchange during which teams engage in team learning processes. This learning that is potentially available in teams may not be fully realized unless 1) teams share, co-construct, and constructively discuss knowledge and ideas, conceptualized as construction, coconstruction, and constructive conflict or team learning behaviors (Argote, McEvily, \& Reagans, 2003; Van den Bossche, Gijselaers, Segers, \& Kirschner, 2006), and 2) step back from their actions to achieve a better understanding of their successes, failures, and potentialities and explore and plan possible remedies (i.e., team reflexivity as defined by West, 2000). As a consequence of these learning processes, teams are expected to be better able to highlight knowledge gaps and (unique and common) knowledge needed for task completion. Next, they should enable them to decide how and when this knowledge needs to be synchronized. In other words, we put forward that these learning processes have the potential to help understand how teams coordinate to improve their performance. In the next section, we describe these learning processes (i.e., construction-co-construction, constructive conflict, and team reflexivityl through which coordination is enabled.

Team learning behaviors (i.e., construction, co-construction, and constructive conflict)

Advanced coordination, and consequently improved team performance, are expected when team members share information and ideas (i.e., construction), add meaning to previous assertions and build new understanding (i.e., coconstruction), and constructively discuss disagreements by setting up their arguments and elaborating (i.e., constructive conflict) (Baker, 1994; Espinosa, Slaugther, Kraut, \& Herbsleb, 2007; Hinsz \& Tindale, 1997; Kraut \& Streeter, 1995; Rentsch, Delise, Salas, \& Letsky, 2010). These team learning behaviors fundamentally address how learning takes place within teams as they depict how teams continuously add new skills and knowledge to their assets (Decuyper, Dochy, \& Van den Bossche, 2010; Edmondson, 1999; London, Polzer, 
\& Omoregie, 2005; London \& Sessa, 2006). Van den Bosche and colleagues (2006) showed that these behaviors predicted the formation of mutually shared cognition and only indirectly team performance. Similarly, we hypothesize that construction, co-construction, and constructive conflict are indirectly related to team performance through knowledge coordination. By explicitly sharing, building upon, and questioning information and knowledge, team members are expected to gain a better understanding of how their knowledge complements each other to handle the task and when they can rely on each other for certain aspects of the task. As a consequence, they can more optimally use their knowledge and in turn, achieve better team outcomes (Espinosa et al., 2007).

\section{Team reflexivity}

Next to the establishment of a dialogical space in which team members share, co-construct, and constructively discuss knowledge, opinions, and ideas, teams need to engage in higher-order or metacognitive activities allowing for proactive analysis of what is happening and what it may mean now and in the future (Decuyper et al., 2010). As such, to learn in the "right" direction, teams also need to collectively evaluate and reflect upon their goals, performance, and strategies or working methods and develop improvement strategies based on these evaluations (Schippers, Den Hartog, Koopman, \& Wienk, 2003). The concept of "team reflexivity" is used to capture this reflection occurring at the team level (West, 2000). Reflective teams who evaluate prior experiences and derive lessons for future performance are likely to make better use of team members' expertise because they are more aware of the consequences of their interdependent actions, of what they still do not know, and what needs to be done differently to achieve a better match of competencies (Hoegl \& Parboteeah, 2006). Conversely, non-reflective teams run the risk of being stuck with inappropriate representations of the task and the team, prematurely leaping into conclusions about the nature of their past achievements or failures, and failing to correct their ineffective approaches (Cannon \& Edmondson, 2005; Wills \& Clerkin, 2009).

\section{Emergent states: task cohesion and group potency}

Finally, we expect that team learning processes can only be effective if team members share favorable beliefs about their capacity to complete the task (i.e., group potency) and about their mutual commitment to the team task (i.e., task cohesion). These beliefs are called "emergent states" (Davison \& Ekelund, 2004). If team members believe that their team is united in trying to reach its goals and 
able to complete the task effectively, they will be more likely to engage in constructive discussion and analysis through which learning occurs. Conversely, if team members share the assumption that there is slight chance to be successful or that the level of commitment is low, they will be less likely to open a dialogical space of knowledge sharing and reflection (Columbia Accident Investigation Board, 2003). While these two shared beliefs have consistently shown positive effects on team effectiveness (Beal, Cohen, Burke, \& Mc Lendon, 2003; Chang \& Bordia, 2001; Gully, Incalacaterra, Joshi, \& Beaubien, 2002; LePine et al., 2008), they have been only recently advanced as important drivers of shared learning (Edmondson, Dillon, \& Roloff, 2007). Hence, these two shared beliefs are considered as preconditions that set the stage for team learning and in turn team coordination.

In sum, we expect that cohesive teams that also believe they are highperforming are more likely to engage in learning activities (i.e., construction, coconstruction, constructive conflict, and team reflexivityl and in turn, exhibit better coordination, which is related to higher performance. Figure 1 depicts the framework that guided our first study (chapter 2) on how teams improve their coordination and performance. This model is validated in a study over four waves of data collection to allow for time consideration. In this experimental study, thirty-three teams completed a complex, fast-paced, and high-workload situation (i.e., four landing missions in a flight simulation) in which teams had to demonstrate continuous learning to achieve their team goal.

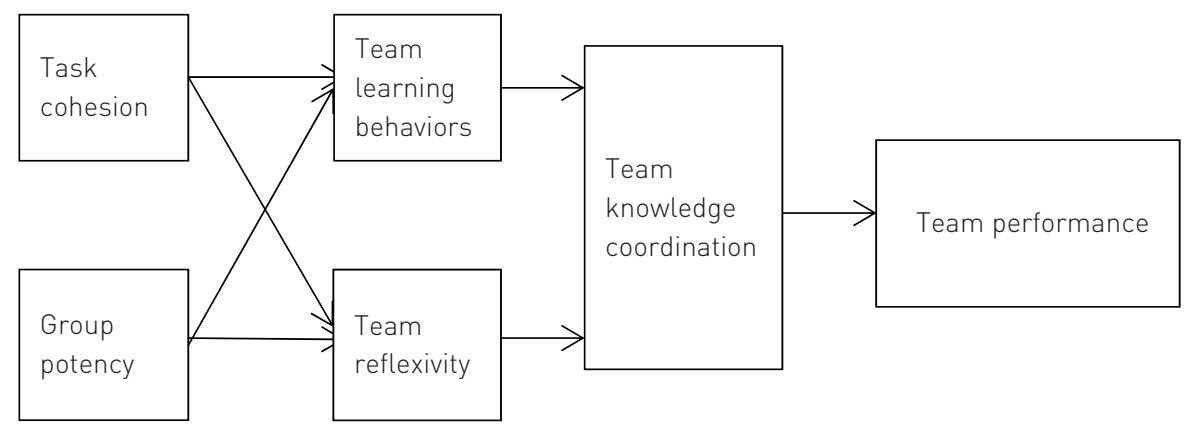

Figure 1. Model depicting the antecedents of team knowledge coordination and performance 


\section{Defining levers of team learning: how do we support teams in becoming effective units?}

Some teams will naturally combine these team learning processes and thus increase their success and reduce the risk of making a mistake because of their learning efforts and newly acquired collective power. Yet, other teams might be less likely to learn without adequate support (Dickinson \& Mclntyre, 1997; Rummel \& Spada 2005). Research on teams in practice has shown that they do not always invest time and effort to learn (Daudelin, 1996; Dickinson \& McIntyre, 1997; Rummel \& Spada 2005; Weingart; 1992). The second question of this dissertation addresses this concern by investigating how to leverage team learning so that teams, once formed, can quickly be "operational" and reduce their probability of making mistakes (Kozlowski \& Illgen, 2006).

\section{Feedback in teams}

Important to the development of team learning is feedback that teams receive from external agents. Feedback in teams has been conceptualized as the delivery of information on actions, events, or processes (London \& Sessa, 2006, p. 304). In general, feedback can serve different functions such as guiding team activity, motivating team members to strive for their goals, highlighting effective or inappropriate behaviors and detecting errors, and stimulating problem identification and solving (London, 2003). Teams are expected to use that feedback to determine what they should change or iterate in the future (London \& Sessa, 2006). In other words, it has been argued that feedback is necessary for teams to learn. At the individual level, there is extensive research on the effect of feedback given to individuals in non-group settings on their learning and achievement le.g., Alvero, Bucklin, \& Austin, 2001; Ilgen, Fisher, \& Taylor, 1979; Kluger \& DeNisi, 1996; Neubert, 1998), while feedback has been relatively ignored at the team level (London \& Sessa, 2006). For example, feedback directed at individuals could be "you have a great ability to quickly change directions on a project when presented with new information", while feedback describing and given to a whole medical team could be: "you saved a patient today thanks to your quick synchronization of actions during the surgery."

When we first explored feedback literature in teams, we observed that this literature was highly fragmented and in need for integration from different disciplines. Further, what was missing was a systematic investigation of factors that influence what effects feedback would have on teams (Gabelica, Van den Bossche, Segers, \& Gijselaers, 2012) since the answer to the question "is feedback truly beneficial" rather appears to be "under certain circumstances". 
Stated differently, there are facilitating conditions that increase the impact of feedback on team processes and performance.

Chapter 3 presents a review of the literature on feedback advanced as a potent lever of team performance. The review integrates findings of literature on feedback given in team settings and presents a framework providing a more comprehensive understanding of the conditions under which feedback does lead to changes in team processes and performance. Among these conditions, the active processing of the feedback by feedback receivers (i.e., the teams) has a critical role to play.

The results of this literature review guide our reasoning and methodological choices in the following empirical studies focusing on this feedback processing, more specifically 1) how feedback processing naturally occurs in teams and 2) how it can be prompted to facilitate learning.

\section{Processing feedback in teams: the concept of team reflexivity}

As supported by London and Sessa (2006) without feedback, teams might be able to change but not to learn. This brings us to the core claim of the present dissertation: team reflexivity is conceived as a factor augmenting feedback effectiveness. More specifically, it is not enough for teams to know whether they had made particular mistakes or in contrary had shown some desirable behaviors and met criteria for good performance. Unless team members take an active part in the feedback process by proactively analyzing their performance and functioning and identifying and operationalizing working strategies, it is difficult to maintain or improve their performance. Stated in different words, teams need to invest time and effort into actively building content-oriented reactions to feedback if we expect visible changes in the way they perform. They need to reflect on the delivered feedback.

Based on the perceived gaps in the research foundation on team feedback and team reflexivity, this dissertation aims at building upon and extending this research strand by 1 ) defining actual behaviors that typify team reflexivity upon feedback and exploring when in the team interaction they are related to team performance (chapter 4) and by 2) investigating the effect of an intervention explicitly stimulating teams to reflect upon feedback on their performance growth (chapter 5).

\section{Reflective behaviors}

In the present thesis, we identify and operationalize feedback processing behaviors as three reflective behaviors, namely evaluating performance and 
strategies, looking for alternatives, and making decisions on how to approach the task differently. Based on the argumentation presented above, we expect that within a context in which teams are provided with detailed and systematic feedback, some teams will actively use these inputs as learning opportunities to proactively analyze and explore possible remedies and reinforce expected behaviors and strategies. A continuous coding of behaviors in the team communication manifesting shared reflection provides a more comprehensive understanding of how and when actual behaviors that make up team reflexivity relate to performance with a dynamic perspective. In this way, we can crucially examine the effect of time and timing of reflective behaviors on future performance, as advocated by many researchers le.g., Ancona, Goodman, Lawrence, \& Tushman, 2001; Ballard, Tschan, \& Waller, 2008; Gersick, 1994; Okhuysen \& Waller, 2002; Waller, 1999). We also explore the impact of prior performance on subsequent reflexivity, questioning the assumed bi-directional relationship between reflection and performance of the research strand on team reflexivity.

Chapter 4 zooms into those behaviors in which teams naturally engage during action (i.e., time spent on completing the task) and transition phases (i.e., time out after action) of the same flight simulation task presented in chapter 2. Teams complete four landing missions and receive specific team-level feedback describing their previous performance during each transition phase before starting a new mission. A written feedback form is given during a ten-minute break from action with no instructions on how to proceed with this feedback.

\section{Guided reflexivity}

Based on the results of the experiment exploring whether teams spontaneously use feedback time for the reflection necessary for engaging in change, we designed an intervention prompting team reflexivity upon feedback. "Guided reflexivity" has been introduced as a formal intervention in which team members are asked to 1) define why and how they succeeded or failed in completing their task, 2) identify alternative ways of approaching the task, and 3) develop plans about next action (Gurtner, Tschan, Semmer, \& Nagele, 2007; Van Ginkel, Tindale, \& Knippenberg, 2009). Encouraging team members to process feedback, and more specifically to engage into newly defined reflective behaviors, was hypothesized to positively impact performance change across several performance episodes. For that purpose, a comparative study (Fig.3) was conducted to contrast conditions implementing feedback with or without an induced reflection component. 
Chapter 5 presents the last study of the dissertation which tests empirically our initial theoretical proposition that feedback needs to be processed in order to achieve performance changes. In this comparative study, two interventions are compared to a control group. During transition phases of the same scenario presented in chapter 2 and 4, teams are either provided with feedback describing their team performance (experimental feedback condition), either with feedback followed by guided reflexivity lexperimental guided reflectivity condition). Their performance trajectories are compared to a condition providing neither explicit feedback nor reflective instructions. We expect that (1) teams receiving performance feedback and guided reflexivity will perform better at each of the tasks following the interventions than teams (a) only receiving feedback without guided reflexivity or (b) receiving neither feedback nor guided reflexivity, (2) teams receiving both interventions will experience a faster learning rate than the other teams (3) teams receiving performance feedback will perform better than teams receiving no feedback.

Table 1

The Experimental Design of the Final Study

\begin{tabular}{lccc}
\hline & $\begin{array}{c}\text { Control } \\
\text { condition }\end{array}$ & $\begin{array}{c}\text { Experimental feedback } \\
\text { condition }\end{array}$ & $\begin{array}{c}\text { Experimental guided } \\
\text { reflexivity condition }\end{array}$ \\
\hline $\begin{array}{l}\text { Feedback form describing team- } \\
\text { level performance }\end{array}$ & $\mathrm{X}$ & $\mathrm{X}$ \\
Guided reflexivity (written prompts) & & $\mathrm{X}$ \\
\hline
\end{tabular}

Finally, in chapter 6 the major findings from the different studies are summarized and discussed. Further, we derive implications for practice and challenges for future research.

\section{Note}

This dissertation is not a book in the traditional sense but a collection of highly related articles. Since every chapter is written to be read on its own, repetitions and overlap across chapters are inevitable. 


\section{References}

Ancona, D. G., Goodman, P. S., Lawrence, B. S., \& Tushman, M. L. (2001). Time: A new research lens. Academy of Management Review, 26, 645-663.

Anseel, F., Lievens, F., \& Schollaert, E. (2009). Reflection as a strategy to enhance task performance after feedback. Organizational Behavior and Human Decision Processes, 110, 23-35.

Alvero, A., Bucklin, B., \& Austin J. (2001). An objective review of the effectiveness and essential characteristics of performance feedback in organizational settings (1985-1998). Journal of Organizational Behavior Management, 21, 3-30.

Argote, L., McEvily, B., \& Reagans, R. (2003). Managing knowledge in organizations: An integrative framework and review of emerging themes. Management Science, 4941, 571-582.

Ballard, D. I., Tschan, F., \& Waller, M. J. (2008). All in the timing: Considering time at multiple stages of group research. Small Group Research, 39, 328-351.

Baker, M. (1994). A model for negotiation in teaching-learning dialogues. Journal of Artificial Intelligence in Education, 5(2), 199-254.

Beal, D. J., Cohen, R. R., Burke, M. J., \& McLendon, C. L. (2003). Cohesion and performance in groups: A Meta-analytic clarification of construct relations. Journal of Applied Psychology, 88(6), 989-1004.

Boud, D., Keogh, R., \& Walker, D. (1985). Promoting reflection in learning: A model. In D. Boud, R. Keogh, \& D. Walker (Eds.), Reflection: Turning experience into learning (pp. 18-40). London: Kogan Page.

Cannon-Bowers, J. A., Salas, E., \& Converse, S. A. (1993). Shared mental models in expert team decision making. In J. N. J. Castellan (Ed.), Current issues in individual and group decision making (pp. 221-246). Hillsdale, NJ: Lawerence Erlbaum.

Cannon, M. D., \& Edmondson, A. C. (2005). Failing to learn and learning to fail (intelligently): how great organizations put failure to work to innovate and improve. Long Range Planning, 38, 299319.

Chang, A., \& Bordia, P. (2001). A multidimensional approach to the group cohesion-group performance relationship. Small Group Research, 32, 379-405.

Cooke, N. J., Gorman, J. C., \& Rowe, L. J. (2009). An ecological perspective on team cognition. In E. Salas, G. F. Goodwin, \& C. S. Burke (Eds.), Team effectiveness in complex organizations: Cross-disciplinary perspectives and approaches (pp. 157-182). New York, NY: Routledge/Taylor \& Francis Group.

Cooke, N. J., Salas, E., Kiekel, P. A., \& Bell, B. (2004). Advances in measuring team cognition. In E. Salas and S. M. Fiore (Eds.), Team Cognition: Understanding the Factors that Drive Process and Performance (pp. 83-106). Washington, DC: American Psychological Association.

Columbia Accident Investigation Board. (2003). Report, 6 volumes. Washington, DC: U.S. Government Printing Office. http://caib.nasa.gov/.

Daudelin, M. W. (1996). Learning from experience through reflection. Organizational Dynamics, 24, $36-48$.

Davison, S. C., \& Ekelund, B. Z. (2004). Effective team processes for global teams. In H. W. Lane, M. L. Maznevski, M. E. Mendenhall, \& J. McNett (Eds.). The Blackwell Handbook of Global Management: A Guide to Managing Diversity (pp. 134-151). Oxford, UK: Blackwell.

Decuyper, S., Dochy, F., \& Van den Bossche, P. (2010). Grasping the dynamic complexity of team learning: An integrative model for effective team learning in organizations. Educational Research Review, 5, 111-133. 
Dickinson, T. L., \& Mclntyre, R. M. (1997). A conceptual framework for teamwork measurement. In M. Brannick, E. Salas, \& C. Prince (Eds.), Team performance assessment and measurement: Theory, methods, and applications. Mahwah, NJ: Erlbaum.

Edmondson, A. C. (1999). Psychological safety and learning behavior in work teams. Administrative Science Quarterly, 44, 350-383.

Edmondson, A. C., Dillon, J., \& Roloff, K. S. (2007). Three perspectives on team learning outcome improvement, task mastery, and group process. The Academy of Management Annals, 1, 269314.

Espinosa, J., Slaughter, S., Kraut, R., \& Herbsleb, J. (2007). Team knowledge and coordination in geographically distributed software development. Journal of Management Information Systems, 2411), 135-169.

Hagen, J. U. (2013). Confronting mistakes: Lessons from the Aviation Industry when Dealing with Error. Basingstoke, UK: Palgrave Macmillan.

Fiore, S. M., \& Salas, E. (2004). Why we need team cognition. In E. Salas \& S.M. Fiore (Eds), Team Cognition: Understanding the factors that drive process and performance (pp. 235-248). Washington, DC: American Psychological Association.

Gabelica, C., Van den Bossche, P., Segers, M., \& Gijselaers, W. (2012). Feedback, a Powerful Lever in teams: a Review. Educational Research Review, オ2), 123-144.

Gerchick, M. (2013, July 10). Asiana crash: more likely than pilot error? Cockpit miscommunication. Time business \& Money. Retrieved from http://business.time.com/.

Gersick, C. J. G. (1994). Pacing strategic change: The case of a new venture. Academy of Management Journal, 37, 9-45.

Gibson, C. B. (2001). From accumulation to accommodation: The chemistry of collective cognition in work groups. Journal of Organizational Behavior, 22,121-134.

Gully, S. M., Incalcaterra, K. A., Joshi, A., \& Beaubien, J. M. (2002). A meta-analysis of team-efficacy, potency, and performance: Interdependence and level of analysis as moderators of observed relationships. Journal of Applied Psychology, 87, 819-832.

Gurtner, A., Tschan, F., Semmer, N. K., \& Nagele, C. (2007). Getting groups to develop good strategies: Effects of reflexivity interventions on team process, team performance, and shared mental models. Organizational Behavior and Human Decision Processes, 102, 127-142.

Hall, D. T. (2002). Careers in and out of organizations. Thousand Oaks, CA: Sage.

Hattie, J., \& Timperley, H. (2007). The power of feedback. Review of Educational Research, 771), 81112.

Hinsz, V. B., Tindale, R. S., \& Vollrath, D. A. (1997). The emerging conceptualization of groups as information processes. Psychological Bulletin, 121, 43-64.

Hoegl, M., \& Parboteeah, K. P. (2006). Team Reflexivity in Innovative Projects. R\&D Management, 36(2), 113-125.

Ilgen, D. R., Hollenbeck, J. R., Johnson, M. D., \& Jundt, D. K. (2005). Teams in organizations: From input-process-output models to IMOI models. Annual Review of Psychology, 56, 517-543.

Ilgen, D. R., Fisher, C. D., \& Taylor, M. S. (1979). Consequences of individual feedback on behavior in organizations. Journal of Applied Psychology, 64, 349-371.

Kernaghan, J. A., \& Cooke, R. A. (1990). Teamwork in Planning Innovative Projects: Improving Group Performance by Rational and Interpersonal Interventions in Group Process. IEEE Transactions on Engineering Management, 372), 109-116.

Kluger, A. N., \& DeNisi, A. (1996). The effects of feedback interventions on performance: A historical review, a meta-analysis, and a preliminary feedback intervention theory. Psychological Bulletin, 119, 254-284. 
Kozlowski, S. W. J., \& Bell, B. S. (2003). Work groups and teams in organizations. In W. C. Borman, D. R. Ilgen, \& R. J. Klimoski (Eds.), Handbook of psychology: Industrial and organizational psychology (Vol. 12, pp. 333-375). New York: Wiley.

Kozlowski, S. W. J., \& Ilgen, D. R. (2006). Enhancing the effectiveness of work groups and teams. Psychological Science in the Public Interest, 7, 77-124.

Kraut, R., \& Streeter, L. (1995). Coordination in large scale software development. Communications of the ACM, 38(3), 69-81.

LePine, J. A., Piccolo, R. F., Jackson, C. L., Mathieu, J. E., \& Saul, J. R. (2008). A meta-analysis of teamwork processes: Tests of a multidimensional model and relationships with team effectiveness criteria. Personnel Psychology, 61, 273-307.

Lewis, K., Belliveau, M., Herndon, B, \& Keller, J. (2007). Group cognition, membership change, and performance: Investigating the benefits and detriments of collective knowledge. Organizational Behavior and Human Decision Processes, 103(2), 159-178.

Lewis, K., Lange, D., \& Gillis, L. (2005). Transactive memory systems, learning, and learning transfer. Organization Science, 16(6), 581-598.

London, M. (2003). Job feedback: Giving, seeking, and using feedback for performance improvement (2nd ed.). Mahwah, NJ: Lawrence Erlbaum.

London, M., Polzer, J. T., \& Omoregie, H. (2005). Interpersonal congruence, transactive memory, and feedback processes: An integrative model of group learning. Human Resource Development Review, 4(2), 114-135.

London, M., \& Sessa, V. I. (2006). Group feedback for continuous learning. Human Resource Development Review, 5(3), 1-27.

MacCurtain, S., Flood, P. C., Ramamoorthy, N., West, M. A., \& Dawson, J. (2010). Top Management Team Knowledge Sharing and New Product Performance: A Study of Irish Software Industry. Creativity And Innovation Management, 193), 219-232.

Marks, M. A., Sabella, M. J., Burke, C. S., \& Zaccaro, S. J. (2002). The impact of cross training on team effectiveness. Journal of Applied Psychology, 87, 3-13.

Mathieu, J. E., Heffner, T. S., Goodwin, G. F., Salas, E., \& Cannon-Bowers, J. (2000). The influence of shared mental models on team process and performance. Journal of Applied Psychology, 85 , 273-283.

Moreland, R. L., \& McMinn, J. G. (2010). Group reflexivity and performance. In S. R. Thye \& E. Lawler (Eds.), Advances in group processes (Vol. 27, pp. 63-95). Bingley, UK: Emerald Press.

Müller, A., Herbig, B., \& Petrovic, K. (2009). The explication of implicit team knowledge and its supporting effect on team processes and technical innovations. An action regulation perspective on team reflexivity. Small Group Research, 40, 28-51.

Neubert, M. J. (1998). The Value of Feedback and Goal Setting Over Goal Setting Alone and Potential Moderators of This Effect: A Meta-analysis. Human Performance, 11, 321-335.

Okhuysen, G., \& Waller, M. J. (2002). Focusing on midpoint transitions: An analysis of boundary conditions. Academy of Management Journal, 45, 1056-1065.

Prins, F. J., Sluijsmans, D. M. A., \& Kirschner, P. A. (2006). Feedback for general practitioners in training: quality, styles, and preferences. Advances in Health Sciences Education, 11, 289-303.

Rentsch, J. R., Delise, L. A., Salas, E., \& Letsky, M. (2010). Facilitating knowledge building in teams: Can a new team training strategy help? Small Group Research, 41, 505-523.

Rico, R., Sánchez-Manzanares, M., Gil, F., \& Gibson, C. (2008). Team implicit coordination processes: A team knowledge based approach. Academy of Management Review, 33, 163-184.

Rummel, N., \& Spada, H. (2005). Learning to collaborate: an instructional approach to promoting collaborative problem solving in computer-mediated settings. The Journal of the Learning Sciences, 14(2), 201-241. 
Salas, E., Stagl, K., \& Burke, C. (2004). 25 years of team effectiveness in organizations: Research themes and emerging needs. In C. Cooper \& I. Robertson (Eds.), International Review of Industrial and Organizational Psychology, Vol. 19 (pp. 47-91). Chichester, UK: John Wiley \& Sons.

Salas, E., Rosen, M., Burke, C. S., \& Goodwin, G. F. (2009). The wisdom of collectives in organizations: An update of the teamwork competencies. In E. Salas, G. F. Goodwin, \& C. S. Burke (Eds.), Team effectiveness in complex organizations. New York, NY: Taylor \& Francis.

Salas, E., Rosen, M. A., \& King, H. (2007). Managing teams managing crisis: principles of teamwork to improve patient safety in the Emergency Room and beyond. Theoretical Issues in Ergonomics Science, 8(5), 381-394).

Schippers, M. C., Den Hartog, D. N., Koopman, P. L., \& van Knippenberg, D. (2008). The role of team leadership in enhancing team reflexivity and team performance. Human Relations, 61, 15931616.

Schippers, M. C., Den Hartog, D. N., Koopman, P. L., \& Wienk, J. A. (2003). Reflexivity and diversity in teams: The moderating effects of outcome interdependence and group longevity. Journal of Organizational Behavior, 24, 779-802.

Schippers, M. C., Den Hartog, D. N., \& Koopman, P. L. (2007). Reflexivity in teams: A measure and correlates. Applied Psychology-An International Review, 56(2), 189-211.

Schippers, M. C., Homan, A. C., \& van Knippenberg, D. (2012). To reflect or not to reflect: Prior team performance as a boundary condition of the effects of reflexivity on learning and final team performance. Journal of Organizational Behavior, 34(1), 6-23.

Seibert, K. W. (1999). Reflection-in-action: Tools for cultivating on-the-job learning conditions. Organizational Dynamics, 27, 54-65.

Sharit J. (2012). Human error and human reliability analysis. In G. Salvendy (Ed.), Handbook of Human Factors and Ergonomics, 4th ed. (pp. 734-800). Hoboken, NJ: Wiley.

Stout, R. J., Cannon-Bowers, J. A., Salas, E., \& Milanovich, D. M. (1999). Planning, shared mental models, and coordinated performance: An empirical link is established. Human Factors, 41, $61-71$

Tjosvold, D., Tang, M. M. L., \& West, M. (2004). Reflexivity for team innovation in China: The contribution of goal interdependence. Group \& Organization Management, 295), 540-559.

Van den Bossche, P., Gijselaers, W., Segers, M., \& Kirschner, P. A. (2006). Social and Cognitive Factors Driving Teamwork in Collaborative Learning Environments. Team Learning Beliefs \& Behaviors. Small Group Research, 375), 490-521.

Van Ginkel, W., Tindale, R. S., \& van Knippenberg, D. (2009). Team reflexivity, development of shared task representations, and the use of distributed information in group decision making. Group Dynamics, 13, 265-280.

Waller, M. J. (1999). The timing of adaptive group responses to nonroutine events. Academy of Management Journal, 42, 127-137.

Weingart, L. R. (1997). How did they do that? The ways and means of studying group processes. Research in Organizational Behavior, 19, 189-239.

West, M.A. (2000). Reflexivity, revolution and innovation in work teams. In M.M. Beyerlein, D.A. Johnson \& S.T. Beyerlein (Eds.), Product development teams, Vol. 5. (pp. 1-29). Stamford, CT: JAl Press.

Wills, K. V., \& Clerkin, T. A. (2009). Incorporating reflective practice into team simulation projects for improved learning outcomes. Business Communication Quarterly, 722), 221-227. 



\section{Chapter 2 Establishing Team Knowledge Coordination from a Learning Perspective $^{2}$}

2 The chapter is based on: Gabelica, C., Fiore, S. M., Van den Bossche, P., Segers, M., \& Gijselaers, W. (resubmitted). Establishing team knowledge coordination from a learning perspective.

Gabelica, C., Van den Bossche, P., Segers, M., \& Gijselaers, W. (2013). When do Professional teams learn to Perform: how Coordination Impacts Performance. Paper presented at the American Educational Research Association (AERA), Division-I Winner of the New Investigator Award, April 27May 1 2013, San Franscisco, California, USA. 


\section{ABSTRACT}

Research has identified the importance of knowledge coordination in highperforming teams. However, little is known on the processes through which these cognitive structures are developed, more specifically on the learning occurring as teams communicate and interact to build new team knowledge. In a multiple-measure experiment, thirty-three teams with no prior experience in flight simulations were assigned to newly formed dyads to complete four successive performance episodes of a flight simulation task, modeling a complex, fast-paced, and high workload task context. The study showed how team learning processes (i.e., team learning behaviors and team reflexivity), driven by task cohesion, and group potency supported coordination development, which in turn predicted team performance. 


\section{INTRODUCTION}

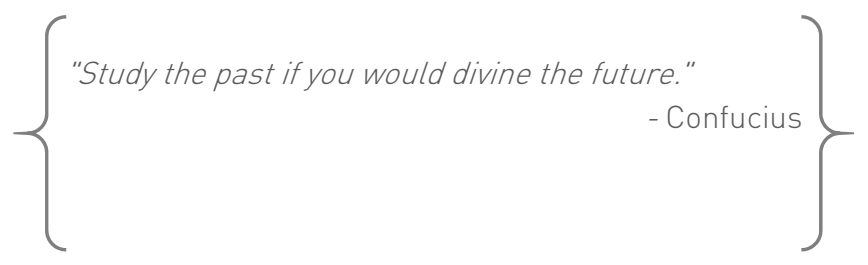

Teams have become the centerpiece of contemporary organizations because of their flexibility and capacity to make high-quality decisions and solve complex problems (e.g., Cooke, Salas, Kiekel, \& Bell, 2004; Salas, Rosen, Burke, \& Goodwin, 2009). Increasingly, organizational teams are composed of individuals with diverse backgrounds and unique knowledge and expertise. However, gathering skilled people together does not guarantee successful team performance (Hackman, 1990; Sims, Salas \& Burke, 2005). Team members also need to combine their contributions into an integrated team response (Hinsz, Tindale, \& Vollrath, 1997). This synchronization is referred to as knowledge coordination in the team literature (Wittenbaum, Vaughan, \& Stasser, 1998). Knowledge coordination ensures the smooth management of knowledge and skills dependencies and prevents unnecessary duplications of expertise within the team. As a consequence, it is a key determinant of team performance le.g., Faraj \& Sproull, 2000; Fisher, Bell, Dierdorff, \& Belohlav, 2012; Rico, SanchezManzanarez, Gil, \& Gibson, 2008).

Nevertheless, our understanding of how knowledge coordination is enabled is limited. Specifically, underlying processes facilitating knowledge coordination should be examined to fully grasp how teams become coordinated units (e.g., Fiore \& Salas, 2004; Gibson, 2001; Ren \& Argote, 2011; Rico et al., 2008). We identify three primary problems in uncovering antecedents of team knowledge coordination. First, empirical studies commonly consider collaborative work as a cognitive activity (cognitive perspective) or as a social process (social perspective). As a result, team research may overlook the socio-cognitive processes affecting the development of knowledge coordination, which is the functional part of cognitive structures at the team level (DeChurch \& MesmerMagnus, 2010; Salas \& Fiore, 2004). Yet, research suggests that teams build their team cognition through interacting with each other (e.g., Cooke, Gorman, \& Rowe, 2009). Team cognition and social context are thus intertwined. As such, the inquiry of both is needed to provide a more coherent and integrated understanding of how teams coordinate more efficiently. Second, few studies have attempted to incorporate the role of time when looking into team cognition 
(DeChurch \& Mesmer-Magnus, 2010; Mohammed, Hamilton, \& Lim, 2008). Certainly, however, the temporal factor plays a key role in the study of teams in organizations (McGrath, 1984). Although few studies have demonstrated that team cognition is not static, but dynamic le.g., Mathieu, Heffner, Goodwin, Salas, \& Cannon-Bowers, 2000), how knowledge coordination improves as a function of established factors is not yet understood (Ren \& Argot, 2011). We posit that collective experience is not sufficient to explain better subsequent knowledge coordination. High-knowledge coordination may not be realized unless interaction processes during which teams learn occur (Goodman \& Dabbish, 2011). Third, this learning potentially available in teams is often conceptualized as a change in team performance and not as the processes by which collective knowledge is built (Kozlowski \& Bell, 2008). To date, little is known on the joint role of different team learning processes on the establishment of team knowledge coordination and performance.

In the present paper, we address these issues and make a contribution to the question of how team learning can be investigated as a process fostering knowledge coordination by: (a) identifying socio-cognitive processes underlying team learning that are hypothesized to be drivers of team knowledge coordination, which in turn predicts performance, (b) looking at team members' beliefs associated with the task and the team, predicting the emergence of these processes, and (c) empirically examining the underpinnings of team knowledge coordination and performance with a multiple-measure experiment allowing for temporal considerations. For this purpose, novice dyads were confronted with successive performance episodes of a simulation modeling a complex, fastpaced, and high workload task context. Two-person teams (dyads) were deliberately chosen as the smallest and simplest form of teamwork and knowledge distribution implemented in many professions le.g., pair programming, flight crews) (e.g., Williams, 2010).

\section{BACKGROUND AND HYPOTHESES}

Drawing on theories of team learning, knowledge coordination, and performance, we formulated predictions about antecedent team behaviors, processes, and beliefs that might explain later high knowledge coordination and performance. The conceptual framework of the present study, depicted in Figure 1 and discussed below, presents the expected relationships between beliefs about the task and the team, team learning behaviors and reflexivity, knowledge 
coordination, and team performance. In this dynamic model, antecedent factors occur earlier in time (T-1) than each subsequent dependent variable.

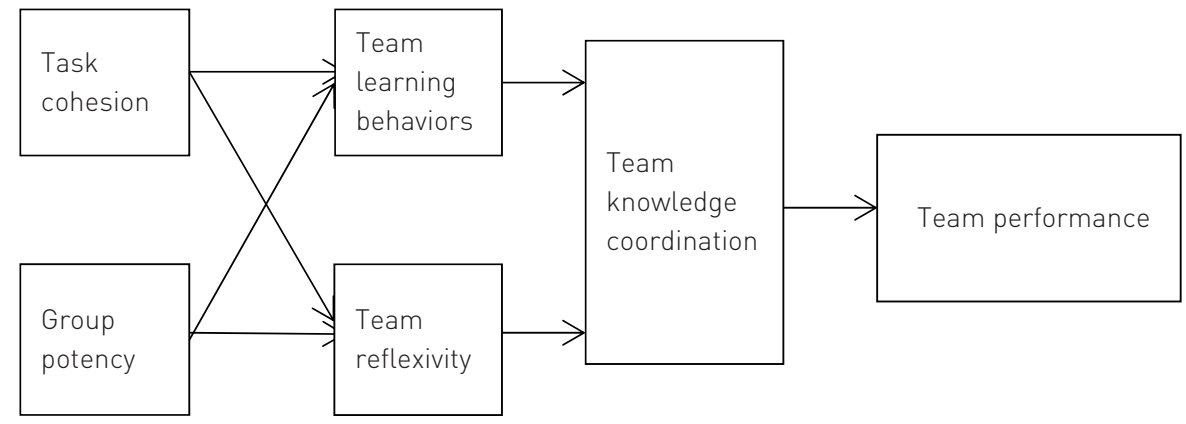

Figure 1. The conceptual framework

\section{Team coordination}

Working in interdependent teams typically necessitates high levels of coordination of members' diverse and unique knowledge and contributions to achieve successful team actions (Hinsz et al., 1997). Team members may effectively manage their individual responsibilities but still lack coordination if they do not take into account the dependencies about sub-tasks, resources, and people (Espinosa, Lerch, \& Kraut, 2004, Malone \& Crowston, 1994). At the basic level, group or team coordination has been defined as the effective synchronization and integration of members' resources, activities, and responses (Cannon-Bowers, Tannenbaum, Salas, \& Volpe, 1995). The term "coordination" has been used as a generic term for teamwork coordination or as a specific term for coordination of various types (e.g., coordination of actions, movements, knowledge, or tangible resources). The most prevalent uses concern the management of team members' actions (typically studied in action teams) and of knowledge and expertise (more critical in knowledge teams) (Faraj \& Sproull, 2000).

In line with various perspectives on the theoretical definition of coordination, the literature seems to display two main approaches to its operationalization. The "output" approach, most commonly adopted, conceptualizes coordination as an output (i.e., state of coordination or coordination success), more specifically the result of emergent knowledge structures le.g., transactive memory systems). In the "process" approach, coordination is rather regarded as a team process (i.e., coordinating) (Espinosa et al., 2004). 
In the "process" approach, coordination depicts the activities team members complete to effectively orchestrate the processing of knowledge and resources (Espinosa et al., 2004). It is argued that by interacting, teams transform knowledge of individual team members into team knowledge that serves as the basis for action (Cooke et al., 2004; Espinosa et al., 2007; Fiore et al., 2010). According to Marks et al. (2001), coordination processes during action phases include verbal communication (i.e., information exchange) and behavioral processes such as teams adjusting their actions to those of other members (Brannick, Roach, \& Salas, 1993). For example, Marks and Panzer (2004) conducted a simulated flight combat team exercise and found that coordination activities and behaviors were predictive of performance outcomes.

In the "output" approach, coordination is seen as the product of team cognition (Fiore \& Salas, 2004). This approach acknowledges that team cognition is more than the sum of individual knowledge available in the team. It is, rather, an emergent knowledge structure derived from the interplay le.g., overlap, dispersion, and complementarityl of team members' individual cognitions (Cooke et al., 2004). This structure contains well-organized and distributed knowledge that is crucial for team functioning (Kozlowski \& Ilgen, 2006). Team knowledge, in turn, allows implicit coordination and thus the anticipation of upcoming events and actions that team members are about to take le.g., Entin \& Serfaty, 1999; Espinosa, Slaugther, Kraut, \& Herbsleb, 2007; Rico et al., 2008; Stout, Canon-Bowers, Salas, \& Milanovich, 1999). One of the most researched team cognitive structures are transactive memory systems (TMSs) (Ren \& Argote, 2011; Wildman et al., 2012). TMSs are based on the idea that individuals are able to benefit from differentiated knowledge insofar as they elaborate a good shared understanding of who knows what in the team and synchronize this knowledge collaboratively to complete tasks efficiently le.g., Austin, 2003; Brandon, \& Hollingshead, 2004; Lewis, 2004; Wegner, 1986). For example, Lewis (2003) conducted a field study in technology companies and demonstrated that knowledge coordination was correlated with performance measures (managers and teams' evaluations). Michinov and Michinov (2009) further demonstrated that knowledge coordination essentially explained the relationship between TMSs and performance.

Notwithstanding the evidence that poor coordination leads to poor performance and that coordinated teams achieve success, it is not entirely clear which socio-cognitive mechanisms may help teams establish this knowledge coordination and likewise prevent poor coordination (Stasser \& Titus, 1985; Rentsch, Delise, Salas, \& Letsky, 2010). These research strands on team 
coordination insufficiently address the question of the underlying processes, activities, and beliefs contributing to coordination success (Ren \& Argote, 2011). Addressing this gap, we propose that knowledge coordination, considered as an output in the present study, is a function of learning mechanisms occurring when teams interact and discuss their task and their team. Interactions and common experience are therefore necessary, but not sufficient conditions for high knowledge coordination since teams have to learn from them to manage their knowledge and expertise more effectively. This learning potential of teams may not be fully achieved unless 1) teams share what they know about the task and mutually refine and build on shared information and ideas (i.e., knowledgebuilding behaviors), 2) explicitly question, analyze, explore, review past events with self-awareness, and discuss possible alternatives and solutions to complete the task more effectively (i.e., team reflexivity) (e.g., Lewis, Lange \& Ellis, 2005; Rentsch, Delise, Salas, \& Letsky, 2010a). By explicitly sharing, exploiting, and questioning information and knowledge and the way they work towards more effective knowledge coordination, teams are expected to be better able to identify knowledge gaps and unique and common knowledge available in the team and decide how and when this knowledge needs to be synchronized (Espinosa et al., 2007). In other words, we approach knowledge coordination through the lens of a learning perspective and posit that these team-level resources have the potential to help understand how teams achieve coordination success. In the next section, we describe these two learning processes (i.e., team learning behaviors and team reflexivityl through which knowledge coordination is enabled.

\section{Processes building team knowledge coordination: team learning behaviors and reflexivity}

We regard knowledge coordination as the product of collaborative processes wherein team members create, share, and evaluate knowledge together. These are fundamentally learning processes. Overall, team learning has proved to be important so that teams become an increasingly high-performing system (Zellmer-Bruhn \& Gibson, 2006). Edmondson et al. (2007) has identified three research streams investigating learning in teams, although some studies have used the word "team" or "group learning" ambiguously or with no clear reference on how it has been operationalized (Goodman \& Dabbish, 2011; Wilson, Goodman, Cronin, 2007). The first research stream focused on team learning curves allowing for the examination of differential rates of learning across teams. The second stream operationalized team learning as an output of 
communication and coordination processes. Work in the third research area adopted a process view of learning and unbundled team learning processes, refining our understanding of their effects on performance. In previous studies, various team learning behaviors and activities have been identified. Taken together, they seem to converge into an iterative process of action and collective reflection (e.g., Argyris \& Schön, 1978; Edmondson, 1999; Kasl, Marsick, \& Dechant, 1997). Team learning behaviors have recently been emphasized as important drivers of team performance (e.g., Argote, Gruengeld, \& Naquin, 2001; Edmondson, 2002; Van den Bossche, Gijselaers, Segers, \& Kirschner, 2006). However, these team learning behaviors and activities have been frequently studied independently with heterogeneity of conceptualization and operationalization (Edmondson et al., 2007).

The present study follows the third research tradition, wherein team learning is operationalized as socio-cognitive team behaviors and activities from which an outcome is improved knowledge coordination, which mediates the relation between team learning and performance. Specifically, we focus on two types of team learning processes which are (1) "basic team learning processes" (i.e., manifesting how teams learn) and (2) 'facilitating team learning processes' (i.e., prescribing how teams should learn) (for review, Decuyper, Dochy, \& Van den Bossche, 2010). These are (1) team learning behaviors that can be seen as "knowledge-building behaviors" (as basic team learning processes) and (2) team reflexivity (as a facilitating team learning process).

Van den Bossche et al. (2006) conceptualized team learning behaviors as three basic processes through which agreement among agents is attained (Galliers, 1989, cited in Baker, 1995). As stressed by Baker (1995), joint understanding, which is supposed to be an essential characteristic of agreement, starts with team members bringing information and ideas (construction). However, a simple accumulation of single contributions is not sufficient since each contribution has to draw on previous ones. Moreover, information sharing will eventually generate new knowledge if information can be translated into knowledge that team members can use (Rentsch, Mello, \& Delise, 2010b). Consequently, co-construction, a mutual process of building meaning (Baker, 1994), is a necessary procedure when dealing with problems (Rentsch et al., 2010a \& 2010b). Negotiation is a central process in this stage (Baker, 1995; Dillenbourg, Baker, Blaye, \& O'Malley, 1996; Van den Bossche at al., 2006). Team members have to negotiate and determine meanings and solutions among different proposals (Baker, 1995). In some cases, meanings are displayed and confirmed (Roschelle \& Teasley, 1995). At the same time, reaching this common ground that forms the base for action is not a simple process. 
Some divergences can generate a rejection, at worst, or further elaboration via argument and clarification, at best. This process is referred to as constructive conflict. Teams will benefit from conflicts generating communication and negotiation. These task conflicts are occasions to re-consider ideas and solutions, learn about members' knowledge more directly and accurately, and discover new ways to integrate knowledge. As a result, they are likely to stimulate the development of more effective knowledge coordination and in turn, performance (Van den Bossche at al., 2006).

Additionally, research on team learning has recently emphasized that effective teams undertake planning activities, think while performing their actions, and debrief about their achievements and failures to understand accomplishments so far (Schippers, Den Hartog, Koopman, \& Wienk, 2003; West, 2000). The concept of team reflexivity is used to capture these facilitating learning processes. It integrates reflection, planning, and improvement (West, 2000). More specifically, before a task execution, reflective teams identify their team goals, the task nature and its requirements, define the problem they are about to face, and plan strategies they would need to reach their objectives. During the task, team members evaluate whether they are on the right track and whether their actions produce the expected results and consider the potential new problems that arise during action. Reflexivity occurring after the task consists of evaluations or debriefings. Specifically, teams review the course of their actions, their unexpected results, the methods used to solve problems or issues during the task and work out what can be learned from past achievements or failures (West, Garrod, \& Carletta, 1997). In turn, reflection on the collaborative process can lead to a better match between team member expertise and elements of the task. Conversely, without reflection on team processes and outcomes, teams may fail to uncover why they did or did not succeed and what knowledge and resources they need to perform more effectively. Further, some misunderstandings may remain unsolved and teams may fail to adjust their future approaches (Wills \& Clerkin, 2009). In teams initially holding inaccurate task representations, a lack of reflection on the task would keep them stuck with an inappropriate approach (Van Ginkel, Tindale, \& Knippenberg, 2009). Importantly, progress might be held back by a sub-optimal use of knowledge and skills available in the team.

High levels of team reflexivity have been found to be positively related to team functioning as well as team outcome variables (e.g., team performance) le.g., De Dreu, 2002; Gurtner, Tschan, Semmer, \& Nägele, 2007; Hoegl \& Parboteeah, 2006; Schippers et al., 2003; Tjosvold, Chun, \& Ziyou, 2003). For example, highly reflective TV-production teams were evaluated by their 
superiors as being more effective (Carter \& West, 1998). However, in their recent review, Moreland and McMinn (2010) highlighted studies in which researchers could not demonstrate the performance benefits of reflexivity. They draw attention to the need for more rigorous evidence-based studies to justify the recent enthusiasm for reflexivity. They argue that the field needs more carefully controlled experimentation to definitively show a causal relationship between reflexivity and performance differences. The present study aims at responding to this concern.

In the present study, we expect teams to improve their knowledge coordination, not only because they spend more time together, expand their experience with the task, or gain access to task-generated feedback (Ren \& Argote, 2011), but more significantly because they interactively engage in these team learning processes involving knowledge sharing and construction and shared reflection (e.g., Brandon \& Hollingshead, 2004; Cooke, Gorman, \& Kiekel, 2008; Fiore et al, 2010). In this respect, Lewis and colleagues (2005) have put forward a learning perspective of the development of TMSs. They have introduced a framework for understanding TMSs as learning agents through which teams can apply what they learned from one task to another. Progressively, as teams interact and share knowledge li.e., team learning behaviors), team members associate others more accurately with specific knowledge areas. This results in the integration of members' knowledge and generation of new knowledge that was previously not available in the team and that needs to be synchronized harmoniously to improve performance. Teams also learn by analyzing what works and what does not work. Based on these evaluations, they can revise and refine their understanding (i.e., team reflexivity). In this way, they build a more elaborate understanding of their task and can anticipate instead of reacting, which in turn helps them perform in a more coordinated and adaptive manner (Lewis et al, 2005; Moreland \& Myaskovksy, 2000).

As such, these team learning activities improve performance through knowledge coordination. Given the highly interdependent nature of the task, we hypothesize that learning as a collective only positively affects team performance through an efficient knowledge coordination of individual inputs. Knowledge coordination ensures that newly constructed knowledge and strategies and remedies are put into practice in a coordinated way. Lewis and colleagues (2005) found that learning transfer li.e., learning from one task to another onel was influenced by the maintenance of expertise across tasks and in particular for those teams who already built their TMS during the first task. 
Thus, earlier TMS has also to be accounted for to explain later improvements. Based on the arguments above, we formulated the following hypotheses:

Hypothesis 1 (H1): Knowledge coordination mediates the positive relation between team learning behaviors and subsequent team performance.

Hypothesis 2 (H2): Knowledge coordination mediates the positive relation between team reflexivity and subsequent team performance.

\section{Antecedents to team learning behaviors and reflexivity: task cohesion and group potency}

The line of research studying processes of team learning has started to explore team members' beliefs that jointly form a broad mental environment for the team interaction which influences team learning (Edmondson, 1999, 2003; Wong, 2004). Relatively little is known about the drivers that render teams more likely to reflect on their experiences, plan for future actions, and co-construct new knowledge (Schippers et al., 2013).

Our model holds that team performance and knowledge coordination are unlikely to be achieved unless favorable beliefs towards the task are installed. As collaborative work is an interactive process, it is argued that team members' appraisal of the task and its relationship to member perceptions are antecedent conditions that facilitate learning in a collaborative effort. In the present study, we focus on the two emergent states that have been investigated the most in team research (e.g., Beal, Cohen, Burke \& Mc Lendon, 2003; Gully, Incalcaterra, Joshi, \& Beaubien, 2002; Mullen \& Copper, 1994), but less frequently related to team learning and not as its antecedents (Wilson et al., 2007): group potency and task cohesion. In a field study with student teams, it has been shown that the shared beliefs that their team is able to perform (i.e., group potency), and that each member is committed to the team task (i.e., task cohesion), were associated with performance and team knowledge-building behaviors (Van den Bossche at al., 2006). Edmondson (1999) has demonstrated that a sense of collective efficacy (i.e., team confidence to succeed in a very specific activity) was related to group reflection in work teams. Collective efficacy is task- and context-specific while group potency is a more generalized belief concerning any situation or demand a team may encounter (Bandura, 1997; Chen et al., 2002; Stajkovic, Lee, \& Nyberg, 2009). These studies help better understand the processes through which task cohesion and group potency may be related to performance. Their power seems to lie in their motivational role in allocating and sustaining effort and attention to the team goal (Kozlowski \& Illgen, 2006), in regulating team processes, sharing information, and solving problems 
encountered (Gully et al., 2002). Tuckman (1965) suggested that favorable perceptions were preconditions allowing teams to focus effectively on their task performance. High task motivation underlying shared commitment and perception of team competence is evidence of the existence of shared goals that teams are trying to reach and of merged forces maintaining team participation (Mullen \& Cooper, 1994). It may trigger teams to adjust and regulate their behaviors by sharing and building new knowledge and reflecting upon their actions and strategies (especially if they had been shown to be ineffective) to achieve these goals (Van den Bossche et al., 2006). Also, it may be that group potency promotes a team's confidence (Edmondson, 1999; Gully et al., 2002), consequently raising the probability that situations are perceived as opportunities instead of threats and that teams will be prone to persevere in the face of problems (Gully et al., 2002). This will influence team ability to reconsider available knowledge and to think of possible alternatives to implement. Based on prior research, we hypothesized the following:

Hypothesis 3 (H3): Task cohesion will be positively associated with subsequent team learning behaviors.

Hypothesis 4 (H4): Task cohesion will be positively associated with subsequent reflexivity.

Hypothesis 5 (H5): Group potency will be positively associated with subsequent team learning behaviors.

Hypothesis 6 (H6): Group potency will be positively associated with subsequent reflexivity.

\section{METHOD}

\section{Participants}

Sixty-six (34 male, 32 female) voluntary undergraduate students were recruited from a university in the Netherlands in exchange for an individual incentive (vouchers). Their ages ranged from 18 to 31 years, $M=22.5, S D=2.8$. They did not have any prior experience in flight simulations. Participants were assigned to two-person newly formed teams and randomly assigned to a specific role, pilot or copilot. They were paired with a same-gender (female and male teams, respectively $n=10$ and $n=11$ ) or a different-gender partner (mixed teams, $n=$ 12), for a total of 33 teams, and completed a flight simulation task. 


\section{Task apparatus}

In the present study we used a computer simulation not to mimic real-work team environments (e.g., transportation teams) but rather to study a constructed set of theoretical relations (i.e., nomological network) among constructs within specific boundaries: a complex, fast-paced, and high-workload situation in which unequally distributed information and knowledge needed to be coordinated to achieve the team goal and keep on learning (Marks, 2000). A PCbased flight simulator of high graphical quality, Microsoft Flight Simulator $X$, was used to simulate this task context. This task context included key elements important to sustain knowledge coordination and emphasized interdependence, cooperation, and communication.

A series of four tasks (landing missions) was sequentially performed by each team. Specifically, students were in command of an aircraft during its descent in preparation for landing. They had to follow the determined traffic pattern of a landing approach, that is to say maintaining an appropriate speed, altitude, and configuration, completing a landing check-list, aligning the plane with the runaway, touching down at the right point, and gently coming to a stop on a landing field. These tasks had an increasing degree of difficulty in the sense that one additional difficulty element was inserted in the simulation at every trial departing from a basic traffic pattern (Mission 1) to a traffic pattern performed under lower visibility and less benchmarks (Mission 4). In this way, a high level of complexity throughout the simulation was ensured while the task remained the same and was comparable across trials. The computer was screened on a white board to increase realism and was equipped with a joystick, a gas controller, and headphones connecting the copilot to the Air Traffic Controller (ATC). Both participants were in the same room and could communicate freely. The team missions were recorded.

\section{Procedure}

Before the experiment, participants were explicitly informed about two criteria for admission: they were supposed to have no prior experience in flight or war simulations and no familiarity with their teammate. Only those matching the criteria were randomly assigned to a role within a team. The experiment lasted approximately 2.5 hours and consisted of three phases. First, upon arriving at the laboratory, participants were told that the purpose of the study was to investigate how teams work together. They were given additional information about the study (timing, sequence of events, and participants' roles), and an overview of the task. Moreover, they completed a short survey about 
demographic information and their use of computer games double-checking for their familiarity with the task and their teammate. Second, team members were individually trained on the assigned roles. The objective of the 45-minute training was to provide both participants with specialized knowledge on their roles and subtasks to fulfill. Each team member was given a booklet containing written information corresponding to the differentiated critical knowledge of piloting or monitoring an aircraft le.g., how to check and regulate the speed and altitude; what are the flaps and landing gears and how to activate them; what is stall speed). The pilots were responsible for flying the plane and using the joystick. To that purpose, they completed an additional 10-minute hands-on training consisting of an individual exercise to become acquainted with the joystick. The copilots were responsible for controlling the gas of the plane and giving indications and directions to the pilot. They could draw from information provided by ATC and cockpit instruments they were trained to interpret. For the training, participants were sitting in separate rooms. Third, teams were back together in the same room to sequentially complete the four landing tasks. They were allowed to restart missions after a crash within a time frame of fifteen minutes, after which the game stopped. Between each mission, teams had a time-out (transition phase) during which they were free to communicate. Before each mission, they were given a brief written description of the mission scenario and the flight objectives. All teams were videotaped performing the simulation. They were debriefed following the fourth team task.

\section{Data collection}

After each landing, participants were required to complete questionnaires. Selfreported measures were collected after the task while objective task performance was rated based on the actual landing for each time (referred to as Time 1, 2, 3, \& 4). Questionnaires were ordered according to the order of appearance of the corresponding variables in the model of the study. More specifically, after Time 1 and 3, individuals completed a questionnaire containing task cohesion, group potency, and knowledge coordination measures. Since task cohesion and group potency were supposed to assess teams' beliefs about their task and their team that would allow or prevent learning activities to occur, they were measured at the first measurement time and before the first measurement of team learning processes. Knowledge coordination was purposely measured at Time 1 too to obtain an immediate rating of expertise coordination at the first team experience and control for initial levels of knowledge coordination, shortly after the specialized training. As such, the 
starting point of coordination was Time 1 and was assessed in relation to the first landing as a team. After Time 2 and 4, they were given the team learning behaviors and reflexivity questionnaire since these processes were expected to be a consequence of task cohesion and group potency measured at T1 and an antecedent of knowledge coordination measured at T3. Items of the questionnaire were assessed on a 7-point Likert scale 11 = completely disagree to 7 = completely agreel. To summarize, we used task cohesion and group potency ratings at Time 1 , team learning behaviors and reflexivity ratings at Time 2, and knowledge coordination and performance measures at Time 3, controlling for knowledge coordination at Time 1 to allow for consideration of temporal (causal) relationships hypothesized in the model. Figure 2 shows all the measures collected for our study and asterisks highlight the measures used in the causal model tested in the present study.

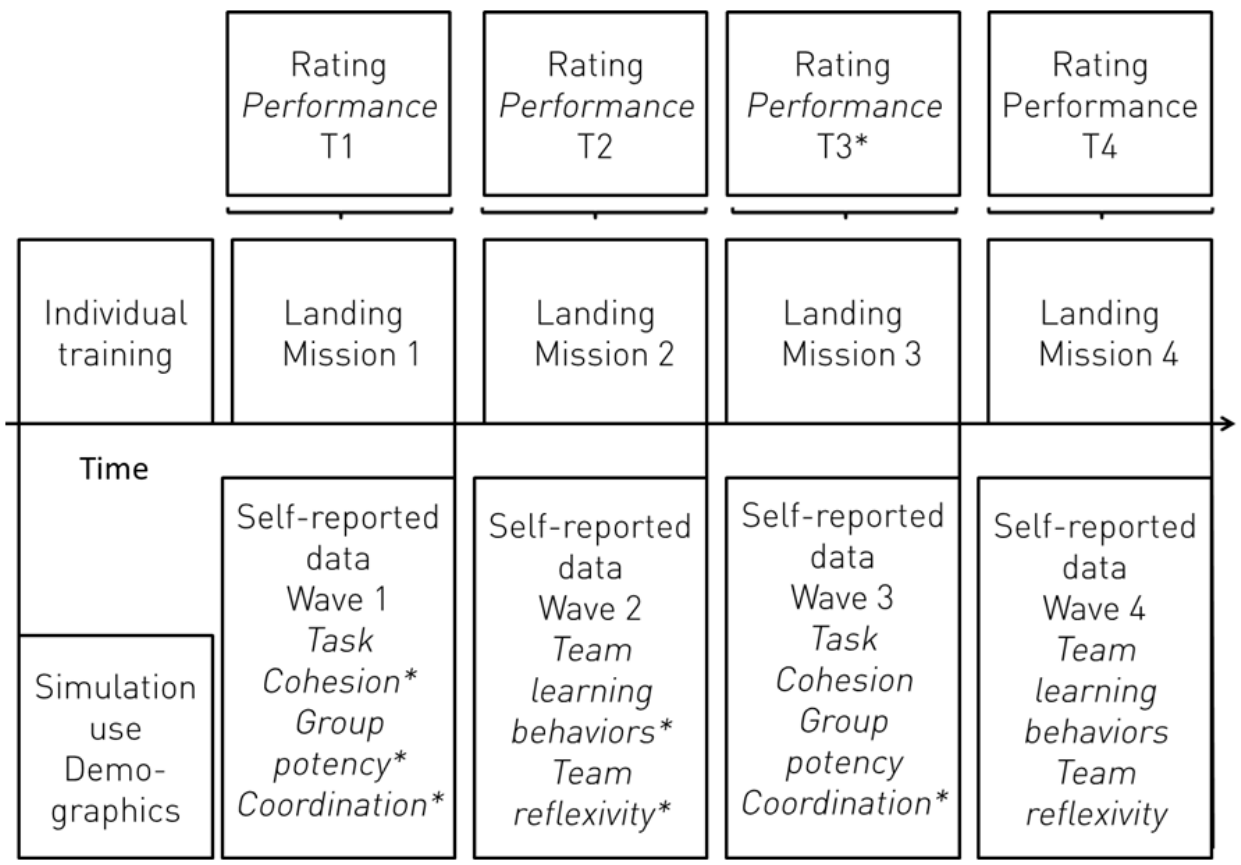

Figure 2. Overview of the measures of the present study. Asterisks signal measures included in the model tested.

\section{Measures}

Performance. An objective performance rating instrument was developed based on two sources. First, a task analysis was conducted with an expert in the flight 
simulation used in the study to extract key criteria to perform a successful flight. Second, the simulation itself provided players with some tests for awarding flight certificates. We used these criteria provided by the simulation developers to refine the criteria and develop the final performance rating form. The form was pretested during a pilot study aiming at testing the whole experimental design.

Team performance for each mission was the total number of points won (correct actions) by the teams relative to objective criteria (e.g., speed, altitude, activation of flaps and landing gear, landing position). It was emphasized that a crash was not a major issue in the experiment. The possibility of re-flying missions after a crash reinforced the relative low weight of "crash" in their overall performance. The fifteen-minute timeframe was set to avoid penalizing teams crashing quickly. With respect to the maximum number of correct actions per mission, although the four missions shared common features and correct actions to be completed in a landing situation, they varied in certain specific aspects. These corresponded to additional gradual difficulties teams had to face throughout the missions. More precisely, to get the maximum score in mission 1, teams had to display nine correct actions. Consequently, the best score in mission 1 was measured on a scale ranging from 0 to 9. In missions 2 and 3 , thirteen correct actions were necessary to get a full score. Mission 4 was the most thorough one with nineteen correct actions needed to perform a perfect flight.

Knowledge coordination. To measure knowledge coordination, we employed a modified version of the Transactive Memory Scale of Lewis's (2003), for which reliability and validity have been established previously. Only the coordination sub-scale was used in the present analyses. Five items covered knowledge coordination (e.g., "Our team worked together in a well-coordinated fashion"). The original Transactive Memory Scale was used in the context of project teams. To fit the specific task employed in the present study, we changed each occurrence of the word "project" by the word "mission". In the present study, the coordination subscale had Cronbach's alphas of .80 and .83 for Time 1 and Time 3 , respectively. Coordination items loaded high (minimum $=.68$ ) on one factor for both times.

Team learning behaviors. Construction, co-construction, and constructive conflict were measured by a questionnaire developed and validated by Van den Bossche et al. (2006). The original 9 items were adapted to fit a flight simulation task. Example items include "Team members elaborate on each other's information and ideas" (co-construction) and "This team tends to handle differences of opinions by addressing them directly" (constructive conflict). We 
found a similar factor analysis pattern uncovering a single underlying factor for all the items. The 9 items were averaged to create a single score of team learning behaviors ( $=.83$ for Time $2,=.85$ for Time 4 ).

Team reflexivity. Reflexivity was tapped with a 9-item measure derived from a questionnaire developed by Schippers et al. (2003). Team member rated these items on a 7-point scale (sample item: "We regularly discuss whether the team is working effectively"). Ratings of reflexivity converged to a single underlying dimension and did not overlap with team learning behaviors (loadings from .58 to .82) as defined by Van den Bossche et al. (2006). Teams were hence assigned a reflexivity score and a score for their team learning behaviors. The reflexivity scale had Cronbach's alphas of .82 and .88 for Time 2 and Time 4, respectively.

Task cohesion. A 4-item scale from Carless and de Paola (2000) was employed to assess task cohesion. The items included, for instance, "This team is united in trying to reach its goals for performance". Cronbach's alpha coefficients were .68 for Time 1 and .75 for Time 3 . The four items taped into a shared construct (minimum $=.65$ for Time 1, and .70 for Time 3).

Group potency. Group potency was measured using an instrument developed in earlier work by Sargent and Sue-Chan (2001), Gibson, Randel, and Earley (2000), and Guzzo, Yost, Campbell, and Shea (1993). The 6 items loaded high on a single factor (minimum: .67 for Time 1 and .81 for Time 3) and produced a reliability coefficient of .83 for Time 1 and .90 for Time 3. A sample item for group potency was, "This team believes it can be very effective".

\section{AgGREGATION ON TEAM LEVEL}

Performance scores were direct measures of team-level performance. In contrast, all the concepts captured by questionnaires were team-level constructs on which individual team members had to provide their perceptions. Consequently, the data gathered from individual team members to measure these team-level variables were aggregated at that level. The multiple-item estimator rwg (James, Demaree, \& Wolf, 1984) was used to assess within-group agreement. This analysis showed mean values of .86 (Time 1) and .90 (Time 3) for task cohesion, 87 (Time 1) and .74 (Time 3) for group potency, .76 (Time 1) and .80 (Time 3) for knowledge coordination, .86 (Time 2) and .87 (Time 4) for team learning behaviors, and .75 (Time 2) and .80 (Time 4) for reflexivity. These results supported the creation of team-level measures. 


\section{METHODS OF ANALYSIS}

Path analysis and model-fitting techniques were used to test the theoretically hypothesized relations depicted in Figure 1 ( $\mathrm{H} 1$ to $\mathrm{H} 6)$. Path analysis is used as a method for assessing the web of relationships among observed variables and the values of the coefficients in the underpinning linear model. The proposed path model was evaluated using LISREL version 8.8 (Jöreskog \& Sörbom, 2006) and based on the Maximum Likelihood method of Estimation (MLE). The statistical significance of estimated path coefficients and statistics specifying goodness of fit for the model as a whole were analyzed. Specifically, the comparative fit index (CFI), the non-normed fit index (NNFI), the root mean squared error of approximation (RMSEA), the standardized root mean square residual (SRMR), and Chi-square $\left(\chi^{2}\right)$ were used as model fit criteria. The model was considered a good or excellent fit to the data if CFI and NNFI were greater than .90 or .95 respectively (Schumacker \& Lomax, 1996). Both comparative fit indexes are not affected by sample size, while NNFI penalizes for a lack of parsimony, in contrast with CFI (Guay, Marsh, \& Boivin, 2003). Values lower than .10 or .08 for SRMR have been recommended as acceptable or good fit values for this measure (Hu \& Bentler, 1999). Finally, RMSEA, an index related to residuals in the model, is interpreted as a good fit measure when values are below .08 and a reasonable fit measure when they are between .05 and .08 (Browne \& Cudeck, 1993).

The procedure used to test the model as a whole was as follows. It was firstly tested how well the team learning model based on previous literature (fig.1) fit the data. We included time as an important factor in the analyses by selecting time measures of the independent variables preceding the dependent variables. Particularly, we used scores at Time 1 for group potency and task cohesion, scores at Time 2 for team learning behaviors and reflexivity, and scores at Time 3 for knowledge coordination and performance. We did not use performance at Time 4 in the analyses because the mean performance at time 4 dropped significantly while it was supposed to be sustained as difficulty level increased. This suggests that the increase of level of difficulty from Mission 3 to Mission 4 was higher than the progression followed from Mission 1 to Mission 3. One control variable, initial knowledge coordination of the teams (measured at Time 1), was allowed to affect knowledge coordination at Time 3. As the team literature does not suggest any directional relationship between the two team learning processes included in this study, we allowed their errors to covary. The model adequacy and path coefficients of each of the hypothesized relationships were hence estimated. Secondly, T-values were used to eliminate the 
insignificant parameters in the path analysis (in the interest of parsimony), while modification indexes were examined for the eventual addition of unspecified parameters (Sörbom, 1989). The revised model was estimated accordingly.

\section{RESULTS}

Descriptive statistics and intercorrelations for the entire sample of the variables in the path model are presented per time period in Table 1. 


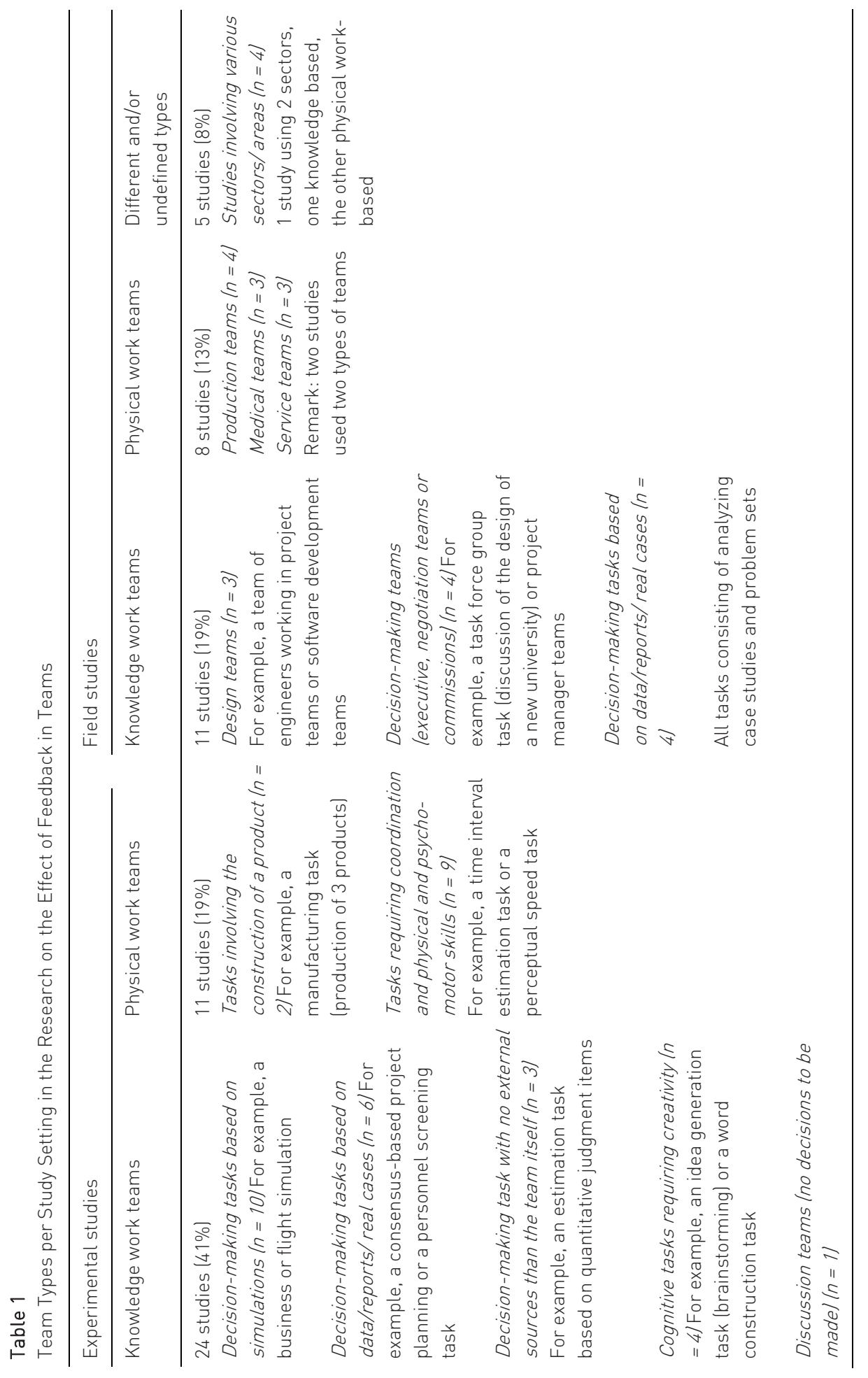


The original model (Model 1) hypothesized that knowledge coordination would develop through team learning behaviors and reflexivity $(\mathrm{H} 1$ and $\mathrm{H} 2)$ which would emerge through initial group potency and task cohesion ( $\mathrm{H3}$ to $\mathrm{H} 6)$ and that knowledge coordination would in turn predict performance lin line with previous literature). This initial model resulted in an almost acceptable fit to the data according to most of the measures $\left(\chi^{2}=14.54, d f=9, p=.10\right.$, RMSEA $=.15$, $\mathrm{CFI}=.93, \mathrm{NNFI}=.83, \mathrm{SRMR}=.065$ ). However, the non-normed fit index (NNFI) was below the desired value of .90 and the RMSEA was above the .05 criterion. Overall, these fit indices suggest the model fit is approaching a reasonable level, however, some model modifications might provide a better model fit.

The original model was improved, based on modification indexes. A path was added from group potency at Time 1 to knowledge coordination at Time 3 , therefore assuming a direct effect of group potency on subsequent knowledge coordination instead of the postulated indirect effect through both team learning processes (H5 and $\mathrm{H} 6)$. The modified model, displayed in Figure 3, showed a good fit $\left(\chi^{2}=11.05, d f=11, p=.44\right.$, RMSEA $=.012, \mathrm{CFI}=.98, \mathrm{NNFI}=.96, \mathrm{SRMR}=$ .070), thus confirming the final model.

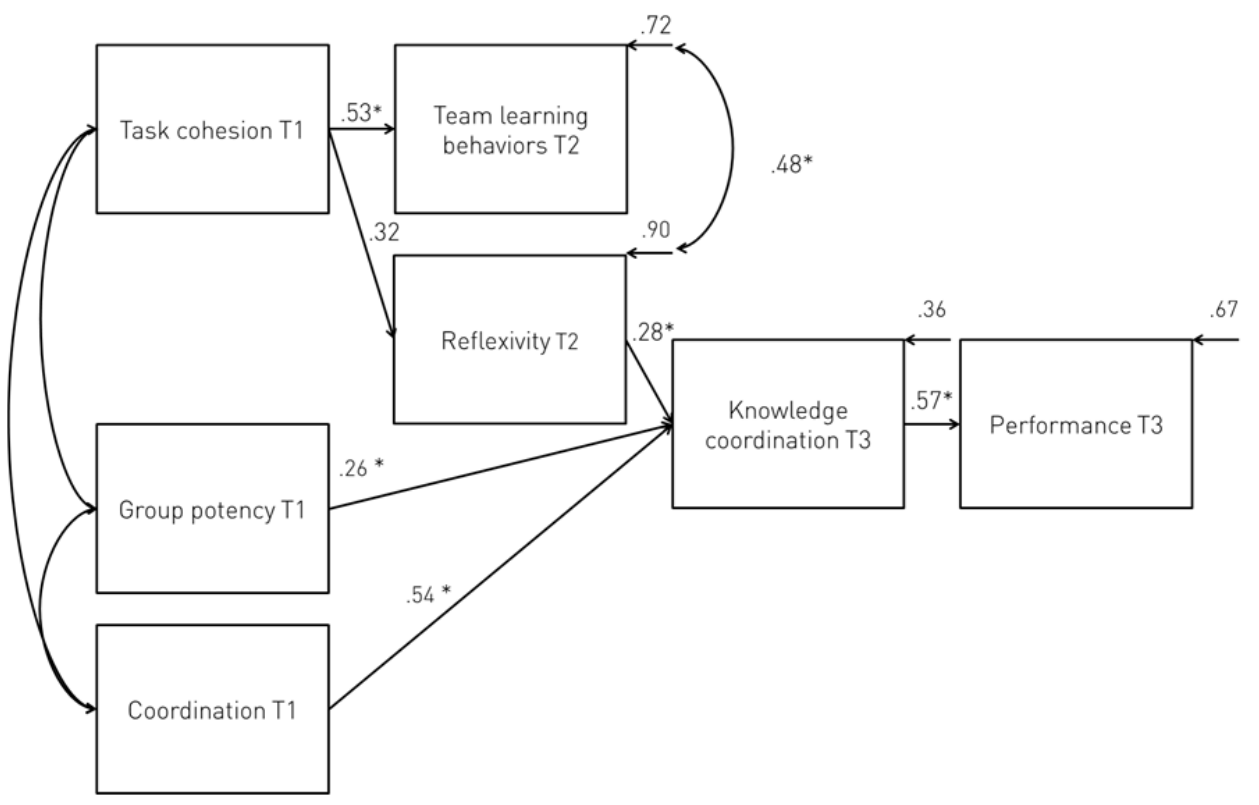

Figure 3. Model 3. Paths with asterisks are statistically significant.

Chi-square, as well as the other model fit statistics, denoted a better model fit to the data than Model 1 (Table 2). In line with prior work, knowledge 
coordination at Time 3 was a good predictor of objective performance even when taking initial knowledge coordination into account $(\beta=.58, t=3.81, p<.001)$. Secondly, consistent with $\mathrm{H} 3$, task cohesion was positively associated with subsequent team learning behaviors $(\beta=.50, t=3, p<.01)$. Thirdly, the results showed support for Hypothesis 2: reflexivity had a positive and significant effect on knowledge coordination $(\beta=.28, t=2.45, p<.01)$, and in turn, on performance. The effect of initial group potency on subsequent knowledge coordination was also significant $(B=.26, t=1.97, p<.05)$. Contrary to $\mathrm{H} 4$, task cohesion and reflexivity were not significantly related $(\beta=.32, t=1.84, p<.10)$. This path had an almost significant t-value. It was consequently not deleted from the model. Finally, the very low T-value of the path between team learning behaviors and knowledge coordination revealed that team learning behaviors were not contributing directly to knowledge coordination (when its co-variance with reflexivity was taken into account). Thus no support was found for $\mathrm{H} 1$.

Table 2

Fit Indices for Model 1 and Final Model

\begin{tabular}{lllllll}
\hline Model & $\chi^{2}$ & CFI & NNFI & PGFI & $\chi^{2}$ diff & Diff NNFI \\
\hline Model 1 (Figure 1) & 14.54 & .93 & .83 & .28 & & \\
Final Model (Figure 3) & 11.05 & .98 & .96 & .36 & 3.77 & .13 \\
\hline
\end{tabular}

The structural equations indicated that a reasonable amount of the variance in each observed variable, with the exception of reflexivity, was accounted for. Objective performance at time 3 had $33 \%$ of its variance predicted, while knowledge coordination had $64 \%$ of its variance explained by the antecedents included in the model. Additionally, the results accounted for $28 \%$ of the variance in team learning behaviors, whilst only 10\% in reflexivity. This latter effect suggests that this construct still has a great deal of unknown antecedents to be identified.

Additionally, the significance of the mediating variables was tested using tests of indirect effect with LISREL (Sobel, 1988). The Sobel tests showed that coordination significantly mediated the relationship between reflexivity and team performance $(z=2.05, p<.05)(\mathrm{H} 4)$, that coordination measured at time 1 exerted significant indirect effect on performance through coordination measured at time $3(z=2.94, p<.01)$, and that group potency had a significant indirect effect on performance through the mediation of coordination $(z=2.23, p$ $<$.05). Conversely, it did not indicate a significant mediation for reflexivity on the relationship between task cohesion and coordination at time $3(z=1.46, p<.10)$. 


\section{CONCLUSION}

Knowledge coordination involves the combination and synchronization of disparate team-member knowledge and expertise (Wittenbaum et al., 1998). The organized execution of team tasks requires a high degree of common understanding of the interrelationships between team members' contributions and mutual adjustments of team activities (Michinov \& Michinov, 2009). Knowledge coordination among team members has been recognized as being important for performance improvement in teams le.g., Cannon-Bowers et al., 1995; Faraj \& Sproull, 2000). In spite of the fact that literature is replete with theoretical and empirical work in the area of knowledge coordination (with different conceptualizations across disciplines), we still know very little about the drivers of knowledge coordination. The present study sought to identify socio-cognitive processes and behaviors allowing effective knowledge coordination to get established in newly-formed teams. We hypothesized that team performance would be predicted by high knowledge coordination within the team that would develop as a function of team learning processes, shaped by the task cohesion and group potency. The present study expands and lends support to previous research by (a) identifying socio-cognitive behaviors supporting knowledge coordination development (more specifically team reflexivity), by (b) highlighting the importance of the shared beliefs about the task (i.e., task cohesion and group potency) to set a mental environment in which these team learning processes emerge, and by (c) allowing multiple time cycles to better understand how teams learn to be coordinated in a complex task. In other words, it was shown that teams believing in their mutual commitment built more team learning behaviors and exhibited more reflexivity, making them better able to coordinate in an efficient fashion, which finally helped them be more efficient. Group potency, or confidence in team effectiveness, also impacted team performance through the mediation of knowledge coordination. Although researchers have previously established a relation between knowledge coordination and performance (e.g., Austin, 2003; Lewis, 2003) and team learning behaviors and emergent states (Van den Bossche et al., 2006), this study builds upon this through the use of a multiple-measure design, to unravel how motivational and socio-cognitive factors combine to predict how well teams would subsequently coordinate and perform. In what follows, we outline the theoretical and practical implications of these findings. 


\section{THEORETICAL IMPLICATIONS}

This study develops and extends research on knowledge coordination. The results are consistent with previous studies showing a positive relationship between knowledge coordination and performance le.g., Cannon-Bowers et al., 1995; Faraj \& Sproull, 2000). More importantly, they broaden our understanding of the underpinnings of knowledge coordination. This adds to the literature by showing that the positive effect of knowledge coordination on performance is bounded by the team ability to learn from its past team experiences and share knowledge and by its shared favorable beliefs about team commitment li.e., task cohesion) and about its competence (i.e., group potency). This study makes a significant contribution to the understanding of why certain teams experience knowledge coordination problems (Cronin \& Weingart, 2007; Marks et al., 2001; Wittenbaum et al., 1998) and of how certain behaviors and processes can help teams fix these to better perform in the future (Wittenbaum et al., 1998). These results suggest that knowledge coordination may not be a sufficient condition for effective team performance, even in tasks with substantial dependencies. Despite knowledge coordination's direct positive impact on performance, it appears that other antecedent factors, of a different nature (social, cognitive, and motivational), are in play to optimize the effect of knowledge coordination. It might be that teams who can coordinate on certain aspects of the tasks may not automatically perform at higher levels unless certain conditions are present as well (Espinosa et al., 2004). As such, it is important for future research on team performance to validate these factors in other settings and identify other possible antecedents that might reinforce and facilitate team ability to learn to be a coordinated unit. The combination of team processes, emergent states, and behaviors we found may change as the task progresses over time (Faraj \& Xiao, 2006). Overall, concerning the time factor, the multiple-measure design appears crucial to better understand how knowledge coordination develops and under which conditions. These findings are promising and should be explored further with more team types and more measures over longer periods of time as well as at different stages of team development.

Another important result regarding team learning processes emerged from the current study. The small but growing research line on team reflexivity li.e., conscious reflection on team functioningl delivers insight into how teams learn from their past (Schippers et al., 2013). The results of this research strand have been mixed. While reflexivity appears to be positively related to performance in many occasions, this is not always the case (Moreland \& McMinn, 2010). Moreland and McMinn (2010) called for rigorous designs showing its 
performance benefits while even more recently, Schippers et al. (2013) raised the question of the drivers and mediators of reflexivity when considering its relation with performance. The present study addresses both calls: we explain the relation between reflexivity and team learning behaviors and performance through the establishment of knowledge coordination and we showed that reflexivity had a potential antecedent, task cohesion, which accounted for $10 \%$ of its variance. The first feeling of strong commitment of the other team member appears to be more essential in the subsequent emergence of knowledgesharing behaviors. Our results suggest that there are some unknown antecedents of reflexivity yet to be uncovered. In the present study, group potency was not related to team learning processes but directly impacted knowledge coordination. Consequently, an important challenge for future research on team reflexivity will be to unravel more factors shaping team ability to put into practice what they learned from the past (Schippers et al., 2013).

\section{PRACTICAL IMPLICATIONS}

The present study provides important benefits for educators, managers, or team leaders responsible for enhancing group coordination and performance. We highlighted key processes and behaviors that have the power to influence the development of knowledge coordination and consequently performance. These could be facilitated through formal interventions that can take place between performance episodes. Although our study does not comprise measures over a long period of time, the temporal relationships allow some general guidelines about group development. If team researchers continue to make systematic efforts to examine knowledge coordination in teams addressing issues discussed in this article, this stream of research may offer more precise prescriptions on how to create a team environment in which team members learn to coordinate effectively and become better able to display implicit coordination patterns and switch to explicit knowledge coordination when important changes arise.

Our results suggest that members quickly develop beliefs about their teams and that these are necessary for learning behaviors and processes to emerge. For example, it may be that during the forming phase of a team (Tuckman \& Jenson, 1977), specific attention to favorable beliefs and appraisals of the task and team (high cohesion and group potency) would help reduce tension arising from the feeling of anxiety and uncertainty often observed in newly formed teams. Moreover, during later phases of a team, when team members start to 
challenge each other, constructive conflict and reflexivity may be critical to support and scaffold so that teams increasingly become more team and selfaware of their processes. However, field studies looking into group learning has emphasized that learning, as a team, is usually difficult and sparse (Wilson et al., 2007). This calls for the implementation and the evaluation of the performance benefits of interventions aiming at facilitating team learning and maintaining high learning opportunities throughout the team tasks (Gabelica, Van den Bossche, Segers, \& Gijselaers, 2012; Hackman \& Wageman, 2005; Schippers et al., 2003). For example, there is an emerging research strand that showed that reflexivity in teams can be induced by formal practical interventions. It is suggested that induced reflexivity helps teams become more effective, especially if their initial performance is low (Schippers, et al., 2013; Gurtner et al., 2007). To confirm these implications for team management, further research should be conducted in more naturalistic team settings and adopt longitudinal designs to focus more specifically on the following questions. First, at what point of team history, or after which event, or observed behaviors, should team managers pay more attention to the setting of a favorable context in which something of significance occurred. Second, how can we assess the emergence of team learning behaviors and how these evolve over time and without a formal structure to facilitate their use. To do so, it seems necessary to develop some behavioral markers specifying observable actions that are involved in team learning and observe their pattern and sequencing over time (Rousseau, Aubé, \& Savoie, 2006).

\section{LIMITATIONS AND FUTURE RESEARCH}

The present study, however, was subject to some limitations. First, it is important to define the team task and context (i.e., complex, fast-paced, and high-workload) used in this experiment that may partially explain some results but also limit their generalizability. The team task defines the workflow structure and knowledge coordination requirements (Kozlowski \& Illgen, 2006). In the present experiment, team members were externally assigned different roles and responsibilities in the completion of a highly structured task. Interdependence was triggered by the study design. Consequently, knowledge coordination of newly acquired knowledge was necessary to perform the task efficiently. As such, our findings may apply to teams in which knowledge coordination and knowledge integration are crucial to carry out complex and divisible tasks and not to teams performing loosely defined tasks and requiring 
Low knowledge coordination and specialized expertise (Lewis, Lange, \& Ellis, 2005). In the experiment we did not set out to model real transportation crews. Rather we created a controlled situation where teams of people experienced high workload in situations requiring knowledge coordination to effectively synchronize unequally distributed information and knowledge (Marks, 2000). Moreover, we chose to look at team learning behaviors and knowledge coordination from their starting and learning phases to get a better insight into how newly formed teams learn to be coordinated and effective. The control for individuals' prior experience and team history allowed us to observe the emergence of team interactions and knowledge in the early stage of performance. However, as complexity of the task increases, individual expertise and previous interactions between longer-tenure team members play an important role in how teams perform. In organizations, established teams need to learn and coordinate knowledge, routines, and behaviors that are more complex as they are embedded in more dynamic environments (Levine \& Choi, 2004; Wilson et al., 2007). This calls for additional field studies taking into account these complex variables that could act as moderators of our findings and testing the external validity of the present findings in real world teams under natural constraints (Mathieu et al., 2005).

Second, we used dyads, whereas team size and team proximity are said to be of influence in intrateam interactions (Daft \& Lengel, 1986). We are aware that there has been a recent debate about whether findings from research on dyads can be simply generalized to larger teams (Moreland, 2010; Williams, 2010). We acknowledge that certain aspects of team processes and dynamics (e.g., coalitions, group socialization) can hardly be grasped by the use of dyads. Also, previous studies have suggested that team size was an important factor in team cognitive capability. Specifically, they highlighted that bigger teams had greater cognitive resources and diversity and dissimilarity of skills and opinions than smaller teams (e.g., Bantel \& Jackson, 1989; Smith et al., 1994). However, we also believe that many two-person teams le.g., aircrews, agile software developers) display the same basic work processes driving team performance as sizable teams, although larger teams may exhibit more complex social interactions. In the present study looking into basic team behaviors displayed by individuals working together to understand a new task, dyads were chosen to test a simple learning model with the most simple form of knowledge distribution in a controlled, experimental way. We follow William's conceptualization of teams and rely on the definition of Salas, Dickenson, Converse, and Tannenbaum (1992) that "a team is a distinguishable set of two or more people who interact, dynamically, interdependently, and adaptively toward 
a common goal/ objective/mission, who have each been assigned specific roles or functions to perform, and who have a limited life-span of membership" (p. 4). This definition fits the dyads used in the present study. Still, further research exploring the dynamics of team coordination with more team members and in different settings will be needed to understand the complexity of how team members with different expertise, knowledge, and possibly high diversity learn collectively to coordinate and perform more efficiently and effectively.

Another limitation of the study was that most collected data were derived from self-report measures. While these measures have obtained reliability and construct validity evidence through both convergent and discriminant validation, we acknowledge that self-reported team-learning processes probably do not fully capture the richness of behaviors and strategies in which teams engage and suggest the use of additional qualitative data to fully grasp team learning and coordination development. For example, coding actual reflective behaviors would help us better understand whether teams exhibiting reflective behaviors before (planning behaviors), during, or after the task (reviewing and strategizing behaviors), are the ones showing the highest coordination and performance. Thus, qualitative data may facilitate the understanding of why certain teams achieve optimal coordination, and others not, and show the resulting changes of effective coordination processes, especially by analyzing the type and object of learning and the structure of interactions leading to a new learning (Goodman \& Dabbish, 2011).

Finally, we tested a basic dynamic model of team coordination establishment. Future research could extend our findings and investigate retroactive models with iterative loops. Feedback loops in which previous performance acts as an input for determining subsequent processes and performance have been recently forwarded as relevant models to understand team dynamics (Ilgen, Hollenbeck, Johnson, \& Jundt, 2005). 


\section{REFERENCES}

Argote, L., Gruengeld, D., \& Naquin, C. (2001). Group learning in organizations. In M. E. Turner (Ed.), Groups at work: Theory and research (pp. 369-412). Mahwah, NJ: Erlbaum.

Argyris, C., \& Schön, D. (1978). Organisational learning: A theory of action perspective. Reading, MA: Addison Wesley.

Austin, J. R. (2003). Transactive memory in organizational groups: The effects of content, consensus, specialization and accuracy on group performance. Journal of Applied Psychology, 88, 866878.

Baker, M. (1994). A model for negotiation in teaching-learning dialogues. Journal of Artificial Intelligence in Education, 5(2), 199-254.

Baker, M. J. (1995). Negotiation in collaborative problem-solving dialogues. In R. J. Beun, M. Baker, \& M. Reiner (Eds.), Dialogue and instruction. Modeling interaction in intelligent tutoring systems (pp. 39-55). Berlin, Germany: Springer-Verlag.

Bandura, A. (1997). Self-efficacy: The exercise of control. New York: Freeman \& Company.

Bantel, K. A., \& Jackson, S. E. (1989). Top management innovations in banking: Does the composition of the top team make a difference? Strategic Management Journal, 10, 107-124.

Beal, D. J., Cohen, R. R., Burke, M. J., \& McLendon, C. L. (2003). Cohesion and performance in groups: A Meta-analytic clarification of construct relations. Journal of Applied Psychology, 88(6), 989-1004.

Brandon, D. P., \& Hollingshead, A. (2004). Transactive memory systems in organizations: Matching tasks, expertise, and people. Organization Science, 1516), 633-644.

Brannick, M. T., Prince, C., Prince, A., \& Salas, E. (1995). The measurement of team process. Human Factors, 37, 641-651.

Brannick, M. T., Roach, R., \& Salas, E. (1993). Understanding team performance: A multi-method study. Human Performance, 6, 287-308.

Browne, M. W., \& Cudeck, R. (1993). Alternative ways of assessing model fit. In K. A. Bollen, \& J. S. Long (Eds.), Testing Structural Equation Models (pp. 136-162). Beverly Hills, CA: Sage.

Cannon-Bowers, J. A., Tannenbaum, S. I., Salas, E., \& Volpe, C. E. (1995). Defining competencies and establishing team training requirements. In R. Guzzo \& E. Salas (Eds.), Team effectiveness and decision making in organizations (pp. 333-380). San Francisco: Jossey-Bass.

Carless, S. A., \& de Paola, C. (2000). The measurement of cohesion in work teams. Small Group Research, 371), 71-88.

Carter, S. M., \& West, M. A. (1998). Reflexivity, effectiveness and mental health in BBC production teams. Small Group Research, 29, 583-601.

Chen, G., Webber, S. S., Bliese, P. D., Mathieu, J. E., Payne, S. C., Born, D. H., \& Zaccaro, S. J. (2002). Simultaneous examination of the antecedents and consequences of efficacy beliefs at multiple levels of analysis. Human Performance, 15(4), 381-409.

Cooke, N. J., Gorman, J. C., \& Kiekel, P. A. (2008). Communication as team-level cognitive processing. In M. P. Letsky, N. M. Warner, S. M. Fiore, \& C. A. P. Smith (Eds.), Macrocognition in teams (pp. 51-64). Burlington, VT: Ashgate.

Cooke, N. J., Gorman, J. C., \& Rowe, L. J. (2009). An ecological perspective on team cognition. In E. Salas, G. F. Goodwin, \& C. S. Burke (Eds.), Team effectiveness in complex organizations: Cross-disciplinary perspectives and approaches (pp. 157-182). New York, NY: Routledge/Taylor \& Francis Group.

Cooke, N. J., Salas, E., Kiekel, P. A., \& Bell, B. (2004). Advances in measuring team cognition. In E. Salas \& S. M. Fiore (Eds.), Team Cognition: Understanding the Factors that Drive Process and Performance (pp. 83-106). Washington, DC: American Psychological Association. 
Cronin, M. A., \& Weingart, L. R. (2007). Representational gaps, information processing, and conflict in functionally diverse teams. Academy of Management Review, 32, 761-773.

Daft, R. L., \& Lengel, R. H. (1986). Organizational information requirements, media richness and structural design. Management Science, 22, 554-571.

DeChurch, L. A., \& Mesmer-Magnus, J. R. (2010). The cognitive underpinnings of team effectiveness: A meta-analysis. Journal of Applied Psychology, 95(1), 32-53.

Decuyper, S., Dochy, F., \& Van den Bossche, P. (2010). Grasping the dynamic complexity of team learning: An integrative model for effective team learning in organizations. Educational Research Review, 5, 111-133.

De Dreu, C. (2002). Team innovation and team effectiveness: The importance of minority dissent and reflexivity. European Journal of Work and Organizational Psychology, 3, 285-298.

Dillenbourg, P., Baker, M., Blaye, A., \& O'Malley, C. (1996). The evolution of research on collaborative learning. In E. Spada \& P. Reiman (Eds.), Learning in humans and machine: Towards an interdisciplinary learning science (pp. 189-211). Oxford, UK: Elsevier.

Edmondson, A. C. (1999). Psychological safety and learning behavior in work teams. Administrative Science Quarterly, 44, 350-383.

Edmondson, A. C. (2002). The local and variegated nature of learning in organizations: A group-level perspective. Organization Science, 13(2), S17-S34.

Edmondson, A. C. (2003). Speaking up in the operating room: How team leaders promote learning in interdisciplinary action teams. Journal of Management Studies, 496), 1419-1453.

Edmondson, A. C., Dillon, J., \& Roloff, K. S. (2007). Three perspectives on team learning outcome improvement, task mastery, and group process. The Academy of Management Annals, 1, 269314.

Entin, E. E., \& Serfaty, D. (1999). Adaptive team coordination. Human Factors, 41(2), 312-325.

Espinosa, J. A., Lerch, J., \& Kraut, R. (2004). Explicit vs. Implicit coordination mechanisms and task dependencies: One size does not fit all. In E. Salas \& S. M. Fiore (Eds.), Team cognition: Understanding the factors that drive process and performance (pp.107-129). Washington, DC: APA Books.

Espinosa, J., Slaughter, S., Kraut, R., \& Herbsleb, J. (2007). Team knowledge and coordination in geographically distributed software development. Journal of Management Information Systems, 2411), 135-169.

Faraj, S., \& Sproull, L. (2000). Coordinating expertise in software development teams. Management Science, 46, 1554-1568.

Faraj, S., \& Xiao, Y. (2006). Coordination in Fast-Response Organizations. Management Science, 52(8), 1155-1169.

Fisher, D. M., Bell, S. T., Dierdorff, E., \& Belohlav, J. (2012). Facet personality and surface-level diversity as team mental model antecedents: Implications for implicit coordination. Journal of Applied Psychology, 974), 825-841.

Fiore, S. M., Rosen, M. A., Smith-Jentsch, K. A., Salas, E., Letsky, M. \& Warner, N. (2010). Toward an Understanding of Macrocognition in Teams: Predicting Processes in Complex Collaborative Contexts. Human Factors, 52(2), 203-224.

Fiore, S. M., \& Salas, E. (2004). Why we need team cognition. In E. Salas \& S.M. Fiore (Eds), Team Cognition: Understanding the factors that drive process and performance (pp. 235-248). Washington, DC: American Psychological Association.

Gabelica, C., Van den Bossche, P., Segers, M., \& Gijselaers, W. (2012). Feedback, a Powerful Lever in teams: a Review. Educational Research Review, 12), 123-144.

Gibson, C. B. (2001). From accumulation to accommodation: The chemistry of collective cognition in work groups. Journal of Organizational Behavior, 22, 121-134. 
Gibson, C. B., Randel, A. E., \& Earley, P. C. (2000). Understanding group efficacy. An empirical test of multiple assessment methods. Group \& Organization Management, 2511), 67-97.

Goodman, P., \& Dabbish, L. (2011). Methodological issues in measuring group learning. Small Group Research, 42, 379-404.

Guay, F., Marsh, H. W., \& Boivin, M. (2003). Academic self-concept and academic achievement: Developmental perspectives on their causal ordering. Journal of Educational Psychology, 9511), 124-136.

Gully, S. M., Incalcaterra, K. A., Johi, A., \& Beaubien, J. M. (2002). A meta-analysis of team efficacy, potency and performance: Interdependence and level of analysis as moderators of observed relationships. Journal of Applied Psychology, 87, 819-832.

Gurtner, A., Tschan, F., Semmer, N. K., \& Nagele, C. (2007). Getting groups to develop good strategies: Effects of reflexivity interventions on team process, team performance, and shared mental models. Organizational Behavior and Human Decision Processes, 102, 127-142.

Guzzo, R. A., Yost, P. R., Campbell, J. R., \& Shea, G. P. (1993). Potency in teams: Articulating a construct. British Journal of Social Psychology, 32, 87-106.

Hackman, J. R. (1990). Groups that work land those that don't): Creating conditions for effective teamwork. San Francisco: Jossey-Bass.

Hackman, J. R., \& Wageman, R. (2005). A theory of team coaching. Academy of Management Review, 30, 269-287.

Hinsz, V. B., Tindale, R. S., \& Vollrath, D. A. (1997). The emerging conceptualization of groups as information processes. Psychological Bulletin, 121, 43-64.

Hoegl, M., \& Parboteeah, K. P. (2006). Team Reflexivity in Innovative Projects. R\&D Management, 36(2), 113-125.

Hu, L., \& Bentler, P. M. (1999). Cutoff criteria for fit indexes in covariance structure analysis: Conventional criteria versus new alternations. Structural Equation Modelling, 6, 1-55.

Ilgen D. R., Hollenbeck J. R., Johnson M., \& Jundt D. (2005). Teams in organizations: From I-P-O models to IMOI models. Annual Review of Psychology, 56, 517-543.

James, L. R., Demaree, R. G., \& Wolf, G. (1984). Estimating within-group interrater reliability with and without response bias. Journal of Applied Psychology, 69, 85-98.

Jöreskog, K. G., \& Sörbom, D. (2002). LISREL 8.53. Mooresville, IN: Scientific Software, Inc.

Kasl, E., Marsick, V., \& Dechant, K. (1997). Teams as learners: A research-based model of team learning. Journal of Applied Behavioral Science, 33(2), 227-246.

Kozlowski, S. W. J., \& Bell, B. S. (2008). Team learning, development, and adaptation. In V. I. Sessa \& M. London (Eds.), Group learning (pp. 15-44). Mahwah, NJ. LEA.

Kozlowski, S. W. J., \& Ilgen, D. R. (2006). Enhancing the effectiveness of work groups and teams. Psychological Science in the Public interest, 7, 77-124.

Levine, J. M., \& Choi, H. S. (2004). Impact of personnel turnover on team performance and cognition. In E. Salas \& S. M. Fiore (Eds.), Team cognition: Understanding the factors that drive process and performance (pp.153-177). Washington, DC: APA Books.

Lewis, K. (2003). Measuring transactive memory systems in the field: Scale development and validation. Journal of Applied Psychology, 88(4), 587-604.

Lewis, K. (2004). Knowledge and performance in knowledge-worker teams: A longitudinal study of transactive memory systems. Management Science, 50, 1519-1533.

Lewis, K., Lange, D. \& Gillis, L. (2005). Transactive memory systems, learning, and learning transfer. Organization Science, 1616), 581-598.

Malone, T. W., \& Crowston, K. (1994). The interdisciplinary study of coordination. ACM Computing Surveys, 26(1), 87-119.

Marks, M. A. (2000). A Critical Analysis of Computer Simulations for Conducting team Research. Small Group Research, 31(6), 653-675. 
Marks, M. A., Mathieu, J. E. \& Zaccaro, S.J. (2001). A temporally based framework and taxonomy of team processes. Academy of Management Review, 26, 355-376.

Marks, M. A., \& Panzer, F. J. (2004). The influence of team monitoring on team processes and performance. Human Performance, 17, 25-42.

Marks, M. A., Zaccaro, S. J., \& Mathieu, J. E. (2000). Performance implications of leader briefings and team interaction training for adaptation to novel environments. Journal of Applied Psychology, 85, 971-986.

Mathieu, J. E., Heffner, T. S., Goodwin, G. F., Cannon-Bowers, J. A., \& Salas, E. (2005). Scaling the quality of teammates' mental models: Equifinality and normative comparisons. Journal of Organizational Behavior, 26, 37-56.

Michinov, N., \& Michinov, E. (2009). Investigating the relationship between transactive memory and performance in collaborative learning. Learning \& Instruction, 19, 43-54.

Mohammed, S., Hamilton, K., \& Lim, A. (2008). The incorporation of time in team research: Past, current, and future. In E. Salas, G. F. Goodwin, \& C. S. Burke (Eds.), Team effectiveness in complex organizations: Cross-disciplinary perspectives and approached (Society for Industrial and Organizational Psychology Frontier Series). Mahwah, NJ: Erlbaum.

Moreland, R. L., \& McMinn, J. G. (2010). Group reflexivity and performance. In S. R. Thye \& E. Lawler (Eds.), Advances in group processes (Vol. 27, pp. 63-95). Bingley, UK: Emerald Press.

Moreland, R. L., \& Myaskovsky, L. (2000). Exploring the performance benefits of group training: Transactive memory or improved communication? Organizational Behavior Human Decision Processes, 82, 117-133.

Mullen, B., \& Copper, C. (1994). The relation between group cohesiveness and performance: An integration. Psychological Bulletin, 11522), 210-227.

Ren, Y., \& Argote, L. (2011). Transactive memory systems 1985-2010: an integrative framework of key dimensions, antecedents, and consequences. The Academy of Management Annals, 511), 189229.

Rentsch, J. R., Delise, L. A., Salas, E., \& Letsky, M. (2010a). Facilitating knowledge building in teams: Can a new team training strategy help? Small Group Research, 41, 505-523.

Rentsch, J. R., Mello, A. L., \& Delise, L. A. (2010b). Collaboration and meaning analysis process in intense problem solving teams. Theoretical Issues in Ergonomics Science, 11(4), 287-303.

Rico, R., Sánchez-Manzanares, M., Gil, F., \& Gibson, C. (2008). Team implicit coordination processes: A team knowledge based approach. Academy of Management Review, 33, 163-184.

Roschelle, J., \& Teasley, S. D. (1995). Construction of shared knowledge in collaborative problem solving. In C. O'Malley (Ed.), Computer-supported collaborative learning (pp. 69-97). New York: Springer-Verlag.

Rousseau, V., Aubé, C., \& Savoie, A. (2006). Teamwork behaviors: A review and an integration of frameworks. Small Group Research, 375), 540-570.

Salas, E., \& Fiore, S. M. (2004). Team Cognition: Understanding the factors that drive process and performance. Washington, DC: American Psychological Association.

Salas, E., Rosen, M. A., Burke, C. S., \& Goodwin, G. F. (2009). The wisdom of collectives in organizations: An update of the teamwork competencies. In E. Salas, G. F. Goodwin, \& C. S. Burke (Eds.), Team Effectiveness in Complex Organizations. Cross- Disciplinary Perspectives and Approaches (pp. 39- 79). New York: Psychology Press.

Salas, E., Sims, D. E., \& Burke, C. S. (2005). Is there "big five" in teamwork? Small Group Research, 36(5), 555-599.

Sargent, L. D., \& Sue-Chan, C. (2001). Does diversity affect group efficacy? The intervening role of cohesion and task interdependence. Small Group Research, 32, 426-450. 
Schippers, M. C., Den Hartog, D. N., Koopman, P. L., \& Wienk, J. A. (2003). Reflexivity and diversity in teams: The moderating effects of outcome interdependence and group longevity. Journal of Organizational Behavior, 24, 779-802.

Schippers, M. C., Homan, A. C., \& van Knippenberg, D. (2013). To reflect or not to reflect: Prior team performance as a boundary condition of the effects of reflexivity on learning and final team performance. Journal of Organizational Behavior, 34111, 6-23.

Schumacker, R. E., \& Lomax, R. G. (1996). A beginner's guide to structural equation modeling. Mahwah, NJ: Lawrence Erlbaum.

Sims, D. E., Salas, E., \& Burke, C. S. (2005). Promoting effective team performance through training. In S. A. Wheelan (Ed.), The Handbook of Group Research and Practice (pp. 407-425). Thousand Oaks, CA: Sage.

Smith, K. G., Smith, K. A., Olian, J. D., Sims, H. P., O'Bannon, D. P. \& Scully, J. A. (1994). Top management team demography and process: The role of social integration and communication. Administrative Science Quarterly, 39, 412-438.

Stajkovic, A. D., Lee, D., \& Nyberg, A. J. (2009). Collective efficacy, group potency, and group performance: Meta-analyses of their relationships, and test of mediation model. Journal of Applied Psychology, 94, 814-828.

Stasser, G., \& Titus, W. (1985). Pooling of unshared information in group decision making: Biased information sampling during discussion. Journal of Personality and Social Psychology, 48, 1467-1478.

Stout, R. J., Cannon-Bowers, J. A., Salas, E., \& Milanovich, D. M. (1999). Planning, shared mental models, and coordinated performance: An empirical link is established. Human Factors, 41. $61-71$.

Tjosvold, D., Chun, H., \& Ziyou, Y. (2003). Conflict management and task team reflection for team inrole and extra-role performance in China. International Journal of Conflict Management, 14. $141-163$.

Tuckman, B. W. (1965). Developmental sequence in small groups. Psychological Bulletin, 63, 384399.

Van den Bossche, P., Gijselaers, W., Segers, M., \& Kirschner, P. A. (2006). Social and Cognitive Factors Driving Teamwork in Collaborative Learning Environments. Team Learning Beliefs \& Behaviors. Small Group Research, 375), 490-521.

Van Ginkel, W., Tindale, R. S., \& van Knippenberg, D. (2009). Team reflexivity, development of shared task representations, and the use of distributed information in group decision making. Group Dynamics, 13, 265-280.

Wegner, D. (1986.) Transactive memory: A contemporary analysis of the group mind. In G. Mullen \& G. Goethals (Eds.), Theories of group behavior (pp. 185-208). New York: Springer-Verlag.

West, M. A. (2000). Reflexivity, revolution and innovation in work teams. In M.M. Beyerlein, D.A. Johnson \& S.T. Beyerlein (Eds), Product development teams, Vol. 5. (pp. 1-29). Stamford, CT: JAl Press.

West, M. A., Garrod, S., \& Carletta, J. (1997). Group decision-making and effectiveness: unexplored boundaries. In C. L. Cooper \& S. E. Jackson (Eds.), Creating tomorrow's organizations: A handbook for future research in organizational behavior (pp. 293-316). Chicester: John Wiley \& Sons Ltd.

Wildman, J. L., Thayer, A. L., Pavlas, D., Salas, E., Stewart, J. E., \& Howse. W. (2012). Team knowledge research: Emerging trends and critical needs. Human Factors, 54, 84-111.

Wills, K. V., \& Clerkin, T. A. (2009). Incorporating reflective practice into team simulation projects for improved learning outcomes. Business Communication Quarterly, 72(2), 221-227.

Wilson, J. M., Goodman, P. S., \& Cronin, M. A. (2007). Group learning. Academy of Management Review, 32(4), 1041-1059. 
Wittenbaum, G. M., Vaughan, S. I., \& Stasser, G. (1998). Coordination in task performing groups. In R. S. Tindale, L. Heath, J. Edwards, E. J. Posevac, F. B. Bryant, J. Myers, et al. (Eds.), Theory and research on small groups (pp. 177-204). New York: Plenum Press.

Wong, S. S. (2004). Distal and local group learning: Performance trade-offs and tensions. Organization Science, 15, 645-656.

Zellmer-Bruhn, M., \& Gibson, C.B. (2006) Multinational organizational context: Implications for team learning and performance. Academy of Management Journal, 493), 501-518. 


\section{Chapter 3 \\ Feedback, a Powerful Lever in Teams ${ }^{3}$}

${ }^{3}$ This chapter is published as Gabelica, C., Van den Bossche, P., Segers, M., \& Gijselaers, W. (2012). Feedback, a powerful lever in teams: A review. Educationnal Research review, 12), 123-144. 


\section{ABSTRACT}

This paper reviews the literature on the effects of feedback provided to teams in higher education or organizational settings. This review (59 empirical articles) showed that most of the feedback applications concerned "knowledge of results" (performance feedback). In contrast, there is a relatively small body of research using feedback conveying information regarding the way individuals or the team performed a task (process feedback). Moreover, no research compared the effectiveness of process versus performance feedback. Concerning feedback effectiveness, half of the studies implementing performance feedback research reported uniformly positive effects while the other half resulted in positive effects on some dependent variables and no effect on others. All the studies using solely process feedback showed mixed positive results: some dependent variables improved while some others did not change. None of the studies reported any negative effects. This review also highlighted 28 key factors supporting feedback interventions effectiveness. 
INTRODUCTION

$$
\left\{\begin{array}{l}
\text { "If you want to build a ship, don't drum up people } \\
\text { together to collect wood and don't assign them tasks } \\
\text { and work, but rather teach them to long for the } \\
\text { endless immensity of the sea." } \\
\text { - Antoine de Saint-Exupéry }
\end{array}\right\}
$$

Teams become increasingly prevalent within educational and organizational settings. A team approach to work is considered more appropriate for complex tasks that could not be handled by high-expert individuals. Indeed, collective cognitive resources are likely to outperform individuals working alone. Nowadays, in a variety of contexts, teams are asked to interact, manage, and carry out challenging tasks by pooling their knowledge and skills. Organizations have shown a shift from individual positions in delimitated environments to teams described as complex, adaptive, and dynamic at all hierarchical levels (McGrath, Arrow, \& Berdahl, 2000). Similarly, in educational settings, different forms of collaborative learning environments requiring peer interactions and shared effort of student teams to solve complex problems have been implemented expansively (Barron, 2000; Dillenbourg, 1999; Druskat \& Kayes, 2000; Kirschner, 2009). Working in teams, however, does not automatically yield to team learning and does not ensure team performance (Roschelle \& Teasley, 1995). Teams may fail to use their potential or consider teamwork timeconsuming and too demanding (Dickinson \& McIntyre, 1997; Rummel \& Spada, 2005). Consequently, providing teams with adequate support is needed to secure teamwork. Research on team learning and performance has increased our understanding of how teams learn but is still in its development phase and in search for leverage points that can be used to trigger team learning (Decuyper, Dochy, \& Van den Bossche, 2010; Edmondson, Dillon, \& Roloff, 2008; Kozlowski \& Ilgen, 2006).

Feedback is argued to be a powerful tool to shape team learning and in turn, team performance (Kozlowski \& Ilgen, 2006; Locke \& Latham, 1990; London \& Sessa, 2006). It has been proposed as a potent feature in any learning process and achievement (Bartram \& Roe, 2008; Boud, 2000; Hattie, 1999; Hattie \& Timperley, 2007) and received considerable research attention as a determinant of individual behavior (Kluger \& DeNisi, 1996). Feedback can serve several purposes such as: bringing the resulting outcomes of the activity or the process into focus, providing information when people move away from initially set goals, helping in adjusting or fixing new goals, guiding activity, and promoting critical reflection on the tasks and situations to bring about new 
insights and approaches (Bartram \& Roe, 2008). London and Sessa (2006) argued that without feedback, teams might be able to change but not to learn as they depend on feedback to monitor and regulate themselves in order to be able to complete their tasks effectively.

The present article deals with feedback interventions in teams defined as the communication of information provided by (an) external agent(s) concerning actions, events, processes, or behaviors relative to a task completion or teamwork (London, 2003, 2005). A large number of studies and feedback reviews have focused on the effects of feedback (Bartram \& Roe, 2008), but it has mainly been delimited to performance feedback le.g., provision of information about performance) at the individual level (Alvero, Bucklin, \& Austin, 2001; London, 2003, 2006). However, results of research on individual-level performance feedback cannot simply be generalized to feedback research on a team-level. Researchers have stressed the differences between the effects of feedback received by an individual considered in isolation versus feedback received in team environments (Barr \& Conlon, 1994; Dewett, 2003; Nadler, 1979). This is due to the distribution of feedback among team members, which is dependent on a complex interaction of individual and unique team-level variables like the team's interactions, communication, and individual perception of feedback (Barr \& Conlon, 1994). Indeed, information provided to teams may be confounded by others' actions and behaviors and confusing for team members. It may convey multi-level data (about themselves, the team as a whole, or both) that have to be interpreted and understood by individuals. For example, if they are given teamlevel information, team members have to figure out to what degree these data reflect their individual input. This interpretation might be difficult as they have a distributed impact on the total team performance and functioning (Hinsz, Tindale, \& Vollrath, 1997; Nadler, 1979).

To conclude, though feedback is widely acknowledged as a valuable tool for individual learning in general, it is unclear whether teams benefit from feedback to enhance their team processes and/or their performance (Barr \& Conlon, 1994; Dewett, 2003; Hinsz et al., 1997) nor is it clear what type and level of feedback is actually efficient and under which conditions (Alvero, Bucklin, \& Austin, 2001). Feedback provided in teams is a complex phenomenon that necessitates considering feedback as a lever dependent on a series of variables related to its implementation and context. It builds up a first step toward the understanding of what makes feedback powerful in teams. Consequently, the goal of the present review of the literature is to address these questions and go beyond previous reviews by (a) considering studies not only implementing performance feedback but also process feedback le.g., information regarding 
the way individuals or the team performed a task), by (b) including studies focusing on team settings and providing feedback targeting the team as a whole or/and the individuals of the team, by (c) adopting an integrated perspective of teams considered as information processors performing cognitive activities la cognitive perspective) and social entities interacting to jointly perform the task la social perspective), and by (d) looking at feedback effect moderators that could explain the success of feedback implementations not only on teams' performance but also on their cognitive and interpersonal processes.

\section{FEEDBACK PROVIDED IN TEAMS}

A team is defined as "a distinguishable set of two or more people who interact, dynamically, interdependently, and adaptively to achieve specified, shared, and valued objectives" (Morgan et al., 1986, p. 3). Providing feedback to teams consists of transferring information to teams or individual team members reflecting their actions, events, performance, processes, or behaviors. Feedback has several functions:"it guides, motivates, and reinforces effective behaviors and reduces or stops ineffective behaviors" (London, 2003, p. 1). Based on this definition, one can discern two types of feedback both included in the present review: performance and process feedback (Geister, Konrad, \& Hertel, 2006; London \& Sessa, 2006). Performance feedback is conceptualized as the provision of information about individual or group performance to reinforce good performance or to correct poor performance enabling improvements to be made. Process feedback is defined as information regarding the way one performed a task and reached expected results. Process feedback can tackle different parts of the process. It could bear upon task-related, interpersonal, and also cognitive aspects. Task-related process feedback consists of information about the task tackled by individuals or the team, more specifically displayed behaviors, actions, and strategies, such as "you set the objective of the meetings" (Geister et al., 2006). Interpersonal feedback describes the social conditions under which teams build their shared understanding such a message that "during this meeting, you built a positive atmosphere by listening to each other, showed a high level of acceptance and mutual respect" (Akkerman et al., 2006), whereas cognitive feedback refers to the actual cognitive interactions or the extent to which information, ideas, or cognitive processes are being shared among the group members (Hinsz et al., 1997) and are being used in a coordinated way. A message like 'your team bore upon each other's' areas of expertise" consists of a cognitive feedback. Feedback in teams may also vary 
according to the unit on which information is provided (Alvero et al., 2001; Geister et al., 2006; London \& Sessa, 2006). It targets the team as a whole (team-level feedback), the individuals of the team (individual-level feedback), or both of them in which case team members have a representation of how the team behaves as an entity along with their individual contribution. For example, the effectiveness of health care delivery is often measured by a team-level outcome: patient satisfaction. Medical teams can be given patient-satisfaction data, meaning team-level performance feedback representing how the whole team performed with regard to the quality of care and service. This feedback does not denote each medical employee's contribution nor does it highlight who did errors or displayed unsafe behaviors during surgeries. Conversely, each health care worker can receive individual-level feedback about his behaviors in the operating room, for example about the patient safety procedures he completed. Feedback level may be confounded with the feedback setting lteams versus non-team settings). We thus rather use the term "team feedback" to depict feedback given in team settings and "individual feedback" to refer to feedback provided to individuals considered in isolation.

Feedback is applied in teams because it is believed to have an effect on their performance but also on the coordinated process through which they complete their tasks, bringing together their cognitive, affective, and behavioral resources (Bartram \& Roe, 2008; Kozlowski \& Ilgen, 2006). In contemporary frameworks, team effectiveness has been shown to be largely affected by team processes and emergent states (Kozlowski \& Ilgen, 2006; Marks, Mathieu, \& Zaccaro, 2001; Mathieu, Maynard, Rapp, \& Gilson, 2008). Team processes are defined as team members' interactions before, during, and after task completion and consist of analyzing the mission, planning, setting goals, strategizing, monitoring the task and team members, and managing conflict, confidence, affects, and team motivation (Marks et al., 2001). Emergent states are conceived as cognitive, motivational, or affective properties of the team and refer to conditions dynamically shaping effective collaboration, such as the collective belief that each member is committed to the team and the task (i.e., cohesion as an affective emergent state) and the distribution of knowledge within teams and its effective use (i.e., transactive memory systems as a cognitive emergent state) (DeChurch \& Mesmer-Magnus, 2010; Mathieu et al., 2008). Beyond the most extensively considered dependent variable "performance", we hypothesized feedback to be an agent through which central team processes and emergent states may be developed and strengthened as well. We thus looked at dependent and moderating variables hinging upon affective, cognitive, and interactional aspects of teams. 
Before presenting our organizing framework on feedback in teams, we turn to previous reviews on team feedback interventions.

\section{RESULTS FROM PREVIOUS REVIEWS}

Many reviews and meta-analyses have shown the well-known effects of individual feedback, mostly performance feedback le.g., Alvero et al., 2001; Balcazar et al., 1985; Denson, 1981; Guzzo, Jette, \& Katzell, 1985; Ilgen, Fisher, \& Taylor, 1979; Kluger \& DeNisi, 1996; Mento, Steel, \& Karren, 1987; Neubert, 1998). However, individual feedback literature showed that performance feedback didn't always reach the expected results, even leading to decreased performance in one third of the studies, as presented by Kluger and DeNisi (1996) in their pivotal review study. To explain this result, they analyzed feedback interventions that were effective and indicated that they comprised cues directing attention on task learning processes. Overall only a few studies adopt a more comprehensive view of feedback effects and emphasize its moderators as well as feedback process. And yet, these factors may also explain some of the negative effects of feedback. For example, Ilgen et al. (1979) drew attention to several dimensions of performance feedback (its timing, sign, and frequency), its reception and acceptance (i.e., the extent to which it is perceived as accurate), and individuals' willingness to respond to it. These findings provide some clues about conditions influencing the effectiveness of feedback interventions at the individual level. The conditions under which feedback effectiveness is optimized in teams are even less well understood.

If individual feedback research is compared to literature reviews addressing feedback given in team settings, it seems like team feedback lespecially based on process datal has not yet been explored extensively. Team feedback was addressed by four previous feedback reviewers, namely Nadler (1979), Balcazar et al. (1985), Hinsz et al. (1997), and Alvero et al. (2001). Surprisingly, the latest review was carried out a decade ago, and yet, teams have become an increasingly popular focus of interest in many studies. Among these studies, Alvero et al. (2001) and Balcazar et al. (1985) embraced a performance-driven view. Nadler (1979) included both process feedback, precisely interpersonal feedback (i.e., information about how the group functions) and performance feedback, whereas Hinsz et al. (1997) adopted a process perspective and more specifically a cognitive one. In the following paragraphs, each review is described in terms of its findings on feedback level and type. 
Nadler (1979) reviewed performance and process (interpersonal) feedback interventions at both levels in experimental task groups. He leaned on a model describing factors on which feedback is contingent. In particular, feedback (including feedback type and levell and team members' characteristics, the nature of the feedback process, and the team task were regarded as key factors to examine feedback usage. First, his analysis showed that team-level feedback was more effective under two conditions: when team members displayed differentiated roles and when the task required their interdependence. Second, team-level versus individual-level feedback appeared to have a differential impact on the reviewed dependent variables. Specifically, team-level feedback gave rise to attitudes toward the team (e.g., attraction, involvement), while individual-level feedback given in a team setting improved individual performance. Third, Nadler observed that individual differences le.g., affiliation versus task or achievement orientation) played a role in people's response to feedback. Regarding feedback type, he concluded that performance information were more likely to produce performance changes, while interpersonal feedback might help teams be more effective if augmented with additional information, although it did lead to better team functioning. However, Nadler reported a very small amount of studies on process feedback, especially on the interpersonal aspect, and stressed the need for additional research on the difference between feedback types and how process information could be augmented. Furthermore, he highlighted the limitations of previous team-level feedback studies due to their experimental procedures. More specifically, these studies rarely compared the use of both feedback levels in separate conditions and sometimes used tasks inducing limited interdependence or communication.

Hinsz et al. (1997)'s dynamic information-processing perspective review considered how teams process and share information and how the team response to feedback might in turn modify the situation. These authors considered both levels of process (cognitive) feedback in small interacting task groups. Interestingly, they selected studies looking at cognitive aspects that could account for team performance variability in cognitive tasks le.g., information sharedness among team members, the variability of their cognitive representations and processes). These results provide insight into reasons for differences in team performance; however, they did not investigate the explanatory power of these cognitive factors with respect to feedback interventions. In relation to feedback effectiveness, they showed that feedback about other teammates' behaviors could influence team processes and outcomes. Concerning feedback level, they pointed out that those individuals provided with individual feedback tented to attribute good performance to 
themselves and failure to the situation, whereas teams given team-level feedback held their team responsible for team success. They suggested that team-level feedback might switch members' focus from themselves to their team as well as contribute to the resolution of disagreements that could not be handled if only individual-level feedback were provided. Their analysis also revealed a differential impact of feedback type. In particular, based on the studies reviewed, they concluded that cognitive feedback should be preferred to task-related process feedback to increase learning and members' satisfaction, although they had a similar impact on group judgment accuracy. The authors noted that some issues related to feedback effectiveness were still not well understood, such as team-level feedback effects on team processes and the balance between performance gains brought about by team-level feedback and some eventual process losses due to the high cognitive load of information required by team collaboration. Moreover, none of the reviewed study compared two conditions providing individual and team-level feedback. Hinsz et al. (1997) underlined the importance of socio-emotional aspects of team process as part of information processes and the need for additional attention on these aspects as well. Yet, they were not taken into account in their review. Additionally, they only considered cognitive tasks, neglecting other types of teams.

A more recent review including team-level feedback and updating the earlier one from Balcazar et al. (1985) was conducted by Alvero et al. (2001). They looked at performance feedback in organizations and focused on field studies, excluding all research conducted in laboratories. Each feedback application was analyzed in the light of its characteristics and combinations to identify the most consistent regarding performance improvements. They showed that 1) feedback used in combination with other procedures (e.g. antecedents stimuli like staff training or behavioral consequences) might reach higher performance than feedback implemented alone, 2) feedback was more consistently effective when provided by supervisors and researchers rather than by supervisors/managers alone, 3) higher performance was attained when performance feedback was verbal and accompanied by graphs, 4) the highest levels of consistency effects were achieved when feedback was both private and public, and 5) when individual members or teams could compare their team or individual performance to a standard of team or individual performance or their previous performance. Among the 43 studies reviewed, individuals were the most common recipients given feedback while teams were targeted in 14 studies. Team-level feedback was accompanied by individual-level feedback in 8 studies. The analyses showed that almost $75 \%$ of the team-level feedback applications uniformly improved performance, against 55\% of the individual- 
level interventions. It appeared that team-level feedback was better able to lead to consistent positive effects. They confirmed the trends shown earlier by Balcazar et al. (1985) to a higher extent. However, some results should be interpreted with caution as some of them draw on a small amount of studies.

Overall, previous reviews suggest that team-level feedback might be more effective in case of task and team interdependence, with team members prone to affiliate with others, when the goal of the feedback giver is to impact attitudes towards the team, members' attribution of performance to the team and reduce disagreement among team members. With reference to feedback type, it seems like process feedback (as defined in this review) has an effect on team functioning, learning, and members' satisfaction while performance feedback appears to improve performance. These findings improve our understanding of feedback differential effects in teams and provide evidence of the existence of many factors that can help or impede feedback use. Nevertheless, a common definition of process feedback is lacking and there is a confusion between the different aspects it can tackle (cognitive, task or interpersonal. Process feedback referred to interpersonal information in Nadler (1979), while it consisted of cognitive data in Hinsz et al. (1997). Furthermore, all the reviewers made clear that team feedback has yet some unknown facets such as how it should be given, the characteristics it should have, and which factors enhance or mitigate its effect. In conclusion, updating earlier reviews looking at feedback in teams turns out to be needed, in particular within the context of an increase use of teams nowadays. Additionally, none of the review provided a complete overview of feedback received in team environments as they only considered one type and/or level of feedback. A more integrated review should include all feedback types and levels and systematically identify the characteristics of feedback applications that contribute to its effectiveness, as was done in some previous reviews.

Prior to analyzing empirical studies implementing feedback in teams, a theoretical consideration of how feedback affects team performance, team processes, and emergent states was needed. Such a framework might help interpret findings and identify determinants of feedback effectiveness and thus understand why feedback may not always lead to significant changes. More importantly, due to the diversity of the feedback studies, it was indispensable to look for an underlying structure in this very complex and scattered domain of research. Nadler (1979) builds on such a framework as described previously. However, although his model is an interesting view on how feedback affects team performance and team members' efforts, a model representing both levels of analyses (individual and team levels) in parallel and examining other types of 
outcomes and mediators besides performance may bring additional insight into what makes the difference between effective and less effective feedback interventions.

\section{A TEAM FEEDBACK MODEL TO ORGANIZE FEEDBACK RESEARCH IN TEAMS}

A team feedback model was thus established to explore how specific features of feedback delivery, situations, characteristics, and perceptions of the team and team members could moderate the widely acknowledged feedback effects (fig.1). Such theoretical model was developed by London and Sessa (2006). They consider that feedback plays a central role in group learning and performance by helping the team regulate its actions, evaluate, and react to its environment, by supporting team development, interdependence, and shared mental models growth. They assume that characteristics of feedback (source, purpose, clarity, and valence) influence perceptions of the feedback (i.e., how the feedback is perceived by the team and its members). Perceptions of feedback are shaped by individual or group characteristics or situations le.g., demands and goals, prior learning experiences) and are hypothesized to affect how feedback is processed, which in turn gives rise to group or individual outcomes.

First, the feedback can have different characteristics. As depicted in Figure 1, based on former reviews studies, three feedback characteristics were defined beforehand to serve as clusters to the feedback literature classification, namely the feedback level (team or individual level), type (process or performance feedback), and the feedback combinations (feedback as a single input or in combination with other components). Regarding the feedback combinations, feedback was either a single component (feedback effect could be isolated) either part of a treatment, program, or training consisting of a set of components (Komaki \& Goltz, 2001). This has important implications in the evaluation of the findings, as the latter can show confounding effects of the diverse components if their effect cannot be isolated.

Second, it is important to consider the characteristics with which teams are endowed and situations in which they are embedded to uncover the ones that are critical to feedback use or that might moderate the effect of feedback on certain groups. For example, teams can be assigned a goal or they may have prior learning experiences.

Third, perceptions of feedback are defined as the extent to which team members believe that feedback is important, accurate, and useful, while 
processing feedback concerns how the team and/or individual members process the received feedback. Indeed, if a feedback is interpreted as irrelevant and not useful for task completion or team functioning, teams or team members can react to this feedback by ignoring, discounting, rejecting, and consequently not processing it. They won't use the feedback to make the desirable changes for improvement nor implement more effective and efficient strategies if they don't assign meaning to the received feedback.

Forth, in the initial model, outcomes comprise task outcomes Itask performancel as well as learning outcomes such as shared mental models. We elaborated on London and Sessa's model (2006) to use it as a framework to analyze studies on feedback interventions in teams, in order to examine all factors shown to be related to feedback effects in the reviewed studies. We operationalized the construct "individual or team outcomes" into three groups of dependent variables on which feedback effects could be investigated: team or individual outcomes (e.g., performance, satisfaction), team processes, and emergent states (i.e., cognitive or affective states emerging from the interactions among team members), the two latest being moderator variables in team effectiveness frameworks (Mathieu at al., 2008).

Finally, we looked at one methodological criterion of the analyzed studies that may act as a moderator of the model and was not part of London \& Sessa's model: the study design (field or laboratory study). On the one hand, feedback can be easily manipulated in laboratories but may lack of a real team context that could render the feedback less meaningful for teams. On the other hand, feedback effects may be confounded with other variables at multiple-levels in real team settings. Moreover, a structural characteristic was added to the analysis; the team/task type appeared as a potential important factor to examine (Nadler, 1979). Feedback interventions included in this article concerned an extensive range of tasks such as a task classification might shed light on how a specific feedback type/level affects certain types of teams. Some teams may be less receptive to certain feedback. Devine (2002) developed a team taxonomy distinguishing knowledge work teams lendowed with tasks with a mostly intellectual nature) and those completing a physical work, physical work teams. Knowledge work teams mainly engage in thinking tasks involving mental skills, within a nonlinear work process, and develop new knowledge and information as final products (e.g., executive teams, design teams). As for physical work teams, they mainly engage in physical work, involving physical skills within a linear work process, employ existing knowledge, and come up with a concrete product/service (e.g. service teams, production teams, medical teams). All these variables and their interrelations are illustrated by Figure 1. 


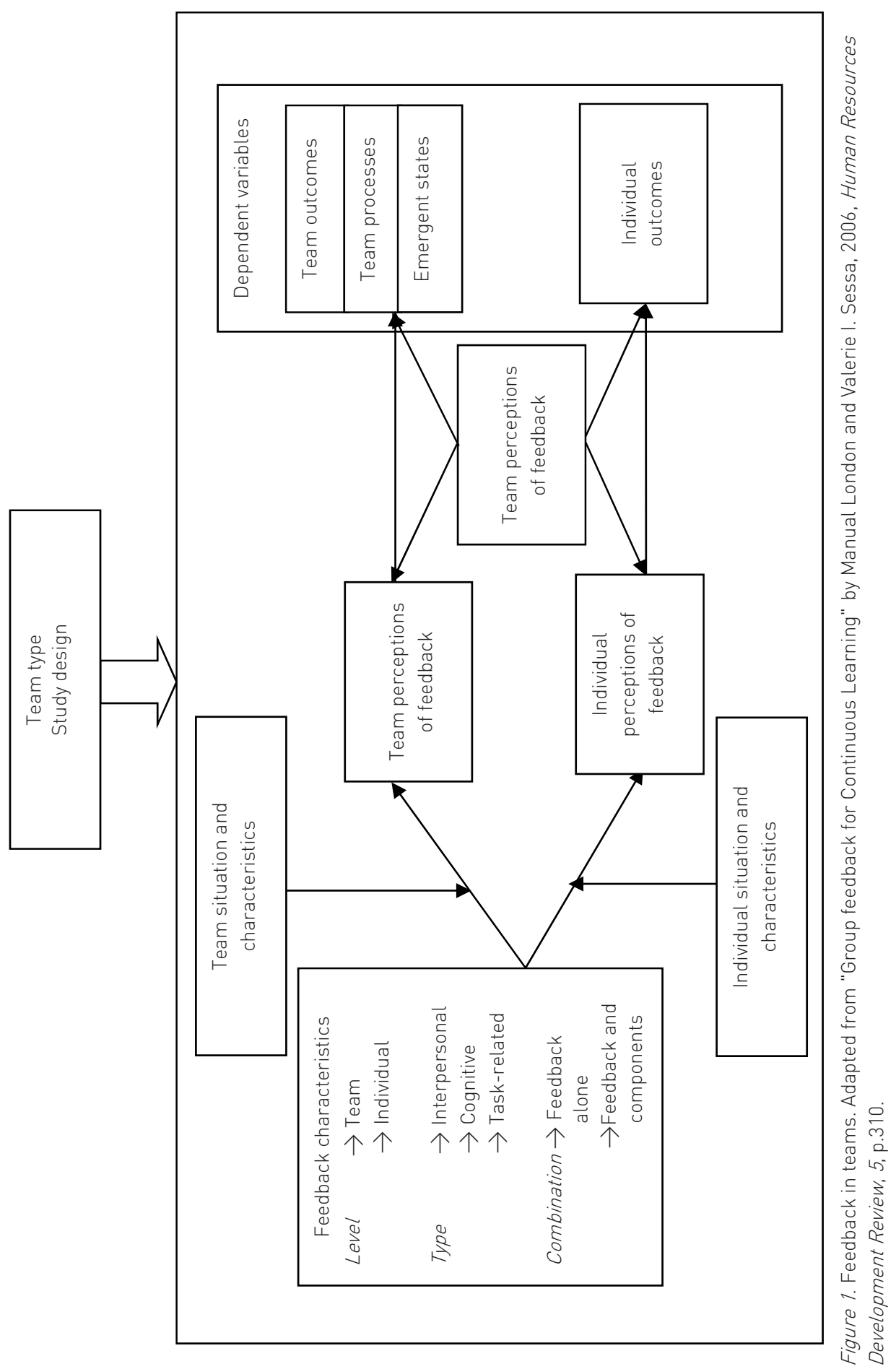




\section{METHODOLOGY}

The aim of the current review is to present an integrated summary of the accumulated state of knowledge concerning the effects of feedback interventions on task performance, team processes, and emergent states in teams. To conduct our review, we first highlighted from previous reviews and theoretical articles some critical characteristics of feedback (feedback level, type, and combinations) that would serve as a first filter to categorize the reviewed studies. Second, we set a series of criteria for inclusion to delimitate the huge feedback research to a manageable group of studies allowing for a comprehensive analysis. Third, once the studies meeting the criteria for inclusion were set, they were reorganized within categories describing the type and level of feedback they applied. Finally, each group of studies was analyzed in the light of the conceptual framework.

\section{Criteria for relevance}

All the studies eligible for the review needed to share several characteristics: they were empirical studies implementing feedback interventions to teams through a third party; they took place in higher education or organizational settings; they used a team task; they reported feedback interventions as an independent variable being a single treatment or combined with other components; they referred to feedback effects on dependent variables (Fig.1), and they explicitly reported how they measured feedback and feedback effects with minimum descriptive information about the feedback content, level, and procedure. According to our definition of a team, team members had to be dependent on each other for gathering relevant information needful for team success, share a common goal, and have their individual outcomes directly affected by team performance. Therefore we excluded all studies in which groups of people were meeting without requiring interaction or interdependence and without a clear common work task like T-groups, therapy groups. As this review focused on the effects that a teacher, manager, supervisor, counselor, or human resource manager reaches while providing feedback to teams, we excluded peer feedback, 360-degree feedback and self-initiated feedbackseeking behavior. Studies involving direct sharing of raw data between team members, feedback stemming from multiple sources or from the task itself (task-generated feedback), or natural feedback processes coming about without an external intervention were not incorporated in the review. Only studies 
comparing various feedback sources to feedback from an external agent were included.

\section{Search terms and databases}

The following online databases were searched: Business Source Premier; CINAHL; EconLit; ERIC; GreenFILE; The International Bibliography of the Social Sciences (IBSS); Library, Information Science \& Technology Abstracts (LISTA); Philosopher's Index; PsycARTICLES; The PsycINFO; Regional Business News; SocINDEX and Psychology \& Behavioral Sciences Collection. We gained access to full-text documents by means of a wide range of search terms or keywords, namely "feedback" combined with "team" or "group"; "feedback", "group" and "group performance"; "feedback intervention"; "process feedback"; "performance feedback"; "cognitive feedback"; "interpersonal feedback", and "social feedback". After checking for replicates, 585 unique sources remained. In the subsequent selection phase, the abstracts of the 585 references were read to select the relevant studies based on our criteria for inclusion. The application of the criteria for inclusion reduced the relevant references to 91 , among which only 59 were fully available. The remaining 32 abstracts seemed to match the criteria but were unavailable online, in libraries, or after an email has been sent to the authors. The reviewed studies were either the object of a published article or part of a dissertation. If several studies were reported in dissertations, they were counted separately. In case series of studies were conducted by the same researchers in one article, they were counted as one single study unless they could be classified in different categories of studies.

\section{Coding}

To keep an overview of the results of this large number of feedback publications, characteristics of each consulted study were encoded in a table, specifically its reference, the database and keywords used, a check of the criteria for inclusion, its setting, participants, the type, form, and level of the feedback delivered, the feedback recipient, all measured variables, the hypotheses, method, main results and limitations of the study, as well as the potential critical factors for feedback effectiveness. The critical factors represented the variables that were shown to be related to feedback effectiveness las defined in London \& Sessa, 2006). This overview allowed a double check of the study relevance. 46 articles providing insight into feedback in team settings but not responding to the criteria for inclusion were stored in a specific table. 


\section{First step in the analysis}

The 59 studies included in the review were divided into categories allowing for a more accurate analysis. First, four general groups of studies were formed based on one characteristic of their feedback interventions, namely the feedback level: studies implementing individual-level feedback, the ones using team-level feedback, the ones comparing the effect of individual versus team-level feedback, and the ones providing both levels indistinctively.

Second, within these groups, feedback applications were subdivided according to the type of feedback they were providing: performance feedback alone; process feedback alone; process feedback versus performance feedback; and both types provided indistinctively. Thus, overall, 8 categories were created. Third, within these categories, the studies were split in two groups: the studies implementing feedback alone and the studies using feedback in combination with other components.

\section{Literature analysis}

After clustering the selected 59 studies, a comprehensive analysis within each feedback subgroup was conducted. A first step was to look at the study design (laboratory or field study) and the team type (knowledge or physical work teams) to eventually draw conclusion on these moderators when there seemed to be different patterns of results and if enough studies allowed any comparison.

A second step has been completed to identify possible moderators of feedback effectiveness. We looked at feedback, individual or team characteristics, feedback perception and processing that were measured and/or manipulated in the reviewed studies and checked whether their impact in the relationship between feedback interventions and the measured independent variables could be highlighted.

Regarding the dependent variables that feedback was expected to influence, they were organized along three subcategories according to the conceptual model: (a) individual or team outcomes (e.g. performance), (b) team processes, (c) emergent states (subcategorized as cognitive or affective). This categorization aimed to explore whether certain types of dependent variables were more affected by a certain feedback type/level. Furthermore, as summarized in Table 2, feedback effect on measured dependent variables was considered as:

- a positive feedback effect when feedback resulted in uniformly positive effects on all the dependent variables

- a negative feedback effect when feedback resulted in uniformly negative effects on all the dependent variables 
- no feedback effect when the studies did not show any changes in any of the dependent variables

- a mixed positive effect when feedback resulted in a positive effect on certain dependent variables and no effect on some others

- a mixed negative effect when feedback resulted in a negative effect on certain dependent variables and no effect on some others.

\section{RESULTS}

The results section starts with an overview of the studies included in the review, more precisely a description of the research designs and team types covered by the studies and the distribution of the studies over the feedback-level categories. Subsequently, studies are examined into details for every feedback level. In particular, feedback effectiveness is cross-examined and variables shown to be related to feedback effectiveness are highlighted. In each group of studies, we look at the nature of the dependent variables impacted by feedback interventions and the type of feedback associated with the effect.

\section{Overview of the 59 studies included in the review}

Most of the studies selected in the review (81\%) were conducted in the United States. Regarding the time line, approximately one third of studies took place during or before the eighties, one third in the nineties and one-third after 2000.

With respect to the research design of the studies, as presented in Table 1, 60\% of the feedback interventions took place in laboratories, while $40 \%$ were conducted in the field. Among these field studies, $80 \%$ studied the target variables in organizational settings, whereas only $20 \%$ examined teams of students in educational settings. Studies experimentally looking into feedback effects mainly consisted of one or more feedback treatment conditions in which participants were provided with feedback information compared to a no feedback control condition. Field studies were of different types. 7 corresponded to descriptive studies. A large group of studies compared feedback intervention(s) to 1) a no intervention group (in 4 studies), 2) a prior baseline period during which teams were not provided with any treatments (in 8 studies) or 3) a group receiving another level of feedback (in one study). Finally, 4 studies were longitudinal with repeated-measures. 


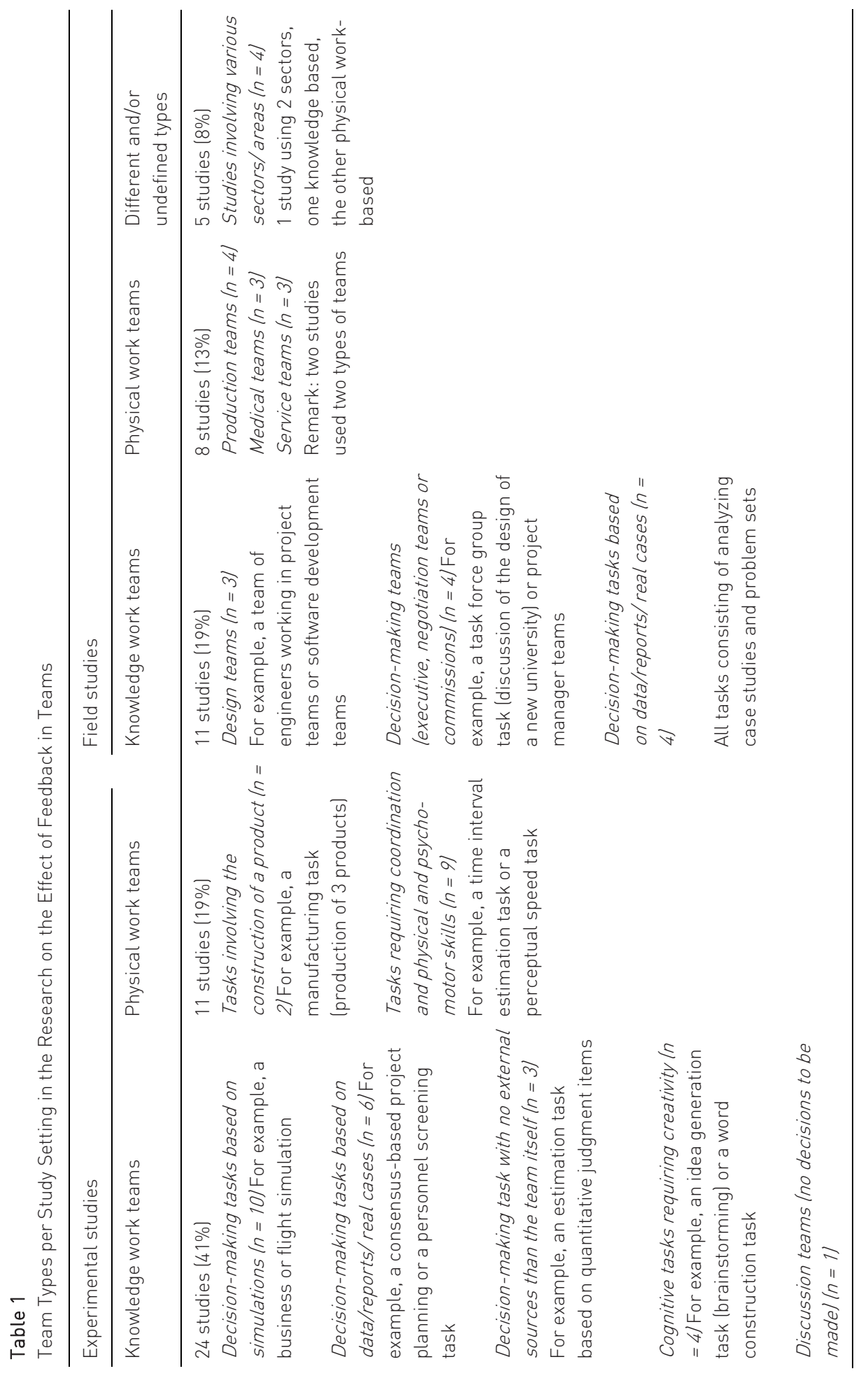


Table 1 also indicates that knowledge work teams appear to be the most frequent team type used in the reviewed studies. More interestingly, when looking at the team types per study design, $68 \%$ of the teams participating to laboratories performed tasks with a primarily intellectual nature. In other words, researchers using experimental designs to manipulate feedback tended to simulate thinking tasks. Specifically, these simulated thinking tasks were mostly tasks during which teams had to make many decisions, set goals, build plans, and monitor task execution. Some studies used simulation games providing teams with very complex environments and information flow and allowing them to make decisions and observe their consequences in a safe environment. Among these, in business simulations, teams had to run virtual companies and thus address organizational issues such as the analysis of their business performance, strategic planning, and the implementation of change plans. In flight, air traffic control, or air defense simulations teams were surrounded with extensive information that they had to integrate to make many non-routine decisions in real time. Besides simulations, other studies provided teams with reports, cases, and data to simulate team-decision scenarios. The difference lies in the medium used to trigger team decision and negotiation. Other cognitive tasks not relying on decision-making were tasks requiring creativity. There is an apparent analogy with design teams conceiving new products or services, frequently named research and development teams or project teams (Devine, 2002). For example, in one study, an idea generation task in which teams had to brainstorm as many solutions as possible to a problem was used (Prussia \& Kinicki, 1996). In laboratories, the remaining physical tasks were mainly tasks requiring coordination and physical and psychomotor skills. For instance, in tracking tasks, team members had to hold a moving cursor steady at zero by manipulating a control knob. Another physical-work example was observed in two feedback interventions requiring teams to construct an object. This is typically a simulation of production teams assembling or constructing concrete products (Devine, 2002). In comparison to laboratories, field studies exhibit a less contrasted trend. Feedback interventions targeting knowledge-work were slightly more frequent than the ones involving physicalwork teams. Again, among the knowledge-work teams, decision-making teams were the most frequent participants.

In educational settings, the tasks mostly required students to analyze a situation involving a decision or the resolution of a problem and to formulate recommendations. In organizational settings, the participating teams were mainly engaged in organizational-level decisions (i.e., executive teams as 
defined in Devine, 2002) or in highly procedural special projects or inquiries entailing judgments or plans (i.e., commissions as defined in Devine, 2002). Also, design teams developing new products participated in three studies. Physicalwork field teams were of three kinds: production teams, medical teams, and service teams (i.e., teams offering goods and services to customers).

Finally, Table 2 shows the number of studies within each feedback characteristic and the overall effectiveness of their feedback interventions. It provides an overview of several questions: how does team feedback research divide among all categories, what is the general trend of feedback research in teams, and what is the overall effects of feedback on various dependent variables. A first look at the distribution of the 59 studies shows three trends. First, most of the team feedback studies split into two categories both using performance feedback interventions as an isolated input: team-level performance feedback research (32\% of the feedback studies) and individual versus team-level performance feedback research la quarter of the feedback applications) comparing the effect of the two levels of feedback. More than half of the studies were hence designed in order to look into team-level feedback effects or solve the question about the superiority of one level compared to the other. Secondly, there is also a relatively small body of research about process feedback, which was used overall in $22 \%$ of the studies. If we leave aside the 8 studies using both types of feedback indistinctively, 46 studies reported performance feedback uses against only 5 using exclusively process feedback. Most of the 13 studies providing process information to teams reported feedback as a single independent variable and were rather team-level or both-levels based than individual-level based. One last striking observation is the absence of studies comparing the use of process and performance feedback in separate conditions, whereas the studies contrasting the levels of the feedback are overrepresented. At a first glance, the question whether it is more effective to target the team as a whole or the individuals with feedback seems more extensively tackled whereas the issue concerning whether information about process or performance or both is more powerful within team contexts seems unanswered. A closer look to the effects brought about by feedback interventions is taken in the following section. The analysis is structured per level of feedback and also looks into the type of dependent variables positively related to feedback interventions as well as the possible sources of variation of the effects of feedback on these variables as depicted in the theoretical framework (see Figure 1). 


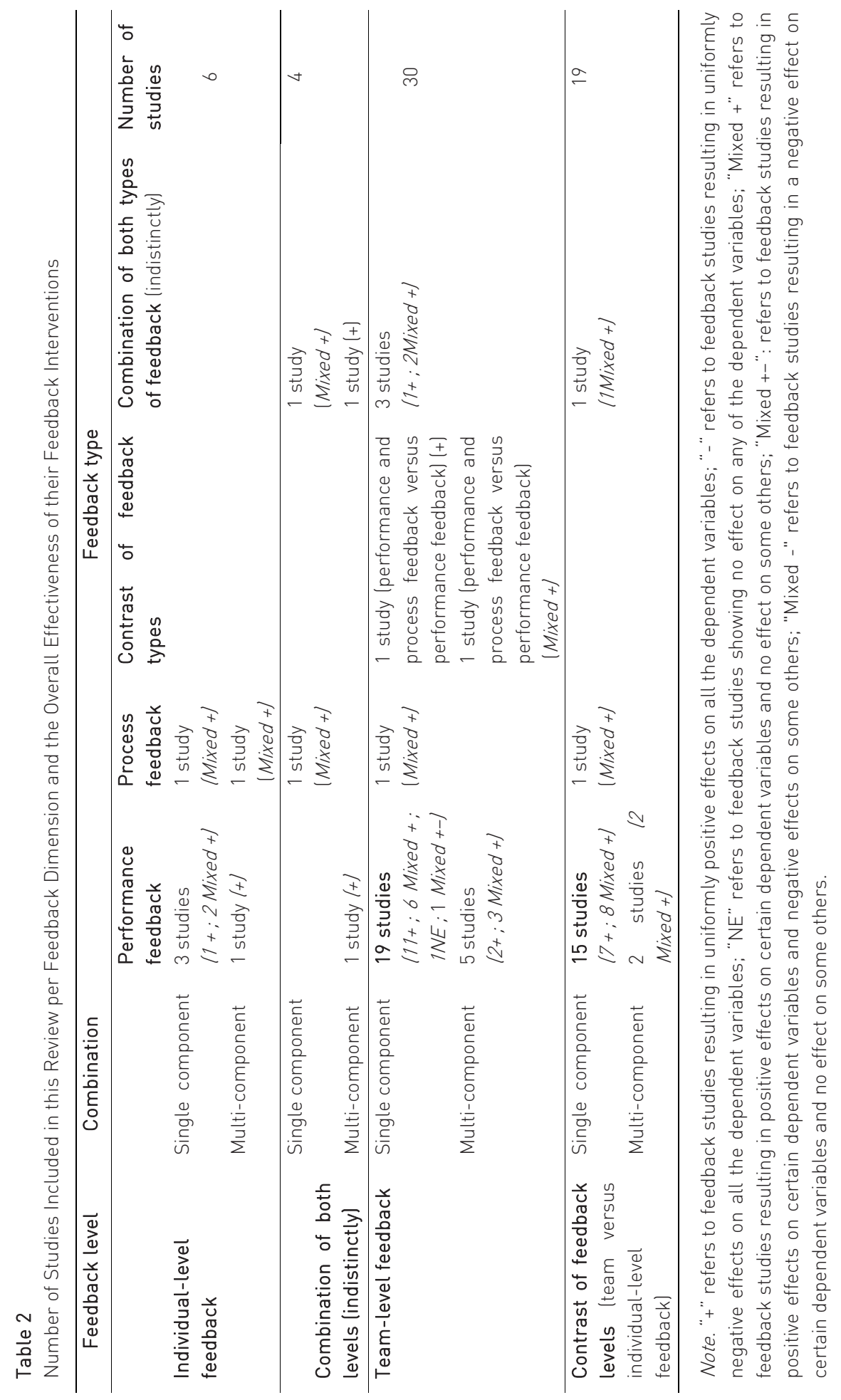


Feedback interventions analysis per feedback level

\section{Individual-level feedback research in teams}

The first question addressed in this section is whether individual-level information provided to individuals working in teams results in some changes. In this review, six studies investigated the effect of feedback that targets individual team members. Half of these used performance feedback as a single input. Two studies employed process feedback but only one revealed the single effect of process (cognitive) feedback. The other implemented process (interpersonal) feedback as part of an intervention. As a result, the effect of feedback could not be identified independently of the other intervention components.

\section{Individual-level performance feedback studies}

Performance feedback was shown to positively impact two team outcomes: group performance and job satisfaction (Hunter, 2006; Moreland \& Myaskovsky, 2000). In their laboratory study, Moreland and Myaskovsky (2000) demonstrated that individual-level performance feedback enhanced group performance when compared to a no feedback group tackling the same team task (radio building), being trained to the task individually beforehand as well but receiving no information about their performance. However, the feedback condition didn't diverge significantly from a team training condition. In the latter, participants learned how to complete the task together, could communicate freely during this learning phase, but didn't have any indication on their performance before completing the team task. Conversely, in the feedback condition, teams were given public individual-level information about their actual radio building skills stemming from the individual learning phase before completing the team task but were not allowed to communicate. Besides, they found support for a positive influence of feedback on two emergent states: a cognitive, namely transactive memory systems (i.e., knowledge distribution within teams), and an affective one, team members' familiarity with one another. Finally, two studies showed that performance feedback improved team processes: motivation (Kerr, Messé, Park, \& Sambolec, 2005) and team members' performance-related assertiveness behaviors (i.e., instances in which team members communicate their ideas, information, and observations in a persuasive way)(Smith-Jentsch, Salas, \& Bakern, 1996). For instance, in their experiment using a physical work task, Kerr et al. (2005) reached a motivation effect (i.e., "Köhler Effect") defined as situations in which team members surpass themselves and work harder in their team than they would if they were working alone. Nevertheless, these 
results were limited to one condition in which individual-level feedback was public so that all team members could detect each individual contribution.

\section{Individual-level process feedback studies}

Effects of process feedback at the individual level have been examined in only two studies, among which feedback was not shown to be significantly related to team performance, contrary to Harmon and Rohrbaugh's (1990) hypothesis. These are the only researchers looking at feedback as a single component. They did, however, find support for a positive effect of cognitive feedback on an individual outcome, individual learning, that is to say the improvement in individual decision making in a cognitive task. They also observed a positive effect on two cognitive emergent states, namely group consensus and reduction in disagreement among members. In their experiment, participants were first asked to render individual predictions about the outcomes of selected horse races based upon available information in racing forms. Subsequently, they were assigned to teams made of members with conflicting judgment policies. These teams were then asked to make team consensus-based predictions. Finally, individual judgments were requested again. Feedback treatments lvarying feedback sharedness) were compared to a no feedback condition. The results indicated that teams receiving cognitive feedback representing explicitly members' differential judgment policies and which sharedness was encouraged reached more consensual decisions with which every team member could agree. They also exhibited less disagreement between team members as could been proved by 1) a higher agreement among team members' individual post judgments, 2) a lower disagreement between post individual-level predictions and the group decision, and 3) higher subjective ratings of the group policy by team members. The other study demonstrated that interpersonal feedback could also enhance team processes, namely interdisciplinary skills, when combined with other strategies. Becker and Godwin (2005) showed that strategies orienting students to a virtual classroom, specifically greater technical support, print-based study guide, enhanced faculty guidance to mentors, and feedback about team members' participation, promoted greater team work skills but did not intensify the frequency of online interactions (students' postings).

In summary, the evidence seems to indicate that individual-level performance feedback can positively impact team outcomes (performance and satisfaction) and that individual-level process feedback resulted in enhanced team processes and cognitive emergent states, but not in better performance. None of the studies established any negative feedback effect. Feedback at the 
individual level did indeed lead to some changes on certain variables but it is important to know under which conditions these effects came about.

\section{Key factors to individual- level feedback interventions effectiveness}

In relation to important variables of feedback effectiveness depicted in the team feedback framework (fig.1), three feedback characteristics were shown to be of importance in individual-level feedback literature; sharedness, timing, and level of publicness of feedback (see the overview in Table 3). Harmon and Rohrbaugh (1990) pointed out that teams provided with individual-level cognitive feedback that was mutually exchanged among team members increased their individual learning and team consensus compared to subjects provided with individualized feedback of which sharing was not especially encouraged or to a no feedback group. Kerr et al. (2005) found that performance feedback timing was related to a group motivation gain ("Köhler Effect"). Specifically, a delayed individual-level performance feedback reduced the group motivation gain that could be attained by an immediate feedback. Concerning feedback level of publicness, they showed that continuous feedback and monitoring of all members' performance during the task was not necessary; the same effect was found when feedback was provided publicly at the end of the trial. However, giving no feedback or providing feedback on one another's performance that was not identifiable to anyone eliminated any gain. This result suggests the need for both a certain level of publicness and a timely feedback to trigger team motivation.

\section{Team-level feedback research}

There is a fair amount of studies in the feedback literature in teams in which feedback depicts the team as a whole and thus examines the effect of feedback at the team level. In total thirty studies address the question of how team-level feedback affects certain outcomes, processes, or emergent states las can be seen in Table 2). The majority of these researchers (75\%) considered performance feedback and mostly as a single independent variable. One study implemented team-level process feedback and enquired into its single effects whereas three studies used both types of feedback provided simultaneously as an isolated input. Additionally two team-level process studies compared the use of process feedback along with performance feedback against performance information alone. In both studies, there was no condition providing process information only. 


\section{Team-level performance feedback studies}

Team-level performance feedback appeared to have a positive impact on variables of diverse natures. First, there is an extensive team-level feedback literature that has incorporated team performance, the most extensively considered criterion variable, as a dependent variable. Feedback effect on performance was researched in 19 studies amongst which only 2 studies considered individual performance (Johnston \& Nawrocki, 1966; Johnston 1967), against 17 studies looking at team-level performance measures (Brannick, Prince, \& Salas, 2005; Cook, 1968; Ellsworth, 1973; Henry, Strickland, Yorges, \& Ladd, 1996; Hoegl \& Parboteeah, 2006; Kim \& Hamner, 1976; Ivancevich \& McMahon, 1982; Jung \& Sosik, 2003; Klaus \& Glaser, 1970; Mesch, Farh, \& Podsakoff, 1996; Passos \& Caetano, 2005; Philo, 2005; Pritchard, Jones, Roth, Stuebing, \& Ekeberg, 1988; Scott-Young \& Samson, 2006; Spoelders-Claes, 1973; Quigley, 2003; Walter \& Van Der Vegt, 2009). Although many researchers agree about performance feedback effectiveness, seven authors didn't find much support for its expected effect on performance (Brannick, Prince \& Salas, 2005; Ellsworth, 1973; Henry, et al., 1996; Hoegl \& Parboteeah, 2006; Jung \& Sosik, 2003; Quigley, 2003; Spoelders-Claes, 1973). For example, in a longitudinal field experiment conducted by Jung and Sosik (2003), one hundred six intact business undergraduate teams completed two complex team decisionmaking tasks, after which they received performance feedback. It appeared that feedback significantly influenced two affective emergent states, namely collective efficacy and group potency, but not team performance. Beyond the prominent performance outcome, two other outcomes measures were found to be impacted by performance feedback. Satisfaction was enhanced by feedback interventions in 4 studies (Hyrkas \& Lehti, 2003; Kim \& Hamner, 1976; Mesch et al., 1996; Pritchard et al., 1988) and organizational commitment in one study (Ivancevich \& McMahon, 1982).

Second, many studies have established feedback positive effects on various team processes, in particular group goal (Mesch et al., 1996; Quigley, 2003), strategy development (Quigley, 2003), coordination behaviors (Brannick et al., 2005), task and relationship conflicts (Peterson \& Behfar, 2003), motivation (Ivancevich \& McMahon, 1982; Staw, 1975), communication and influence (Staw, 1975), and team processes defined as the extent to which team members set goals, analyzed information, monitored their environment, set and implemented strategies, and coordinated their activities (Quigley, 2003). For instance, in their longitudinal field study, Peterson and Behfar (2003) demonstrated that initial performance feedback strongly influenced subsequent team interactions. In 
particular, teams completing two successive case studies and given the more negative team-level performance feedback after the first task encountered the more subsequent relationship and task conflicts, which also predicted a poorer team performance at the second task. They underlined that these processes could cause and be impacted by low team performance, creating then a negative performance spiral.

Third, some research has considered the effect of feedback on emergent states. This body of work has primary focused on affective emergent states and provided evidence that feedback reinforced the following team affective properties: goal commitment (Hoegl \& Parboteeah, 2006), leader efficacy (Quigley, 2004) group potency (Jung \& Sosik, 2003), collective or team efficacy (Jung \& Sosik, 2003; Quickley, 2003; Scott-Young \& Samson, 2006), cohesion (Philo, 2005; Staw, 1975), attitudes toward the task and levels of aspiration (Cook, 1968), openness to change (Staw, 1975), and group members' perceptions of heterogeneity and outcome expectation (Jung \& Sosik, 1999). For example, Scott-Young and Samson (2006) demonstrated that performance feedback was a significant predictor of team efficacy, which was associated with better performance in manager teams (knowledge work teams).

Cognitive emergent states have been a dependent variable of interest in only one experimental study. Specifically, Henry et al. (1996) showed that providing knowledge work teams talking about undemonstrable solutions with feedback rendered them better able to identify their best member, more precisely through assessing the relative quality of team members' inputs in the discussions.

To conclude, it is noteworthy to highlight that although team-level performance feedback literature failed to significantly relate feedback use to certain variables (mostly performance) in some studies, it did not yield negative effects, except in one study. In the later, Peterson and Behfar (2003) highlighted the danger of providing initial negative feedback to teams comprising members who distrust one another.

\section{Team-level process feedback studies}

As presented in Table 2, the few studies looking into team-level process feedback are divided into four groups: (a) one single study investigating process feedback (Kernaghan \& Cooke, 1990), (b) one study contrasting two feedback treatments; the first treatment combining process feedback with performance feedback and the other one implementing performance feedback alone (Hollenbeck, Ilgen, LePine, Colquitt, \& Hedlund, 1998), (c) one study comparing the same two feedback treatments but complementing feedback with another 
component (McLeod, Liker, \& Lobel, 1992), and (d) three studies using both types of feedback indistinctively (Gear, Marsh, \& Sargent, 1985; Prussia \& Kinicki, 1996; Voelker, 2003).

First, Kernaghan and Cooke (1990) conducted the only experiment providing team-level process feedback to teams carrying out a project-planning task (knowledge work task). They found that interpersonal feedback (e.g., active listening, clarifying, supporting others' opinions) was insufficient to improve team outcome quality as opposed to task-related process feedback le.g, analyzing the situation, setting objectives, developing alternatives) but only when team members of the consensus groups had the ability to process it. Indeed, feedback effect was not supported for the whole sample; they only found it in high-ability groups. Moreover, they observed that providing both types of feedback didn't lead to superior team performance.

Second, the study complementing process (cognitive) feedback with performance feedback suggested that it might be an effective combination in decision-making teams (knowledge work task). Hollenbeck et al. (1998) investigated the effect of feedback on the constructs of the theory of team decision-making, namely decision informity, individual validity, and dyadic sensitivity. Decision informity referred to the extent to which members had all information necessary to play their part in the team; individual validity was defined as members' possibility to make recommendations predictive of the correct decision; dyadic sensitivity was the degree to which leader weighted each recommendation. The authors expected that teams receiving cognitive feedback on these core constructs would outperform teams that were only provided with performance feedback. Moreover, they assumed that the relationship between process feedback and team performance would be mediated by the aforementioned core-constructs. The results supported their hypotheses.

Third, in an experiment by McLeod, Liker, and Lobel (1992), teams carrying out two consensual decision-making tasks were given a midpoint feedback about their interpersonal behaviors and their performance as well as an explicit discussion time during which they were asked to set a goal for the second task. They were compared to teams provided with performance feedback and given time for an unstructured discussion. Interpersonal behaviors consisted of the evaluation of the dominance behaviors (whether displayed behaviors were dominant or submissive) and the group orientedness (whether the displayed behaviors were oriented to the task or to socioemotional aspects). The results indicated that interpersonal feedback along with performance feedback and goal setting reduced the dominance behaviors of the team members but did not 
improve performance. These dominant behaviors were hypothesized to be detrimental to teams as they could drive other teammates to behave submissively in response and thus avoid speaking up in their teams.

Fourth, none of the studies providing teams with process along with performance feedback highlighted any significant effect of process feedback on performance. Prussia and Kinicki (1996) and Voelker (2003) tested this relationship in their respective studies, the first one with task-related process feedback, and the other one with interpersonal feedback on cooperation in the team, but both failed to find significant performance changes. Rather, this group of studies demonstrated that process feedback could enhance team processes, namely team behaviors such as making suggestions, asking directions, or giving support (Gear et al., 1985) and cooperation (Voelker, 2003), as well as three affective emergent states, group affective evaluations, collective efficacy (Prussia \& Kinicki, 1996), and perceived strategy effectiveness (Voelker, 2003). For example, Prussia and Kinicki (1996) didn't find a direct path between feedback and group effectiveness in teams completing a knowledge work task but proved that this relationship was mediated by group affective evaluations (i.e., team satisfaction regarding their output quantity and their process behaviors) and collective efficacy (i.e., evaluation of the team ability to achieve a particular situation).

In summary, the few studies looking into team-level process feedback seem to produce positive but still mitigated results. Three authors out of five failed to associate team-level process feedback with performance (McLeod et al., 1992; Prussia \& Kinicki; 1996; Voelker, 2003) but all did find support for positive changes in terms of team processes and emergent states. With respect to feedback type, it seems like interpersonal feedback about teams' social aspects used in four studies (Gear et al., 1985; Kernaghan \& Cooke, 1990; McLeod at al., 1992; Voelker, 2003) lack the power to directly influence performance while having a consistent impact on other process variables. Indeed, this is in line with the traditional assumption that interpersonal feedback supports task completion by enhancing interpersonal processes (Dominick, Reilly, \& McGourty, 1997; McLeod et al., 1992), which in turn enhance team performance (Hackman, 1987; McGrath, 1991). On the contrary, in a decision making task, a team-level cognitive feedback may improve the decision-making performance if combined with outcome information. With regard to task-related process feedback, two studies obtained contradicting results. Prussia and Kinicki (1996) didn't find any direct path between task-related process feedback and performance whereas Kernaghan and Cooke (1990) could highlight this relationship with high ability team members. This process feedback research is interesting and encouraging, 
although there is a need for clear conceptual definitions of the processes that a feedback can describe. In addition, in comparison to team-level performance feedback, team-level process feedback has been examined scarcely, so that any decisive conclusion cannot be given as yet. Similarly, the question of whether the effectiveness of performance feedback can be increased when it is paired with process feedback still needs to be documented.

\section{Key factors to team-level feedback interventions effectiveness}

Looking into determinants of team-level feedback effects is a step toward a better understanding of how feedback proceeds. Eleven important variables to feedback effectiveness were highlighted in these team-level studies las summarized in Table 3). Three variables all based on performance feedback research pertained to feedback characteristics: frequency $(n=2)$, valence $(n=4)$ and feedback source ( $n=2)$.

Feedback frequency was shown to positively influence performance, attitudes towards the task, level of aspiration (Cook, 1968), and team proficiency (Klaus \& Glaser, 1970). Both studies provided support for the use of frequent feedback.

Regarding feedback valence, four studies supported its effects on individual performance, self-evaluation of the performance (Johnston, 1967), group performance (Mesch et al., 1996), group affective evaluations, collective efficacy (Prussia \& Kinicki, 1996), relationship and task conflicts (Peterson \& Behfar, 2003), group goals, group satisfaction with performance, and group strategies (Mesch et al., 1996). There seems to be convergence among researchers concerning positive feedback, which acted as a reinforcer of the beforementioned variables. There is less agreement on the effect of negative feedback. On the one hand, Peterson and Behfar (2003) showed that negative team-level performance feedback produced subsequent higher relationship and task conflicts. These results suggest that informing teams at an early stage they performed below average could be detrimental to their subsequent relationships, especially for those teams with low initial intragroup trust. On the other hand, Mesch et al. (1996) came to the conclusion that negative feedback could be a trigger. In their laboratory study, although teams provided with negative performance feedback were less satisfied, they had higher group performance, group goals, and strategy development than positive feedback groups.

The question of the feedback source effect was addressed in two studies exhibiting contradicting results. Kim and Hamner (1976) conducted a field study in which service teams received either extrinsic (supervisory) feedback, either 
intrinsic (self-generated) feedback, or both paired with goal setting. Selfgenerated feedback stemmed from team members' rating of the service quality and was kept private. Extrinsic feedback and praise (i.e., congratulations for good performance) was given to the teams by a supervisor and relied on goals teams were regularly setting for the work week. These conditions were compared to a goal setting only condition, in which teams were only asked to define their goals. It was found that feedback outperformed goal setting implemented alone, that the highest enhancement on two performance measures (cost and safety) was observed for groups receiving feedback from both sources, praise, and goal setting opportunity but that extrinsic feedback was better at improving service. Satisfaction was enhanced in all the conditions except in the intrinsic feedback group. Conversely, in a field study with design teams, Ivancevich and McMahon (1982) compared extrinsic feedback, selfgenerated feedback, and feedback from co-workers to a no feedback condition. The results demonstrated that goal setting groups with self-generated feedback outperformed supervisory feedback teams and those receiving co-workers feedback on two team performance measures, satisfaction and commitment. However no condition with intrinsic feedback alone was implemented so that feedback source and goal setting effects were both accountable for the performance changes.

Eight factors were team or individual situation and characteristics; two were individual-related (individual proficiency and positive mood) and the others were team-related: team structure, task structure, team goal setting ( $n=4)$, strategizing, a "high performance" belief, and previous intragroup trust. Most empirical work on team-level feedback has thus focused on team-level variables.

In a series of experimental studies conducted by Klaus and Glaser (1970), team performance was shaped by individual proficiency (i.e., individual ability measured at the experimental task) as well as the structure of the team and of the physical work task. In particular, they showed that having redundant members performing simultaneously the same subtasks or occupying the same position and using tasks requiring minimal interdependence among team members were detrimental to team performance. Differently stated, tasks structured so that team members had to collaborate in an interdependent manner and coordinate their actions resulted in performance improvements.

Four studies showed that a combination of goal setting and performance feedback leaded to higher performance (Ivancevich \& McMahon, 1982; Kim \& Hamner, 1976; Pritchard et al., 1988) and that interpersonal feedback along with goal setting changed team members' dominant behaviors (McLeod et al., 1992). 
For example, Pritchard et al. (1988) conducted a field study in an Air Force base in which they implemented a team-level performance feedback, goal setting, and incentive system. A baseline was first established during which no feedback was given, followed by a period of feedback delivery to each unit, after which goal setting and then incentives were added. They observed an increase of productivity of $50 \%$ over baseline for feedback, $75 \%$ over baseline for group goal setting, and $76 \%$ over baseline for group incentives.

Besides setting team goals to strive for, it was shown that formulating team strategies to make changes and improvements could also facilitate team functioning and performance. Philo (2005) indicated that time spent on strategizing, more precisely collectively discussing the ways to react to negative performance feedback and achieve improvements during a team feedback meeting, was positively related to an affective emergent state, namely team members' shared commitment to the team (i.e., team cohesion) and a performance measure, team membership stability over time (i.e., team viability).

Two group characteristics were also found to be influential. The extent to which team members believed they were in an effective team had an impact on how they perceived their group processes (e.g., cohesiveness, openness to new ideas, communication) in a study carried out by Staw (1975). In particular, teams believing they were high performing evaluated their team processes better than teams believing they were low-achievers. Additionally, Peterson and Behfar (2003) showed that groups not trusting each other before receiving a negative feedback were at risk to ongoing relationship conflicts and poor performance. These results support the effect of previous process experiences on upcoming interactions.

Finally, one factor referred to the role of perception of the team feedback. Walter and Van der Vegt (2009) demonstrated that feedback perception moderated the relation between team members' positive mood and the degree to which team members engaged in team learning behaviors (i.e., team learning facilitation). Positive mood only promoted team learning facilitation when the well-being individuals perceived they had been provided with team-level performance feedback to a high extent.

In sum, team-level feedback literature provided insight into potential facilitators of feedback effect. It was proven that feedback that was frequent, positive, shared, and available to all team members helped teams perform or function better. Second, team members having interdependent roles, setting team goals, given incentives, reflecting upon possible strategies to achieve these goals, trusting each other, and believing they performed well appeared better 
able to achieve some changes. Finally, well-being individuals seemed to engage more in team learning behaviors.

\section{Combination of both levels of feedback (team-level and individual-level)}

Four researchers provided teams with information about the team as a whole along with information allowing team members to detect their own contribution through individual-level inputs. One study looked at performance feedback combined with another component; one used process feedback as a single component, and finally, two studies provided both feedback types and levels, one implementing feedback as a single component, the other using it as part of a training. As individual and team level-feedback were provided indistinctly, these studies don't allow for a conclusion concerning the most effective level on which feedback should be given but show how valuable the combined use of both levels can be.

\section{Individual and team-level performance feedback study}

Austin, Kessler, Riccobono, and Bailey (1996) evidenced that individual and team-level performance feedback along with various possible behavioral consequences (monetary reinforcement or time off) increased two team outcomes in a production team: productivity and safety performance li.e., the use of safety behaviors).

In one study, cognitive feedback was shown to improve a cognitive aspect of decision-making behavior: the degree to which team members or the team control(s) the execution of their or its decision strategy, which is hypothesized to help teams learn new decision strategies. In a decision-making experiment, Sengupta and Te'eni (1994) demonstrated that information about members' decision strategy and its execution had a positive effect on the level of cognitive control over the decision-making process but no significant effect on the degree of similarity amongst team members' decision strategies li.e., strategy convergence) compared to a no feedback group.

In a case study, Sivunen (2006) demonstrated that performance and process (interpersonall feedback given at both levels indistinctly improved an affective emergent state: members' identification with the team.

Finally, in a survey study conducted by Hey, Pietruschka, Bungard, and Joens (2000), 357 team workers from service and production teams rated the overall effectiveness of individual and team-level feedback they were receiving in their respective companies as low, only a part of it being perceived as leading to higher performance or cooperation. They also stated that team feedback was not 
regular, was not given immediately after a certain performance or behavior, and was not received directly nor it was specific enough.

\section{Key factors to team-level feedback interventions effectiveness}

There are four feedback characteristics presented as relevant for its effectiveness in Hey et al. (2000): feedback timing, frequency, specificity, and constructiveness. These were provided to the team respondents as criteria to rate feedback received at their workplace and were evaluated as insufficiently met in their respective companies.

Only one study investigated the effect of a team situation and characteristic related to feedback effect. As described earlier, Austin et al. (1996) found that behavioral consequences (monetary reinforcement or time off) were associated with performance improvements.

\section{Team-level feedback versus individual-level feedback}

The studies reviewed so far focused on one feedback level or both simultaneously. Next to these, a range of studies examined feedback level as a potential source of variation of feedback effect and tested if the extent to which feedback targeted the team as a whole, team members, or both brought about changes. The question about the appropriate level of feedback to be provided in teams has been the central issue of 19 studies in total. Again most of the studies contrasted the use of performance feedback at both levels and looked into its single effect.

At a first glance, one may perceive conflicting and somewhat inconclusive results between four groups of studies in disagreement about the level(s) of feedback found to be more effective. In this section, the studies are grouped according to their findings on the more efficient feedback level they identified. That implies that feedback effect is examined per group of studies lending support to the same conclusion.

First, five studies evidenced the effectiveness of team-level performance feedback over individual-level feedback. Positive effects were found on a team outcome, namely team performance, in three studies (Doerr, Mitchell, Klastorin, \& Brown, 1996; Goltz, Citera, Jensen, Favero, \& Komaki, 1989; Tindale, 1989). Additionally, they demonstrated that it enhanced three team processes, namely task motivation, effort, and persistence intentions (Barr \& Colon, 1994; Doerr et al., 1996), and one affective emergent state, namely pride in group performance (Berkowitz \& Levy, 1956). These studies involved either experimental decisionmaking teams or existing production teams completing a team product. For 
example, Barr and Colon (1994) looked at the effect of feedback as a single component, manipulated the feedback sign given to individuals and to the teams (positive or negative), and the distribution of individual feedback received by team members (majority positive or majority negative) in a business decisionmaking simulation. They confirmed their hypothesized main effect of team-level feedback on individual persistence intentions (i.e. self-rating of the probability to persist in a newly introduced behavior). Furthermore, groups provided with positive team-level feedback displayed higher intentions to continue the new behavior than groups receiving negative feedback. They also showed that individual-level feedback had an effect on persistence intentions only when the received feedback was negative. Finally, they established that team members provided with a majority feedback, which is an individual feedback that does not differ from those received by group members, displayed more persistence intentions, than those receiving a minority feedback. For example, when an individual member gets a positive feedback and the other team members receive a positive feedback as well, he will keep on displaying his behavior more than if he has been provided with a negative feedback.

Secondly, alternatively, some researchers contended that team members might be confused by ambiguous team-level inputs not conveying any diagnostic information on how they could improve their own individual behaviors driving team performance. Three studies demonstrated that providing both individual and team-level performance feedback affected team performance more than individual or team-level feedback provided alone (Matsui, Kakuyama, \& Onglatco, 1987; Rosenberg \& Hall, 1958; Zander \& Wolfe, 1964). These were laboratory studies all employing tasks requiring physical and psycho-motor skills. For instance, Matsui et al. (1987) investigated the effect of feedback and goal attainment using a perceptual speed task. Teams were asked to set individual and team goals and were given feedback concerning their goal attainment. More specifically, they were told they were above or below the previously specified target. They found interaction effects of both levels of feedback, meaning that individual and team-level feedback were complementary and could maximize feedback effectiveness. They supported that if team members were not given individual-level information, those below target with respect to their individual performance would not enhance it in the case their team performance was meeting their team goal. Conversely, with no team-level feedback delivery, those subjects whose team was not on course to meet their target goal would not increase performance when they were on target individually. 
Thirdly, yet one may argue that team members may be overwhelmed by multiple-level data provided continuously and thus fail to carry out effectively their team tasks. Four studies demonstrated the superiority of individual-level performance feedback compared to team-level feedback on performance (Burgio et al., 1990; Burnstein \& Wolff, 1964; Stone, 1971). For example, in a field study, Burgio et al. (1990) observed that after team-level performance feedback was introduced to medical teams, their performance showed an improvement that declined gradually after several months. When individual-level feedback data were provided, team performance recovered. However, these results didn't control for sequence effects as both levels of feedback were given sequentially to the same people. Additionally, in one study by Smith (1972), individual-level process (interpersonall feedback produced more changes in participation, an interaction process, than team-level feedback. Overall, this group of studies didn't converge on the team type they used.

Fourth, two studies showed no effect of feedback level. Roberts (2000) didn't find any association between performance feedback levels and performance. Sniezek, May, and Sawyer (1990) conducted the only study contrasting feedback levels and types (both types versus performance feedback) and compared these conditions to a no feedback condition and a condition under which members expressed their expectations about each other's commitment. In their experimental setting, they created a conflict between individual and team interests through the rewarding system of a resource allocation task and provided feedback about the team or individuals' contribution to the team task (cognitive feedback) and the individual or group outcome amount (performance feedback). Significant increased resource allocations to the group were observed in groups receiving cognitive feedback, specifically if that feedback was at the individual-level over team-level feedback. However, the effect of feedback level no longer existed when team members expressed their expectations about other members' future contribution to the group. This study suggested that cooperation and greater concern for team outcomes was increased by knowledge of members' contributions to the group whether this information was provided or self-generated.

\section{Key factors to team and individual- level feedback interventions effectiveness}

Although these four groups of studies were not in agreement with reference to which feedback level they found more effective than the other, it is worth exploring possible moderators of their findings so far. A plausible hypothesis 
would be that team type might play a role. For example, in the first group of studies providing support for the stronger effect of team-level feedback, all studies took place in teams whose performance was depicted on a team-level, whether they were production teams interdependently contributing to a final team product or decision-making teams confronted with team decisions to be made. Conversely, studies in which individual-level feedback was proved to be more influential converged on the team task they used (task requiring physical and psycho-motor skills). This naturally puts forward the hypothesis that the decision of which feedback level to use may depend on the specific task or team type on which changes are expected. This premise introduces the last group of studies: those explicitly looking at a differential answer to the question of whether it is more effective to target the team, the individuals, or both with feedback.

Unlike the previous four groups of studies looking for a uniform answer to this question, this fifth group of five studies would answer that the effects of feedback level may depend on certain characteristics of the people involved or on certain team or individual situations in which teams are embedded. This underlies the assumption that feedback levels may have a differential impact on certain variables. These studies provide for a more comprehensive analysis of the influential variables in feedback effectiveness. All five studies involved knowledge work teams, mostly decision-making teams. DeShon, Kozlowski, Schmidt, Milner, and Wiechmann (2004) embraced a goal-oriented view of feedback delivery taking into account the level of the goals on which to focus during a task. Team members engaged in a simulated radar task and provided solely with individual-level performance feedback directed their effort on individual performance and thus displayed the highest individual performance. In contrast, members given team-level performance feedback would focus on the team performance, yielding to the highest team performance. Providing both levels of feedback didn't allow for an optimal capitalization of feedback information. Varca and Levy (1984) examined how individual characteristics, namely repression (i.e., the tendency to avoid the threat) and sensitization (i.e., the tendency to approach the threat) moderate the effect of negative feedback in a design team simulation. They observed differential attitudes lattraction to the group, task interest, attributions) in the individual and team sessions according to the team members' characteristics. For example, sensitizers' task interest and team attraction was higher in the individual-level feedback session than repressors' but attributed more their team performance to ability or effort in the team-level feedback sessions. Zander and Wolfe (1964) found a differential pattern of performance feedback level in their experimental study simulating 
coordinating committees. In the team-level feedback condition, team members provided more information and rewards to others, displayed a higher motivation to get a good personal score and a higher trust in others. In the individual condition, teams showed more disinterest in collaboration, less wish to achieve a good score, less trust, and more strain in interpersonal relations. In contrast, in the condition providing both levels of feedback, teams reached the higher improvement in personal scores and an increase of negotiation. Tindale, Kulik, and Scott (1991) also emphasized an independent impact of both feedback levels. They conducted an experiment in which participants taking part in a consensus-based team decision-making task were given individual and teamlevel bogus performance feedback. They showed that both could impact individual performance. However, an improved individual performance didn't automatically enhance team performance. Moreover, individual-level feedback influenced team responses to the task, while team-level feedback appeared to have a greater effect on reactions to the other team members. They also highlighted the mediation role of expectations of future performance on the effect of both feedback levels on individual performance. Finally, Bailey and Thompson (2000) detected an interesting pattern in their experiment in which teams were tackling simulated radar-based Air Traffic Control tasks under different aircraft densities (simulating workload). Groups given team-level performance feedback exhibited greater team cohesion and team performance under low aircraft density (lower workload). These improvements decreased when aircraft density increased. In contrast, more complete shared mental models were observed in the high-density conditions irrespective of the level of the feedback received.

If we analyze these studies in the light of our main question of which feedback level to use, this fifth group of studies highlights that beyond the effect of feedback level, it seems like other individual or team characteristics (team workload, goal setting, teams' expectations, repression and sensitization traits, and team typeltask) interact to produce changes. It is in line with our model of potential moderators of feedback effects (fig.1). These variables stemming from the fifth group of studies can be complemented by the ones shown to be of importance by the authors contrasting the levels of feedback in the other four groups of studies. Overall, they pointed out nine variables las summarized in Table 3).

Three variables concerned feedback characteristics: the valence, frequency, and distribution of the feedback. Positive or favorable feedback (depicting high performancel was found to be linked to pride in group performance and task motivation (Berkowitz \& Levy, 1956), individual performance (Tindale et al., 
1991), and positive ratings of other group members and task interest (Tindale et al., 1991). Tindale (1989) demonstrated that frequent performance feedback (after each decision) improved decision performance. Finally, Barr and Conlon (1994) showed that a majority feedback augmented the persistence intentions, compared to a minority feedback.

Six team-level characteristics or situations were also identified: team workload, organization, goal attainment, goal setting, expectations, and rewards. Stone (1971) observed that project teams given performance feedback improved their performance and displayed a higher satisfaction than team organized by specialization. As for Doerr et al. (1996), interdependent tasks brought about higher levels of effort and productivity although more idle time than independent tasks. Matsui et al. (1987) demonstrated that individual and team-level feedback effect on performance was significant for groups below target whereas subjects on target sustained their previous level of performance. These results thus also support negative feedback as an incentive to reach set goals. Team goal setting also appeared to be a significant factor along with rewards in Doerr et al. (1996) research. Finally, expectations seem to play a role. Tindale et al. (1991) showed that team members' perception of how well they and their team would complete a comparable task in the future was playing a mediational role. Additionally, Sniezek et al. (1990) brought about interesting results in their experimental study showing the effect of stating expectations about other members' future contributions. They observed an increase of cooperation with information about other members' contributions to the group whether this information was provided or self-generated.

\section{CONCLUSION AND DISCUSSION}

In the present review, we examined feedback as a potential "lever" that could regulate team processes and cognitive and affective emergent states and enhance team effectiveness (Kozlowski \& Ilgen, 2006). Previous reviews addressing feedback in teams brought out several research gaps. Although feedback had a substantial research foundation, some feedback research areas were shown to be limited such as team-level feedback, process feedback, and team-level feedback effect on team cognitive and social variables. This review considered these and started from a framework describing variables that could potentially influence feedback effectiveness and relating feedback to dependent variables of diverse natures. We aimed to gain a deeper understanding of how feedback proceeds in teams and to identify the moderators that might explain 
why feedback did not always lead to expected changes. Following conclusions can be drawn.

First, the present review showed a similar pattern than previous reviews: process feedback has been far less studied than performance feedback. Research at the team process level seems still in its infancy. The two most frequent areas of feedback research in teams were: studies looking at teamlevel performance feedback and those comparing the effect of individual versus team-level performance feedback. This trend is clearly shown in Table 2. Studies contrasting different feedback levels were indeed more frequently published than previously. It seems that researchers increasingly recognize the potential interest of providing teams with feedback at different levels, yet none of them compared or contrasted different types of feedback.

Second, with respect to feedback overall effectiveness, while previous evidence seemed to indicate that feedback might have negative effects le.g., Kluger \& DeNisi, 1996), only one study reported a decrease in the dependent variable. Moreover, only two studies showed no feedback effect on any of the dependent variables. As Table 2 showed, performance feedback research covered 23 studies reporting uniformly positive effects and 21 studies resulting in positive effects on some dependent variables and no effect on others (mixed positive effects). In contrast, every single study implementing exclusively process feedback showed mixed positive results: some dependent variables increased while some others did not change. No study revealed any negative effect. Concerning studies contrasting feedback levels, their results have been mixed in 12 studies (among 19), but several (i.e. 7 studies) reported some consistent positive effects on all the dependent variables. In summary, feedback research in the context of teams showed mixed positive results. On the one hand, it was demonstrated in many studies that feedback might impact a huge diversity of critical team processes lamongst which the three most frequent variables: motivation, team goal, and collaboration/cooperation) and emergent states lamong which the most frequent variables: collective efficacy, cohesion, ouctome expectations, and task concern/interest) and occasionally have a direct effect on team performance (in 23 studies overall). On the other hand, some studies confirmed that feedback might not always lead to significant or at least measurable changes and thus not fulfill its function as a leverage point that can be used to support teams.

However, the studies analyzed uncovered patterns that transcended the straightforward question of whether feedback interventions are effective in teams. It seems that the key question was rather under which conditions improvements occur. To answer this question, we leaned on a framework 
depicting how feedback proceeds in teams. As summarized in Table 3, we used this model to highlight key factors that might enhance and support feedback effectiveness. Having established feedback potential positive effects, we identified nine feedback characteristics (established in 15 studies), eleven group situations and characteristics, seven individual characteristics and situations, only one variable related to feedback reception, and none to feedback processing. In practical terms, it appears that feedback intervention effectiveness might be improved if feedback is accurate, given in a timely manner, regular, non-threatening, shared, given directly to teams it targets, and when its distribution is fairly equal. Concerning feedback sign, positive feedback was generally shown to be positively linked to performance and team process variables. However, despite its potential detrimental effect on members' affective reactions, unfavorable feedback does not always bring negative outcomes, as shown by Matsui et al. (1987) and Mesch et al. (1996); it may produce some motivational positive effects. The role of the feedback source was still unclear, with a study supporting the effectiveness of feedback from the task itself over feedback from an external supervisor and another showing the effect of both sources. Another possible source of variation of feedback related to the feedback data lies in its level and type. Regarding the type, it seems as if process feedback is more effective in driving team processes, while performance feedback may also trigger performance. However, it appears that the types of process depicted in the feedback may show a different pattern. One study associated cognitive feedback and performance, although this relationship is as yet unclear and needs additional research. Furthermore, studies showing how performance feedback can be augmented were overrepresented, whereas very few studies looked at whether process feedback might be more effective if augmented in a particular way. Indeed, there is insufficient knowledge on how to optimize the effects of process information, in particular of the three aspects it can cover (interpersonal, task-related, or cognitive).

As far as team or individual situation and characteristics were concerned, it was shown that teams with no redundant members and no overlaps in task completion, project teams, teams setting goals and strategies, given incentives and rewards, provided with information concerning their goal attainment, believing they were high performing, with no unsolved intragroup conflicts, and with a flexible workload were likely to show improvements. Furthermore, feedback to high-ability individuals, in a positive mood given individual incentives, rewards and reinforcements and having the opportunity to set individuals goals and expectations is also like to be more powerful. Finally, team type may be of importance to decide which type and level of feedback to provide 
to teams. The role of this factor emerged in the group of studies contrasting feedback levels. All studies prescribing both individual and team-level feedback occurred in physical-work teams. It may be that these teams engaged in a linear work process can benefit from team-level performance information while having access to their individual contribution as well. In contrast, knowledge work teams engaged in a less linear work flow and whose final products is intangible may need more flexible patterns of feedback interventions, or one level over the other, depending on their need for interactions. All the studies showing that the appropriate level of feedback depends on some characteristics of the situation or the team members did base their assumptions on knowledge-based teams. Although no definite conclusion can be given as yet about the role of team type, as mentioned, some interesting patterns can be discerned. These observations are promising and should be explored by both laboratory and field studies varying the team types engaged in physical and knowledge work to come up with specific factors that might mitigate feedback effectiveness in each team type.

Finally, the only study providing support for the importance of feedback perception showed positive results (Walter \& Van der Vegt, 2009). Clearly, a great deal of work remains to be done on the effect of how feedback is perceived and processed. How teams process feedback they receive has been neglected and appears to be a black box that has yet to be understood. A question that still deserves further investigation is what are the processes occurring between feedback reception, feedback acceptance, and the eventual subsequent changes. If teams do not assign meaning to the received feedback and do not consider it as relevant, important, and useful for their practice, they probably won't implement any changes. Conversely, teams valuing feedback they received are more likely to modify their strategies and behaviors. Team learning behaviors could be a reflection of how the feedback is dealt with. These are knowledge sharing behaviors during which the team builds meaning and reaches a common understanding. They could then be the mean by which teams collectively try to make sense of the received feedback and eventually decide to act accordingly. Qualitative data would be useful to grasp the complexity of feedback in teams, especially on how the feedback is used, acted, and reflected upon by the team and team members. 
Table 3

Feedback Characteristics, Individual and Team Characteristics and Situations, the Perception and Processing of Feedback Shown to Be Effective in the Reviewed Studies

\begin{tabular}{|c|c|c|c|c|}
\hline $\begin{array}{c}\text { Characteristics } \\
\text { of feedback }\end{array}$ & $\begin{array}{c}\text { Individual } \\
\text { situation and } \\
\text { characteristics }\end{array}$ & $\begin{array}{c}\text { Group situation } \\
\text { and } \\
\text { characteristics }\end{array}$ & $\begin{array}{l}\text { Perception of } \\
\text { feedback }\end{array}$ & $\begin{array}{c}\text { Processing } \\
\text { feedback }\end{array}$ \\
\hline \multicolumn{5}{|c|}{ Individual-level feedback } \\
\hline \multicolumn{5}{|l|}{$\begin{array}{l}\text { Sharedness } \\
\text { (Harmon \& } \\
\text { Rohrbaugh, 1990) } \\
\text { Timing (Kerr, } \\
\text { Messé, Park, \& } \\
\text { Sambolec, 2005) } \\
\text { Level of } \\
\text { publicness (Kerr } \\
\text { at al., 2005) }\end{array}$} \\
\hline \multicolumn{5}{|c|}{ Team-level feedback research } \\
\hline $\begin{array}{l}\text { Valence/Sign } \\
\text { (Johnston, 1965; } \\
\text { Mesch, Farh, \& } \\
\text { Podsakoff, 1996; } \\
\text { Peterson } \quad \text { \& } \\
\text { Behfar, 2003; } \\
\text { Prussia \& Kinicki, } \\
\text { 1996) } \\
\text { Frequency (Cook, } \\
\text { 1968; Klaus \& } \\
\text { Glaser, 1970) } \\
\text { Source (Kim \& } \\
\text { Hamner, 1976; } \\
\text { Ivancevich \& } \\
\text { McMahon, 1982) }\end{array}$ & 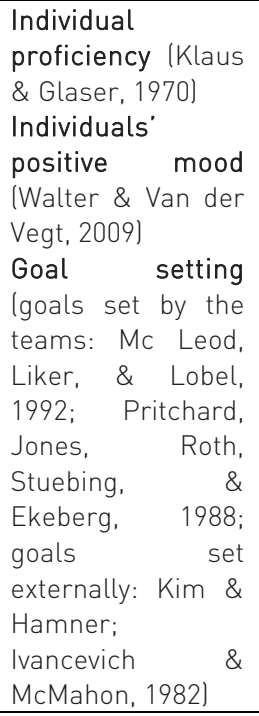 & $\begin{array}{l}\text { Task structure } \\
\text { (Klaus \& Glaser, } \\
\text { 1970) } \\
\text { Team structure } \\
\text { (Klaus \& Glaser, } \\
\text { 1970) } \\
\text { Incentives } \\
\text { (Pritchard et al., } \\
\text { 1988) } \\
\text { Previous } \\
\text { intragroup trust } \\
\text { (Peterson } \\
\text { Behfar, 2003) } \\
\text { Strategy } \\
\text { formation (Philo, } \\
\text { 2005) } \\
\text { "High } \\
\text { performance } \\
\text { group" belief } \\
\text { (Staw, 1975) }\end{array}$ & $\begin{array}{l}\text { Perceived } \\
\text { team } \\
\text { feedback } \\
\text { (Walter \& Van } \\
\text { der Vegt, } \\
\text { 2009) }\end{array}$ & \\
\hline \multicolumn{5}{|c|}{ Combination of both levels of feedback (team-level and individual-level) } \\
\hline $\begin{array}{l}\text { Timing (Hey, } \\
\text { Pietruschka, } \\
\text { Bungard, } \\
\text { Joens, 2000) }\end{array}$ & $\begin{array}{l}\text { Reinforcement } \\
\text { and Behavioral } \\
\text { consequences } \\
\text { (Austin, et al., } \\
\text { 1996) }\end{array}$ & & & \\
\hline $\begin{array}{l}\text { Frequency (Hey, } \\
\text { Pietruschka, } \\
\text { Bungard \& Joens, } \\
2000 \text { ) } \\
\text { Specificity (Hey } \\
\text { et al., 2000) } \\
\text { Constructiveness } \\
\text { (Hey et al., 2000) }\end{array}$ & & & & \\
\hline
\end{tabular}


Contrast of levels of feedback individual versus team-level feedback

\begin{tabular}{|c|c|c|}
\hline 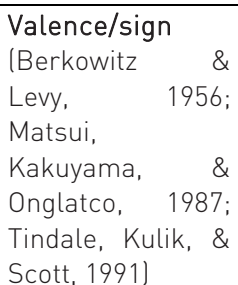 & $\begin{array}{l}\text { Goal attainment } \\
\text { (Matsui et al., } \\
\text { 1987) }\end{array}$ & $\begin{array}{l}\text { Organization of } \\
\text { the team (Stone, } \\
\text { 1971) }\end{array}$ \\
\hline $\begin{array}{l}\text { Frequency } \\
\text { (Tindale, 1989) }\end{array}$ & $\begin{array}{l}\text { Expectations } \\
\text { (Sniezek, ExpeMay, } \\
\& \text { Sawyer, 1990; } \\
\text { Tindale at al., } \\
\text { 1991) }\end{array}$ & $\begin{array}{l}\text { Workload (Bailey } \\
\text { \& Thompson, 2000) }\end{array}$ \\
\hline $\begin{array}{l}\text { Distribution } \\
\text { (major or minor; } \\
\text { Barr \& Conlon, } \\
\text { 1994) }\end{array}$ & $\begin{array}{l}\text { Rewards (Doerr, } \\
\text { Mitchell, Klastorin, } \\
\text { \& Brown, 1996) }\end{array}$ & $\begin{array}{l}\text { Goal setting } \\
\text { lexternally and } \\
\text { internally set } \\
\text { (Doerr et al., 1996) }\end{array}$ \\
\hline & $\begin{array}{l}\text { Repression } \\
\text { sensitization } \\
\text { (Levy, 1984) }\end{array}$ & \\
\hline
\end{tabular}

Kozlowski and Ilgen (2006), in their review of work group and team effectiveness, called attention to feedback as a potent key leverage point and stated that it was a promising topic of research in the search for team effectiveness, but yet to be extended. Our results corroborate their conclusion: feedback has multiple facets and its effects may be enhanced in so many different ways. To most effectively implement feedback interventions, we must understand why feedback modifies behavior. Future research should adopt a more dynamic and integrative view of teams. It should be integrative for two reasons. First, teams provided with feedback are embedded in a context and shaped by team (members) characteristics, actions, interactions, and boundaries. Consequently, it is important to bring together all the important variables that might contribute to its effectiveness and to look at the whole picture to better identify the underlying mechanisms that explain any contingencies in the link between feedback and team performance. Second, integrating insight from various perspectives le.g., social and cognitive perspectives) is needed to better understand all the facets of a team. To be able to perform cognitive tasks, in other words to think, create, solve problems, make decisions, and plan some changes, a team needs to be able to communicate and interact. Future research should also embrace a dynamic point of view as team situations and characteristics as well as team dynamics may change over time thus driving changes in team processes and performance. This could be done by conducting longitudinal studies with repeated-measures at different stages of team development. For example, it might be that certain feedback types and 
characteristics play a more prominent role at the beginning of a team experience when the team is formed and still needs to discover team requirements, challenges, and opportunities, while being less powerful at a later stage. The great challenge will be to come up with new dynamic conceptual frameworks tailored to each team type and development time to achieve a more elaborate understanding of what makes a feedback intervention powerful.

Further work is also needed on cognitive variables. Work to date has focused predominantly on affective emergent states and less on cognitive properties of the team. Furthermore, little is known about the effect of team cognition on feedback effects, reception, acceptance, and effective use. The cognitive aspect of feedback is yet insufficiently understood and documented, so are the other aspects a process feedback can tackle linterpersonal and taskrelated. And yet this is a promising strand of feedback-research as teams are omnipresent and raise specific cognitive and social processes that come into play in team performance.

\section{PRACTICAL IMPLICATIONS}

This review study provides organizations and teachers with insights and tools to support their teams. It highlights that feedback is indeed a potent key practice in which organizations should allocate resources: both trainings and on-the-job interventions should be tailored to the team situations and characteristics to support life-long learning. In educational settings, teachers should continuously observe their students when engaged in a team task so that they can provide them with timely feedback that could help teams optimize their teamwork. Usually, teams receive a team grade at the end of their assignment and are not monitored during the process when they may benefit and learn most from it to make improvements.

Moreover, besides performance feedback effectiveness, the present review demonstrated that process feedback interventions could influence important interaction processes and team properties that facilitate learning and performance. In order for a team to function effectively, it is essential for its members to improve their team skills and communication. These team skills necessitate different feedback interventions conveying information about how teams communicate, interact, establish the team atmosphere, define their team objectives, strategies, monitor their performance, come to a common understanding of the task and its requirements, build upon each other's expertise, make team decisions, or coordinate in an efficient way. Process 
feedback helps team members identify specific areas for improvement and ways to improve. For example, teams displaying problems of communication or irrelevant strategies may lack information about what and how to improve or may not be aware of their behaviors. Since feedback has so many facets and can be augmented in various ways, teachers, managers, and trainers should first pay attention to the team setting, context, and characteristics, observe and monitor their teams on a regular basis to develop relevant team interventions that facilitate and reinforce positive team behaviors and in turn, performance. Moreover, implementing a feedback intervention acts as a prescriptive reference against which teams can evaluate their own behaviors. It helps them understand what is meant by effective (team)work in their specific setting and provide them with an opportunity to learn. 


\section{REFERENCES}

Akkerman, S., Van den Bossche, P., Admiraal, W., Gijselaers, W., Segers, M., Simons, R.-J., \& Kirschner, P. (2006). Reconsidering group cognition: From conceptual confusion to a boundary area between cognitive and socio-cultural perspectives? Educational Research Review, 211), $39-63$.

Alvero, A., Bucklin, B., \& Austin J. (2001). An objective review of the effectiveness and essential characteristics of performance feedback in organizational settings (1985-1998). Journal of Organizational Behavior Management, 21, 3-30.

Austin, J., Kessler, M. L., Riccobono, J. E., \& Bailey, J. S. (1996). Using feedback and reinforcement to improve the performance and safety of a roofing crew. Journal of Organizational Behavior Management, 16 (2), 49-75. (*)

Bailey, L. L., \& Thompson, R. C. (2000). The effects of performance feedback on air traffic control team coordination: A simulation study (Rep. No. DOT/FAA/AM00/25). Washington, DC: Office of Aviation Medicine. $\left({ }^{*}\right)$

Balcazar, F. E., Shupert, M. K., Daniels, A. C., Mawhinney, T. C., \& Hopkins, B. 0. (1989). An objective review and analysis of ten years of publication. Organizational Behavior Management, 10, 7-38.

Bartram, D., \& Roe, R. A. (2008). Individual and organizational factors in competence acquisition. In W. Nijhof (Ed.), The Learning Potential of the Workplace. Rotterdam: Sense Publishers.

Barr, S. H., \& Conlon, E. J. (1994). Effects of distribution of feedback in work groups. Academy of Management Journal, 37, 641-655. (*)

Barron, B. (2000). Achieving coordination in collaborative problem-solving groups. The Journal of the Learning Sciences, 9, 403-436.

Becker, E. A., \& Goodwin, E. M. (2005). Methods to improve teaching interdisciplinary teamwork through computer conferencing. Journal of Allied Health, Fall, 34(3), pp. 169-76. (*)

Berkowitz, L., \& Levy, B. I. (1956). Pride in group performance and group task motivation. Journal of Abnormal and Social Psychology, 53, 300-306. (*)

Boud, D. (2000). Sustainable assessment: rethinking assessment for the learning society. Studies in Continuing Education, 2(22), 151-167.

Brannick, M. T., Prince, C., \& Salas, E. (2005). Can PC-based systems enhance teamwork in the cockpit? The International Journal of Aviation Psychology, 15(2), 173-187. (*)

Burgio, L. D., Engel, B. T., Hawkins, A., McCormick, K., \& Scheve, A. (1990). A staff management system for maintaining improvements in continence with elderly nursing home residents. Journal of Applied Behavior Analysis, 23, 111-118. (*)

Burnstein, W. W., \& Wolff, P. C. (1964). Shaping of three-man teams on a multiple DRL-DRH schedule using collective reinforcement. Journal of the Experimental Analysis of Behavior, 7, 191-199. $(*)$

Cook, D. M. (1968). The impact of managers of frequency of feedback. Academy of Management Journal, 11, 263-277. (*)

DeChurch, L. A., \& Mesmer-Magnus, J.R. (2010). The cognitive underpinnings of team effectiveness: A meta-analysis. Journal of Applied Psychology, 95, 1, 32-53.

Decuyper, S., Dochy, F., \& Van den Bossche, P. (2010), Grasping the dynamic complexity of team learning: An integrative model for effective team learning in organizations. Educational Research Review, 5, 111-133.

Denson, R. W., (1981). Team Training: Literature Review and Annotated Bibliography (Brooks Air Force Base, TX, Air Force Human Resources Laboratory). 
DeShon, R. P., Kozlowski, S. W. J., Schmidt, A. M., Milner, K. R., \& Wiechmann, D. (2004). A multiplegoal, multilevel model of feedback effects on the regulation of individual and team performance. Journal of Applied Psychology, 896), 1035-1056. (*)

Devine, D. J. (2002). A review and integration of classification systems relevant to teams in organizations. Groups Dynamics, 6, 291-310.

Dewett, T. (2003). Towards an Interactionist Theory of Group-Level Feedback. Management Research News, 26(10-11), 1-121.

Dickinson, T. L., \& McIntyre, R. M. (1997). A conceptual framework for teamwork measurement. In M. T. Brannick, E. Salas, \& C. Prince (Eds.), Team performance and measurement: Theory, methods, and applications (pp.19-43). Mahwah, NJ: Lawrence Erlbaum Associates.

Dillenbourg, P. (1999). What do you mean by collaborative learning? In P. Dillenbourg (Ed.), Collaborative learning: Cognitive and Computational Approaches (pp. 1-19). Oxford: Elsevier

Doerr, K. H., Mitchell, T. R., Klastorin, T. D., \& Brown, K. A. (1996). Impact of material flow policies and goals on job outcomes. Journal of Applied Psychology, 81, 142-152. (*)

Dominick P. G., Reilly, R. R., \& McGourty, J. (1997). The effects of peer feedback on team member behavior. Group and Organization Management, 22, 508-520.

Druskat, V. U., \& Kayes, D. C. (2000). Learning versus performance in short-term project teams. Small Group Research, 31(3), 328-353.

Edmondson, A. C., Dillon, J., \& Roloff, K. S., (2008). Three perspectives on team learning outcome improvement, task mastery, and group process. The Academy of Management Annals, 1, 269314.

Ellsworth, R. B. (1973). Feedback: Asset or liability in improving treatment effectiveness? Journal of Consulting and Clinical Psychology, 40,383-393.

Gear, T. E., Marsh, N. R., \& Sargent, P. (1985). Semi-automated feedback and team behavior. Human Relations, 3818), 707-721. (*)

Geister, S., Konradt, U., \& Hertel, G. (2006). Effects of process feedback on motivation, satisfaction and performance in virtual teams. Small Group Research, 375), 449-489.

Goltz, S. M., Citera, M., Jensen, M., Favero, J., \& Komaki, J. L. (1989). Individual feedback: Does it enhance effects of group feedback? Journal of Organizational Behavior Management, 192), 77-92. $\left({ }^{*}\right)$

Guzzo, R. A., Jette, R. D., \& Katzell, R. A. (1985). The effects of psychologically based intervention programs on worker productivity: A meta-analysis. Personnel Psychology, 3812), 275-291.

Hackman, J. R. (1987). The design of work teams. In J.W. Lorsch (Ed.), Handbook of organizational behavior (pp. 315- 342). Englewood Cliffs, NJ: Prentice-Hall.

Harmon, J., \& Rohrbaugh, J. (1990). Social judgment analysis and small group decision making: Cognitive feedback effects on individual and collective performance. Organizational Behavior and Human Decision Processes, 46, 34-54. (*)

Hattie, J. (1999). Influences on student learning. Inaugural lecture. Professor of Education. University of Auckland, August 2.

Hattie, J., \& Timperley, H. (2007). The power of feedback. Review of Educational Research, 771), 81 112.

Henry, R. A., Strickland, O. J., Yorges, S. L., \& Ladd, D. (1996). Helping groups determine their most accurate member: The role of outcome feedback. Journal of Applied Social Psychology, 26, 1153-1170. $\left(^{*}\right)$

Hey, A. H., Pietruschka, S., Bungard, W., \& Joens, I. (2000). Feedback as a supporting system for work groups. In M. Vartiainen, F. Avallone, \& N. Anderson (Eds.), 67 Innovative theories, tools, and practices in work and organizational psychology (pp. 125-140), Seattle, WA: Hogrefe \& Huber Publishers. (*) 
Hinsz, V. B., Tindale, R. S., \& Vollrath, D. A. (1997). The emerging conception of groups as information processors. Psychological Bulletin, 121, 43-64.

Hoegl, M., \& Parboteeah, K. P. (2006). Team goal commitment in innovative projects. International Journal of Innovation Management, 193), 299-324. (*)

Hollenbeck, J. R., Ilgen, D. R., Lepine, J. A., Colquitt J. A., \& Hedlund J. (1998). Extending the multilevel theory of team decision making: effects of feedback and experience in hierarchical teams. Academy of Management Journal, 41(3), 269-282. (*)

Hunter, P. E. (2006). Viability of the Job Characteristics Model in a team environment: prediction of job satisfaction and potential moderators. Unpublished doctoral dissertation, University of North Texas, Texas. $(*)$

Hyrkas, K., \& Lehti, K. (2003). Continuous quality improvement through team supervision supported by self-monitoring of work and systematic patient feedback. Journal of Nursing Management, 11, 177-188. $\left.{ }^{*}\right)$

Ilgen, D. R., Fisher, C. D., \& Taylor, M. S. (1979). Consequences of individual feedback on behavior in organizations. Journal of Applied Psychology, 64, 349-371.

Ivancevich, J. M., \& McMahon, J. T. (1982). The effects of goal setting, external feedback, selfgenerated feedback on outcome variables: A field experiment. Academy of management journal, 25(2), 359-372. $(*)$

Johnston, W. A., \& Nawrocki, L.H. (1966). Effect of simulated team feedback on the performance of good and poor trackers. Air Force Office of Scientific Research Technical Report No. 66-2541. (*)

Johnston, W. A. (1967) Individual performance and self-evaluation in a simulated team. Organizational Behavior and Human Performance, 2, 309-328. $\left({ }^{*}\right)$

Jung, D. I., \& Sosik, J. J. (1999). Effects of group characteristics on work group performance: A longitudinal investigation. Group Dynamics: Theory, Research, and Practice, 3, 279-290. (*)

Jung, D. I., \& Sosik, J. J. (2003). Group potency and collective efficacy: Examining their predictive validity, level of analysis, and effects of performance feedback on future group performance. Group \& Organization Management, 28, 366-391. (*)

Kernaghan, J. A., \& Cooke, R. A. (1990). Teamwork in Planning Innovative Projects: Improving Group Performance by Rational and Interpersonal Interventions in Group Process. IEEE Transactions on Engineering Management, 372), 109-116. $\left({ }^{*}\right)$

Kerr, N. L., Messé, L. M., Park, E. S., \& Sambolec, E. (2005). Identifiably, performance feedback and the Köhler effect. Group Processes and Intergroup Relations, 8(4), 375-390. (*)

Kirschner, P. A. (2009). Epistemology or pedagogy, that is the question. In S. Tobias \& T. M. Duffy. Constructivist theory applied to instruction: Success or failure? New York: Routledge.

Kim, J. S., \& Hamner, W. C. (1976). Effect of performance feedback and goal setting on productivity and satisfaction in an organizational setting. Journal of Applied Psychology, 61, 48-57.

Klaus, D. J., \& Glaser, R. (1970). Reinforcement determinants of team proficiency. Organizational Behavior and Human Performance, 5, 33-67. (*)

Kluger, A. N., \& DeNisi, A. (1996). The effects of feedback interventions on performance: A historical review, a meta-analysis, and a preliminary feedback intervention theory. Psychological Bulletin, 119, 254-284.

Komaki, J. L., \& Goltz, S. M. (2001). Within-group research designs: Going beyond program evaluation questions. In C. M. Johnson, W. K. Redmon, \& T. C. Mawhinney (Eds.), Handbook of organizational performance: Behavior analysis and management (pp. 81-137). Binghamton, NY: The Haworth Press, Inc.

Kozlowski, S. W. J., \& Ilgen, D. R. (2006). Enhancing the effectiveness of work groups and teams. Psychological Science in the Public Interest, 7, 77-124. 
Locke, E. A., \& Latham, G. P. (1990). A theory of goal setting and task performance. Englewood Cliffs, NJ: Prentice-Hall.

London, M. (2003). Job feedback: Giving, seeking, and using feedback for performance improvement (2nd ed.). Mahwah, NJ: Lawrence Erlbaum.

London, M., Polzer, J. T., \& Omoregie, H. (2005). Interpersonal congruence, transactive memory, and feedback processes: An integrative model of group learning. Human Resource Development Review, 42), 114-135.

London, M., \& Sessa, V. I. (2006). Group feedback for continuous learning. Human Resource Development Review, 5(3), 1-27.

Marks, M. A., Mathieu, J. E., \& Zaccaro, S. J. 2001. A temporally based framework and taxonomy of team processes. Academy of Management Review, 26(3), 356-376.

Mathieu, J., Maynard, M. T., Rapp, T., \& Gilson, L. (2008). Team effectiveness 1997-2007: a review of recent advancements and a glimpse into the future. Journal of Management, 34, 410-476.

Matsui, T., Kakuyama, T., \& Onglatco, L. U. (1987). Effects of goals and feedback on performance in groups. Journal of Applied Psychology, 72, 407-415. (*)

McGrath J. E. (1991). Time, interaction and performance (TIP): A theory of groups. Small Group Research, 22, 147-174.

McGrath, J. E., H. Arrow, \& J. Berdahl. (2000). The study of groups: Past, present, and future. Personality \& Social Psychology Review, 411), 95-105.

McLeod, P. L., Liker, J. K., \& Lobel, S. A. (1992). Process feedback in task groups: An application of goal setting. Journal of Applied Behavioral Science, 28, 15-52. $(*)$

Mento, A., Steel, R. P., \& Karren, R. J. (1987). A meta-analytic study of the effects of goal setting on task performance: 1966-1984. Organizational Behavior and Human Decision Processes, 39, 52-83.

Mesch, D. J., Farh, J. L., \& Podsakoff, P. M. (1994). Effects of feedback sign on group goal setting, strategies, and performance. Group and Organization Management, 19, 309-333. (*)

Moreland, R. L., \& Myaskovsky, L. (2000). Exploring the performance benefits of group training: Transactive memory or improved communication? Organizational Behavior and Human Decision Processes, 82, 117-133. (*)

Nadler, D. A. (1979). The effects of feedback on task group behavior: a review of the experimental research. Organization Behavior and Human Performance, 23, 309-338.

Neubert, M. J. (1998). The Value of Feedback and Goal Setting Over Goal Setting Alone and Potential Moderators of This Effect: A Meta-analysis. Human Performance, 11, 321-335.

Passos, A. M., \& Caetano, A. (2005). Exploring the effects of intragroup conflict and past performance feedback on team effectiveness. Journal of Managerial Psychology, 20, 231-244. (*)

Peterson, R. S., \& Behfar, K. J. (2003). The dynamic relationship between performance feedback, trust, and conflict in groups: A longitudinal study. Organizational Behavior and Human Decision Processes, 92, 102-112. (*)

Philo, Joel Richard (December 2004). An examination of team reactions to negative performance feedback and their relationship to team performance. Doctoral dissertation, Texas A\&M University. Available electronically from http://handle .tamu .edu/1969.1/1555. (*)

Pritchard, R. D., Jones, S. D., Roth, P. L., Stuebing, K. K., \& Ekeberg, S. E. (1988). The effects of feedback, goal setting, and incentives on organizational productivity. Journal of Applied Psychology (Monograph Series), 73, 337-358. (*)

Prussia, G. E., \& Kinicki, A. J. (1996). A motivational investigation of group effectiveness using socialcognitive theory. Journal of Applied Psychology, 81, 187-198. (*)

Quigley, N. R. (2003). The relationship between leader core self-evaluations, team feedback, leader efficacy, transformational leadership, team efficacy, team goals, team action and transition processes, and team performance. Doctoral dissertation, University of Maryland. $\left.{ }^{*}\right)$ 
Roberts, M. K. (2000). Performance measurement, feedback, and rewards processes in research and development work teams: Effects on perceptions of performance. Doctoral dissertation, University of North Texas, Texas. (*)

Roschelle, J., \& Teasley, S. D. (1995). Construction of shared knowledge in collaborative problem solving. In C. O'Malley (Ed.), Computer-supported collaborative learning (pp. 69-97). New York: Springer-Verlag.

Rosenberg, S., \& Hall, M. L. (1958). The effects of different social feedback conditions upon performance in dyadic teams. Journal of Abnormal and Social Psychology, 57, 271-277. (*)

Rummel, N., \& Spada, H. (2005). Learning to collaborate: an instructional approach to promoting collaborative problem solving in computer-mediated settings. The Journal of the Learning Sciences, 14, 2, 201-241.

Scott-Young, C., \& Samson, D. (2006). Modeling Team Efficacy in Capital Projects: An Exploratory Study. Best Paper Proceedings, Academy of Management Annual Meeting, Atlanta, GA. $\left(^{*}\right)$

Sengupta, K., \& Te'eni, D. (1993). Cognitive feedback in GDSS: Improving control and convergence. MIS Quarterly, 171), 87-114. (*)

Sivunen, A. (2006). Strengthening identification with the team in virtual teams: The leaders' perspective. Group Decision and Negotiation, 15, 345-366. (*)

Smith, K. H. (1972). Changes in group structure through individual and group feedback. Journal of Personality and Social Psychology, 24, 425-428. (*)

Smith-Jentsch, K. A., Salas, E., \& Baker, D. P. (1996). Training team performance-related assertiveness. Personnel Psychology, 49, 909-936. (*)

Sniezek, J. A., May, D. R., \& Sawyer, J. E. (1990). Social uncertainty and interdependence: A study of resource allocation decisions in groups. Organizational Behavior and Human Decision Processes, 46, 155-180. (*)

Spoelders-Claes, R. (1973). Small group effectiveness on an administrative task as influenced by knowledge of results and sex composition of the group. European Journal of Social Psychology, 3, 389-402. (*)

Stone, T. H. (1971) Effects of mode of organization and feedback level on creative task groups. Journal of Applied Psychology, 55, 324-330. (*)

Staw, B. M. (1975). Attribution of the "causes" of performance: A general alternative interpretation of cross-sectional research on organizations. Organizational Behavior and Human Performance, 13, 414-432. (*)

Tindale, R. S., Kulik, C. T., \& Scott, L. A. (1991). Individual and group feedback and performance: An attributional perspective. Basic and Applied Social Psychology, 12, 41-62. (*)

Tindale, R. S. (1989). Group vs. individual information processing: The effects of outcome feedback on decision making. Organizational Behavior and Human Decision Processes, 44, 454-473. (*)

Varca, P. E., \& J. Levy. (1984). Individual differences in response to unfavorable group feedback. Organizational Behavior and Human Performance, 33, 100-111. (*)

Voelker, M.I. (2003). Effects of feedback and competition on behavior change, task strategy, and task performance in problem-solving groups, Marquette University. $\left(^{*}\right)$

Walter, F., \& Van der Vegt, G. S. (2009). Harnessing positive mood for team learning facilitation: The role of perceived team feedback. Academy of Management Conference, Chicago, IL. (*)

Zander, A., \& Wolfe, D. (1964). Administrative rewards and coordination among committee members. Administrative Science Quarterly, 9, 50-69. (*)

${ }^{*}$ ) studies included in the review 


\section{Chapter 4 \\ Dynamics of Team Reflexivity after Feedback ${ }^{4}$}

4 This chapter is published as: Gabelica, C., Van den Bossche, P., Segers, M., Gijselaers, W. (2014). Dynamics of team reflexivity after feedback. Frontline Learning Research, 2(2), 64-91. doi:10.14786/flr.v2i2.79 


\section{ABSTRACT}

A great deal of work has been generated on feedback in teams and has shown that giving performance feedback to teams is not sufficient to improve performance. To achieve the potential of feedback, it its stated that teams need to proactively process this feedback and thus collectively evaluate their performance and strategies, look for alternatives, and make clear decisions about ways to tackle their task. This concept of team reflexivity has been commonly described as a sequence of behaviors, which relative importance has not been demonstrated. Further, empirical research investigating the dynamic aspects of reflexivity has been scarce. This study sought to explore how reflexivity evolves over time and at which moments of the team interaction it is related to team performance. Thirty-two student dyads participated to a cognitively complex task (flight simulation) over four performance episodes comprising action phases followed by transition (feedback) phases. High interdependence between participants (pilots and co-pilots) was ensured through the distribution of complementary knowledge in the dyads. The results showed that teams seldom engaged in full cycles of reflective behaviors. When looking into individual behaviors, teams exhibited more reflective behaviors during action over time, while their reflective behaviors during feedback did not change, demonstrating a suboptimal feedback processing as time goes by. Additionally, it was demonstrated that teams were capable to learn from their past and act upon feedback to better subsequent team performance but also that initial performance acts as a trigger to future reflective behaviors. 


\section{INTRODUCTION}

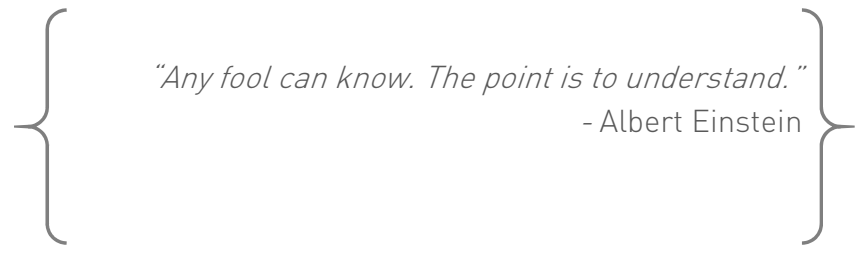

Small group work has gradually progressed to being one of the dominant approaches in the domain of learning and instruction and professional development (e.g., Kirschner, 2009). Collaborative learning is one of the most successful and widespread instructional practice implemented in schools and universities (e.g., Dillenbourg, 1999; Johnson \& Johnson, 1992). Similarly, work teams have become a central element in the functioning of organizations in many domains (e.g., health care, military, and aviation) (Salas, Stagl, Burke, \& Goodwin, 2007). Both professional teams and learning teams face similar challenges inherent to collaboration and joint understanding (Barron, 2000; Järvelä, Volet, \& Järvenoja, 2010). Specifically, in both environments, interdependent team members need to interact and communicate effectively, share knowledge and experiences, and capitalize each other's skills and resources to successfully complete a common task (e.g., Johnson, Johnson, \& Stanne, 2000; Salas, Dickinson, Converse, \& Tannenbaum, 1992). Although scholars in these areas have tended to remain isolated within their own disciplines despite obvious overlaps in research interests, they generally agree that the success of collaborative efforts does not occur naturally (Johnson \& Johnson, 1992; Rummel \& Spada, 2005; Sims, Salas, \& Burke, 2005). The awareness that not all teams show fruitful collaboration nor learn from their experiences and with/from each other, and as a consequence may reach substandard group performance, raises the need to outline deliberate interventions to build learning in teams. More and more, new research interests focus on the nature of team processes and what can be done to leverage learning in teams and improve their performance le.g., Decuyper, Dochy, \& Van den Bossche, 2010; Salas, Stagl, \& Burke, 2004). Despite these renewed efforts, it seems that potential leverage points (such as training or the provision of feedback) calibrated for teams need to be better specified and validated (Kozlowski \& Ilgen, 2006).

Giving teams feedback on their team process and performance has been identified as a leverage point that shapes team learning and can improve team performance (Gabelica, Van den Bossche, Segers, \& Gijselaers, 2012; Johnson \& 
Johnson, 2002; London \& Sessa, 2006; Phielix, Prins, \& Kirschner, 2010). In school and beyond, teams need feedback to monitor and regulate their work (Hattie \& Timperley, 2007). Previous theoretical work on feedback provided by external agents at the team level of analysis (e.g., Goodman, Wood, \& Hendrickx, 2004; London \& Sessa, 2006) suggests that to achieve changes in team learning and performance, teams need to process received feedback, be receptive to this feedback, understand its value, and actively engage in collaborative activities during which they use feedback cues to make improvements. Nevertheless, empirical work on the added value of active feedback processing to the mere reception of feedback in teams has considerably lagged behind theoretical development (Hattie \& Timperley, 2007). This feedback processing has yet to be empirically examined (Gabelica et al., 2012). More specifically, the more interesting question about feedback effectiveness is rather how learning naturally happens during the team feedback process and how effective are these learning processes (e.g., Adcroft, 2011). Moreover, previous work in both team and collaborative learning research leaves much about the dynamics of feedback processing in teams unspecified, such as 1) how do teams respond to repeated (external) feedback in dialogue over the course of ongoing activities, and 2) when (i.e., at which point in time) are these behaviors related to effective learning and performance. There is a general agreement across disciplines that we should consider feedback loops in which behavioral changes resulting from each cycle are inputs in cycles that follow le.g., Soller, Monés, Jermann, \& Mühlenbrock, 2005) but this is rarely reflected in research designs (e.g., Ilgen, Hollenbeck, Johnson, \& Jundt, 2005).

Concerning how teams process feedback, we propose that they do so by performing shared reflective activities, that is by collectively discussing and reflecting upon their functioning le.g., Schippers, Den Hartog, \& Koopman, 2007). It has been shown that reflective teams evaluate their performance and strategies, look for alternatives to consider situations, and make decisions about new ways to tackle their task. The concept of team reflexivity, as proposed in organizational psychology, mirrors these activities (West, Garrod, \& Carletta, 1997). In educational settings, generic forms of intra-group reflection such as collective/social metacognition (McCarthy \& Garavan, 2008), reflection (Edmondson, 1999), collaborative reflection (Morris \& Stew, 2007; Yukawa, 2006), peer reflection, or reflective self-explanation (Rummel, Spada, \& Hauser, 2009) have been increasingly used. This recent research area is an extension of the work on individual reflection or reflective practice le.g., Boud, Keogh, \& Walker, 1985) that adds interactions and communication with peers to the learning process. Many authors agree that team reflexivity (in any generic sense) allows 
teams to reach a more accurate understanding of their task and, as a result, better performance (e.g., McCarthy \& Garavan, 2008; Schippers, Homan, \& Van Knippenberg, 2013). Although the very recent research strand on team reflexivity acknowledges the importance of the dynamics of team performance when considering team reflexivity, the empirical work is only beginning to consider under which circumstances team reflexivity relates to changing performance, but not in contexts with systematic performance data on which to reflect (Schipper et al., 2013). Across disciplines, external and specific feedback is not systematically part of the reflective process while it is usually agreed that reflection can only occur if people have accurate knowledge about their current and desired learning state (Hattie, 2013). Also, the relation between time and timing of reflexivity and team performance remains in question, such as does reflecting right from the start of a team activity help the team get started and allow later success or does sustained reflection after events later in a team's life also matter for sustained performance?

Thus, when teams process feedback appears as a gap in both feedback and reflexivity research. Previous research on feedback and team performance suggests that feedback effects are not static but dynamic (e.g., McGrath, 1993); it cannot be understood as a single-cycle linear path from inputs (e.g., feedback) through outcomes (e.g., team performance). In the same vain, how teams learn from feedback should also be considered with a dynamic glance (Ilgen et al., 2005).

The purpose of the present study is therefore to address the abovementioned gaps by shedding light on how reflective behaviors relate to performance over a period of time in a complex, fast-paced, and high-workload situation in which two individuals with distributed information have to keep on learning to achieve success. Specifically, the following questions are explored: 1) how do teams naturally overtly reflect when provided with feedback depicting their performance, 2) how do reflective behaviors grow over time during and/or after action, 3) how does the timing at which team reflexivity occurs relate to performance?

\section{FEEDBACK INTERVENTIONS}

Prior to addressing feedback in team settings, it is critical to briefly solicit input from multiple disciplines to better understand how the much more substantial body of research on feedback given to individuals has shaped the feedback concept in teams. 
In the learning sciences, feedback is an instructional practice that is expected to enhance motivation and learning (Mulder \& Ellinger, 2013; Shute, 2008). Learning scientists have acknowledged feedback as a key characteristic of quality teaching decades ago in non-team settings (e.g., Mory, 2003; Shute, 2008; Yang \& Carless, 2013). Much of the extensive work on feedback given to individuals has come to two main conclusions: 1) learners should be given feedback containing learning information (e.g., Duijnhouwer, Prins, \& Stokking, 2012; Gibbs \& Simpson, 2004) and 2) researchers should consider feedback from the perspective of the feedback receiver and thus incorporate the uptake and the receptivity of feedback in the feedback process (e.g., Boud \& Molloy, 2013; Eva et al., 2012). This also introduces the idea of a feedback process that goes beyond the provision of feedback (Mulder, 2013). Since feedback is traditionally part of instructional programs, the drawback of multi-component interventions is that it is not always possible to causally assign behavioral changes to feedback interventions (e.g., van der Pol, van den Berg, Admiraal, \& Simons, 2008). Further, most studies concern primary school and high school students (e.g.,

Johnson \& Johnson, 1993), which raises the question of the generalizability of findings to higher education or workplace ladult) learning.

By contrast, organizational, social, and behavioral psychology have incorporated feedback delivery in many (semilexperimental research and extensively investigated its added value with or without other components (such as goal setting) to human performance (e.g., Kluger \& DeNisi, 1996) while the feedback process has largely remained a black box. Furthermore, feedback is often mere "knowledge of performance or results" (e.g., performance data of a company or score on a simulation gamel instead of elaborated informational feedback (e.g., Austin, Kessler, Riccobono, \& Bailey, 1996). The learning value of feedback seems to be a consistent omission. Moreover, this research tradition has primarily focused on post-secondary levels.

Taken together these disciplines have given rise to a new question transcending the simple question of whether or not feedback is truly effective: how and under which conditions feedback improves learning and performance. This concern has been echoed in the relatively smaller research strand on feedback to teams.

\section{FEEDBACK TO TEAMS}

Feedback at the team level of analysis is defined as the communication of information provided by (an) external agent(s) concerning actions, events, 
processes, or behaviors relative to task completion or teamwork (Gabelica et al., 2012, London, 2003).

It is widely accepted that feedback can provide teams with accurate information on their performance and may steer, motivate, support, and reinforce future team behavior. Feedback is considered as a leverage point in the team's development of a collective view of expectations and awareness about its behaviors, capabilities, and skills (London \& Sessa, 2006; Prins, Sluijsmans, \& Kirschner, 2006). Research in collaborative learning environments has highlighted that feedback has the power to draw the team's attention to specific aspects of its task and hence encourage task-related discussion (Johnson \& Johnson, 2002). In the workplace, feedback can also serve as a motivational trigger. For example, Scott-Young and Samson (2009) showed that providing teams of managers with performance feedback reinforced teams' confidence in themselves and in turn, their performance.

Despite many potential benefits of feedback delivery, a recent review by Gabelica et al. (2012) integrated findings from fifty-nine empirical studies investigating the effects of feedback in teams in educational and professional settings and showed mixed results. Approximately one third of the studies did not find support for its expected positive effect on performance. For example, in a field experiment, Jung and Sosik (2003) found that giving feedback to teams performing decision-making tasks had positive benefits on group members' collective confidence (i.e., collective efficacy and group potency) but not on team performance. Based on these inconsistent results, analogue to feedback research in non-team settings, Gabelica and colleagues (2012) concluded that the key question of whether team feedback is effective depends on the conditions under which feedback is given, and not only on feedback as such le.g., its quality).

Based on educational research, it can be argued that in addition to factors related to the feedback giver and environment, feedback receivers have a critical role to play. Research on team feedback suggests that teams given feedback will only change if they perceive a learning need and opportunity and if they attend, interpret, and act upon feedback (e.g. London \& Sessa, 2006; Phielix, et al., 2010). In other words, teams need to proactively process the content of feedback, and thus invest time and effort into actively building content-oriented reactions if we expect visible changes in the way they perform. Yet, how teams process information cues contained in feedback, and thus what specific processing behaviors and activities are dynamically related to performance remains largely unknown (Gabelica et al., 2012). Although there are few studies on peer feedback exploring the role of feedback receivers during the feedback 
process in teams (e.g. Prins et al., 2006), the interconnections between uptakes of feedback receivers and ongoing performance are still unclear. Also, since the success of feedback in terms of an effective uptake from the receivers depends at least partially on the feedback quality provided by others, studying the uptake of standardized feedback (i.e., of constant quality and constant source) would allow us to isolate the learning effects of providing feedback.

In sum, there seems to be an agreement that reaching an intersubjective understanding of the content of the feedback in teams by discussing what can be learned and worked out from past experiences is a potent factor augmenting feedback effectiveness (e.g., Boud et al., 1985). Despite a lack of direct evidence establishing the benefits of feedback processing behaviors, the consensus appears to be that the construct holds enough potential to warrant further investigation. The recent research strand on team reflexivity depicting the extent to which teams reflect upon and modify their functioning informs our understanding of these processing behaviors (Schippers et al., 2013).

\section{TEAM REFLEXIVITY}

In pedagogy, individual reflection- or reflective practice- can be traced back to the early 1900s (Dewey, 1910, 1997) but has been introduced more extensively into the field of professional learning by Schön (1983) as professionals' critical consideration of what they are working on while they are working on it. On a simple level, one can consider reflection in the past, present, and future tense. Schön refers to "reflection-in-action" as analysis in the present tense (i.e., reflection on the spot) and "reflection-on-action" as analysis in the past tense (i.e., review of past actions). Killion and Todnem (1991) underlie a lack of forward thinking implicit in Dewey's work and propose that reflection should also inform future action. Thus, they added "reflection-for-action" as reflection oriented towards the future li.e., identification of guidelines to follow to succeed in the future).

Reflection as an individual critical thinking process has been recently extended to a view of reflection as a collaborative critical thinking process consisting of cognitive and social interactions between two or more individuals who examine their experiences to construct novel intersubjective understandings (Boud et al., 1985; Yukawa, 2006). In the learning sciences, there are multiple labels denoting this concept. For example, the following terms have been used: collaborative reflection (Morris \& Stew, 2007; Yukawa, 2006), peer reflection, reflective self-explanation (Rummel, Spada \& Hauser, 2009), or 
collective or social metacognition (McCarthy \& Garavan, 2008). In small group research, principally one label "team reflexivity" has been introduced by West (1996) as a set of collaborative reflective behaviors and activities during which the team objectives, strategies, and processes are discussed openly. We use the term "team reflexivity" throughout this paper as a unique label for reflection at the team level.

Originally, the concept of team reflexivity has not been explicitly connected to the feedback process. However, it is generally acknowledged that reflection is enabled by feedback to ensure accuracy in learning (Hattie, 2013). As a result, team reflexivity can be conceptualized as ways teams collectively try to extract meaning and cues for future behaviors from received feedback, generate intentions and plans, and ultimately decide to act upon feedback. Thus, when performance feedback that is merely evaluative is given to teams, the process that follows this feedback moment might be shared reflection on the task and the team process. The underlying assumption is that team feedback gives goaloriented information but teams are still responsible for its mindful uptake. It can be argued that reflective teams consider reasons, rationales, and evidence for this evaluation of past performance, weigh alternative perspectives to construct a better understanding of their collective experience that, in turn, better guides their future action (Yukawa, 2006).

Three behaviors that reflect complementary dimensions of team reflexivity can hence be derived from previous work on team reflexivity across disciplines (e.g., Schippers et al., 2007; Yukawa, 2006): (a) evaluating present and past performance and strategies, (b) looking for alternatives, and (c) making decisions. Evaluating refers to team members reviewing their goals, performance, strategies, and possible reasons behind success or failures. Looking for alternatives occurs when teams make an inventory of possible ways to achieve the task. Finally, making decisions consists of clearly stating a decision about how to handle the task differently and acting upon it. Evaluating and looking for alternatives reflect the capability of the team to be self-aware of its behaviors and the necessity to make changes. According to Schippers and colleagues (2007), this is necessary but not sufficient to engage in change. Teams also need to implement the adapted actions. This is reflected by our conceptualization of "making decisions" that depicts both the "intention to act" and "carrying out the decision". Hence, this suggests a time-ordered sequence of reflective behaviors that might constitute reflective cycles, although no empirical work supports the necessity of full three-phase sequences.

Overall, reflective teams have the ability to uncover why they succeeded or failed, solve misunderstandings, and correct their future approaches as new 
challenges emerge (Tschan, Semmer, Nägele, \& Gurtner, 2000; Wills \& Clerkin, 2009). As a consequence, team reflexivity has been recognized as an important contributor to effective collaboration and performance le.g., Kramarski, 2004; Rummel, Mullins \& Spada, 2012; Schippers, Den Hartog, Koopman, \& van Knippenberg, 2008; Tjosvold, Tang, \& West, 2004; van Ginkel, Tindale, \& Knippenberg, 2009). However, in their review of small group research Moreland and McMinn (2010) draw attention to 1) the lack of significant relation between reflexivity and team performance found in some studies (e.g., Edmondson, Bohmer, \& Pisano, 2001; Savelsbergh, van der Heijden, \& Poell, 2009) and 2l relatively limited experimental evidence of the effect of reflexivity on team performance (e.g., Lewis, Belliveau, Herndon, \& Keller, 2007; Müller, Herbig, \& Petrovic, 2009). They concluded that reflexivity could be beneficial to team performance under certain circumstances. In the learning sciences, a similar trend has been observed: although team reflexivity in collaborative teams is highly important for the learning process, it does not always yield better learning gains (e.g., Prinsen, Terwelb, Zijlstrac, \& Volman, 2013).

Given these mixed results, limitations of the small but growing research strand on team reflexivity need to be synthesized. First, reflexivity does not happen in a vacuum. Teams will eventually adapt their operating methods and ways of working based on feedback cues from their environment. We could expect reflexivity to only improve team performance when teams have access to feedback describing their objective and accurate performance (Schippers et al., 2013). Yet, reflexivity is seldom conceptualized as a process augmenting the effect of feedback on performance (Seibert, 1999). Moreover, little is known about how people reflect on feedback at the team level, while there has been empirical evidence of the effect of reflection upon feedback at the individual level (e.g., Duijnhouwer et al., 2012). For example, Anseel, Lievens, and Schollaert (2009) have tested the effect of feedback augmented with reflection at the individual level and demonstrated that the combined use of individual-level feedback and reflection improved performance better than individual feedback alone. At the team-level, only one series of studies isolated the effect of feedback from its combination with reflection in computer-supported collaborative learning in high-school teams (Phielix, Prins, \& Kirschner, 2010; Phielix, Prins, Kirschner, Erkens, \& Jaspers, 2011). The authors expected shared self and peer assessment and shared reflection to have complementary effects. They did not find any significant effect of reflection alone or of the combined use of feedback and reflection on objective performance (i.e., grade), but demonstrated that the joint use of feedback and reflection lead to higher group process satisfaction and social and cognitive behavior. Interestingly, they draw 
attention to the fact that feedback (based on peer and self-perceptions) and reflection did not decrease unrealistic positive perceptions teams generally have about their own and other performance. This could be a reason for a lack of effect on objective performance. We do not know what are the effects of external feedback based on objective criteria for task achievement.

Second, as in most research in organizational psychology, the vast majority of small group research measuring team reflexivity in relation to team performance has used self-report instruments. Self-report measures are limited by team members' level of awareness of their own behaviors and states and distorting biases such as social desirability. Calls for studying reflective behaviors in teams have generally gone unheeded (West, 1996). In the learning sciences, Dillenbourg, Baker, Blaye, and O'Malley (1996) have advised researchers to zoom in the "black box" of collaborative processes. Subsequent to this call, there has been a recent proliferation of process-oriented research on collaboration (e.g., De Wever, Schellens, Valcke, \& Van Keer, 2005) that advanced our understanding on interaction features contributing to more effective learning. Most of this collaborative learning research strand has focused on individual learning without explicitly investigating how collaborative processes influence team performance le.g., Janssen, Kirschner, Erkens, Kirschner, \& Paas, 2010). Nevertheless, these insights underscore the value of observational methods to provide crucial information about the context in which reflective behaviors occur and relate to team performance le.g., Leicht, Hunter, Saluja, \& Messner, 2010).

Finally, one area in which our understanding is incomplete across disciplines concerns the role of time and timing of reflective behaviors and their relation with team performance (e.g., Ballard, Tschan, \& Waller, 2008; Janssen et al., 2010; Okhuysen \& Waller, 2002; Reimann, 2007; Waller, 1999). There is a general agreement in the team literature that team performance is the product of ongoing and recurrent processes and actions (McGrath, 1993). Marks and colleagues (2001) conceptualize these cycles as performance episodes. Performance episodes consist of repeated cycles of action (i.e., when teams perform an activityl and transition (or "interrupts") phases between actions. These interrupts are opportunities for teams to stop and reflect about their progresses for engaging in change (Okhuysen \& Waller, 2002). The most common conceptualization of team reflexivity does stipulate that shared reflection can occur before, during, and after a task (West, 2000; Schippers et al., 2007). However, scholars have generally measured it as an overall working style (Gurtner, Tschan, Semmer, \& Nagele, 2007) or as an aggregated measure of collaborative activities and have not differentiated the moments at which it 
occurs (e.g., Lajoie \& Lu, 2012). Specifically, they have not tested whether team reflexivity was more or less beneficial in certain phases, in relation to team performance dynamics, as suggested by certain authors (Hoeg \& Parboteeah, 2006; Janssen et al., 2010; Schippers et al., 2003). This time-related issue of team reflexivity is elaborated upon in the following section.

\section{TIME AND TIMING OF TEAM REFLEXIVITY}

We identify three primary issues in understanding the dynamic aspects of team reflexivity. First, although the importance of dynamic conditions experienced by teams over time is widely accepted (e.g., Waller, 1999), empirical work on how team reflexivity changes over time is missing (e.g., Janssen et al., 2010). On the one hand, it may be that overt communication is no longer needed as teams improve their implicit coordination over time, thus decreasing reflective interactions (e.g., Entin \& Serfaty, 1999). Additionally, teams tend to define their goals and strategies at an early stage of their work and not to deliberatively review them after some work has been accomplished (Argote, 1989; Hackman \& Wageman, 2005). Also, in line with arguments from Schippers and colleagues (2003), reflexivity might decline over time in diverse teams as viewpoints and perspectives become incompatible. On the other hand, they suggest that this declining effect might be reduced by the provision of feedback. It may be that the availability of accurate performance data highlighting deficiencies and a sustained task complexity trigger learning needs for teams perhaps calling for more reflection over time (Rulke \& Rau, 2000). As such, feedback provision occurring during transition can act as a formal mechanism, a temporal punctuation likely to encourage reflection without necessarily giving a predetermined framework to follow (Okhuysen \& Waller, 2002).

Second, the role of timing of reflective behaviors is similarly not well understood. The scarce previous research on the question "does reflection during action and/or transition lead to better performance" has shown mixed results in contexts without explicit feedback. For example, in a study conducted by Moreland and McMinn (2010), none of the (scarce) reflective behaviors occurring during transition was significantly related to changes in team performance. By contrast, research looking into the impact of "interrupts" on group processes concluded that these were triggers of change in groups (Okhuysen \& Eisenhardt, 2002). Team members appear to naturally interrupt their work around the midpoint of the allocated time for task completion and be more likely to put into practice strategies they set during these time outs 
(Gersick, 1989). Concerning reflection during action, Moreland and his colleague suggest that it might have more impact on performance. This reflection-inaction would be more directly related to the activities team members perform and thus prevent errors from being committed in real time. Conversely, it is likely that reflection while performing has a cost especially in a task that combines active processing of information and coordinated actions (Kirschner, Paas, \& Kirschner, 2009; Schippers et al., 2013). That is, reflecting while executing a complex task places an extra burden on teams which may overload their working memory occasioning less optimal performance (Kirschner et al., 2009).

Furthermore, it is generally recognized that what happens in the early part of the team interaction might provide insight into subsequent effectiveness (e.g., Eriksen \& Dyer, 2004; Kaplan, Laport, \& Waller, 2013). Team decision-making literature has provided preliminary insights into this issue of timing of behaviors. It was shown that in teams with distributed information (i.e., comprising team members holding unique information), early agreements might harm decision quality because teams are less focused on exchanging and integrating distributed information Ivan Ginkel et al., 2009; van Ginkel \& van Knippenberg, 2009). Accordingly, jumping too early into task completion might lead to process losses and performance decline (Mathieu \& Rapp, 2008). On the contrary, it was demonstrated that effective teams share and elaborate upon distributed information at the beginning of interaction (van Ginkel at al., 2009). Rulke and Rau (2000) came to a similar conclusion when examining how teams develop a shared understanding of "who knows what" in the team li.e., transactive memory systems), proved to be an important factor to achieve better success. They observed that teams with high transactive memory systems were those whose members shared understandings and evaluated each other's expertise early in their team interactions. In another example from computer-supported collaborative learning research, Kapur, Voiklis, and Kinzer (2008) demonstrated that a high quality contribution at the beginning of a problem solving process had more impact than those occurring later during team interactions. Therefore, the temporal pattern within reflective interactions should be taken into account in further understanding team reflexivity upon feedback. Also, presently, in the team reflexivity literature the question "do the three behaviors making up reflexivity have differential effects on subsequent performance at an early stage of team interaction" remains unanswered. No empirical work has shown the necessity of a certain order of these reflective behaviors nor whether, and if so when, certain reflective behaviors were more conducive to better performance. For example, if we look into reflective behaviors individually, we do not know if 
evaluating and looking for alternatives during teams' first moment of interaction promote elaboration and understanding of the task whereas making decisions at an early stage is detrimental to subsequent performance.

Third, the direction of the relation between reflexivity and performance can be questioned (e.g., Janssen et al., 2010). In line with the core assumption of previous research on team reflexivity, does reflexivity lead to subsequent better performance? Alternatively or at the same time, do teams learn from previous performance, and thus reflect more as a consequence of how they performed previously? Research still has to prove the theoretical claim that teams can learn from the past through reflection with clear sight of performance criteria and information about their attainment. Only recently, Schippers and colleagues (2013) have given indirect evidence in this regard. In this study, self-report reflexivity was measured at two points in time in teams of students working on their bachelor thesis. This study showed that low-performing teams had the capability to translate information from performance feedback into effective task approaches. However, students were only given a grade and not feedback describing attainment of specific performance criteria. As suggested by Waller, Gupta, and Giambatista (2004) the timing of errors and subsequent behaviors has to be recorded to answer the question of causality. Further, investigating the timing of reflective activities in teams can help detect the points at which team reflexivity occurs and may need to be supported (Lajoie, \& Lu, 2012).

\section{THE PRESENT STUDY}

In the present study, we seek to understand the dynamics of team reflexivity and the relation (uni or bi-directional) between team reflexivity and performance. Therefore, we explore the two following questions. 1) Does the occurrence of team reflexivity augment or decline over time during action and transition phases of teamwork? 2) How is the timing at which reflective behavior occurs related to performance? Specifically, is reflexivity during action and/or during transition related to higher performance (a)? Does each behavior making up reflexivity have the same impact on performance when occurring during teams' first moment of interaction (b)? 


\section{METHOD}

\section{Participants}

Sixty-four students (32 males and 32 females) were recruited from a university in the Netherlands and randomly assigned to thirty-two dyads ( $N=32)$. Their ages ranged from 18 to 29 years, $M=22.3, S D=2.4$. Participants were not eligible if any of the following exclusion criteria were present: experience in flight or related simulations and familiarity with each other. They were either paired with a same-gender partner (female and male teams, $n=11$ and $n=11$ respectively) or different-gender partner (mixed teams, $n=10$ ). By random assignment, half of the sample was assigned to a role of pilot and the other half to a role of co-pilot. Subjects participated voluntarily in exchange for vouchers.

\section{Task}

Participants in the role of pilot and co-pilot were required to complete four landing missions of the computer simulation "Microsoft Flight Simulator X". The task, a complex, fast-paced, and high-workload situation, was chosen to stimulate ongoing learning in a controlled environment. Cognitively complex and interactive simulation tasks, such as flight-simulations, are commonly used in team research to investigate processes related to team performance (e.g., Bowers, Salas, Prince, \& Brannick, 1992; Villado \& Arthur, 2013). We did not use this computer simulation to mimic real-work team environments but rather to examine a set of theoretical relations (i.e., nomological network) among constructs within specific and controlled boundaries: a complex, fast-paced, and high-workload situation in which team members with unequally distributed information have to learn from each other to achieve their team goal and extend their learning to more complex variations of the task (Marks, 2000). To avoid that good-performing teams would have less need to learn as a consequence of their reflection on performance (Schippers et al., 2013), the level of complexity of the missions increased gradually over time. The abundance of information teams received before and during the missions and the high level of interdependence between pilot and co-pilot ensured a high level of complexity across performance episodes. In each mission, teams had to follow a predetermined traffic pattern during which they were required to maintain appropriate levels of speed, altitude, and a correct configuration of the airplane. The missions were completed when the team managed to land safely on the runway. The computer was connected to a whiteboard on which the game was screened. 


\section{Procedure}

The whole experiment lasted approximately two and a half hours. After introduction to the experiment and random assignment to the role of pilot or copilot, participants were individually trained during forty-five minutes. Items of information necessary for achieving a good landing were distributed between the team members. Pilots and co-pilots were seated in separate rooms to study the task material containing critical role-specific knowledge of piloting or monitoring the aircraft. The task of the pilot was to fly the plane and operate the joystick. For that purpose, pilots received an additional 10-minute hands-on training to practice. The task of the co-pilot was to control the gas of the plane and provide the pilot with indications and directions. Only the co-pilot had the access to the air traffic control (ATC)'s instructions, given through headphones, and knew how to interpret the cockpit instruments. After the training, participants were seated together to complete four landing missions. Teams had up to fifteen minutes to complete each mission and were also allowed to restart a mission if they had crashed. Before each mission the team received a written description of the flight objectives and the general mission scenario. Moreover, before starting missions 2, 3, and 4, teams were given specific performance feedback about their previous performance. Performance feedback described the attainment of success criteria such as speed, altitude, rate of descent, pitch, touchdown, and traffic pattern. The participants were allowed to communicate freely with one another. During the experiment, all teams were videotaped.

\section{Measures}

\section{Performance}

Two performance scores were computed: the total number of errors during a mission and the number of times teams crashed. The number of errors was derived from an instrument rating objective performance criteria le.g., speed, altitude, activation of flaps and landing gear, landing position) of a good landing approach. This instrument was based on two sources: firstly, to identify key factors of a good flight, we performed a task analysis with a flight expert. Secondly, we used tests that the game itself provides its players to refine these criteria. Examples of deficiencies (i.e., errors) included failure to extend the flaps before landing, to maintain a certain speed interval during descent, to reduce the speed before touchdown, to keep a constant rate of descent, to align with the runaway, or to have one touchdown on the runaway. The total number of potential errors varied in the four missions. This variation reflects the increasing 
level of difficulty of the missions. We chose the number of crashes to depict one of the most salient manifest of performance for participants. There were four measurement times in total (i.e., T1, T2, T3, and T4).

\section{Categories of team reflective behaviors}

Team communication was coded to identify representative behaviors that could be taken as evidence of team reflexivity (Rourke \& Anderson, 2004). We developed the coding scheme of the present study through a series of steps assuring its validity and reliability (Schippers et al., 2007). First, we determined the granularity of the unit of analysis. The unit of meaning was applied (Rourke, Anderson, Garrison, \& Archer, 2001). Specifically, to consider a verbal statement a significant unit, we decided that utterances had to be individual messages (questions or statements) that 1) were expressed by one team member, 2) dealt with one topic, idea, or argument chain, 3) reflected one unique behavior, and 4) related to the topic at hand or the team. Thus, one semantic feature lunit of meaning) and one activity feature (team member speaking) were used for segmentation of the communication content into units (Chi, 1997). As such, as soon as the topic or the speaker changed, a new behavior was coded (VisschersPleijers, Dolmans, de Leng, Wolfhagen, \& van der Vleuten, 2006). In addition to verbal statements, one unambiguous non-verbal behavior was set as an evidence of one of the reflective behaviors.

Second, we discriminated verbal interactions types that typified reflexivity. To do this, we adapted and expanded the initial framework of reflexivity (West, 1996, 2000) and an existing questionnaire from Schippers and colleagues (2003). Reflexivity was originally defined as an iterative process including three broader behaviors, namely reflection, planning, and acting/adapting. As shown in Table 1, the coding scheme covers three reflective behaviors: evaluating or reviewing present or past team performance and strategies, looking for alternatives, and making decisions. Information directly forwarded from the ATC (repetitions) and the literal reading of the feedback form were excluded from the coding. 
Table 1

The Coding Scheme for the Content Analysis of Team Reflexivity

\begin{tabular}{|c|c|c|}
\hline Categories & Description & Examples \\
\hline $\begin{array}{l}\text { Evaluating or reviewing } \\
\text { performance or strategies }\end{array}$ & $\begin{array}{l}\text { Statements or questions about } \\
\text { team performance (e.g., whether } \\
\text { the team does/did well, is/was on } \\
\text { the right track according to plans } \\
\text { or received instructions), the goal } \\
\text { of the mission and its } \\
\text { requirements, actions and } \\
\text { strategies (mis)used, reasons } \\
\text { behind success, failure, or } \\
\text { problems (e.g., he/she gives } \\
\text { examples of behaviors, task or } \\
\text { team strategies that may explain } \\
\text { why they achieved success or } \\
\text { encountered problems during this } \\
\text { mission). }\end{array}$ & $\begin{array}{l}\text { "We are going in the wrong } \\
\text { direction." } \\
\text { "We crashed because we were } \\
\text { always too fast." } \\
\text { "Something went wrong, } \\
\text { maybe the nose of the plane } \\
\text { went too low?" }\end{array}$ \\
\hline Looking for alternatives & $\begin{array}{l}\text { Suggestions or discussions of } \\
\text { alternatives in how they } \\
\text { approached the task lat the task } \\
\text { or team levels) and of the } \\
\text { sequence of actions undertaken. } \\
\text { In other words, teams discuss } \\
\text { how they could do or could have } \\
\text { done differently. }\end{array}$ & $\begin{array}{l}\text { "We could have reduced the } \\
\text { speed by pitching up or } \\
\text { reducing the throttle." } \\
\text { "We could lower the speed by } \\
\text { extending the flaps, pitching } \\
\text { up, or lower the gas." } \\
\text { "We could either make a U- } \\
\text { turn either still try to lower } \\
\text { speed and make a sharp } \\
\text { descent." }\end{array}$ \\
\hline Making decisions & $\begin{array}{l}\text { Statements clearly depicting a } \\
\text { decision about a new direction to } \\
\text { take or observable behaviors } \\
\text { following a decision. Team } \\
\text { members' utterances depicting } \\
\text { very explicit decisions about the } \\
\text { way they were going to approach } \\
\text { the task or work as a team, } \\
\text { explicit statements about the } \\
\text { intention to follow decisions made } \\
\text { within the team, and explicit } \\
\text { reaction to a decision by an action } \\
\text { le.g., by pressing the flaps, pulling } \\
\text { the gas controller). }\end{array}$ & $\begin{array}{l}\text { "We are going to make a U- } \\
\text { Turn" or "This time, you look at } \\
\text { the speed indicator and I will } \\
\text { pitch down." }\end{array}$ \\
\hline
\end{tabular}

Third, we ran a pilot study to test and validate the coding scheme. This lead to adaptations, clarifications of the reasoning behind the framework definitions 
and the boundaries of the units, and the addition of typical examples. Fourth, we extensively trained two coders, each blind to the hypotheses of the experiment, to optimize reliability and consequently reduce errors in observation. They were provided with clear examples (of inclusion and exclusion) of the manifestation of the behaviors and had rating exercises with multiple rounds and discussions to attain consistency among coders. Fifth, videotapes were coded with the newly developed coding scheme. Finally, the two coders coded independently one-third of the videotapes to estimate interrater reliability (Cohen's kappa). Kappas were calculated for all the categories. These kappas ranged from .65 to .88 , with an average of .78, indicating a 'substantial' to 'almost perfect agreement' across the two coders as to the occurrence of the specific behaviors (Landis \& Koch, 1977). Coders and two trainers resolved any discrepancies. The research design is displayed in Figure 1. 


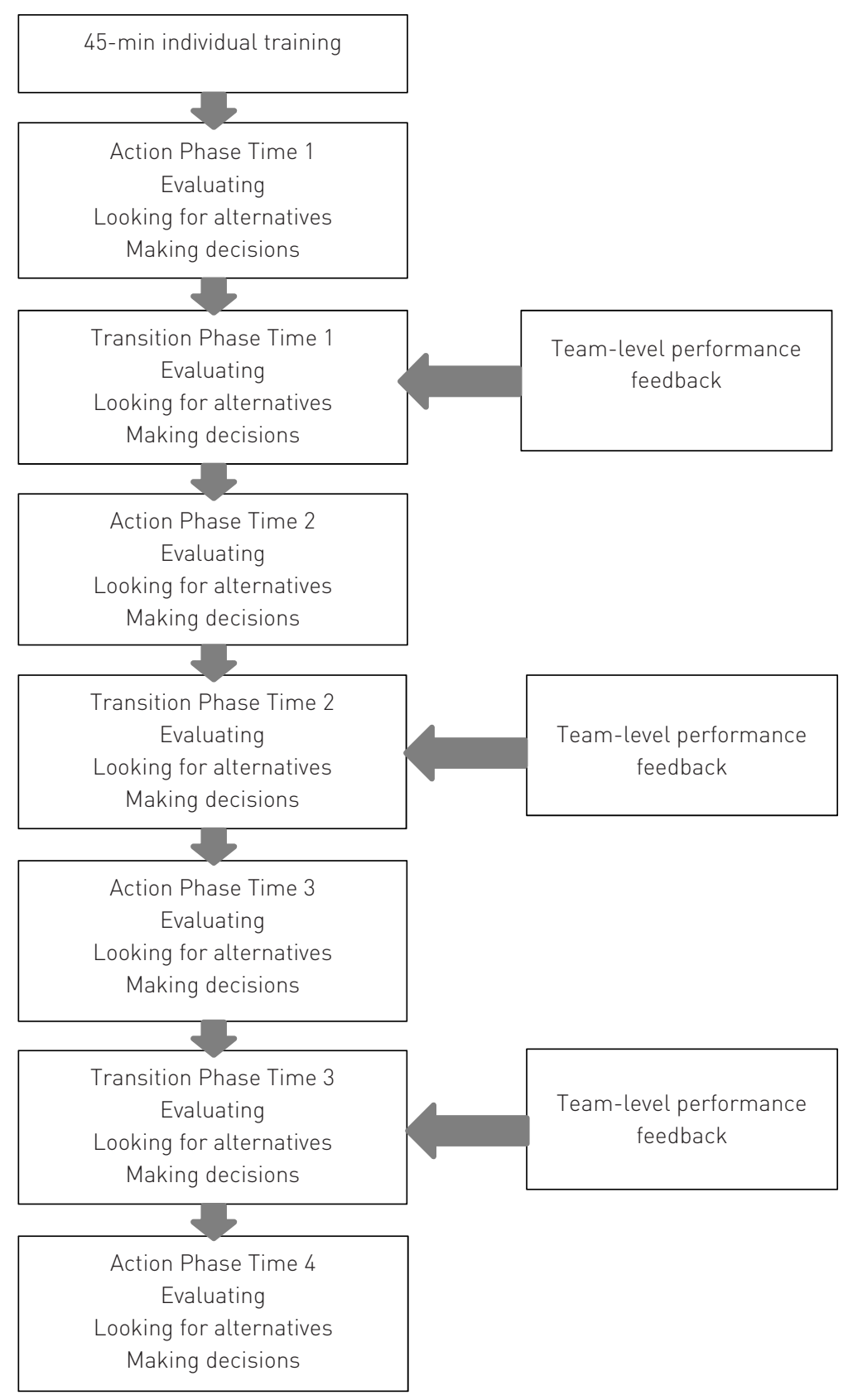

Figure 1. Overview of the experiment and behaviors measured at each wave of data. 


\section{ANALYSES}

For the coding, we used The Observer ${ }^{\circledR}$ XT 10.5, a computer software aimed for quantitative analysis of observational data. Videotapes were directly coded without transcripts. The extent to which teams engaged in each behavior was expressed in terms of frequencies of occurrence of the behavior for each mission (i.e., action phase) and for each feedback (transition) phase. Additionally, aggregated measures were computed, namely the overall team reflexivity (i.e., aggregation of the three behaviors) for each time measurement for action and feedback.

We coded acts on the basis of utterances of reflective behaviors. Besides utterances, we examined phases lor "when", specifically action or transition, earlier interaction or later interaction) in which some performance events (i.e., crashes and errors) were related to reflective behaviors. Behaviors were coded at four points in time during action and feedback phases (Time 1, Time 2, Time 3 , and Time 4).

\section{RESULTS}

In the following section, we first present an overview of the frequencies of individual reflective behaviors and of the frequencies of sequences comprising two or three behaviors. Second, we test whether reflective behaviors change over time during action and feedback using repeated-measures analyses of variance. Third, correlations between reflective behaviors and performance are examined, more specifically (a) the relations between prior performance and subsequent reflexivity and (b) prior reflexivity and subsequent performance.

\section{Frequencies of individual behaviors}

Figures 2, 3, and 4 depict means and standard deviations of the reflective categories across time during action and feedback phases. It can be seen that evaluating is the most frequent reflective behavior. Looking for alternatives during action at Time 1 appears very scarce. During feedback, it seems that looking for alternatives is not a frequent practice. The same trend can be noted for making decisions. It is more frequent during missions than after feedback reception. It has to be noted that standard deviations reflect important differences between teams. In sum, reflective behaviors, when examined 
individually, tend to follow a similar pattern: they appear more frequent during action while they are low during feedback.

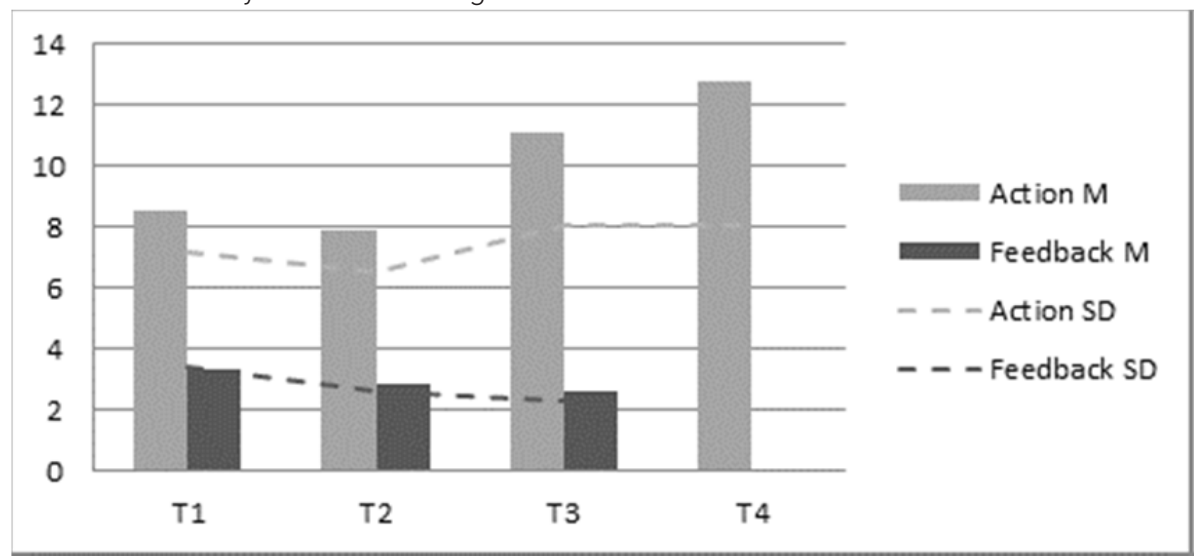

Figure 2. Means and standard deviations of Evaluating for each measurement time and phase.

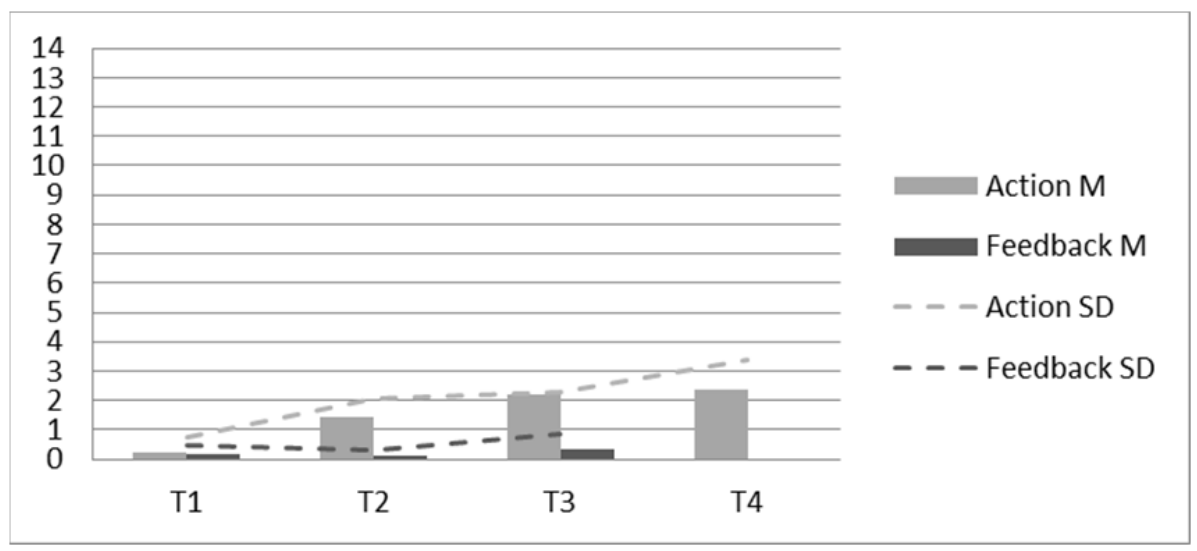

Figure 3. Means and standard deviations of Looking for alternatives for each measurement time and phase. 


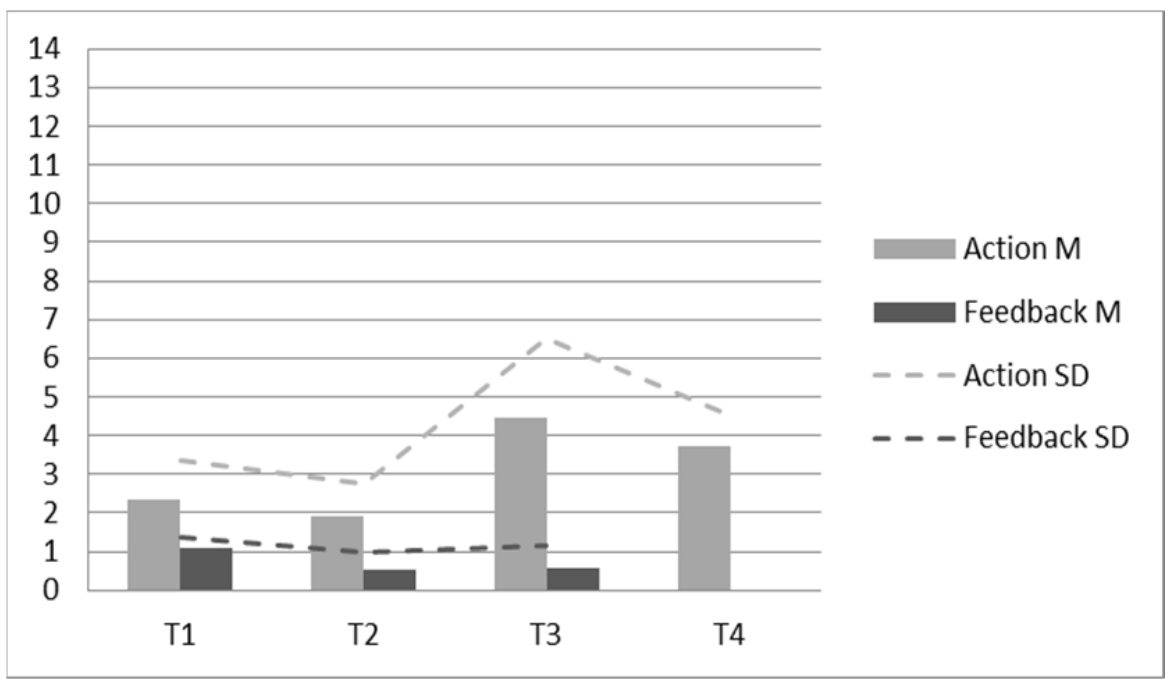

Figure 4. Means and standard deviations of Making decisions for each measurement time and phase.

\section{Sequences of evaluative behaviors}

The coded reflective acts described above are single communication behaviors. In the present study, team reflexivity was conceptualized as a collection of three behaviors. We explored whether teams actually completed full "reflective cycles" comprising all three behaviors in a sequence. Since there has been no empirical work demonstrating the necessity of all three behaviors we also considered the most basic behavioral patterns consisting of two subsequent reflective behaviors. As can be seen in Table 2, most reflective communication across teams can be summarized by two main two-behavior sequences: sequences starting with evaluating and looking for alternatives and ending with clear decisions about a different way to handle the task. In these sequences, teams "skipped" the evaluation or search for alternatives phases. While sequences of looking for alternatives followed by decisions seemed to grow over time during action, except for the last mission, the frequencies of the sequences starting with an evaluative comment and ending with a decision stayed relatively stable over time, except for a drop at Time 2. During feedback, the same trend than for individual behaviors is observed; sequences are very scarce. Importantly, full cycles were almost never completed, suggesting that teams were not naturally systematic in their reflective process. The absence of reflective cycles does not allow us to further investigate their change over time and relatedness to team performance. Still, how individual reflective behaviors evolve over time and are related to team performance is of importance to map 1) how teams naturally 
respond to feedback and 2) whether some behaviors appear more important than others in the feedback process.

Table 2

Frequencies of Sequences of Reflective Behaviors at each Wave of Data, at the Team Level ( $N=32$ )

\begin{tabular}{lllllccc}
\hline Sequences & Time 1 & \multicolumn{3}{c}{ Time 2 } & Time 3 & Time 4 \\
\hline & Action & Feedback & Action & Feedback & Action & Feedback & Action \\
B1-B2 & 2 & 2 & 3 & 0 & 15 & 1 & 9 \\
B1-B3 & 30 & 14 & 15 & 7 & 29 & 0 & 29 \\
B2-B3 & 2 & 2 & 18 & 0 & 30 & 3 & 23 \\
B1-B2-B3 & 0 & 0 & 1 & 0 & 2 & 0 & 0 \\
\hline
\end{tabular}

Note. B1 = Evaluating, B2 = Looking for alternatives, B3 = Making decisions .

\section{Does reflexivity change over time?}

To test for significant changes of reflexivity behaviors (taken individually) over time, we computed repeated-measures analyses of variance with a GreenhouseGeisser correction (as sphericity was violated for all behaviors) and with the four times each behavior was measured as a within-team factor. Pairwise comparisons with Bonferroni corrections controlling for inflation of Type I error were also computed. Evaluating during action changed significantly from Time 1 to Time 4, $F(2.26,65.67)=5.04, p=.05$, with pairwise comparisons showing that evaluating at Time 4 was significantly more frequent than evaluating at Time 2 l $p$ $=$.019). In contrast, evaluating during feedback did not change over time. Regarding looking for alternatives during action there was also an overall significant difference between the means at the different time points, $F$ (2.24, 64.84) $=5.76, p=.004$. A pairwise comparison confirmed a difference between Time 1 and Time 2 ( $p=.034)$, Time 1 and Time $3(p=.000)$, and Time 1 and Time 4 ( $p=.0006)$, signifying an increase of the behavior over missions. Looking for alternatives during feedback, making decisions during action and during feedback did not change significantly over time with a Bonferroni correction. With Tukey's test, making decision during action at Time 4 was significantly higher than at Time $3(p=.043)$ and Time $2(p=.045)$. Finally, while overall reflexivity across feedback did not change significantly over time, the mean scores for overall reflexivity across missions (i.e., aggregated behaviors) were significantly different, $F(2.33,67.56)=5.46, p=.004$. Specifically, reflexivity 
during mission at Time 4 was higher than reflexivity during mission at Time 1 ( $p$ $=.027)$ and Time $2(p=.035)$. It is worthwhile noting that if the less conservative Tukey post hoc test is used, the score in mission 3 is higher than at Time 1 l $p=$ .015) and Time $2(p=.043)$.

Is reflexivity related to performance?

Intercorrelations between reflective behaviors and performance measures are presented per time period in Table 3. 
Table 3

Correlations between Coded Categories and Performance Measures at each Point in Time ( $N=32)$

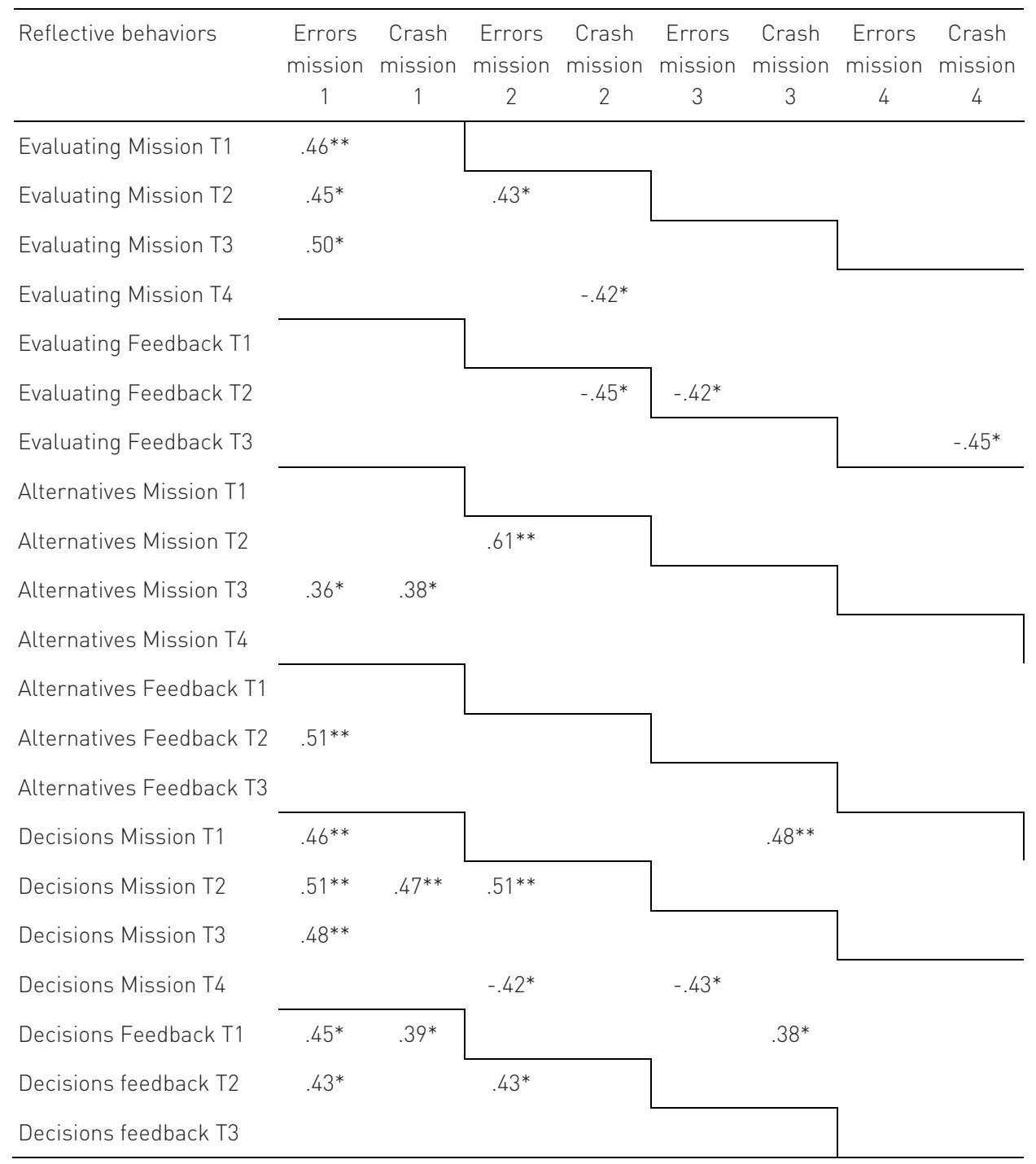

Note. ${ }^{*} p<.05 .{ }^{* *} p<.01 . \mathrm{T} 1=$ Time $1 ; \mathrm{T} 2=$ Mission 2; T3 = Mission3; T4 = Mission 4. Only significant correlations are indicated 


\section{The impact of prior performance on team reflexivity}

At first glance, initial errors seem to be beneficial to subsequent reflective behaviors, while the trend that errors trigger reflection tends to decline with time. Specifically, the number of errors teams made during the first action phase was positively correlated with numerous reflective behaviors and to all reflective categories. The number of crashes teams initially faced followed the same path. Teams did not seem to be discouraged by their first experience with crash. For example, the initial number of crashes was positively related to more decision-making behaviors after it occurred, both during the feedback phase following the "failure" $(r=.39, p<.05)$ and during the next action at Time 2 ( $r=$ .47, $p<.01$ ). In contrast, errors committed at Times 2 and 3 were not related to higher subsequent reflective behaviors, with the exception of errors at Time 2 appearing as a trigger for decision making during the transition phase immediately following that mission $(r=.43, p<.05)$. Conversely, errors at Times 2 and 3 seem to hamper decision making during action at Time 4 (respectively $r$ $=-.42, p<.05$ and $r=-.43, p<.05)$, while the number of crashes at Time 2 was related to less frequent evaluative behaviors during feedback at Time $2(r=-.45$, $p<.05)$ and during action at Time $4(r=-.42, p<.05)$. In sum, these first results seem to suggest that initial failure acts as an eye opener to evaluate what went wrong, look for alternative ways of approaching the task, and make more decisions, while later, as task becomes more complex, it might relate to less subsequent reflection.

\section{The impact of team reflexivity on subsequent performance}

Concerning the impact of reflexivity on subsequent performance, the correlations indicate a differential impact depending on the type of behavior considered. The extent to which teams evaluated their performance and strategies during feedback at Time 3 was related to lower number of crashes at Time $4(r=-.45, p<.05)$. Similarly, the extent to which teams engaged in evaluative behaviors during feedback at Time 2 significantly related to fewer errors at Time $3(r=-.42, p<.05)$. What is particularly noticeable is that these significant relationships concern 1) evaluative behaviors and 2) periods of team transition, suggesting a positive effect of processing feedback on subsequent performance. Reflection during action does not seem to be significantly related to subsequent performance when bivariate correlations are computed.

In contrast, the extent to which teams made decisions during action at Time 1 was related to more crashes at Time $3(r=.48, p<.01)$, suggesting that making 
decisions during the initial moments of team development on this novel task (with its specific characteristics) may impede subsequent performance.

\section{DISCUSSION}

To uncover when giving teams feedback about their performance creates an opportunity for learning, it has been posited that it is important to examine how teams actively process feedback and thus collaboratively evaluate information about past activities and derive alternative recommendations for next action. However, research on this feedback processing has been scarce in the learning sciences and organizational psychology (Gabelica et al., 2012; London \& Sessa, 2006; Phielix et al., 2010). It is shown that the specific activities teams perform to deal with feedback and when these activities are related to performance remain to be considered.

Following from these perceived gaps, we conducted a study attempting to build upon and extend research in this domain by 1) identifying actual behaviors enabling feedback processing (i.e., team reflexivity) and 2) providing a more finegrained analysis of dynamic aspects of team reflexivity in a context with systematic and explicit feedback. While theoretical work seems to suggest team reflexivity is an iterative three-step cycle that involves evaluating performance and strategies, looking for alternatives, and making decisions le.g., Schippers et al., 2007; Yukawa, 2006), we do not know if to perform well, it is necessary to follow this series of steps and if some steps are more dominant and influential than others in relation to team performance. We explored the development of team reflective behaviors and the relation between timing of reflective behaviors and performance during four performance episodes.

Following conclusions could be drawn. Firstly, teams never completed full cycles of evaluating, looking for alternatives, and making decisions. They did, however, complete two behavior-sequences starting with evaluating or looking for alternatives and ending with a clear decision. Moreover, these sequences were very scarce during transition li.e., interrupts during which team performance feedback was delivered). While the reflective cycle is usually described sequentially, teams seem to rarely follow a rigid series of steps to deal with feedback. Instead, it seems like they often skip steps or even go back through steps several times.

When taken individually, reflective behaviors were overall more frequent and increased over time during action, whereas reflexivity during transition was relatively less frequent and did not change. Looking for alternatives was very 
scarce but also increased over time during action only. There might be two reasons for this growth of reflection-in-action. First, natural reflection might arise as a response to an immediate learning need when a team observes cues of ineffective behaviors or experiences misunderstanding or uncertainty le.g., they get lost) while completing the task. Additionally, this learning need could have been triggered by the increasing complexity of the task (i.e., more cues to understand and interpret). Second, preceding feedback, which has been advanced as a way to counteract the natural decline of team reflexivity (Schippers et al., 2003), could also have had a delayed effect on next reflectionduring action. In the learning sciences, feedback has been shown to impact subsequent learning (e.g., Mory, 2003). It may be that teams only see the learning content of a feedback when they have to deal with a similar situation. This high reflexivity-in-action suggests that teams are more reactive than proactive and adaptive to anticipated circumstances when faced with higher complexity and workload. This is in line with a common rationale some authors have been using to speculate on the causes of a lack of actual reflection in teams (Arvaja, Häkkinen, Eteläpelto, \& Rasku-Puttonen, 2000; Morris \& Stew, 2007). They state that teams are more driven by their results (i.e., producing and performingl than the learning they can gain, especially when they are under pressure and despite the obvious benefits of strategy development (Gurtner et al., 2007; Karau \& Kelly, 1992). A possible explanation of why teams did not use transition phases to increase reflection in the same way lies in teams' tendency to set their goals and strategies early and not to actively question them later (Argote, 1989; Hackman \& Wageman, 2005; Weingart, 1992). Further, it may be that the concurrent cognitive demands of collaborating on the complex task, making sense of the received feedback, and trying to prepare for the next task were too high for teams to make the most of their learning experience (Kirschner et al., 2009; Rummel \& Spada, 2009). Reflecting is a challenging high-order activity (Jay \& Johnson, 2001). The concept of reflection assumes individuals have the capacity to engage in self-examination and open-minded analysis of their own knowledge. Additionally, even if team members can reflect in solo-learning situations, they may not be able to coordinate and co-reflect in a team, communicate their reflective thoughts, nor agree on ways to address the task (Chan, 2012).

Secondly, we uncovered patterns that transcended the straightforward question of whether team reflexivity can change performance in teams given explicit feedback. It seems that the key question is rather when improvements occur. (Lajoie \& Lu, 2012) As signified in recent research on team reflexivity (e.g., Moreland \& MacMinn, 2010; Schippers et al, 2013), reflexivity was not 
uniformly beneficial. We showed instances in which timing of reflective behaviors determined its effect (positive, negative, or neutral) on performance. First, early decision-making was related to lower subsequent outcomes. These findings are in accordance with previous studies on timing of decision-making indicating that early decision making might prevent deep processing and sharing of unevenly distributed information (van Ginkel, et al., 2009; van Ginkel \& van Knippenberg, 2008). Second, after that first experience with their task, teams were able to derive insights from past performance (depicted by feedback) and correct misunderstandings that prevented effective action (Tjosvold et al., 2004). However, only evaluative behaviors performed during feedback phases were related to later improved performance. For example, teams were able to reduce their errors in the last high-workload task with more preparation li.e., evaluating during preceding feedback time). As such, the effect of evaluative behaviors seems to be contingent on the phase during which they are performed (during transition rather than during action). This points a paradox: though they could experience positive consequences of reflecting during these time outs, teams did not increase reflection during feedback over time. Third, reflection during action does not seem to be significantly related to better subsequent performance when bivariate correlations are computed. As such, no empirical support could be found for Moreland and McMinn's (2010) proposition that reflecting during the task could be more beneficial to teams due to the immediate possibility to adjust to the situation. However, this (increasing) reflection during action did not harm team performance either and showed that, in general, teams remained connected despite the increasingly higher workload of their task. Communication breakdowns could have been expected. Previous team research on non-routine working situations (e.g., Waller et al., 2004) has demonstrated that low-performing teams become cognitively overwhelmed in case of high workload and consequently tend to focus more on their individual sub-task instead of collaborating (e.g., Salas, Rosen, \& King, 2007).

Finally, initial errors appeared to be a driver of subsequent reflexivity while later errors mostly did not have this motivational role. These preliminary findings open up the possibility that there might exist some time-specific effects of previous errors that are determinant to trigger motivation to improve. Maybe the first mistake does not really hurt while repeated errors would be more detrimental to performance?

Importantly, these results raise the question of the causality of the relation between reflexivity and performance (e.g., Janssen et al., 2010). These analyses seem to rather show a more dynamic and retroactive relation between past and future performance and reflexivity, raising the need for time-series-analyses. 
This is however behind the scope of the present explorative study. This suggests that the question "does prior performance trigger reflexivity or does prior reflexivity generate better performance" should rather be changed into: when do performance and reflexivity dynamically interact to trigger team learning and better subsequent performance. As we found a reversed effect as well, it could be formulated that initial errors do matter and that teams have the capability to learn from them under certain circumstances.

Taken together, these findings underscore the importance of a careful evaluation of how the team is doing and why during transition phases corresponding to feedback reception. We could not empirically test the effects of three-step reflective cycles since they did not naturally occur but we provided evidence that teams using the feedback opportunity to stop and analyze their performance and strategies were able to translate information about performance into corrective behaviors since their performance got improved. These results are in line with studies on the impact of interrupts (e.g., Okhuysen \& Waller, 2002) and theories on feedback in teams that stipulate that feedback receivers' involvement plays a critical role to explain feedback effectiveness in teams (e.g., Gabelica et al., 2012).

\section{LIMITATIONS AND FUTURE DIRECTIONS}

Although we have specified behaviors signifying reflexivity, we have not explored depth of processing (Volet, Summers, \& Thurman, 2009). It is likely that deeper reflection (e.g., reflective statements conveying inferences) generates better insight into the feedback content and use in subsequent tasks (Anseel et al., 2009).

Also, previous research has acknowledged that developing strategies for action is important and necessary but does not always ensure actual strategy implementation (Gurtner et al., 2007; Marks et al., 2001; Tschan et al., 2000). Our third reflective category (i.e., making decisions) encompassed both strategy development (i.e., clear decisions about new strategies and actions) and strategy implementation (i.e., clear gesture or overt behavior showing the team acting upon a decision). Despite the fact that teams were provided with feedback based on specific criteria, improvement strategies defined by teams could still have been too general or abstract to be directly put into action, or coordination problems could have rendered the well-defined plans unused. A further investigation of implementation strategies and their quality seems warranted. 
Overall, this empirical study was designed to meet methodological requirements of a rigorous experimental design with high internal validity, based on its temporal sequencing and the collection of objective performance data. Capturing fundamental processes in a controlled environment is a first step to better understand complex phenomena. To that purpose, we used a flight simulation as a research platform to simulate and control task and team features. Simulations constitute an interesting environment that offers standardized performance measures with possibilities of controlling complexity, information overload, and cues available from the environment (Mathieu, 2000). In a learning perspective, they also allow learners to apply their knowledge and understanding to a task and observe the effects of their decisions in a reactive environment that offers real-time feedback (Bronack, Riedl, \& Tashner, 2006; Gredler, 2004). Prior work on simulations has shown that they stimulate numerous cognitive processes, such as higher-level reasoning or creative thinking (Moreno \& Mayer, 2005; Moreno, Mayer, Spires, \& Lester, 2001). As a trade-off, laboratory environments overlook natural factors in real-world contexts that may mediate learning. As such, the extent to which the results from our controlled design can be generalized to real had-hoc teams has to be considered with cautious. The artificial and temporal nature of the team and the limited number of team members must be acknowledged. Teams of more than two team members and/or knowing each other before completing a team task might exhibit more complex interaction patterns. In this regard, we acknowledge that there has been a recent debate about whether findings from research on dyads can be simply generalized to larger teams (Moreland, 2010; Williams, 2010). We are aware that certain aspects of team processes and dynamics (e.g., group socialization) can hardly be grasped by the use of dyads and that the addition of team members increases complexity of team communication and coordination (Michinov \& Michinov, 2009; Noroozi et al. 2012). However, since research into the dynamic aspects of co-reflection in teams is a relatively new area, the present study looking into the timing of basic team behaviors in the smallest form of teams provides a very good start for further research. A replication study with triads and larger groups is needed to corroborate our results and explore the relationship between team size and successful team reflexivity. Moreover, although novelty of the task was controlled, we did not account for group-ability composition while research has demonstrated its influence on the accuracy and quality of explanations in teams (Webb et al., 1998). Finally, the use of students is sometimes considered as a possible limitation. Nevertheless, previous studies have established that little difference holds between the use of students and professional teams when using problem 
solving and decision-making scenarios (Balijepally et al., 2009; Yoo \& Alavi, 2001). Still, further research exploring the effects of reflexivity with explicit feedback with more team members and in different settings will be needed to understand the complexity of how team members with different expertise, knowledge, and possibly high diversity deal with feedback that describes the aggregated group effort towards a shared goal. Furthermore, future field studies obviously need to consider critical contextual factors that influence and constraint team behaviors (Kozlowski \& Ilgen, 2006).

Another limitation of the study is the relatively lower frequency of some reflective behaviors (e.g., looking for alternatives). Similarly, sequences of reflective behaviors did not occur very often, limiting the possible analyses relating these to performance improvements. This necessitates caution about drawing premature conclusions and underlines the need for replication studies with larger samples. Additionally, this limitation could be overcome in future research by stimulating or training teams to become reflexive (e.g., King, 1991) and comparing occurrences of reflective behaviors and their relation with team performance with a no-training condition. Another challenging issue is motivational: we do not know why teams did not frequently reflect after feedback. Motivational factors behind a lack of reflection and receptivity to feedback should be investigated in further research.

Finally, the relation between team performance (signified by accurate and specific feedback) and team reflexivity should be analyzed in longitudinal designs. Additional measurement points of team reflexivity spaced over time would provide a more fine-tuned understanding of under which circumstances previous performance has more impact on learning. Feedback loops in which previous performance acts as an input for determining subsequent processes and performance have been recently forwarded as relevant models to understand team dynamics (llgen et al., 2005). 


\section{REFERENCES}

Anseel, F., Lievens, F., \& Schollaert, E. (2009). Reflection as a strategy to enhance task performance after feedback. Organizational Behavior and Human Decision Processes, 110, 23-35. doi:10.1016/j.obhdp.2009.05.003

Adcroft, A. (2011). The mythology of feedback. Higher Education Research and Development 304), 405-419. doi:10.1080/07294360.2010.526096

Argote, L. (1989). To centralize or not to centralize: the effects of uncertainty and threat on group structure and performance. Organizational Behavior and Human Decision Processes, 43, 5874. doi:10.1016/0749-5978/89/90058-7

Arvaja, M., Häkkinen, P., Eteläpelto, A., \& Rasku-Puttonen, H. (2000). Collaborative processes during report writing of a science learning project: The nature of discourse as a function of task requirements. European Journal of Psychology of Education, 15(4), 455-466. doi:10.1007/BF03172987

Austin, J., Kessler, M. L., Riccobono, J. E., \& Bailey, J. S. (1996). Using feedback and reinforcement to improve the performance and safety of a roofing crew. Journal of Organizational Behavior Management, 16(2), 49-75. doi:10.1300/J075v16n02_04

Ballard, D. I., Tschan, F., \& Waller, M. J. (2008). All in the timing: Considering time at multiple stages of group research. Small Group Research, 39, 328-351. doi:10.1177/1046496408317036

Balijepally, V., Mahapatra, R., Nerur, S., \& Price, K. H. (2009). Are two Heads better than one for Software Development? The Productivity Paradox of Pair Programming. MIS Quarterly, 33(1), 91-118.

Barron, B. (2000). Achieving coordination in collaborative problem-solving groups. Journal of the Learning Sciences, 9, 403-436. doi:10.1207/S15327809JLS0904_2

Boud, D., Keogh, R., \& Walker, D. (1985). Promoting reflection in learning: A model. In D. Boud, R. Keogh, \& D. Walker (Eds.), Reflection: Turning experience into learning (pp. 18-40). London: Kogan Page.

Boud, D., \& E. Molloy. (2013). Rethinking Models of Feedback for Learning: The Challenge of Design. Assessment \& Evaluation in Higher Education, 38(6), 698-712. doi:10.1080/02602938.2012.691462

Bowers, C. A., Salas, E., Prince, C., \& Brannick, M. T. (1992). Games teams play: A methodology for investigating team coordination and performance. Behavior Research Methods, Instruments, and Computers, 24,503-506. doi:10.3758/BF03203594

Bronack, S., Riedl, R., \& Tashner, J. (2006) Learning in the zone: A social constructivist framework for distance education in a 3D virtual world. Interactive Learning Environments, 1413), 219-232. doi:10.1080/10494820600909157

Chan, C. K. K. (2012). Co-regulation of learning in computer-supported collaborative learning environments: a discussion. Metacognition and Learning, 11), 63-73. doi:10.1007/s11409-012$9086-z$

Chi, M. T. H. (1997). Quantifying qualitative analysis of verbal data: A practical guide. The Journal of the Learning Sciences, 6, 271-315. doi:10.1207/s15327809jls0603_1

Decuyper, S., Dochy, F., \& Van den Bossche, P. (2010). Grasping the dynamic complexity of team learning: An integrative model for effective team learning in organizations. Educational Research Review, 5,111-133. doi:10.1016/j.edurev.2010.02.002

De Wever, B., Schellens, T., Valcke, M., \& Van Keer, H. (2006). Content analysis schemes to analyze transcripts of online asynchronous discussion groups: A review. Computers \& Education, 46(1), 6-28. doi:.1016/j.compedu.2005.04.005

Dewey, J. (1910/1997). How we think. Mineola, New York: Dover. 
Dillenbourg, P. (1999). Collaborative Learning: Cognitive and Computational Approaches. Advances in Learning and Instruction Series. New York, NY: Elsevier Science, Inc.

Dillenbourg, P., Baker, M., Blaye, A, \& O'Malley, C. (1996). The evolution of research on collaborative learning. In E. Spada \& P. Reiman (Eds), Learning in Humans and Machine: Towards an interdisciplinary learning science (pp. 189-211). Oxford: Elsevier.

Duijnhouwer, H., Prins, F. J., \& Stokking, K. M. (2012). Feedback providing improvement strategies and reflection on feedback use: Effects on students' writing motivation, process, and performance. Learning and Instruction, 22(4), 171-184. doi: 10.1016/j.learninstruc.2011.10.003

Edmondson, A. C. (1999). Psychological safety and learning behavior in work teams. Administrative Science Quarterly, 4412), 350-383. doi:10.2307/2666999

Edmondson, A. C, Bohmer, R. M, \& Pisano, G. P. (2001). Disrupted Routines: Team Learning and New Technology Implementation in Hospitals. Administrative Science Quarterly, 46, 685-716. doi: $10.2307 / 3094828$

Edmondson, A. C., Dillon, J., \& Roloff, K. S., (2007). Three perspectives on team learning outcome improvement, task mastery, and group process. The Academy of Management Annals, 1, 269314. doi:10.1080/078559811

Entin, E. E., \& Serfaty, D. (1999). Adaptive team coordination. Human Factors, 41(2), 312-325. doi:10.1518/001872099779591196

Eriksen, J., \& Dyer, L. (2004). Right from the start: Exploring the effects of early team events on subsequent project team development and performance. Administrative Science Quarterly, 49, 438-471. doi:10.2307/4131442

Eva, K. W., Armson, H., Holmboe, E., Lockyer, J., Loney, E., Mann, K., et al. (2012). Factors influencing responsiveness to feedback: On the interplay between fear, confidence, and reasoning processes. Advances in Health Sciences Education: Theory and Practice, 1オ11, 1526.

Gabelica, C., Van den Bossche, P., Segers, M., \& Gijselaers, W. (2012). Feedback, a Powerful Lever in teams: a Review. Educational Research Review, 72), 123-144. doi:10.1016/j.edurev.2011.11.003

Gersick, C. J. G. (1989). Marking time: Predictable transition in task groups. Academy of Management Journal, 32, 274-309. doi:10.2307/256363

Gibbs, G., \& Simpson, C. (2004). Conditions Under Which Assessment Supports Students' Learning. Learning and Teaching in Higher Education, 1, 3-31.

Goodman, J. S., Wood, R. E., \& Hendrickx, M. (2004). Feedback specificity, exploration, and learning. Journal of Applied Psychology, 892), 248-262. doi:10.1037/0021-9010.89.2.248

Gredler, M. E. (2004). Games and simulations and their relationships to learning. In D. H. Jonassen (Ed.), Handbook of research for educational communications and technology (2nd ed., pp. 57182). Mahwah, NJ: Lawrence Erlbaum Associates.

Gurtner, A., Tschan, F., Semmer, N. K., \& Nagele, C. (2007). Getting groups to develop good strategies: Effects of reflexivity interventions on team process, team performance, and shared mental models. Organizational Behavior and Human Decision Processes, 102, 127-142. doi:10.1016/j.obhdp.2006.05.002

Hackman, J. R., \& Wageman, R. (2005). A theory of team coaching. Academy of Management Review, 30, 269-287. doi:10.5465/AMR.2005.16387885

Hattie, J. (2013). Calibration and confidence: Where to next? Learning and Instruction, 24, 62-66. doi:10.1016/j.learninstruc.2012.05.009

Hattie, J., \& Timperley, H. (2007). The power of feedback. Review of Educational Research, 771), 81 112. doi: $10.3102 / 003465430298487$

Hoegl, M., \& Parboteeah, K. P. (2006). Team goal commitment in innovative projects. International Journal of Innovation Management, 193), 299-324. doi:10.1142/S136391960600151X. 
Ilgen D. R., Hollenbeck J. R., Johnson M., \& Jundt D. (2005). Teams in organizations: From I-P-O models to IMOI models. Annual Review of Psychology, 56, 517-543. doi:10.1146/annurev.psych.56.091103.070250

Jay, J. K., \& Johnson, K. L. (2001). Capturing complexity: A typology of reflective practice for teacher education. Teaching and Teacher Education, 1811), 73-85. doi:10.1016/S0742-051X(01)00051-8

Janssen, J., Kirschner, F., Erkens, G., Kirschner, P. A., \& Paas, F. (2010). Making the black box of collaborative learning transparent: Combining process-oriented and cognitive load approaches. Educational Psychology Review, 22,139-154. doi:10.1007/s10648-010-9131-x

Järvelä, S., Volet, S., \& Järvenoja, H. (2010). Research on motivation in collaborative learning: Moving beyond the cognitive-situative divide and combining individual and social processes. Educational Psychologist, 45, 15-27. doi:10.1080/00461520903433539

Johnson, D. W., \& Johnson, R. T. (1992). Key to effective cooperation. In R. Hertz-Lazarowitz, \& N. Miller (Eds.), Interaction in cooperative groups. The theoretical anatomy of group learning lpp. 174-199). New York, NY: Cambridge University Press.

Johnson, D. W., \& Johnson, R. T. (1993). What we know about cooperative learning at the college level. Cooperative Learning, 13(3), 17-18.

Johnson, D. W., Johnson, R. T., \& Stanne, M. E. (2000). Cooperative Learning Methods: A metaanalysis. University of Minnesota, Minneapolis: Cooperative Learning Center. Retrieved from: http://www.co-operation.org/pages/cl-methods.html.

Jung, D. I., \& Sosik, J. J. (2003). Group potency and collective efficacy: Examining their predictive validity, level of analysis, and effects of performance feedback on future group performance. Group \& Organization Management, 28,366-391. doi:10.1177/1059601102250821

Kaplan, S., LaPort, K., \& Waller, M. J. (2013). The role of positive affect in team effectiveness during crises. Journal of Organizational Behavior, 3414), 427-580. doi:10.1002/job.1817

Kapur, M., Voiklis, J., \& Kinzer, C. K. (2008). Sensitivities to early exchange in synchronous computer-supported collaborative learning (CSCL) groups. Computers \& Education, 51(1), 5466. doi:10.1016/j.compedu.2007.04.007

Karau, S. J., \& Kelly, J. R. (1992). The effects of time scarcity and time abundance on group performance quality and interaction process. Journal of Experimental Social Psychology, 28, 542-571. doi:10.1016/0022-1031(92)90045-L

Killion, J., \& Todnem, G. (1991). A process for personal theory building. Educational Leadership, 48(6), 14-16.

King, A. (1991). Effects of training in strategic questioning on children's problem-solving performance. Journal of Educational Psychology, 83(3), 307-317.

Kirschner, P. A. (2009). Epistemology or pedagogy, that is the question. In: S. Tobias \& T.M. Duffy (eds.), Constructivist theory applied to instruction: Success or failure? (pp. 144-157). New York: Routledge.

Kirschner, F., Paas, F., \& Kirschner, P. A. (2008). A cognitive load approach to collaborative learning: United brains for complex tasks. Educational Psychology Review, 21, 31-42. doi:10.1016/j.chb.2008.12.008

Kluger, A. N., \& DeNisi, A. (1996). The effects of feedback interventions on performance: A historical review, a meta-analysis, and a preliminary feedback intervention theory. Psychological Bulletin, 119, 254-284. doi:10.1037/0021-9010.73.1.87

Kozlowski, S. W. J., \& Ilgen, D. R. (2006). Enhancing the effectiveness of work groups and teams. Psychological Science in the Public Interest, 7, 77-124. doi:10.1111/j.1529-1006.2006.00030.x

Kramarski, B. (2004). Making sense of graphs: Does metacognitive instruction make a difference on students' mathematical conceptions and alternative conceptions. Learning and Instruction, 14, 593-619. doi:10.1016/j.learninstruc.2004.09.003 
Lajoie, S. P., \& Lu, J. (2012). Supporting collaboration with technology: Does shared cognition lead to co-regulation in medicine. Metacognition and Learning, 7, 45-46. doi:10.1007/s11409-0119077-5

Landis, J. R., \& Koch, G. G. (1977). The Measurement of Observer Agreement for Categorical Data, Biometrics, 33, 159-174.

Leicht, R. M., Hunter, S. T., Saluja, C., \& Messner, J. I. (2010). Implementing observational research methods to study team performance in construction management. Journal of Construction Engineering and Management, 13611), 76-86. doi:10.1061/(ASCE)C0.1943-7862.0000080

Lewis, K., Belliveau, M., Herndon, B., \& Keller, J. (2007). Group cognition, membership change, and performance: Investigating the benefits and detriments of collective knowledge. Organizational Behavior and Human Decision Processes, 103(2), 159-178. doi:10.1016/j.obhdp.2007.01.005

London, M. (2003). Job feedback: Giving, seeking, and using feedback for performance improvement (2nd ed.). Mahwah, NJ: Lawrence Erlbaum.

London, M., \& Sessa, V. I. (2006). Group feedback for continuous learning. Human Resource Development Review, 5(3), 1-27. doi:10.1177/1534484306290226

Marks, M. A., Mathieu, J. E., \& Zaccaro, S. J. (2001). A temporally based framework and taxonomy of team processes. Academy of Management Review, 26, 356-376. doi: 10.2307/259182

Mathieu, J. E., \& Rapp, T. L. (2009). Laying the foundation for successful team performance trajectories: The role of team charters and performance strategies. Journal of Applied Psychology, 94, 90 -103. doi:10.1037/a0013257

McCarthy, A., \& Garavan, T. (2008). Team learning and metacognition: A neglected area of HRD research and practice. Advances in Developing Human Resources, 10, 509-524. doi:10.1177/1523422308320496

McGrath, J. E. (1993). The JEMCO workshop: Description of a longitudinal study, Small Group Research, 24, 285-306. doi:10.1177/1046496493243002

Michinov, N., \& Michinov, E. (2009). Investigating the relationship between transactive memory and performance in collaborative learning. Learning and Instruction, 1911, 43-54. doi:10.1016/j.learninstruc.2008.01.003

Moreland, R. L., \& McMinn, J. G. (2010). Group reflexivity and performance. In S. R. Thye \& E. Lawler (Eds.), Advances in group processes (Vol. 27, pp. 63-95). Bingley, UK: Emerald Press.

Moreno, R., Mayer, R. E., Spires, H. A., \& Lester, J. C. (2001). The case for social agency in computerbased teaching. Do students learn more deeply when they interact with animated pedagogical agents? Cognition and Instruction, 192), 177-213. doi:10.1207/S1532690XCI1902_02

Mory, E. H. (2003). Feedback research revisited. In D. H. Jonassen (Ed.), Handbook of research on educational communications and technology (pp. 745-783). Mahwah, NJ: Erlbaum.

Morris, J., \& Stew, G. (2007). Collaborative reflection: how far do 2:1 models of learning in the practice setting promote peer reflection. Reflective Practice, 8(3), 419-432. doi:10.1080/14623940701425220

Mulder, R. H., \& Ellinger, A. D. (2013). Perceptions of quality of feedback in organizations: Characteristics, determinants, outcomes of feedback, and possibilities for improvement: Introduction to a special issue. European Journal of Training and Development, 3711, 4-23. doi:10.1108/03090591311293266

Mulder, R. H. (2013). Exploring feedback incidents, their characteristics and the informal learning activities that emanate from them. European Journal of Training and Development, 371), 4971. doi:10.1108/03090591311293284

Müller, A., Herbig, B., \& Petrovic, K. (2009). The explication of implicit team knowledge and its supporting effect on team processes and technical innovations. An action regulation perspective on team reflexivity. Small Group Research, 40, 28-51. doi:10.1177/1046496408326574 
Mullins, D., Rummel, N., \& Spada, H. (2011). Are two heads always better than one? Differential effects of collaboration on students' computer-supported learning in mathematics. International Journal of Computer Supported Collaborative Learning, 6(3), 421-443. doi:10.1007/s11412-011-9122-z

Noroozi, O., Weinberger, Biemans, H. J. A., Mulder, M., \& Chizari, M. (2012). Argumentation-based computer supported collaborative learning (ABCSCL). A systematic review and synthesis of fifteen years of research. Educational Research Review, 12), 79-106. doi:10.1016/j.learninstruc.2008.03.001

Okhuysen, G. A., \& Eisenhardt, K. M. (2002). Integrating knowledge in groups: How simple formal interventions help. Organization Science, 13, 370-386. doi:10.1287/orsc.13.4.370.2947

Okhuysen, G., \& Waller, M. J. (2002). Focusing on midpoint transitions: An analysis of boundary conditions. Academy of Management Journal, 45, 1056-1065. doi:10.2307/3069330

Phielix, C., Prins, F. J., \& Kirschner, P. A. (2010). Awareness of group performance in a CSCL environment: Effects of peer feedback and reflection. Computers in Human Behavior, 26, 151161. doi:10.1016/j.chb.2009.10.011

Phielix, C., Prins, F. J., Kirschner, P. A., Erkens, G., \& Jaspers, J. G. M. (2011). Group awareness of social and cognitive performance in a CSCL environment: Effects of a peer feedback and reflection tool. Computers in Human Behavior, 273), 1087-1102. doi:10.1016/j.chb.2010.06.024

Prins, F. J., Sluijsmans, D. M. A., \& Kirschner, P. A. (2006). Feedback for general practitioners in training: quality, styles, and preferences. Advances in Health Sciences Education, 11, 289-303. doi:10.1007/s10459-005-3250-z

Prinsen, F. R., Terwel, J., Zijlstra, B. J. H., \& Volman, M. M. L. (2013). The effects of guided elaboration in a CSCL programme on the learning outcomes of primary school students from Dutch and immigrant families. Educational Research and Evaluation, 1911. 39-57. doi:10.1080/13803611.2012.744694

Reimann, P. (2007). Time is precious: Why process analysis is essential for CSCL land can also help to bridge between experimental and descriptive methods). In C. Chinn, G. Erkens \& S. Puntambekar (Eds.), Mice, minds, and society. Proceedings of the computer-supported collaborative learning conference ICSCL 2007) (pp. 598-607). New Brunswick, NJ: International Society of the Learning Sciences.

Rourke, L., \& Anderson, T. (2004). Validity in quantitative content analysis. Education Technology Research and Development, 5211, 5-18. doi:10.1007/BF02504769

Rourke, L., Anderson, T., Garrison, D. R., \& Archer, W. (2001). Methodological issues in the content analysis of computer conference transcripts. International Journal of Artificial Intelligence in Education, 12, 8-22

Rulke, D. L., \& Rau, D. (2000). Investigating the encoding process of transactive memory development in group training. Group \& Organization Management, 25, 373-396.

Rummel, N., Mullins, D., \& Spada, H. (2012). Scripted collaborative learning with the Cognitive Tutor Algebra. International Journal of Computer Supported Collaborative Learning, 12), 307-339. doi:10.1007/s11412-012-9146-z

Rummel, N., \& Spada, H. (2005). Learning to Collaborate: An Instructional Approach to Promoting Collaborative Problem Solving in Computer-Mediated Settings. Journal of the Learning Sciences, 1421, 201-241. doi:10.1207/s15327809jls1402_2

Rummel, N., Spada, H., \& Hauser, S. (2009). Learning to collaborate from being scripted or from observing a model. International Journal of Computer-Supported Collaborative Learning, 411). 69-92. doi:10.1007/s11412-008-9054-4

Salas, E. Dickinson, T. L., Converse, S. A., \& Tannenbaum, S. I. (1992). Toward an understanding of team performance and training. In R. W. Swezey \& E. Salas (Eds.), Teams: Their training and performance (pp. 3-29). Norwood, NJ: Ablex. 
Salas, E., Rosen, M. A., \& King, H. (2007). Managing teams managing crises: Principles of teamwork to improve patient safety in the emergency room and beyond. Theoretical Issues in Ergonomics Science, 855), 381-394. doi:10.1080/14639220701317764

Salas, E., Stagl, K. C., \& Burke, C. S. (2004). 25 years of team effectiveness in organizations: Research themes and emerging needs. In C. L. Cooper \& I. T. Robertson (Eds.), International review of industrial and organizational psychology (pp. 47-91). New York: Wiley.

Savelsbergh, C., Heijden, B. I. J. M. van der, \& Poell, R. F. (2009). The development and empirical validation of a multi-dimensional measurement instrument for team learning behaviors. Small Group Research, 405), 578-607. doi:10.1177/1046496409340055

Schippers, M. C., Den Hartog, D. N., \& Koopman, P. L. (2007). Reflexivity in teams: A measure and correlates. Applied Psychology-An International Review, 5612), 189-211. doi:10.1111/j.14640597.2006.00250.x

Schippers, M. C., Den Hartog, D. N., Koopman, P. L., \& Wienk, J. A. (2003). Diversity and team outcomes: The moderating effects of outcome interdependence and group longevity and the mediating effect of reflexivity. Journal of Organizational Behavior, 24, 779-802. doi:10.1002/job.220

Schippers, M. C., Den Hartog, D. N., Koopman, P. L., \& van Knippenberg, D. (2008). The role of transformational leadership in enhancing team reflexivity. Human Relations, 61, 1593-1616. doi:10.1177/0018726708096639

Schippers, M. C., Homan, A. C. \& van Knippenberg, D. (2013). To reflect or not to reflect: Prior team performance as a boundary condition of the effects of reflexivity on learning and final team performance. Journal of Organizational Behavior, 3411), 6-23. doi:10.1002/job.1784

Schön, D. (1983). The reflective practitioner: How professionals think in action. New York: Basic.

Scott-Young, C., \& Samson, D. (2009). How team efficacy beliefs impact project performance: An empirical investigation of team potency in capital projects in the process industries. World Academy of Science, Engineering and Technology, 3, 6-28. doi:10.1.1.308.8306

Seibert, K. W. (1999). Reflection-in-action: Tools for cultivating on-the-job learning conditions. Organizational Dynamics, 27, 54-65. doi:10.1016/S0090-2616(99)90021-9

Soller, A., Monés, A. M., Jermann, P., \& Mühlenbrock, M. (2005). From Mirroring to Guiding: A Review of State of the Art Technology for Supporting Collaborative Learning. International Journal on Artificial Intelligence in Education, 1555), 261- 290. doi:10.1.1.26.2186

Sims, D. E., Salas, E., \& Burke, C. S. (2005). Promoting effective team performance through training. In S. A. Wheelan (Ed.), The Handbook of Group Research and Practice (pp. 407-425). Thousand Oaks, CA: Sage.

Shute, V. J. (2008). Focus on formative feedback. Review of Educational Research, 78, 153-189. doi:10.3102/0034654307313795

Tschan, F., Semmer, N. K., Nägele, C., \& Gurtner, A. (2000). Task adaptive behavior and performance in groups. Group Processes and Intergroup Relations, 3(4), 367-386. doi: $10.1177 / 1368430200003004003$

Tjosvold, D., Tang, M. M. L., \& West, M. (2004). Reflexivity for team innovation in China: The contribution of goal interdependence. Group \& Organization Management, 295), 540-559. doi: $10.1177 / 1059601103254911$

van Ginkel, W., Tindale, R. S., \& van Knippenberg, D. (2009). Team reflexivity, development of shared task representations, and the use of distributed information in group decision making. Group Dynamics, 13, 265-280. doi:10.1037/a0016045

van Ginkel, W. P., \& van Knippenberg, D. (2009). Knowledge about the distribution of information and group decision making: When and why does it work? Organizational Behavior and Human Decision Processes, 108(2), 218-229. doi:10.1016/j.obhdp.2008.10.003 
Van der Pol, J., Van den Berg, I., Admiraal, W. F., \& Simons, P. R. J. (2008). The nature, reception, and use of online peer feedback in higher education. Computers \& Education, 51, 1804-1817. doi:10.1016/j.compedu.2008.06.001

Villado, A. J., \& Arthur, W. Jr. (2013). The comparative effect of subjective and objective after-action reviews on team performance on a complex task. Journal of Applied Psychology, 98, 514-528. doi:10.1037/a0031510

Visschers-Pleijers, A. J. S. F., Dolmans, D. H. J. M., De Leng, B. A., Wolfhagen, H. A. P., \& Van der Vleuten, C. P. M. (2006). Analysis of verbal interactions in tutorial groups: A process study. Medical Education, 40, 129-137. doi:10.1111/j.1365-2929.2005.02368.x

Volet, S., Summers, M., \& Thurman, J. (2009). High-level co-regulation in collaborative learning: how does it emerge and how is it sustained? Learning and Instruction, 19, 128-143. doi:10.1016/j.learninstruc.2008.03.001

Waller, M. J. (1999). The timing of adaptive group responses to nonroutine events. Academy of Management Journal, 42, 127-137. doi:10.2307/257088

Waller, M. J., Gupta, N., \& Giambatista, R. C. (2004). Effects of adaptive behaviors and shared mental models on control crew performance. Management Science, 50, 1534-1544. doi:10.1287/mnsc.1040.0210

Weingart, L. R. (1992). Impact of group goals, task component complexity, effort, and planning on group performance. Journal of Applied Psychology, 775), 682-693. doi:10.1037/00219010.77 .5 .682

West, M. A. (Ed.) (1996). Handbook of work group psychology, Chichester: John Wiley \& Sons, Ltd.

West, M. A. (2000). Reflexivity, revolution and innovation in work teams. In M. M. Beyerlein, D.A. Johnson \& S.T. Beyerlein (Eds), Product development teams, Vol. 5. (pp. 1-29). Stamford, CT: JAl Press.

West, M. A., Garrod, S., \& Carletta, J. (1997). Group decision-making and effectiveness: unexplored boundaries. In C.L. Cooper \& S.E. Jackson (Eds.), Creating tomorrow's organizations: A handbook for future research in organizational behavior (pp. 293- 316). Chichester: John Wiley \& Sons Ltd.

Williams, K. D. (2010). Dyads can be groups (and often are). Small Group Research, 41, 268-274. doi: $10.1177 / 1046496409358619$

Wills, K. V., \& Clerkin, T. A. (2009). Incorporating reflective practice into team simulation projects for improved learning outcomes. Business Communication Quarterly, 72(2), 221227. doi:10.1177/1080569909334559

Yang, M., \& Carless, D. (2013). The feedback triangle and the enhancement of dialogic feedback processes. Teaching in Higher Education. 18(3), 285-297. doi:10.1080/13562517.2012.719154

Yoo, Y., \& Alavi, M. (2001) Media and group cohesion: Relative influences on social presence, task participation, and group consensus. MIS Quarterly, 25(3), 371-390. doi: 10.2307/3250922

Yukawa, J. (2006). Co-reflection in online learning: Collaborative critical thinking as narrative. Journal of Computer-supported Collaborative Learning, 1, 203-228. doi:10.1007/s11412-0068994-9 


\section{Chapter 5}

The Effect of Team Feedback and Guided Reflexivity on Team
Performance Change

5 This chapter is published as: Gabelica, C., Van den Bossche, P., De Maeyer, S., Segers, M., \& Gijselaers, W. (2014). The effect of team feedback and guided reflexivity on team performance change. Learning and Instruction, 34, 86-96. doi:10.1016/j.learninstruc.2014.09.001 


\section{ABSTRACT}

Providing teams with feedback has been forwarded as a powerful practice to improve their learning and performance. Yet, this learning potential may not be realized unless teams actively process this feedback by stepping back from their team activity, building plans, and ultimately putting them into action. In an experimental study ( $N=212$ undergraduate students), we compared the effects of team-level feedback with or without an intervention prompting shared reflection on the feedback (i.e., guided reflexivity) to a no feedback control group on team performance growth. The results showed that only the combination of team performance feedback and guided reflexivity lead to performance change, at the beginning of team activity. These findings suggest that prompting feedback processing at an early stage of collaborative work has the power to help teams benefit from their past experiences and improve performance. 


\section{INTRODUCTION}

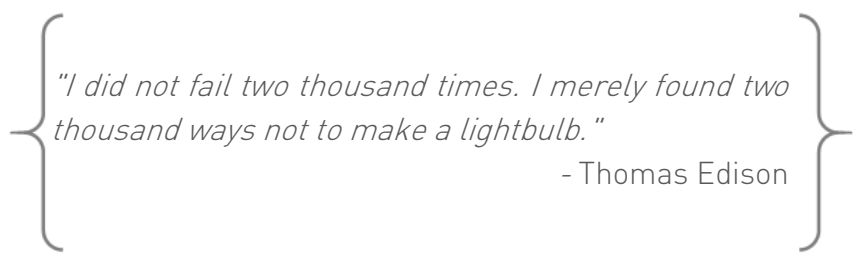

For many years, collaborative learning has been at the top of the research agenda in the domain of learning and instruction le.g., Kirschner, 2009; Tolmie et al., 2010). There is a general agreement that it plays a fundamental role in shaping learning and achievement in school and beyond (e.g., Kirschner, Paas, \& Kirschner, 2009). More specifically, team learning has been addressed as a specific form of collaborative learning and investigated in educational and workplace settings (Decuyper, Dochy, \& Van den Bossche, 2010). In both environments, learning and working units are established as teams which can be defined as two or more interdependent individuals (i.e., dyads, triads, and larger groups) who pursue a common goal, require social interaction, share responsibility for a team product, and have clear differentiated responsibilities and roles (Salas, Dickinson, Converse, \& Tannenbaum, 1992). Importantly, teams are not static in their behavior: they learn from the interactions taking place between their members, their work on task(s), and how the social environment responds to their work. Accordingly, team learning has been defined as "an ongoing process of reflection and action" (Edmondson, 1999, p. 353) during which teams reflect on their own prior activities and consequently plan adjustments for future practice (see Decuyper et al., 2010, for a review). Unfortunately, however, the learning behaviors of many teams rarely conform to theoretical models since they are seldom employed spontaneously (Edmondson, 1999). As such, while scholars have made progress in understanding predictors and consequences of team learning (Decuyper et al., 2010), it remains a matter of concern to identify interventions that can shape the learning potential of teams (Kozlowski \& Ilgen, 2006).

Research on individual learning provides insight in this regard. Providing individuals with feedback has been outlined as an effective intervention in any learning process and achievement (e.g., Shute, 2008). Individuals do not only need feedback to improve their strategies and gain deep understanding of their task, but also to monitor and regulate their work (Hattie \& Timperley, 2007). However, research at the individual-level cannot be simply applied in team settings due to the additional complexity of dealing with unique team-level 
properties that emerge from team interactions, communication, and the collective knowledge pool (Barr \& Conlon, 1994). Whereas scholars (e.g., Barr \& Conlon, 1994; London \& Sessa, 2006) seem to agree on the need to study feedback at the team-level of analysis, this effort is somewhat fragmented and incomplete.

Although research at the team-level of analysis shows that feedback given to teams on their performance has the power to steer, motivate, support, and reinforce future team behavior, 1) feedback effects on team performance are inconsistent (see Gabelica, Van den Bossche, Segers, \& Gijselaers, 2012, for a review), and 2) very little empirical work is available on the mechanisms relating team-level feedback to team performance improvement (London \& Sessa, 2006). To address these challenges, theoretical work puts forward team reactions to feedback as the immediate antecedents of performance improvement. In fact, teams critically need to process feedback, that is collectively attend to and discuss its content, build a common ground and understanding of their experience, and come to a consensus on whether feedback contains cues for improved future behaviors to make the desirable changes. In other words, teams need to reflect upon feedback to capitalize it (London \& Sessa, 2006; Prins, Sluijsmans, \& Kirschner, 2006).

The concept of team reflexivity connotes those reflective activities during which teams use information coming from performance feedback to reach new meanings and understandings and consensus on necessary changes. It is defined as the extent to which teams collaboratively reflect upon their own functioning with a dual focus on the past (i.e., evaluation of accomplishments) and the future (e.g., identification of new strategies) (West, Garrod, \& Carletta, 1997). The emergent research strand on team reflexivity suggests it should follow a time-ordered sequence of three activities (i.e., reflective cycles). Specifically, teams are expected to be more effective when they sequentially al evaluate their past performance and strategies, b) search for alternatives in how they could have approached their task, and cl develop new actions and strategies to change their future practice (e.g., Schippers, Den Hartog, \& Koopman, 2007). When team members discuss and elaborate on feedback, it creates a collective space of concepts and knowledge ("common ground") that they use to guide their actions and thus improve their team performance (Yukawa, 2006). Hence, we argue that to optimize their performance, teams need to be given accurate feedback describing their achievement, but also be directly stimulated and prompted to use the feedback opportunities to reflect on this feedback in a systematic way (i.e., guided reflexivity) (Noroozi, Biemans, Weinberger, Mulder, \& Chizari, 2013; Wills \& Clerkin, 2009). Therefore, in the 
present paper, we aim to provide empirical evidence that team-level performance feedback in combination with guided team reflexivity will be more effective than feedback alone. This is studied with highly interdependent student dyads performing a complex multiple-trial task increasing in difficulty across four performance episodes.

\section{FEEDBACK INTERVENTIONS}

Prior to addressing feedback in teams, it is important to derive lessons from the much more substantial body of research on feedback given to individuals. In the learning sciences it is pointed out that feedback is an instructional practice that has both informational value, in terms of supporting learning, and motivational value, in terms of stimulating greater effort (Shute, 2008). Despite the prevalent claims about its performance benefits, Kluger and DeNisi (1996), in their pivotal review on individual-level feedback, did find a substantial number of ineffective applications. They concluded that performance feedback (i.e., information concerning performance outcomes) was not always beneficial to individuals and advised future researchers to consider the process of how feedback leads to performance. Later research has provided two major insights in this regard: to be effective, feedback should 1) contain learning information (e.g., Duijnhouwer, Prins, \& Stokking, 2012; Gibbs \& Simpson, 2004) and 2) stimulate cognitive activities of the learners (e.g., Boud \& Molloy, 2013). The latter introduces the notion that the feedback process is more than simply providing feedback (Mulder, 2013); it should critically include the uptake of feedback by its receivers. For example, Hattie and Timperley (2007) have argued that feedback needed to induce three questions in receivers' mind to trigger its processing: 1) where am I going? (feed-up), 2) how am I going (feed-back), and 3) where to next (feedforward). Alike, reflection has been forwarded as a useful strategy to enhance feedback processing (Duijnhouwer et al., 2012; Seibert, 1999). In the relatively smaller research strand on feedback to teams, the issue of how feedback impacts team performance has been largely neglected (Gabelica et al., 2012; Gabelica, Van den Bossche, Segers, \& Gijselaers, 2014).

\section{FEEDBACK IN TEAMS}

Recent years have shown an increased research interest in feedback interventions at the team level. These are defined as the communication of 
information, provided by (an) external agent(s), concerning actions, events, processes, or behaviors relative to task completion or teamwork (Gabelica et al., 2012; London, 2003). For example, medical teams can receive patientsatisfaction data, specifically team-level performance feedback depicting how the whole team operated regarding the quality of care and service. Feedback has diverse functions such as: highlighting the outcome of the team activity or the process, conveying information against which teams can recalibrate their goals when they move away from them, steering the team activity, and detecting errors, but also stimulating discussion and argumentation with others (Bartram \& Roe, 2008). Only recently, a literature review (Gabelica et al., 2012) summarized the findings of fifty-nine studies on feedback in teams. On the one hand, this review also showed that feedback might influence a wide range of critical team processes and states le.g., motivation, team goal, team collaboration, and team cohesion) and occasionally performance. For example, in their experimental study, Prussia and Kinicki (1996) demonstrated that teamlevel feedback affected team performance through the mediation of the collective efficacy of teams performing a brainstorming task. On the other hand, the review highlighted that a considerable number of studies was not able to establish any performance benefits of feedback (Gabelica et al., 2012). For example, in an experiment conducted by Brannick, Prince, and Salas (2005), intact Navy teams did not improve their technical problem-solving proficiency compared to a no feedback group in a flight simulation.

Based on these mixed results, the review concluded that although feedback seems to be beneficial, certain conditions need to be created to increase its effects. First, the performance effects of providing feedback depend on its quality (i.e., accurate, specific, well-timed, regular, non-threatening, shared, directed at teams it targets, and distributed fairly amongst team members). Second, feedback will be more likely to produce performance changes in teams with no redundant members or tasks, working in projects, setting goals and strategies or given information about goal attainment, provided with incentives and rewards, believing they are high-performing, and exhibiting no unsolved intragroup conflicts and a flexible workload. Third, theoretical work le.g., London \& Sessa, 2006) proposes that feedback receivers should perceive the feedback as a learning need and opportunity and use this opportunity to instigate improvements. Hence, teams should become aware of their performance and (in)effective behaviors and engage in shared reflective activities during which team members reach an intersubjective understanding of the meaning of the feedback and extract cues for future behaviors (Boud, Keogh, \& Walker, 1985; London \& Sessa, 2006; Prins et al., 2006). While critically considering reasons 
and supporting evidence of the content of the feedback and scrutinizing alternative perspectives, teams are expected to establish and maintain common ground and shared understanding that allow them to perform their team task more effectively. In conclusion, team feedback will only demonstrate performance improvement if teams actively process and thus reflect upon this feedback. However, this feedback processing operated by team reflective activities has yet to be empirically examined. We propose that the small but growing research line on team reflexivity, grasping reflection at team-level, can deliver insight into feedback processing.

\section{REFLEXIVITY IN TEAMS}

Without reflection, teams may fail to uncover why they did or did not succeed based on the mere feedback. More importantly, some misunderstandings may remain unsolved and teams may fail to correct their future approaches (Wills \& Clerkin, 2009). Solving these questions allow teams to better understand their task and subsequently perform better. As originally defined by West et al. (1997), team reflexivity is the extent to which team members collectively reflect upon their teams' objectives, strategies, and processes. The importance of team reflexivity as a determinant of team behavior and performance has been recently acknowledged in the literature (e.g., De Dreu, 2007; Decuyper et al., 2010; van Ginkel \& van Knippenberg, 2009), although the supporting research is sparse and inconsistent (Moreland \& McMinn, 2010). For example, Lewis, Belliveau, Herndon, and Keller (2007) conducted analyses to explain the disruptive effect of replacing team members in on-going teams on performance and established that this effect was no longer present when teams reflected before their task.

Previous theoretical work on team reflexivity suggests that reflection in teams follows a three-step iterative process that starts with the evaluation of past performance and strategies. Specifically, teams review their goals, performance, and strategies and identify underlying reasons for success or failure. Second, they make an inventory of alternatives in how they could have approached their task. Finally, they decide how to handle their task differently in the near future and make specific plans. These three reflective activities denote complementary dimensions of team reflexivity and might constitute reflective cycles (e.g., Schippers et al., 2007; Yukawa, 2006). The two first activities, indicating team awareness of their behaviors and their consequences, are necessary but not sufficient to engage in change. Deriving alternatives for work strategies and implementation intentions has been proposed as a necessary 
condition to apply the best actions to the current environment (Edmondson, 1999; Schippers et al., 2007; West et al., 1997). So far, there has been no empirical evidence of these three steps at the team level of analysis (MacCurtain, Flood, Ramamoorthy, West, \& Dawson, 2010; Schippers, Homan, \& van Knippenberg, 2013).

\section{GUIDED REFLEXIVITY}

Having pointed out the importance of team reflexivity, it is essential to consider that regular and deliberate reflection is rarely observed in teams, even when teams are shown evidence of their dysfunctional behavior (Gersick \& Hackman, 1990; Weingart; 1992). It seems that team members are reluctant to future planning and reflection (Daudelin, 1996; Gurtner, Tschan, Semmer, \& Nagele, 2007). Possible explanations can be found in people's tendency to focus on the immediate results of their activity and not on the learning they can gain from their experience due to factors such as time pressure and the profusion of activities in which they are involved (Karau \& Kelly, 1992). Moreover, teams tend to define their goals and strategies at an early stage of their work and not to deliberatively review them in the course of actions (Argote, 1989; Hackman \& Wageman, 2005). People may feel uncomfortable about that practice, possibly because of the fear of negative comments or blaming behavior (Moreland \& McMinn, 2010). Finally, team members have difficulties attributing failures and problems to the group responsibility and rather think individually instead of collectively about what behaviors need to be changed (Wilson, Goodman, \& Cronin, 2007). These tendencies call for research examining interventions stimulating reflexivity (Hackman \& Wageman, 2005; Schippers et al., 2013).

Guided reflexivity or structured reflection (Gurtner et al., 2007) can be conceptualized as an intervention designed to prompt team reflexivity upon feedback reception. This formal and structured intervention provides teams with 1) devoted time (time-out from action), 2) space, and 3) specific guidelines (or prompts) about how to collaboratively extract meaning from the provided feedback and set new goals and strategies for future performance. We assume that, for adults, a lack of engagement in thoughtful deliberation of team experience is not a symptom of a lack of ability to perform reflection (i.e., availability deficiencyl but a lack of execution of available skills (i.e., production deficiency). Hence, prompting reflection appears an appropriate intervention to enhance teams' motivation to engage in team reflexivity and to elicit learning 
strategies which teams would not spontaneously demonstrate (Veenman \& Elshout, 1999).

Previous work on guided team reflection in any generic sense such as "selfcorrection" (e.g., Blickensderfer, Cannon-Bowers, \& Salas, 1997; SmithJentsch, Cannon-Bowers, Tannenbaum, \& Salas, 2008) or "after-action reviews" (AARs) or "debriefs" (see Tannenbaum \& Cerasoli, 2013, for a meta-analysis) implemented as means of team building has provided important insights into the training of reflective skills. For example, a study by Villado and Arthur (2013) contrasted conditions with AARs comprising feedback to a non-AAR condition. The results showed that whereas the AARs, guided by facilitators, did not influence teams' levels of declarative knowledge, they impacted team performance, team efficacy, openness of communication, and cohesion, compared to teams with no AAR. The authors noted the lack of guidance concerning the sequence of steps necessary for completing an AAR. Notably, no condition merely providing feedback was compared to the AARs conditions. In general, the design of these studies on AARs and self-correction comprises multiple components. As a result, it becomes difficult to unambiguously link feedback or active processing of feedback to performance benefits as any of the components of the training could have some positive effects on its own. Also, researchers often investigate intact teams and measure pre and post training performance, not accounting for existing reflective skills. Additionally, external and specific feedback is not systematically part of these implementations whereas we consider specific team-level performance feedback given by an external agent as a necessary pre-condition to guided reflexivity since teams might have imperfect knowledge about their own performance. External and objective feedback gives teams the opportunity to evaluate their work and perceive their own learning realistically (Spinath \& Spinath, 2005). Also, without performance feedback, team reflection is not focused and consequently is likely to be less effective (Anseel, Lievens, \& Schollaert, 2009). Overall, AAR studies suggest to pay specific attention to the following methodological considerations 1) the random assignment of participants to conditions to control for their existing reflective skills, 2) the isolation of feedback from feedback augmented with guided reflexivity to make sure the results are driven by that process, and 3 ) the use of a script to prime clear steps to reflect in a systematic way.

Only one series of studies isolated feedback from its combination with reflection in the context of computer-supported collaborative learning in highschool teams (Phielix, Prins, \& Kirschner, 2010; Phielix, Prins, Kirschner, Erkens, \& Jaspers, 2011). The authors hypothesized that a shared self and peer assessment tool and a shared reflection tool had complementary effects. They 
could not highlight any significant effect of the reflection tool alone or of the combined use of feedback and reflection on objective performance (i.e., grade), but demonstrated that teams using both tools reported higher group process satisfaction and social and cognitive behavior. Interestingly, they showed that the combined use of both tools did not reduce unrealistic positive perceptions teams generally have about their own and other performance. We suggest that these tendencies might also be counteracted by external and objective feedback related to clear criteria for task achievement.

\section{RESEARCH QUESTIONS AND HYPOTHESES}

Based on these theoretical considerations, we addressed the following research questions: Firstly, we investigated whether the combination of feedback and guided reflexivity as a tool to foster feedback processing would enable teams to speed up their learning curves when repeatedly confronted to a new complex task. We expected heterogeneous learning curves (different slopes or rates of improvement for the same amount of experience) across conditions (feedback only condition, feedback and guided reflexivity condition, and no feedback control condition). Accordingly, we predicted that those groups who received both teamlevel performance feedback and guided reflexivity would have a faster improvement rate than teams receiving feedback and no feedback nor prompts (Hypothesis 1). Secondly, we addressed the question at what rate do teams receiving feedback improve their team performance. The provision of feedback itself should successfully stimulate acceleration of performance in those groups who had feedback as compared with teams who had not (Hypothesis 2). Finally, besides expected differential rates of improvement, we were interested in actual differences in team performance scores at each measurement time for teams receiving feedback and prompts to process it compared to teams only receiving feedback and teams not prompted nor given performance feedback. We expected that for each of the tasks following the interventions, teams receiving performance feedback and guided reflexivity would outperform the other groups (Hypothesis 3). 


\section{METHOD}

\section{Sample}

Two hundred and twelve $(111$ male, 101 female) voluntary undergraduate students were recruited from a university in the Netherlands in exchange for an individual incentive (money compensation). Their ages ranged from 18 to 31 years, $M=22.3, S D=2.47$. Two criteria for admission were applied, namely participants' lack of prior experience in flight games and familiarity with each other. They were paired with a same-gender (female and male teams, respectively $n=32$ and $n=37$ ) or a different-gender partner (mixed teams, $n=$ 37), for a total of one hundred and six dyads, and randomly assigned to a specific role, pilot or copilot. Each team was randomly assigned to one of three conditions: a performance feedback only group ( $n=32$ teams), a feedback and reflexivity condition ( $n=41$ teams), and a no feedback control group $(n=33$ teams) and completed a flight simulation task.

\section{Task}

A PC-based flight simulator of high graphical quality, Microsoft Flight Simulator $X$, was used. This task environment was interactive, dynamic, and required team members' interdependence and cooperation. In the present study the computer simulation game did not aim at mimicking real-work team environments le.g., transportation teams) but rather investigating theoretical relations (i.e., nomological network) among constructs (i.e., feedback and reflexivity combined effect on performancel within specific boundaries: a complex, fast-paced, and high-workload situation in which small newly formed teams had to learn to accomplish a novel task and keep on learning to achieve their team goal (Marks, 2000).

A series of four tasks (landing missions) was sequentially performed by each team. Specifically, students had to take command of an aircraft during its descent in preparation for landing and land safely on the runaway. These tasks had an increasing degree of complexity. This was deliberately implemented because we wanted to avoid that teams that already performed well would have less need to learn as a consequence of their reflection on their performance (Schippers et al., 2013). The computer was screened on a white board to increase realism and was equipped with a joystick, a gas controller, and headphones connecting the copilot to the Air Traffic Controller (ATC). 


\section{Procedure}

The experiment approximately lasted $2 \mathrm{~h}$ and a half. First, upon arrival at the laboratory participants were told that the purpose of the study was to investigate how teams work together. They were given additional information about the study (timing, sequence of events, and participants' roles) and completed a short survey about their demographics and use of computer games. Second, team members were individually trained on the assigned roles. To be able to land on the runaway, information was needed about several characteristics of a fight situation. These pieces of information were distributed between the two team members in such a way that none of them had all the pieces of information needed to land the aircraft. The objective of the 45-minute training was thus providing both participants with specialized knowledge. Each team member was given a booklet containing information corresponding to his role. The pilots were responsible for flying the plane and using the joystick. To that purpose, they completed an additional 10-minute hands-on training. The copilots were responsible for controlling the gas of the plane and giving indications and directions to the pilots. They could bear upon information provided by ATC and cockpit instruments they were trained to interpret. For the time of the training, participants were sitting in separate rooms. Third, teams were back together in the same room and allowed to communicate freely. All teams completed four cycles of action (i.e., landing missions) and transition (or "interrupts") phases between actions of the same duration. They could restart missions after a crash until a time interval of 15 minutes had elapsed. They were given a brief written description of the mission scenario and the flight objectives. All teams were paid and debriefed following the fourth team task.

\section{Design}

We used a longitudinal design involving three groups of teams.

No feedback-No team reflexivity (control) condition. Teams completed each performance episode without any instructions or feedback during transition.

Feedback only condition. During transition, teams were provided with a standardized feedback form per mission identifying their correct actions during the last flight they completed. The feedback form displayed all the criteria of a perfect landing (e.g., expected value for speed, altitude, landing position) and highlighted the criteria that were met and not met by the team for that particular flight. This standardized feedback was thus immediate, regular, accurate, objective, shared, and delivered by an external agent. 
Feedback and team reflexivity condition. Teams were given team-level performance feedback along with reflective guidelines during each transition. Three steps were described to the teams on a written form. Immediately after feedback reception, team members were asked to co-reflect and provide specific information on 1) the reasons they succeeded or failed in the task completion and the underlying task and teamwork strategies that were effective or ineffective, 2) possible alternatives that could have been put into practice in terms of task and teamwork strategies, and 3) strategies and goals they would formulate to improve their performance for the next task. They were asked to discuss these steps together and to name strategies and not to conclude that they, for example, "had to work better together".

\section{Measures}

An objective performance rating instrument (also used for the feedback) was developed based on two sources. First, a task analysis was conducted with an expert in the flight game used in the study to extract key criteria to perform a successful flight. Second, we used the criteria provided by the simulation developers to refine our final performance rating form. Team performance for each mission was the total number of points won (correct actions) by the teams relative to objective criteria le.g., speed, altitude, activation of flaps and landing gear, landing position). The possibility of re-flying missions after a crash reinforced the relative lower weight of "crash" in their overall performance. With respect to the maximum number of correct actions per mission, although the four missions shared common features and correct actions to be completed in a landing situation, they varied in certain specific aspects. These corresponded to additional gradual difficulties teams had to face throughout the missions. Performance was assessed 1) in real time (during action) by an external observer to deliver a standardized feedback form to teams immediately after each task completion (during transition) and 2) based on the video recording for double-coding purposes. For the analyses, we transformed percentages of correct actions into logits. Four waves of performance data were collected (Time 1, Time 2, Time 3, and Time 4).

We controlled for the confounding effects of task and team experience, that have been shown to influence team performance le.g., Espinosa, Slaughter, \& Herbsleb, 2007). We controlled for task experience by a priori screening participants to exclude those with experience playing the game of the study (double-checked by an initial questionnaire measuring their experience playing games) and having groups from all conditions complete the same tasks, in the 
same sequence. We controlled for team experience by forming teams of strangers and separating team members during initial training. Additionally, gender composition was equally distributed across conditions (e.g., Rogelberg \& Rumery, 1996). This controlled for gender effects a priori.

\section{Data analysis}

We conducted random coefficient growth curve modeling to examine the degree to which feedback and guided reflexivity interventions impacted change in team performance within a multi-level analysis framework (Duncan, Duncan, \& Strycker, 2006; Singer \& Willett, 2003). This method models repeated measures of an observed variable on latent variables reflecting the initial status of individuals (in the present study, team performance at Time 1) and the rate of change in the outcome across time periods. It allows the simultaneous examination of the development of a dependent variable and of the variables associated with these different trajectories. For these analyses, the computing environment R and the NLME (Nonlinear and Linear Mixed Effects models) package (Pinheiro \& Bates, 2000) were used.

A model-contrasting approach was followed, starting from a basic level (Step 1 analyses), adding complexity step-by step, and including the predictor "condition" in the last stage (Step 2 analyses). Step 1 analyses enabled to characterize each team's pattern of change over time and thus evaluated withinteam change (i.e., improvement or deterioration). Step 2 analyses looked into inter-team differences in change in order to detect eventual heterogeneity in change across teams. Specifically, these analyses tested whether teams manifested different growth trajectories according to the conditions to which they were assigned and whether teams in the experimental conditions grew at a faster or slower rate compared to the control condition. Additionally, we tested contrasts for each measurement point based on the validated model. Step 1 and Step 2 form a "multilevel model for change". In the present data, variation in fitted intercepts across teams represented observed inter-team differences in performance at time 1, the first wave of data collection. They thus estimated teams' initial status while the variation in slopes summarized observed interteam differences in the rates at which team performance changed over missions. 


\section{ANALYSES}

\section{Descriptives}

Descriptive statistics for the repeated-measure dependent variable are presented in Table 1 for the total sample. They revealed that the average level of the initial level for all teams $(M=57.48, S D=16.05)$ rose slightly to attain the maximum mean score of 60.23 percent at Mission 2 and then decreased by 17 percent from Mission 3 to Mission 4 ( $M=42.05, S D=18.18)$.

\section{Table 1}

Percentages of Correct Actions and Standard Deviations for each Wave of Data $(N=106)$

\begin{tabular}{ll}
\hline & $\%$ \\
\hline Score Task 1 & 57.48 \\
& $(16.05)$ \\
Score Task 2 & 60.23 \\
& $(18.83)$ \\
Score Task 3 & 59.5 \\
& $(19.98)$ \\
Score Task 4 & 42.05 \\
& $(18.18)$ \\
\hline
\end{tabular}

Step 1: team performance change over time

Table 2 displays preliminary Step 1 analyses that examined the shape of the effect of time on team performance. Models were contrasted using likelihood tests. Model 4, considering a curvilinear trend of time and allowing the shape of the curve to vary across teams, showed a better fit than did a model that fixed the non-linear shape to be constant across teams $\left(\chi^{2}(5)=11.07, p=.05\right)$. This model indicates that teams (throughout all conditions) displayed curvilinear, rather than straight-line, performance trajectories (first increasing from time 1 to 2 then decliningl and that change might appear linear for some teams, curvilinear for others. In addition, a negative correlation between the intercept and the slope indicated that teams with lower team performance at Time 1 evidenced faster rates of improvement than those with higher performance at Time 1. Conversely, teams that tended to show higher team performance scores in Time 1 also tended to show smaller gains in team performance. When the pattern of average performance changed and showed deterioration, the 
correlation between slope (Time ${ }^{2}$ ) and intercept was positive. This suggests that teams with lower initial performance exhibited a more rapid decrease when complexity of the game attained its higher level.

\section{Table 2}

Likelihood Tests Contrasting Team's Pattern of Change over Time (Step-1Analyses)

\begin{tabular}{|c|c|c|c|c|c|}
\hline & & $\mathrm{AlC}$ & LR & $d f$ & $p$-value \\
\hline Model 1 & $\begin{array}{l}\text { Linear effect of time, only intercept } \\
\text { variance at team level }\end{array}$ & 1130.20 & & & \\
\hline Model 2 & $\begin{array}{l}\text { Curvilinear effect of time, only intercept } \\
\text { variance at team level }\end{array}$ & 1094.20 & 38.018 & 1 & $<.001$ \\
\hline Model 3 & $\begin{array}{l}\text { Cubic effect of time, only intercept variance } \\
\text { at team level }\end{array}$ & 1112.00 & 0.803 & 1 & .371 \\
\hline Model 4* & $\begin{array}{l}\text { Curvilinear effect of time, variance for } \\
\text { intercept, slope and quadratic term at team } \\
\text { level }\end{array}$ & 1093.10 & 11.069 & 5 & .050 \\
\hline Model 5 & Model 4 + main effect of feedback condition & 1089.90 & 7.152 & 2 & .028 \\
\hline Model 6 & $\begin{array}{l}\text { Model } 5+\text { interaction between feedback } \\
\text { condition and time-effects }\end{array}$ & 1087.00 & 10.962 & 4 & .027 \\
\hline
\end{tabular}

Note. ${ }^{*}$ LR comparison to model 2

Step 2: the effect of feedback and induced reflexivity on performance change

Step 1 analyses showed that a quadratic model (Model 4) allowing slope, intercept, and the curvilinear trend to vary across teams fit the data the best. As an additional step, Step 2 analyses aimed at testing the effect of the predictor "condition" on team performance growth, hereby testing the hypotheses of the present article.

As depicted in Figure 1, on average all teams started at the same initial level while their rate of change was different per condition, the feedback and reflexivity group being the one growing a lot faster at a higher level from Time 1 to Time 2 and decreasing at a higher rate from Time 3 to Time 4, on average. These average change trajectories per condition are displayed to allow an easy comparison. They do not describe the underlying shapes of the individual team trajectories. 


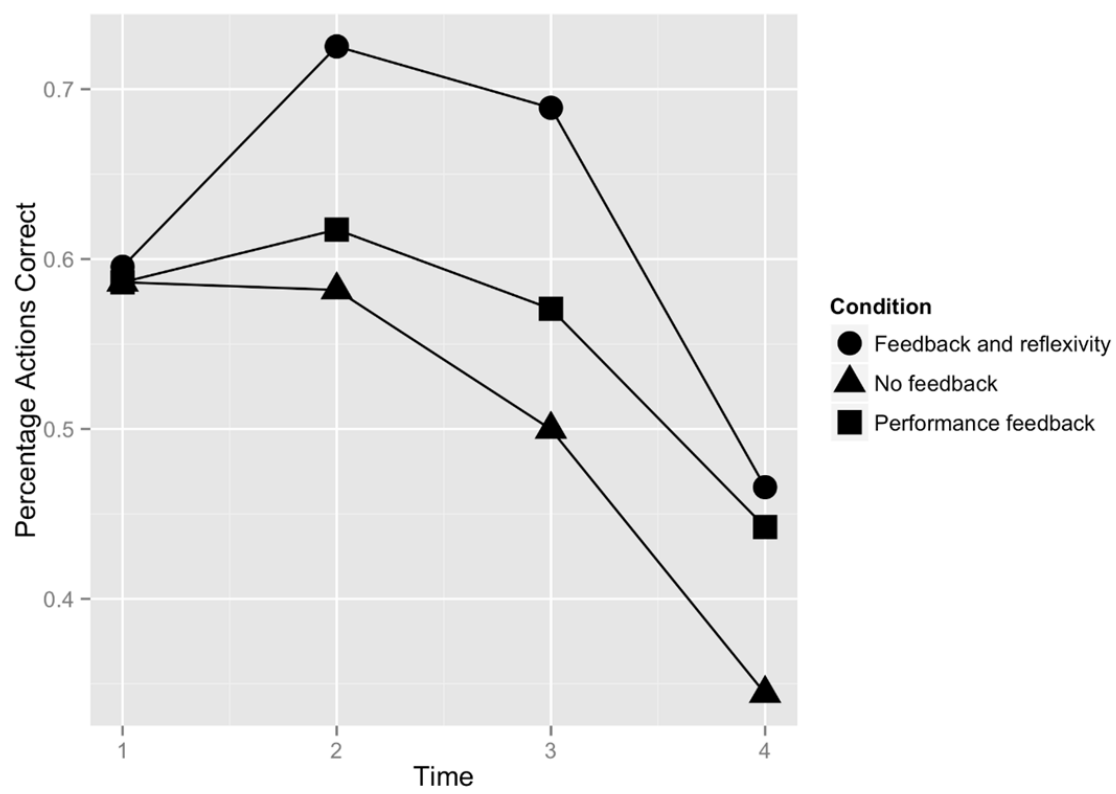

Figure 1. The relation between time and performance per condition (in percentages of correct actions) based on the last model (on average)

The interaction effect of condition and time (included condition $x$ time $^{2}$ ) was tested in the final model: it showed an even better fit $\left(\left.\chi\right|^{2}(4)=10.96, p<.05\right)$ than a model only including condition as a fixed predictor of performance (Table 3). The $t$-values of the interaction showed that teams in the feedback and reflexivity condition grew faster $(t=2.82, p<.01)$ and that the decrease in the last mission was larger than in the control condition $(t=-2.39, p<.05)$. This only partially confirms Hypothesis 1 since teams receiving both treatments did experience a faster learning of the task (faster initial improvement rate) but also a steeper later drop of performance compared to the control group.

In addition, there was no significant difference in rate of change (degree of improvement at first and deterioration of performancel based on receiving only feedback, contrary to Hypothesis 2. 
Table 3

Parameter Estimates (Est.) and Standard Errors for the Estimates (S.E.) Based on the Final Model: The Effect of Condition and Time on Performance Growth

\begin{tabular}{lll}
\hline & Est. & S.E. \\
\hline Initial status & $0.349^{*}$ & 0.156 \\
Slope (Time) & 0.137 & 0.227 \\
Quadratic slope (Time 2$)$ & $-0.156^{*}$ & 0.071 \\
Performance feedback condition & -0.0002 & 0.220 \\
Reflexivity land Feedback) Condition & 0.038 & 0.209 \\
Performance feedback x Time & 0.154 & 0.321 \\
Reflexivity x Time & $0.825^{* *}$ & 0.305 \\
Performance feedback x Time & -0.005 & 0.101 \\
Reflexivity x Time & $-0.223^{2}$ & 0.096 \\
\hline
\end{tabular}

Note. ${ }^{*} p<.05 .{ }^{* *} p<.01$.

Figure 2 depicts the last model and exhibits team trajectories across time per condition. Additional to the random coefficient growth curve modeling, the analysis of planned contrasts revealed that teams given feedback along with guided reflexivity performed significantly better than teams from the other two conditions at Times 2 and 3. As for Time 4, contrary to expectations, they did not differ significantly anymore from the other groups. Hence, it only partially confirms our third hypothesis that the guided reflexivity group would outperform the two other groups. 


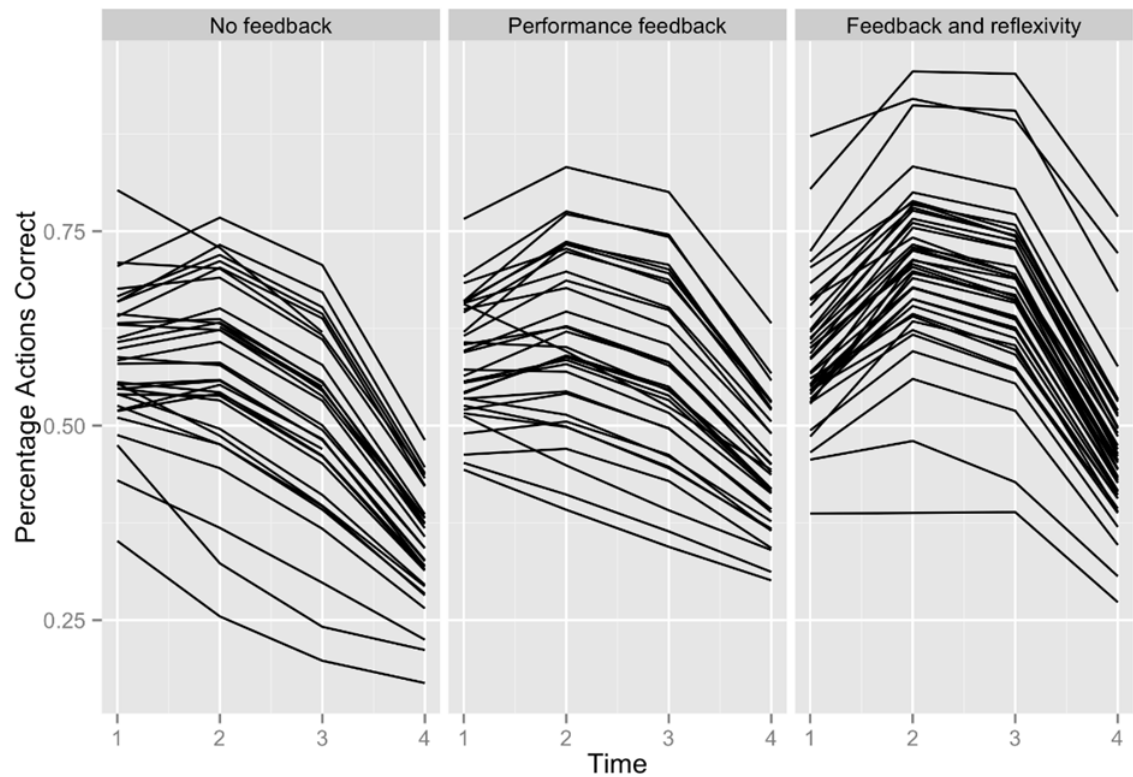

Figure 2. The relation between time and performance per condition and team lin percentages of correct actions) based on the last model.

\section{DISCUSSION}

Findings of the present study revealed that when teams were repeatedly stimulated to co-reflect upon feedback delivery, in other words to process feedback, a beneficial effect was found on performance growth over teams only given performance feedback or not given any information about their performance at the beginning of their team experience. They exhibited a faster initial improvement rate and remained more effective than their counterparts until the third wave of data. Importantly, we showed that the availability of performance feedback was not sufficient to initially speed up the learning of a new task but that processing of the feedback was needed. These results provide a first step towards more insights into a factor that is frequently advanced in feedback literature to explain feedback effectiveness but hardly empirically tested (e.g., Gabelica et al., 2012; Kluger \& DeNisi, 1996; London \& Sessa, 2006). Surprisingly, the pattern of results changed for the fourth task. Teams being provided with both components were no longer performing significantly better. Trying to understand this unexpected result is important both for theory and practice. Several (non-exhaustive) alternate explanations may account for this inconsistent result. First, since the last situation differed considerably for 
previous ones (in terms of increased complexity, physical features such as type of cockpit, and increased information load), teams that performed higher and appeared to have used the reflection opportunities to process feedback so far might have lost their advantage due to a lack of transfer of learning to this last task (Prawat, 1989). It may be that they have not recognized the relevance of their prior approaches to the fourth task that appeared too different from the one from which they learned previously. Alternatively, the development of specific procedures for processing feedback might impede the development of adaptive strategies that fit novel demands in a situation that differs considerably from the previous situations (Porter, Webb, \& Gogus, 2010). Second, teams may simply not have extensively reflected on the feedback provided after the third task. Given that feedback processing was induced by repetitive prompts, actual reflection was only assumed. For instance, it may be that the proposed reflective cycle especially stimulates the expected behaviors on the early stages of the feedback process (e.g., understanding and processing feedback content), but suffers from erosion in the long term if no facilitator helps to direct the process. Teams may rapidly routinize their behaviors and become less reflexive over time (Goodman \& Leyden, 1991). Third, teams might have concluded that they did well previously and this may have generated overconfidence during the final task (Schippers et al., 2013). Over time, learning curves flatten as new learning decreases (Edmondson, Dillon, \& Roloff, 2007). Expectations of a similar task could have lowered learning efforts. Finally, it is possible that teams did not focus their attention on relevant aspects of the task and have not developed accurate understanding of the task at hand (e.g. shared mental models) because of misperceptions, resulting in maladaptive strategies (Gurtner et al., 2007).

To conclude, the present study made four important contributions to the feedback and reflexivity literature: (1) Prompting feedback processing took the form of a formal and simple script instructing teams to follow three steps from evaluation of the past to articulation of implementation intentions. These steps allowed teams to initially pick up the feedback more quickly than teams only given feedback or no feedback at all at the very beginning of team activity. (2) It was possible to isolate the additional effect of processing feedback (i.e., via reflective prompts at the team level) from simple feedback delivery. (3) It was possible to speed up initial learning about the past by generating reflexivity, but these benefits did not endure over time. (4) Performance improvements of inducing feedback processing might not last over time under certain conditions that still need to be identified (e.g., high complexity, cognitive overload, limited expertise). This study also added to the reflexivity literature. The importance of reflexivity has been frequently emphasized as a crucial characteristic for 
professional competence in many disciplines (Mann, Gordon, \& MacLeod, 2009; Moreland \& McMinn, 2010) while its research foundation has been mixed. We showed that guided reflexivity in a simple form could be of added value in contexts providing accurate performance feedback in a team initial stage of activity, but may not have long-lasting effects.

\section{LIMITATIONS AND FUTURE RESEARCH}

The present research had several strengths, among them a longitudinal design, a comparative approach with a control group, a controlled and standardized environment supporting the internal validity of a new team intervention, and objective measures of team performance. Yet, there are some limitations that need to be acknowledged and addressed.

This study did not directly measure actual team reflexivity, as mentioned above. Therefore we were not able to analyze whether performance improvements are, in fact, mediated by the prompted strategies. A more qualitative approach, such as video analyses, could gain more insight into the characteristics and quality of team reflection, but also into how and why the combined effects of feedback and prompts on team performance fluctuate over time, and under which circumstances feedback is reflected upon. Recent process-oriented research on collaboration zooming in the "black box" of collaborative processes has mostly addressed individual learning without explicitly examining how collaborative processes shape team performance le.g., Janssen, Kirschner, Erkens, Kirschner, \& Paas, 2010). Consequently, future research should fill this gap to better map the dynamics of on-going reflection and emergence of team performance.

Second, one needs to be attentive to the generalizability of the results and the ecological validity of the study. The specific setting of our research sets important boundary conditions for generalizing our findings that should be acknowledged and considered to prompt further research issues and directions. The present study involved newly formed teams of novices performing a complex, dynamic, and interactive simulation with no expectations of subsequent interactions. Also, this task was highly interdependent, such that to perform it successfully, team members had to closely work together. However, although the experimental task was carefully designed to attain high levels of interdependence and complexity, the representativeness of what teams face in organizations is by definition limited. Moreover, many factors that could potentially moderate the relationship between feedback and team performance 
were unmeasured or controlled for. Team interaction as well as performance outcomes vary, at least to some extent, as a function of team size, the degree of novelty of the task, team familiarity, task expertise, team composition, temporal duration of the team, and team mental model of the organization (Devine, 2002; Kozlowski \& Ilgen, 2006). For example, research shows that familiar teams learn at a significantly faster rate than unfamiliar teams and that as team members work together they develop transactive memory systems and shared mental models, both crucial to team effectiveness (e.g., Lewis, Lange, \& Gillis, 2005; Staats, Gino, \& Pisano, 2010). Another example (Nihalani, Mayrath, \& Robinson, 2011) showed that prior knowledge of the content might enable collaborative groups to effectively use information from feedback. Furthermore, the artificial and temporal nature of the team and the limited number of team members must be considered. Teams of more than two team members might exhibit more complex interaction patterns. There have been debates about whether to distinguish dyads from teams made up of three or more people. We believe that many two-person teams (e.g., aircrews, agile teams) display the same basic work processes driving team performance as sizable teams, although larger teams may exhibit more complex social interactions. Importantly, the participants in our study were recruited from a university setting and not a work organization. Differences between these two settings might be expected. For example, expertise distribution within teams in educational settings may be limited. In turn, this may limit the inputs team members have available to effectively act upon feedback, especially in dyads. All this clearly means that generalization to applied settings must be made with appropriate caution and that more comparative field studies with rigorous designs must be carried out to confirm these results.

Third, this study investigates a certain feedback type in combination with reflexivity at the team level. It would be worthwhile to investigate eventual differential effects of feedback types on team processes and performance change (e.g., Prichard, Stratford, \& Bizo, 2006). For example, what would be the effect of feedback about the way teams completed the task, their teamwork processes, or their cognitive strategies? The combination of performance and process feedback might result in even more substantial changes.

Finally, since performance improvements faded away over time in the present study, what we still do not know is how and when feedback and guided reflexivity should be implemented to sustain long-lasting effects of the prompts. The next challenges for future research will be to identify intervention components (e.g., more or less structure and control from external aids or facilitators) and enabling factors that help teams maintain a high-level of 
reflexivity over time and at which temporal points in their life cycle teams need interruptions in the flow of work (Hoegl \& Parboteeah, 2006). Recent research on collaboration scripts offers a possible avenue in this regard. Although research on script fading and its impact on learning is scarce, literature suggests that once teams have acquired the expected skills, the external scaffolding is no longer needed and should thus be faded out to reduce cognitive overload (e.g., Dillenbourg, 2002; Jermann \& Dillenbourg, 2003). "Overscripting" might also impair teams' interest and motivation to enact the reflective steps prescribed by the script in the long-term. Hence, future research should also explore motivational and cognitive factors underlying team responses to feedback. Finally, erosion of the effects of guided reflexivity might result from the teams engaging in low-level reflection that is not sufficient as task complexity increases. The effects of an initial training or a facilitator's modeling of how to successfully perform deep reflection could be investigated and compared in future studies. Teams could be asked to perform specific behaviors as a practice first (e.g., training) and then as a routine. This offers myriad of possibilities for future work on feedback guidance.

\section{CONCLUSION}

Over the past decade, team research has grown steadily and has offered to explain why some teams outperform others. With the present study, we take one step further and identify how to leverage, better establish, develop, and manage effective teams by providing feedback in such a way that it leads to performance improvements. As a whole, our findings support the value of giving accurate and timely feedback in teams only if we seek to encourage active engagement from and reflective interactions between team members. However, since the benefits of such feedback fade away with time, the results also point to the importance of pursuing work on how feedback and guided reflexivity interventions can be implemented to sustain on-going learning. 


\section{REFERENCES}

Anseel, F., Lievens, F., \& Schollaert, E. (2009). Reflection as a strategy to enhance task performance after feedback. Organizational Behavior and Human Decision Processes, 110, 23-35. doi:10.1016/j.obhdp.2009.05.003

Argote, L. (1989). To centralize or not to centralize: the effects of uncertainty and threat on group structure and performance. Organizational Behavior and Human Decision Processes, 43, 5874. doi:10.1016/0749-5978(89)90058-7

Barr, S. H., \& Conlon, E. J. (1994). Effects of distribution of feedback in work groups. Academy of Management Journal, 37, 641-655

Bartram, D., \& Roe, R. A. (2008). Individual and organizational factors in competence acquisition. In W. Nijh of (Ed.), The Learning Potential of the Workplace. Rotterdam: Sense Publishers.

Blickensderfer, E. L., Cannon-Bowers, J. A., \& Salas, E. (1997). Theoretical bases for team selfcorrections: Fostering shared mental models. In M. M. Beyerlein, D. Johnson, \& S. Beyerlein (Eds.), Advances in interdisciplinary studies of work teams (Vol. 4, pp. 249-279). Greenwich, CT: JAl.

Boud, D., Keogh, R., \& Walker, D. (1985). Promoting reflection in learning: A model. In D. Boud, R. Keogh, \& D. Walker (Eds.), Reflection: Turning experience into learning (pp. 18-40). London: Kogan Page.

Boud, D., \& E. Molloy. (2013). Rethinking Models of Feedback for Learning: The Challenge of Design. Assessment \& Evaluation in Higher Education, 3816), 698-712. doi:10.1080/02602938.2012.691462

Brannick, M. T., Prince, C., \& Salas, E. (2005). Can PC-based systems enhance teamwork in the cockpit? The International Journal of Aviation Psychology, 1522), 173-187.

Daudelin, M. W. (1996). Learning from experience through reflection. Organizational Dynamics, 24. 36-48. doi: doi:10.1016/S0090-2616(96)90004-2

De Dreu, C. K. W. (2007). Cooperative outcome interdependence, task reflexivity and team effectiveness: A motivated information processing approach. Journal of Applied Psychology, 92, 628-638. doi:10.1037/0021-9010.92.3.628

Decuyper, S., Dochy, F., \& Van den Bossche, P. (2010). Grasping the dynamic complexity of team learning: An integrative model for effective team learning in organizations. Educational Research Review, 5, 111-133. doi:10.1016/j.edurev.2010.02.002

Devine, D. J. (2002). A review and integration of classification systems relevant to teams in organizations. Group Dynamics: Theory, Research, and Practice, 6, 291-310. doi:10.1037/10892699.6.4.291

Duijnhouwer, H, Prins F. J, \& Stokking, K. M. (2012). Feedback providing improvement strategies and reflection on feedback use: Effects on students' writing motivation, process, and performance. Learning and Instruction. 2211), 171-184. doi:10.1016/j.learninstruc.2011.10.003

Duncan, T. E., Duncan, S. C., \& Strycker, L. A. (2006). An introduction to latent variable growth curve modeling. Mahwah, NJ: LEA.

Edmondson, A. C. (1999). Psychological safety and learning behavior in work teams. Administrative Science Quarterly, 44, 350-383. doi:10.2307/2666999

Edmondson, A. C., Dillon, J., \& Roloff, K. S., (2007). Three perspectives on team learning outcome improvement, task mastery, and group process. The Academy of Management Annals, 1, 269314. doi:10.1080/078559811

Espinosa, J. A., Slaughter, S. A., Kraut, R. E., \& Herbsleb, J. D. (2007). Team Knowledge and Coordination in Geographically Distributed Software Development. Journal of Management Information Systems, 24(1), 5- 12. 
Gabelica, C., Van den Bossche, P., Segers, M., \& Gijselaers, W. (2012). Feedback, a Powerful Lever in teams: a Review. Educational Research Review, 72), 123-144. doi:10.1016/j.edurev.2011.11.003

Gersick, C. J. G., \& Hackman, J. R. (1990). Habitual routines in task-performing teams. Organizational Behavior and Human Decision Processes, 47, 65-97. doi:10.1016/07495978(90)90047-D

Gibbs, G., \& Simpson, C. (2004). Conditions Under Which Assessment Supports Students' Learning. Learning and Teaching in Higher Education, 1, 3-31.

Gurtner, A., Tschan, F., Semmer, N. K., \& Nagele, C. (2007). Getting groups to develop good strategies: Effects of reflexivity interventions on team process, team performance, and shared mental models. Organizational Behavior and Human Decision Processes, 102, 127-142. doi:10.1016/j.obhdp.2006.05.002

Hackman, J. R., \& Wageman, R. (2005). A theory of team coaching. Academy of Management Review, 30, 269-287. doi:10.5465/AMR.2005.16387885

Hattie, J., \& Timperley, H. (2007). The power of feedback. Review of Educational Research, 771), 81 112. doi: $10.3102 / 003465430298487$

Hoegl, M., \& Parboteeah, K. P. (2006). Team goal commitment in innovative projects. International Journal of Innovation Management, 193), 299-324. doi:10.1142/S136391960600151X

Janssen J., Kirschner F., Erkens G., Kirschner P. A., \& Paas F. (2010). Making the black box of collaborative learning transparent: combining process-oriented and cognitive load approaches. Educational Psychology Review, 22, 139-154. doi:10.1007/s10648-010-9131-x

Karau, S. J., \& Kelly, J. R. (1992). The effects of time scarcity and time abundance on group performance quality and interaction process. Journal of Experimental Social Psychology, 28, 542-571. doi:10.1016/0022-1031(92)90045-L

Kirschner, P. A. (2009). Epistemology or pedagogy, that is the question. In: S. Tobias \& T.M. Duffy (eds.), Constructivist theory applied to instruction: Success or failure? (pp. 144-157). New York: Routledge

Kirschner, F., Paas, F., \& Kirschner, P. A. (2009). Individual and group-based learning from complex cognitive tasks: Effects on retention and transfer efficiency. Computers in Human Behavior, 25, 306-314. doi:10.1016/j.chb.2008.12.008

Kluger, A. N., \& DeNisi, A. (1996). The effects of feedback interventions on performance: A historical review, a meta-analysis, and a preliminary feedback intervention theory. Psychological Bulletin, 119, 254-284. doi:10.1037/0021-9010.73.1.87

Kozlowski, S. W. J., \& Ilgen, D. R. (2006). Enhancing the effectiveness of work groups and teams. Psychological Science in the Public Interest, 7, 77-124. doi:10.1111/j.1529-1006.2006.00030.x

Lewis, K., Belliveau, M., Herndon, B, \& Keller, J. (2007). Group cognition, membership change, and performance: Investigating the benefits and detriments of collective knowledge. Organizational Behavior and Human Decision Processes, 103(2), 159-178. doi:10.1016/j.obhdp.2007.01.005

Lewis, K., Lange, D., \& Gillis, L. (2005). Transactive memory systems, learning, and learning transfer. Organization Science, 1616), 581-598. doi:10.1287/orsc.1050.0143

London, M. (2003). Job feedback: Giving, seeking, and using feedback for performance improvement (2nd ed.). Mahwah, NJ: Lawrence Erlbaum.

London, M., \& Sessa, V. I. (2006). Group feedback for continuous learning. Human Resource Development Review, 5(3), 1-27. doi:10.1177/1534484306290226

MacCurtain, S., Flood, P. C., Ramamoorthy, N., West, M. A., \& Dawson, J. (2010). Top Management Team Knowledge Sharing and New Product Performance: A Study of Irish Software Industry. Creativity And Innovation Management, 193), 219-232. doi:10.1111/j.1467-8691.2010.00564.x

Mann, K., Gordon J., \& MacLeod, A. (2009). Reflection and reflective practice in health professions education: A systematic review. Advances in Health Sciences Education 1414), 595-621. doi:10.1007/s10459-007-9090-2 
Marks, M. A. (2000). A Critical Analysis of Computer Simulations for Conducting team Research. Small Group Research, 37(6), 653-675. doi:10.1177/104649640003100602

Moreland, R. L., \& McMinn, J. G. (2010). Group reflexivity and performance. In S. R. Thye \& E. Lawler (Eds.), Advances in group processes (Vol. 27, pp. 63-95). Bingley, UK: Emerald Press.

Mulder, R. H. (2013). Exploring feedback incidents, their characteristics and the informal learning activities that emanate from them. European Journal of Training and Development, 371), 4971.

Müller, A., Herbig, B. \& Petrovic, K. (2009). The explication of implicit team knowledge and its supporting effect on team processes and technical innovations. An action regulation perspective on team reflexivity. Small Group Research, 40, 28-51. doi:10.1177/1046496408326574

Nihalani, P. K., Mayrath, M., \& Robinson, D. H. (2011). When Feedback Harms and Collaboration Helps in Computer Simulation Environments: An Expertise Reversal Effect. Journal of Educational Psychology, 103(4), 776-785.

Noroozi, O., Biemans, H. J. A., Weinberger, A., Mulder, M., \& Chizari, M. (2013). Scripting for construction of a transactive memory system in a multidisciplinary CSCL environment. Learning and Instruction, 25(1), 1-12. doi:10.1016/j.learninstruc.2012.10.002

Phielix, C., Prins, F. J., \& Kirschner, P. A. (2010). Awareness of group performance in a CSCL environment: Effects of peer feedback and reflection. Computers in Human Behavior, 26, 151 161. doi:10.1016/j.chb.2009.10.011

Phielix, C., Prins, F. J., Kirschner, P. A., Erkens, G., \& Jaspers, J. G. M. (2011). Group awareness of social and cognitive performance in a CSCL environment: Effects of a peer feedback and reflection tool. Computers in Human Behavior, 273), 1087-1102. doi:10.1016/j.chb.2010.06.024

Pinheiro, J. C., \& Bates, D. M. (2000). Mixed-Effects Models in S and S-PLUS, Springer.

Porter, C. O. L. H., Webb, J. W., \& Gogus, C. I. (2010). When goal orientations collide: Effects of learning and performance orientation on team adaptability in response to workload imbalance. Journal of Applied Psychology, 955), 935-943. doi:10.1037/a0019637

Prawat, R. S. (1989). Promoting access to knowledge, strategy, and disposition in students: A research synthesis. Review of Educational Research, 59, 1-41. doi:10.3102/00346543059001001

Prins, F. J., Sluijsmans, D. M. A., \& Kirschner, P. A. (2006). Feedback for general practitioners in training: quality, styles, and preferences. Advances in Health Sciences Education, 11, 289-303. doi:10.1007/s10459-005-3250-z

Prichard, J. S., Stratford, R. J., \& Bizo, L. A. (2006). Team-skills training enhances collaborative learning. Learning and Instruction, 16, 256-265. doi:10.1016/j.learninstruc.2006.03.005.

Prussia, G. E., \& Kinicki, A. J. (1996). A motivational investigation of group effectiveness using socialcognitive theory. Journal of Applied Psychology, 81, 187-198.

Rogelberg, S. G., \& Rumery, S. (1996). Gender diversity, team decision quality, time-on-task, and interpersonal cohesion. Small Group Research, 27, 79-90. doi:10.1177/1046496496271004

Salas, E. Dickinson, T. L., Converse, S. A., \& Tannenbaum, S. I. (1992). Toward an understanding of team performance and training. In R. W. Swezey \& E. Salas (Eds.), Teams: Their training and performance (pp. 3-29). Norwood, NJ: Ablex.

Schippers, M. C., Den Hartog, D. N., \& Koopman, P. L. (2007). Reflexivity in teams: A measure and correlates. Applied Psychology-An International Review, 56(2), 189-211. doi:10.1111/j.14640597.2006.00250.x

Schippers, M. C., Homan, A. C., \& van Knippenberg, D. (2013). To reflect or not to reflect: Prior team performance as a boundary condition of the effects of reflexivity on learning and final team performance. Journal of Organizational Behavior, 34(1), 6-23. doi:10.1002/job.1784

Seibert, K. W. (1999). Reflection-in-action: Tools for cultivating on-the-job learning conditions. Organizational Dynamics, 27, 54-65. doi: 10.1016/S0090-2616(99)90021-9 
Singer, J. D., \& Willett, J. B. (2003). Applied Longitudinal Data Analysis: Methods for Studying Change and Event Occurrence. New York: Oxford University Press.

Shute, V. J. (2008). Focus on formative feedback. Review of Educational Research, 78, 153-189. doi: $10.3102 / 0034654307313795$

Smith-Jentsch, K. A., Cannon-Bowers, J. A., Tannenbaum, S. I., \& Salas, E. (2008). Guided team selfcorrection: Impacts on team mental models, behavior, and effectiveness. Small Group Research, 393), 303-327. doi:10.1177/1046496408317794

Spinath, B., \& Spinath, F. M. (2005). Longitudinal analysis of the link between learning motivation and competence beliefs among elementary school children. Learning and Instruction, 15, 87-102. doi:10.1016/j.learninstruc.2005.04.008

Staats, B. R., Gino, F., \& Pisano, G. P. (2010). Varied experience, team familiarity, and learning: The mediating role of psychological safety. Working paper 10-016, Harvard Business School.

Tannenbaum, S. I., \& Cerasoli, C. P. (2013). Do team and individual debriefs enhance performance? A meta-analysis. Human Factors: The Journal of Human Factors and Ergonomics Society, 5511), 231-245. doi: 10.1177/0018720812448394.

Van Ginkel, W., Tindale, R. S., \& van Knippenberg, D. (2009). Team reflexivity, development of shared task representations, and the use of distributed information in group decision making. Group Dynamics, 13, 265-280. doi:10.1037/a0016045

Veenman, M. V. J., \& Elshout, J. J. (1999) Changes in the relation between cognitive and metacognitive skills during the acquisition of expertise. European Journal of Psychology of Education, 14, 509-523.

Villado, A. J., \& Arthur, W. (2013). The Comparative Effect of Subjective and Objective After-Action Reviews on Team Performance on a Complex Task. Journal of Applied Psychology, 98(3), 514528. doi:10.1037/a0031510

Weingart, L. R. (1992). Impact of group goals, task component, complexity, effort, and planning on group performance. Journal of Applied Psychology, 77/5), 682-693. doi:10.1037/00219010.77 .5 .682

West, M. A., Garrod, S., \& Carletta, J. (1997). Group decision-making and effectiveness: unexplored boundaries. In C.L. Cooper \& S.E. Jackson (Eds.), Creating tomorrow's organizations: A handbook for future research in organizational behavior (pp. 293- 316). Chichester: John Wiley \& Sons Ltd.

Wilson, J. M., Goodman P. S., \& Cronin, M. (2007). Group learning. Academy of Management Review, 32, 1041-1059. doi:10.2307/20159355

Wills, K. V., \& Clerkin, T. A. (2009). Incorporating reflective practice into team simulation projects for improved learning outcomes. Business Communication Quarterly, 722), 221227. doi:10.1177/1080569909334559

Yukawa, J. (2006). Co-reflection in online learning: Collaborative critical thinking as narrative. Journal of Computer-supported Collaborative Learning, 1, 203-228. doi: 10.1007/s11412-0068994-9 



\section{Chapter 6 \\ General Conclusions}


186 I CHAPTER 6 


\section{GENERAL CONCLUSIONS}

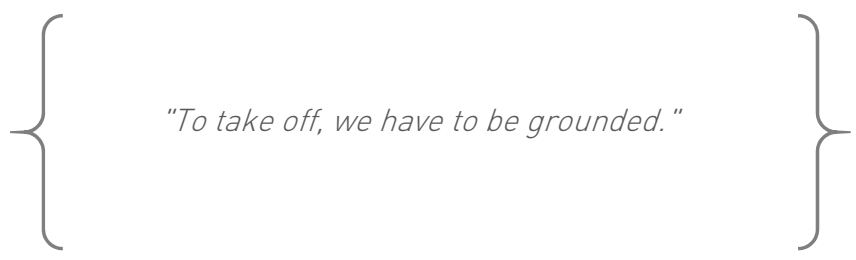

The critical role teamwork plays in effective operations has been recognized in many organizations, specifically those dealing with complex, fast-changing, and uncertain environments such as healthcare, aviation, the military, or business (e.g., Salas, Rosen, Burke, \& Goodwin, 2009). However, research and practice have shown that despite the diversity of knowledge and expertise available within teams, the potential of these teams is not always reached (Salas, Sims, \& Burke, 2005). They have the challenge of learning about and with each other to constantly update their knowledge and coordinate their efforts to adapt or improve (Edmondson, Dillon, \& Roloff, 2007). Yet teamwork is not an automatic consequence of co-locating individuals together. Previous research on team learning has provided insights in this regard (Decuyper, Dochy, \& Van den Bossche, 2010; Edmondson et al., 2007). It shows that differential rates of learning across teams are not only explained by practice and experience but most importantly by how learning is managed le.g., Reagans, Argote \& Brookes, 2005). Further, previous work on team learning has identified team-level cognitive systems (e.g., knowledge coordination) that allow mastery of novel tasks. Finally, an increasing number of studies have unraveled various team learning processes that, altogether, seem to form a process of iterating between action and reflection (Argyris \& Schön, 1978; Edmondson, 1999; Gibson \& Vermeulen, 2003; Van der Vegt \& Bunderson, 2005). Overall, although much is known about the nature of effective teams and teamwork, theory and research to date have still to unravel how these learning processes combine their effects to explain high coordination and team success, and identify potent interventions to manage and make this team learning happen (Kozlowski \& Ilgen, 2006).

\section{Which learning processes contribute to team coordination and team performance during team task execution?}

In chapter 2, we conceptualize coordination as the effective combination and synchronization of distributed knowledge within the team (Kozlowski \& Bell, 2003). Due to the complex interdependence requirements they face, teams need to complete the extra task of working in concert to achieve success, compared 
to individuals (Espinosa, Lerch, \& Kraut, 2004). In an effort to illuminate the determinants of team coordination, the first empirical study presented in chapter 2 identifies four crucial conditions allowing team coordination and team performance to emerge, namely prior team learning processes, more specifically 1) team reflexivity (i.e., collective reflection upon team goals, performance, and working methods and development of improvement strategies) and 2) team learning behaviors conceptualized as construction (i.e., sharing knowledge), co-construction (i.e., building upon previous assertions), and constructive conflict (i.e., constructively discussing disagreements), 3) group potency (i.e., team members' beliefs about their capacity to complete the task) and 4) task cohesion (i.e., team members' beliefs about their mutual commitment to the team task).

Our results show that cohesive teams are more likely to engage in learning processes (i.e., team reflexivity and team learning behaviors) and in turn, exhibit better coordination during a subsequent team task, which is related to higher performance. Further, those with a stronger collective belief that their team is effective are more likely to coordinate and perform effectively. In combination, these beliefs and learning processes allow teams to be more efficient and better able to optimize knowledge available in the team. These results suggest that when people collaborate on a new task, from the start on they hold beliefs on the degree of mutual commitment in the team and of the team capacity to complete its task successfully that encourage them or prevent them from performing learning activities, such as sharing and creating knowledge, reflecting together on their functioning, or directly addressing disagreements. In turn, those interactions during which they discuss what they know about the task and how they should operate also affect their ability to improve their coordination and correct their mistakes. For example, in high-stake environments such as health care, if team members do not develop shared beliefs of mutual commitment and confidence in the success of the team, they run the risk of not sharing crucial information about a patient, accepting decisions that do not best match the situation, and not discussing treatment options. As a result, this might lead to a lack of coordination, a sub-optimal quality of treatment received, and in the worst case, medical errors. What happened to the cockpit crew described in the example of the introduction can also be related to poor coordination and a lack of learning behaviors in the team. The team members failed to share relevant knowledge about their task and team and did not question their shared (and wrong) representation of the situation. They draw conclusions, formed judgments, and made decisions based on their mere assumptions without explicit communication (Hagen, 2013). As a 
consequence, a lack of synchronization of all pieces of information and knowledge available in the team (i.e., team knowledge coordination) contributed to the fatal accident of the Air France Flight 447.

To conclude, our empirical study presented in chapter 2 takes a learning perspective on a cognitive concept (i.e., team knowledge coordination) that has been studied extensively in the cognitive and organizational science literature. Effective knowledge coordination lies at the heart of team performance. As such, a large body of research in different domains has shown the benefits of high coordination on performance le.g., Espinosa, Slaugther, Kraut, \& Herbsleb, 2007; Faraj \& Sproull, 2000; Rico, Sanchez-Manzanarez, Gil, \& Gibson, 2008; LePine, Piccolo, Jackson, Mathieu, \& Saul, 2008). However, although teams can be well positioned to coordinate effectively and as a consequence perform well, there has been relatively little research examining underlying team learning processes that contribute to team coordination (e.g., Edmondson, 1999). Thus, the current study on how team coordination arises from early team beliefs and learning processes offers new avenue for team learning research but also raises new questions related to the actual process of team learning (Kozlowski \& Ilgen, 2006). For example, since most of the data collected relied on self-report instruments that probably do not fully grasp the complex learning phenomena occurring in teams, a natural question would be "in which context do specific learning behaviors occur and when do these learning behaviors relate to high performance"? Chapter 4 zooms into these learning behaviors with a processoriented approach. Process-oriented research on collaboration must be undertaken to advance our understanding on interaction features contributing to more effective learning (e.g., De Wever, Schellens, Valcke, \& Van Keer, 2005). Additionally, our model accounted for $28 \%$ of the variance in team learning behaviors, while only $10 \%$ in reflexivity. There is thus considerable room left for team-level inputs factors or planned interventions to affect the development of these team learning processes. Based on this, we turn towards the second overarching question of this dissertation: "how can we better support teams in developing their potential effectiveness?"

\section{Is Feedback truly effective in teams? Under which circumstances?}

The results of the study presented in chapter 2 demonstrate that learning processes have a critical influence on subsequent team coordination and performance. However, we still have a limited understanding of the basic conditions one can establish such that teams will evolve into an ever more competent performing unit. We argue that to be able to learn from their 
experiences, teams should be given feedback. With feedback describing objective team performance, teams are expected to be better able to share relevant knowledge and jointly build cues and information, correct their faulty interpretations, reinforce their effective behaviors, and regulate their work by setting more effective and efficient strategies (Hattie \& Timperley, 2007). In turn, this increased learning in the team would allow them to better coordinate their skills and perform more effectively. As such, this dissertation argues that feedback is a potent intervention that can be used to leverage team learning and increase team performance. Since literature on feedback in team settings appears to be scattered, we conducted a literature review on the effects of feedback in teams. In this review presented in chapter 3, we sought to (a) clarify and contribute to the research strand on feedback in teams by providing a clarification of the nature of feedback via an integration of team feedback interventions investigated in fifty-nine studies, (b) establish the boundary conditions of feedback for improving team outcomes and processes by identifying key success factors proved to enhance its effect, and (c) provide valuable information for trainers, educators, and organizational stakeholders charged with managing teams. Addressing these objectives was meant to provide deeper insights into the effectiveness of team feedback.

Our review of the literature on feedback in teams shows that although feedback might aid teams in the development of a huge diversity of key team processes (e.g., motivation, team goal, and collaboration/cooperation) and emergent states (e.g., collective efficacy, cohesion, outcome expectations, and task concern/interest), it only has occasional positive consequences on performance (Gabelica, den Bossche, Segers, \& Gijselaers, 2012). Armed with a theory and empirical evidence about underlying mechanisms explaining why not all feedback is beneficial to performance, one can generate nuanced hypotheses about when feedback effects are likely to occur. First, we show that feedback effectiveness can be improved if feedback itself is of high quality, namely specific, well-timed, regular, non-threatening, shared, directed at teams it targets, and distributed fairly amongst team members. Concerning feedback valence, positive feedback (i.e., feedback describing success) has been generally found to positively affect performance and team processes, while negative feedback (i.e., describing failure) triggers both beneficial and detrimental effects (Matsui, Kakuyama, \& Onglatco, 1987; Mesch, Farh, \& Podsakoff 1996). Second, types of feedback (i.e., focused on performance or on the process) have differential effects. Generally, the studies we reviewed reveal that process feedback appears to be helpful in improving team processes, while performance feedback can also lead to better performance. Third, feedback is more likely to 
be effective in certain situations. In particular, feedback appears more profitable in teams with no redundant members or tasks, working in projects, setting goals and strategies or given information about goal attainment, provided with incentives and rewards, believing they are high-performing, and exhibiting no unsolved intragroup conflicts and a flexible workload. Further, individual members in a positive mood, provided with individual incentives, rewards, reinforcements, and opportunities to set individual goals and expectations are more likely to benefit from feedback. Finally, we found only one study providing empirical evidence of the importance of how feedback is perceived (Walter \& Van der Vegt, 2013) and none of how feedback is processed by team members.

Our results corroborate previous work on feedback in teams le.g., Kozlowski \& Ilgen (2006; Phielix, Prins, \& Kirschner, 2010) that highlights feedback as a potent key intervention yet requiring further development and research attention. More specifically, Kozlowski and Ilgen (2006) advise, in their review on team effectiveness, that future research should examine particular facets of feedback that contribute to desired team regulatory processes and responses. In this regard, feedback receivers have a crucial role to play in the feedback process (e.g. Prins, Sluijsmans, \& Kirschner, 2006). Feedback cannot be considered as information forwarded to passive recipients. Understanding teams in the context of the feedback exchange is thus crucial to its effectiveness. While processes occurring between feedback reception and the eventual subsequent changes have been consistently advanced as central to feedback effects in theoretical work in the domain (e.g., London \& Sessa, 2006), no empirical study had been published that empirically validated the importance of feedback processing nor identified specific feedback processing behaviors. Clearly, how teams process feedback to regulate their actions and in turn, to improve their future performance appears to be a black box that is not well understood. This direction for future research informed the design of the two following empirical studies of this dissertation (chapters 4 and 5). We first looked into how teams spontaneously process feedback, that is proactively engage in feedback analysis and exploration and implementation of possible strategies and remedies (chapter 4). Next, we designed an intervention aimed at stimulating feedback receptivity and processing to isolate the effect of prompting feedback processing compared to the mere delivery of feedback (chapter 5). 


\section{How are reflective behaviors after feedback related to performance?}

As we've seen in our literature review on feedback in teams presented in chapter 3 (Gabelica et al., 2012), a great deal of work has shown that team-level performance feedback is not sufficient to alter team behaviors towards better performance. It is argued that making such changes involves receptiveness, understanding of the value of the feedback, and proactive engagement from the recipients. Hence, the feedback recipients (i.e., the teams), in the center of the feedback process, will increase or decrease the likelihood that the learning potentially available in the team will be realized.

In the study presented in chapter 3, we introduced the concept of team reflexivity (i.e., teams' overt reflection about their objectives, strategies, and processes) as a set of relevant indicators grasping feedback processing. We operationalized team reflexivity as three main behaviors following feedback reception, namely evaluating performance and strategies, looking for alternatives, and making decisions about new ways to tackle the task. Specifically, in the third study we addressed the relation between the timing at which team reflexivity occurs (during action versus during feedback and during the early interactions versus later interactions of the team) and its relation to performance. Also, we investigated whether reflective behaviors during action and during feedback would decrease or increase over time. In an experiment, dyads performed a series of landing tasks of increasing complexity in a flight simulation. Between action phases, they were provided with time-outs li.e., feedback phases) during which they received specific feedback depicting whether or not they had met criteria of a good landing during their previous task. We applied the criteria of high-quality feedback as identified in the review of the literature presented in chapter 3. Hence, feedback was specific, well-timed (given immediately after the task execution), regular (repeated after each performance episode), non-threatening, shared, directed at teams it targets, and fairly distributed amongst team members.

The following conclusions can be drawn from this empirical study. First, when provided feedback, teams do not naturally perform sequences of all three reflecting behaviors (i.e., evaluating, looking for alternatives, and making decisions about new methods and strategies to tackle the next task). They do, however, complete sequences of two behaviors ending by a clear decision. This indicates that teams regularly "skip" the extensive evaluation of what and how they completed the task or the brainstorm phase during which alternatives are weighted. Second, if we consider behaviors individually, teams evaluate their performance and strategies more often than they make decisions or look for 
alternative ways of performing the task. This behavior is also more frequent during action than during feedback. Evaluating and making decisions also increase over time during action only, reflecting a sub-optimal use of time-outs during which feedback is provided and thus missed opportunities to process this feedback. Third, results reveal that timing of reflective behaviors is an important factor to better understand the role of team reflexivity. While initially making decisions is detrimental to subsequent performance lvan Ginkel \& van Knippenberg, 2009), evaluating during later feedback is related to better subsequent outcomes. Fourth, our results challenge the assumption that reflection generates better performance. The other direction of the relationship between reflexivity and performance can also be true: (initial) performance likewise affects subsequent team reflexivity. This clearly underlines the potential of feedback loops in models looking into team learning.

To conclude, we extend previous research on team feedback and team reflexivity by 1 ) demonstrating the positive effect of reflecting during feedback (i.e., processing feedback) on subsequent team performance, 2) showing that the relationship between team reflexivity and performance might be bidirectional, and 3) unraveling teams' suboptimal use of feedback to plan future action and 4) the absence of "reflective cycles". Our results are in line with the theoretical work of London and Sessa (2006) indicating that teams do not always attend to the content of feedback. In a team, it appears to be crucial to reach an intersubjective understanding of the meaning of the feedback and thus to discuss it constructively and openly to work out what can be learned from past achievements or failures (Boud, Keogh, \& Walker, 1985; London \& Sessa, 2006). Therefore, to optimize its effectiveness, feedback should not only make teams aware of their performance and effective behaviors but also involve a process during which teams communicate about how they process, make sense of these data, and extract cues for future behaviors (Boud \& Molloy, 2013; London \& Sessa, 2006; Prins, Sluijsmans, \& Kirschner, 2006). Importantly, we add to the literature on team reflexivity and feedback by distinguishing time and timing at which these team reflective behaviors occur. This dynamic perspective on team reflexivity does not consider team reflexivity as a general working style but as behaviors dynamically related to performance.

Interestingly, analogue to what is commonly observed in non-team settings, it appears that teams are more driven by their immediate action and performance le.g., Gurtner, Tschan, Semmer, \& Nagele, 2007; Karau \& Kelly, 1992), and do not spontaneously reflect on feedback they receive in a systematic way. These results have been used to develop a targeted intervention, presented in chapter 5, aimed at stimulating an iterative three-step reflective cycle that 
involves evaluating performance and strategies, looking for alternatives, and making decisions (e.g., Schippers et al., 2007; Yukawa, 2006), to generate subsequent performance changes.

\section{Does processing feedback through team reflexivity promote changes?}

The results of the previous study reveal that not all teams spontaneously engage in reflective behaviors and use feedback they receive to review past performance and prepare future action. These failures in process present a hurdle to the effective articulation of aspects of a problem, a full understanding of the problem, and the generation and evaluation of options to improve performance. Thus, we propose that team reflexivity needs to be induced by an intervention (i.e., guided reflexivity) prompting its use during transition. Guided reflexivity is a structured intervention providing time, space, and specific guidelines lor steps that teams are expected to follow) explicitly instructing team members to reflect together, more specifically to analyze previous performance, develop alternatives, and derive new goals, strategies, and procedures between performance episodes (Gurtner et al., 2007; van Ginkel \& van Knippenberg, 2009). Based on previous work on team reflexivity and team-level feedback, we predicted that both components (team-level performance feedback followed by guided reflexivityl were essential in reaching performance changes. Performance feedback provides teams with opportunities to obtain a clear sight of performance criteria and goals to achieve. Guided reflexivity enables them to process and use this information to adapt to anticipated situations by diagnosing deficiencies, adjusting their goals and strategies accordingly, and consequently reducing the gap between expected goals and current performance (Covey, 1989; Hattie \& Timperley, 2007). This means that the positive effect of feedback is contingent on the reflective behavior of teams. We examined team performance trajectories under the conditions of feedback and guided reflexivity facilitation (respectively, provision of feedback alone, feedback followed by guided reflexivity, and no feedback nor guided reflexivity).

Our results indicate that over the course of four performance episodes of a set of increasingly complex tasks, teams repeatedly engaged in guided reflexivity after the reception of team-level performance feedback demonstrated higher performance outcomes as compared to teams who were not prompted nor given feedback. These teams even started with a sharper learning curve suggesting these two interventions have the power to speed up the learning of a new task. Interestingly, teams who received feedback only did not benefit from it; they did 
not perform differently than teams who were not given any performance information.

A fascinating result, though unexpected, is the sudden drop of performance on the last task for teams provided with both interventions. Those teams did not differ from the other groups anymore. This finding can possibly be explained by the more rapid increase of the complexity and consequently cognitive load of the last task. It might be that when a task becomes too complex, teams are cognitively overwhelmed by performing the task and do not use the strategies they set previously since this implementation would require additional cognitive resources (Kirschner, Paas, \& Kirschner, 2009). Also, the amount of cognitive load necessary to acquire information and thus use relevant information to succeed in a task depends on a team's expertise. If expertise is limited lsuch as in the experiment), cognitive load is very high. Under certain circumstances, it may be that the presentation of feedback and prompts to reflect provide too much additional stimuli that prevent team from assimilating the effect of the prompts on performance tasks. Another explanation for this outcome is that teams do not perceive sufficient similarities between the previous tasks and the more complex task and as a result, consider the strategies and remedies they identified as being obsolete and inapplicable. This adaptation to a subsequent task presenting more complex features than the one teams completed beforehand have occurred before task 4 (for tasks 2 and 3). It may also be that fatigue, boredom, or a poorer implementation of the reflective prompts by the teams share responsibility for the lower performance for all study participants. As such, it is important to consider what changed in terms of objective features of the task and engagement of the team members to better explain changes in performance. More research is needed to better understand when task complexity interacts with team reflexivity to impact performance.

To conclude, the results reported in this study are consistent with feedback research emphasizing that feedback might not always generate expected changes (Kluger \& DeNisi, 1996, Gabelica et al., 2012). As suggested by London and Sessa (2006) and Gabelica and colleagues (2012), feedback processing is a relevant moderator of feedback effectiveness at the team-level. This study makes a significant contribution to the feedback literature by providing evidence for the "power of feedback" but only when teams are provided with guidance on how to reflect upon and thus process this feedback. Hence, it provides empirical support for a factor that is frequently advanced in feedback literature to explain feedback effectiveness le.g., Gabelica et al., 2012; London \& Sessa, 2006; Nadler, 1979) but hardly confirmed. Moreover, we demonstrate that we cannot consider feedback delivery without considering feedback reception. Teams are 
at the heart of the feedback process; they have an important responsibility in the impact of feedback on their behaviors. Even if feedback is ideally organized and provided under ideal conditions, the impact is still influenced by the reactions of the learners.

\section{STRENGTHS AND LIMITATIONS}

This dissertation used mixed methods such as a literature review, empirical laboratory experiments, and quantitative and qualitative techniques to contribute to the advancement of the implementation of feedback interventions in team settings with a learning perspective on teamwork.

Overall, the empirical studies described in chapters 2, 4, and 5 were designed to meet methodological requirements of a rigorous experimental design with high internal validity, based on its temporal sequencing and the collection of objective performance data. The controlled laboratory environment in which a standardized task and training content are used supports the internal validity of the interventions that are being tested. Laboratory studies ruling out uncontrolled extraneous influences and focusing on precision in capturing fundamental processes are a first step to better understand complex phenomena and compare different approaches for learning. The flight simulation that we used as a research platform to simulate and control task and team features was complex and engaging enough for the participants in our study. We believe that such a simulation - as traditionally used in team research allows a more detailed look at team cognition in dynamic environments le.g., Driskell \& Salas, 1992; Mathieu, Heffner, Goodwin, Salas, \& Cannon-Bowers, 2000; Weaver, Bowers, Salas, \& Cannon-Bowers, 1995).

Further, the temporal sequencing of the design provides a better basis to test causal effects than a cross-sectional design (Bliese \& Ployhart, 2002; Duncan, Duncan, \& Strycker, 2006; Wildman et al., 2012). The inclusion of time as an important factor to study team learning and performance provides a more fine-tuned understanding of how teams use time and temporal milestones to learn (e.g., Waller, 1999). Although this experimental approach is necessary and useful for research on intra-team processes, it has some limitations, which we will address below.

One issue that often arises when conducting a laboratory study is the generalizability of the results to the intended recipients and its ecological validity. The studies of this dissertation involved newly formed teams of novices performing a complex, dynamic, and interactive simulation with no expectations 
of subsequent interactions. As such, although the experimental task was carefully designed to attain high levels of uncertainty and complexity, the extent to which the task being used is representative of what teams face in organizations is by definition limited. Additional research is obviously needed to translate the findings of the present research for business practice. For example, team interaction as well as performance outcomes vary, at least to some extent, as a function of team size, the degree of novelty of the task, team familiarity, temporal duration of the team, and team mental model of the organization and its norms for working together (Devine, 2002; Kozlowski \& Ilgen, 2006). Hence, these factors must be considered in follow-up research.

We do also recognize the debate over the inclusion/exclusion of dyads in team/group research (Moreland \& Levine, 2012; Williams, 2010) and that this distinction might be a boundary condition of the present findings, although we follow Williams (2010) and his reasoning that dyads are the smallest form of a team/group. Further, the task nature and the feedback cues the environment provides might differ. For example, in the simulation there was a clear correct way of completing the task and an obvious cue for failure (i.e., crash). However, most organizational problems don't have a unique solution and do not always lead to a clear feedback on the correctness of the proposed solution. Also, the amount of knowledge and skill available in the team contribute to team performance (Hackman \& Oldham, 1980). The confounding effects of skilled task behavior (Webb et al., 1998) were experimentally controlled in the present research but should be accounted for in future research in work teams.

Finally, the use of students is sometimes considered as a possible limitation. However, previous studies have established that little difference holds between the use of students and professional teams when using problem solving and decision-making scenarios (Balijepally, Mahapatra, Nerur, \& Price, 2009; Yoo \& Alavi, 2001). All this clearly means that generalization to applied settings must be made with appropriate caution and that more comparative field studies with rigorous designs must be carried out to build further on our results.

\section{SUGGESTIONS FOR FUTURE RESEARCH}

Our results point important areas for future research. A number of avenues can be pursued to better understand how team members become more effective collective entities and support these processes. We found that better coordination and performance would naturally emerge from exposure to certain events: from working and learning collectively, from sharing favorable beliefs 
about the team capacity to be successful and its commitment, or from having access to performance data from previous performance. These findings can be integrated in future research looking into these constructs with a more developmental glance. Follow-up research could be aimed at investigating the extent to which each predictor defined in the study presented in chapter 2 le.g., task cohesion and group potencyl would change over time and subsequently generate coordination and performance changes in tasks differing more or less from the learning task.

We also showed that not all teams would learn naturally and that the explicit organization of learning opportunities was of great help to optimize team learning. We demonstrated that we could improve the receptivity to feedback in teams through the use of prompts to reflect. Future research could provide more insights into how feedback about the ways teams completed the task, their teamwork processes, or their cognitive strategies (i.e., process feedback) might prompt targeted reflection on these aspects. It would be valuable to examine if these feedback types have a differential impact on team processes change with quantitative and qualitative methods (e.g., Prichard, Stratford, \& Bizo, 2006). The content of reflective interactions following the prompts could hence be analyzed to classify the type of strategies discussed in the team and test their impact on subsequent performance and processes.

Temporal aspects of teamwork have been recognized as one of the most overlooked aspects of team research (Kozlowski \& Bell, 2003; McGrath \& Argote, 2001). The inclusion of time in our studies adds to the literature about team learning in which hypotheses are often time-insensitive and hence provide insights about group statics, but not dynamics (McGrath, 1986). The present research investigates team dynamics to a certain extent. In chapter 2, the testing of a model with constructs measured at different points in time allowed the examining of antecedents of team coordination and performance. Further, in chapter 4, all constructs under investigation were measured at four points in time and bi-directional relationships were explored. Finally, in the last study, we examined growth curves. Current literature does not usually integrate assumptions about time ordering or erosion/ growth of effects on outcomes variables (Mitchell \& James, 2001). Our dynamic perspective gives other fruitful directions for future research. One of the fundamental time-related questions about team learning relates to causal direction. For example, it is important to establish whether feedback and guidance on its processing only function as inputs-facilitating and thus preceding performance- or also as results of how well teams have performed in the past. If the past (previous mistakes or successes) matters, when does it have the most impact on future team 
performance? Another important feature of how time might moderate the impact of team interventions is reflected in the use of structures and scripts (e.g., instructions on how team members should interact) over time. Literature on scripts in educational settings suggests scripts land thus structured guidance) could be faded out to reduce cognitive overload (Dillenbourg, 2002; Jermann \& Dillenbourg, 2003). This might also be the case for professional teams. We only used prompted scripts (i.e., cues encouraging team reflexivity), leaving a lot of research possibilities. The use of more or less structure and control from external aids or facilitators and the effect of a training on how to use reflective behaviors on team performance over time could be investigated and compared in future studies. The first assumption would be that guidance should be more prominent in the early interactions and flexible enough to allow teams to adapt the prompted skills to circumstances. Guidance vary along a continuum from free interactions with light support to well-controlled scenarios in which teams are strictly asked to perform specific behaviors in a certain order as a practice first (e.g., trainingl and then as a routine. This offers myriad of possibilities for future work on feedback guidance.

\section{PRACTICAL IMPLICATIONS}

Not only do the results of this dissertation provide new areas for future research, they can also be used to formulate practical implications for the guidance of teams. The most important conclusions of our research, with the most potential for enhancing team learning and change are summarized in Table 1. 
Table 1

Key Conclusions of the Empirical Research of the Present Dissertation

- Strongly cohesive teams are more inclined to share knowledge and reflect collectively about what they are doing.

-The facilitative effects of task cohesion on team learning and team confidence in its success result in better coordination among team members.

- The more teams share, build upon, and discuss information and reflect on their team and task, the better they coordinate and perform.

- Teams using time-outs from action to analyze successful and failed experience are more likely to improve their future performance

- Teams are not systematic in their reflective process: when given feedback on their team performance, they often leave out the systematic evaluation of their performance and/or the search for alternatives to how they approached the task.

- Not only can team reflection boost performance, early failures seem to generate reflection.

- Teams cannot learn from feedback they receive on their performance if they are not provided with opportunities to work on the feedback and improve their behaviors and performance as a team

- When teams are guided to be more reflective on their practice based on feedback they receive, the positive effect of guidance fades away with time. Teams return back to their routines.

Based on the present studies we suggest the following recommendations for teams in practice.

Building team confidence and cohesion. Initial team meetings should be arranged to reach a high commitment to team goals and at the same time, a great emphasis on the interactions among members should be placed. Also, attention must be taken to ensure the creation and maintenance of an environment of openness in which everyone can hold each other accountable and contribute to the team in a safe and receptive environment. Making assumptions of team members about their task and teammates explicit could also prevent reinforcing unfavorable assumptions that restraint team communication.

Encouraging knowledge sharing and building and constructive conflict. Managers seeking to promote knowledge coordination should draw attention to 
tasks that create interdependence, clarify areas of expertise associated with the task, stimulate ongoing discussions of task issues, and regularly reconsider who knows what in the team (Brandon \& Hollingshead, 2004). By asking critical questions and challenging the team with competing perspectives and interpretations, they can broaden discussions and promote deeper levels of reflection.

Giving frequent, timely, and specific feedback to teams. Feedback can be used to enhance efforts to change behavior in teams. It should be specific, welltimed, regular, non-threatening to the person, shared, and fair and should contain learning information that teams can use to improve their future performance. The mere introduction of a feedback instrument provides people with referencing information that might shape their notions of what represents effectiveness (London \& Smither, 1995). Feedback informs teams about their achievement and clarifies standards and criteria for good performance but is only evaluative in nature.

Explicitly organizing and stimulating active processing of feedback by teams. As such, feedback delivery should be designed in a form that stimulates teams to use it in a very pragmatic way. For example, team meetings lor timeouts from task completion) can be facilitated to prompt teams to work out how they can do a better job by evaluating feedback, asking critical questions, discussing alternatives, and deriving strategies or creative ideas. This active processing of performance data should take place for both team successes and team errors or failures (Ellis \& Davidi, 2005). Moreover, teams should not only review their prior success or mistakes but also plan time to think forward: they should be stimulated to ask themselves what they can do to improve their future performance. Planning the implementation of changes increases the chances to actually perform effective changes.

In the long-term, reflective practice at the team level can become part of practitioners' working routine. Teams first need to be convinced about the importance of reflexivity upon feedback and given clear ways to achieve this shared reflection (McCarthy \& Garavan, 2008). Team reflexivity should be introduced and modeled at an early stage of a team-based work so that teams can get acquainted to how to proceed with appropriate guidance and examples of effective reflective behaviors. With the sight of positive long-term effects, teams should be given space with an appropriate level of reflection upon feedback to open up learning opportunities (Edmondson, 1999; Schippers, Den Hartog, \& Koopman, 2007).

Developing on-the-job interventions and team training programs. Developing on-the-job interventions and team training programs concurrently 
could lead to gains in effectiveness. For example, intact teams should be trained to engage in reflective behaviors and collaboratively implement these reflective pauses. To do so, simulated work environments appear to be of relevance in many settings (e.g., medicine, aviation, business) as they offer opportunities for practice with novel approaches without taking any costly risks (Gredler, 2004; Kozlowski, 1998; Marks, 2000). After any training or simulation, the transfer of the new skills to the work environment should also be considered by organizing the conditions under which teams can use the team skills they learned during practice.

In summary, teams can substantially improve their performance when feedback is provided together with opportunities for guided reflection. 


\section{REFERENCES}

Argyris, C., \& Schön, D. (1978). Organisational learning: A theory of action perspective. Reading, MA: Addison Wesley.

Balijepally, V., Mahapatra, R., Nerur, S., \& Price, K. H. (2009). Are two Heads better than one for Software Development? The Productivity Paradox of Pair Programming. MIS Quarterly, 33(1), 91-118.

Bliese, P. D., \& Ployhart, R. E. (2002). Growth modeling using random coefficient models: Model building, testing, and illustrations. Organizational Research Methods, 5, 362-387.

Boud, D., Keogh, R., \& Walker, D. (1985). Promoting reflection in learning: A model. In D. Boud, R. Keogh, \& D. Walker (Eds.), Reflection: Turning experience into learning (pp. 18-40). London: Kogan Page.

Boud, D., \& E. Molloy. (2013). Rethinking Models of Feedback for Learning: The Challenge of Design. Assessment \& Evaluation in Higher Education, 3816), 698-712.

Covey, S. R. (1989). The seven habits of highly effective leaders. Amsterdam: Business Contact.

Decuyper, S., Dochy, F., \& Van den Bossche, P. (2010). Grasping the dynamic complexity of team learning: An integrative model for effective team learning in organizations. Educational Research Review, 5, 111-133.

Devine, D. J. (2002). A review and integration of classification systems relevant to teams in organizations. Groups Dynamics, 6, 291-310.

De Wever, B., Schellens, T., Valcke, M., \& Van Keer, H. (2006). Content analysis schemes to analyze transcripts of online asynchronous discussion groups: A review. Computers \& Education, 46(1), 6-28.

Dillenbourg, P. (2002). Over-scripting CSCL: The risks of blending collaborative learning with instructional design. In P. A. Kirschner (Ed). Three worlds of CSCL. Can we support CSCL Ipp. 61-911. Heerlen, Open Universiteit Nederland.

Driskell, J. E., \& Salas, E. (1992). Collective behavior and team performance. Human Factors, 34, 277-288.

Duncan, T. E., Duncan, S. C., \& Strycker, L. A. (2006). An introduction to latent variable growth curve modeling. Mahwah, NJ: LEA.

Edmondson, A. C. (1999). Psychological safety and learning behaviour in work teams. Administrative Science Quarterly, 44(2), 350-383.

Edmondson, A. C., Dillon, J., \& Roloff, K. S. (2007). Three perspectives on team learning outcome improvement, task mastery, and group process. The Academy of Management Annals, 1, 269314.

Ellis, S., \& Davidi, I. (2005). After-event reviews: Drawing lessons from successful and failed experience. Journal of Applied Psychology, 90, 857-871.

Espinosa, J. A., Lerch, J., \& Kraut, R. (2004). Explicit vs. Implicit coordination mechanisms and task dependencies: One size does not fit all. In E. Salas \& S. M. Fiore (Eds.), Team cognition: Understanding the factors that drive process and performance (pp.107-129). Washington, DC: APA Books.

Espinosa, J., Slaughter, S., Kraut, R., \& Herbsleb, J. (2007). Team knowledge and coordination in geographically distributed software development. Journal of Management Information Systems, 2411), 135-169.

Faraj, S., \& Sproull, L. (2000). Coordinating expertise in software development teams. Management Science, 46, 1554-1568.

Gabelica, C., Van den Bossche, P., Segers, M., \& Gijselaers, W. (2012). Feedback, a Powerful Lever in teams: a Review. Educational Research Review, 12), 123-144. 
Gibson, C., \& Vermeulen, F. (2003). A healthy divide: Subgroups as a stimulus for team learning behavior. Administrative Science Quarterly, 48(2), 202-239.

Gredler, M. E. (2004). Games and simulations and their relationships to learning. In D. H. Jonassen (Ed.), Handbook of research for educational communications and technology (2nd ed., pp. 57182). Mahwah, NJ: Lawrence Erlbaum Associates.

Gurtner, A., Tschan, F., Semmer, N. K., \& Nagele, C. (2007). Getting groups to develop good strategies: Effects of reflexivity interventions on team process, team performance, and shared mental models. Organizational Behavior and Human Decision Processes, 102, 127-142.

Hackman, J. R., \& Oldham, G. R. (1980). Work redesign. Reading, MA: Addison- Wesley.

Hagen, J. U. (2013). Confronting mistakes: Lessons from the Aviation Industry when Dealing with Error. Basingstoke, UK: Palgrave Macmillan.

Hattie, J., \& Timperley, H. (2007). The power of feedback. Review of Educational Research, 771), 81 112.

Brandon, D. P., \& Hollingshead, A. (2004). Transactive memory systems in organizations: Matching tasks, expertise, and people. Organization Science, 15(6), 633-644.

Jermann, P., \& Dillenbourg, P. (2003). Elaborating new arguments through a CSCL scenario. In J. Andriessen, M. Baker, \& D. Suthers (Eds.), Arguing to Learn: Confronting Cognitions in Computer-Supported Collaborative Learning Environments. Kluwer, Amsterdam, NL.

Karau, S. J., \& Kelly, J. R. (1992). The effects of time scarcity and time abundance on group performance quality and interaction process. Journal of Experimental Social Psychology, 28, 542-571.

Kluger, A. N., \& DeNisi, A. (1996). The effects of feedback interventions on performance: A historical review, a meta-analysis, and a preliminary feedback intervention theory. Psychological Bulletin, 119, 254-284.

Kirschner, F., Paas, F., \& Kirschner, P. A. (2009). A cognitive load approach to collaborative learning: United brains for complex tasks. Educational Psychology Review, 21, 31-42.

Kozlowski, S. W. J. (1998). Training and developing adaptive teams: Theory, principles, and research. In J. A. Cannon-Bowers \& E. Salas (Eds.), Decision making under stress: Implications for training and simulation (pp. 115-153). Washington, DC: APA Books.

Kozlowski, S. W. J., \& Ilgen, D. R. (2006). Enhancing the effectiveness of work groups and teams. Psychological Science in the Public Interest, 7, 77-124.

Kozlowski, S. W. J., \& Bell, B. S. (2003). Work groups and teams in organizations. In W. C. Borman, D. R. Ilgen, \& R. J. Klimoski (Eds.), Handbook of psychology: Industrial and organizational psychology (Vol. 12, pp. 333-375). New York: Wiley.

LePine, J. A., Piccolo, R. F., Jackson, C. L., Mathieu, J. E., \& Saul, J. R. (2008). A meta-analysis of teamwork processes: Tests of a multidimensional model and relationships with team effectiveness criteria. Personnel Psychology, 61, 273-307.

Lewis, K., Lange, D., \& Gillis, L. (2005). Transactive memory systems, learning, and learning transfer. Organization Science, 1616), 581-598.

London, M., Polzer, J. T., \& Omoregie, H. (2005). Interpersonal congruence, transactive memory, and feedback processes: An integrative model of group learning. Human Resource Development Review, 4(2), 114-135.

London, M., \& Sessa, V. I. (2006). Group feedback for continuous learning. Human Resource Development Review, 5(3), 1-27.

London, M., \& Smither, J. W. (1995). Can multi-source feedback change perceptions of goal accomplishment, self-evaluations, and performance-related outcomes? Theory based applications and directions for research. Personnel Psychology, 48, 803-839.

Matsui, T., Kakuyama, T., \& Onglatco, L. U. (1987). Effects of goals and feedback on performance in groups. Journal of Applied Psychology, 72, 407-415. 
Marks, M. A. (2000). A critical analysis of computer simulations for conducting team research. Small Group Behavior, 31, 653-675.

Marks, M. A., Sabella, M. J., Burke, C. S., \& Zaccaro, S. J. (2002). The impact of cross-training on team effectiveness. Journal of Applied Psychology, 87, 3-13.

Mathieu, J. E., Heffner, T. S., Goodwin, G. F., Salas, E., \& Cannon-Bowers, J. A. (2000). The influence of shared mental models on team process and performance. Journal of Applied Psychology, $85,273-283$.

Mathieu, J. E., \& Rapp, T. L. (2009). Laying the foundation for successful team performance trajectories: The role of team charters and performance strategies. Journal of Applied Psychology, 94, 90-103.

McCarthy, A., \& Garavan, T. (2008). Team learning and metacognition: A neglected area of HRD research and practice. Advances in Developing Human Resources, 10, 509-524.

McGrath, J. E. (1986). Studying groups at work: Ten critical needs for theory and practice. In P. Goodman \& Associates (Eds.), Designing effective work groups (pp. 362-391). San Francisco: Jossey-Bass.

McGrath, J. E., \& L. Argote. (2001). Group processes in organizational contexts. In M. A. Hogg, R. S. Tindale (Eds.), Blackwell Handbook of Social Psychology, (Group Processes, Vol. 3, pp. 603627). Oxford, UK: Blackwell.

Mesch, D. J., Farh, J. L., \& Podsakoff, P. M. (1994). Effects of feedback sign on group goal setting, strategies, and performance. Group and Organization Management, 19, 309-333.

Mitchell, T. R., \& James, L. R. (2001). Building better theory: Time and the specification of when things happen. Academy of Management Review, 26, 530 - 547.

Moreland, R. L. (2010). Are dyads really groups? Small Group Research, 41, 251-267.

Moreland, R. L., \& Argote, L. (2003). Transactive memory in dynamic organizations. In R. Peterson \& E. Mannix (Eds.), Leading and managing people in the dynamic organization (pp. 135-162). Mahwah, NJ: Erlbaum.

Moreland, R. L., \& McMinn, J. G. (2010). Group reflexivity and performance. In S. R. Thye \& E. Lawler (Eds.), Advances in group processes (Vol. 27, pp. 63-95). Bingley, UK: Emerald Press.

Nadler, D. A. (1979). The effects of feedback on task group behavior: a review of the experimental research. Organization Behavior and Human Performance, 23, 309-338.

Prins, F. J., Sluijsmans, D. M. A., \& Kirschner, P. A. (2006). Feedback for general practitioners in training: quality, styles, and preferences. Advances in Health Sciences Education, 11, 289-303.

Prichard, J. S., Stratford, R. J., \& Bizo, L. A. (2006). Team-skills training enhances collaborative learning. Learning and Instruction, 16, 256-265.

Rico, R., Sánchez-Manzanares, M., Gil, F., \& Gibson, C. (2008). Team implicit coordination processes: A team knowledge based approach. Academy of Management Review, 33, 163-184.

Reagans, R., Argote, L., \& Brooks, D. (2005). Individual experience and experience working together: Predicting learning rates from knowing who knows what and knowing how to work together. Management Science, 51(6), 869-881.

Ruhstaller, T., Roe H., Thurlimann, B., \& Nicoll, J. J. (2006). The multidisciplinary meeting: An indispensable aid to communication between different specialties. European Journal of Cancer, 42, 2459-2462.

Salas, E., Rosen, M. A., Burke, C. S., \& Goodwin, G. F. (2009). The wisdom of collectives in organizations: An update of the teamwork competencies. In E. Salas, G. F. Goodwin, \& C. S. Burke (Eds.), Team Effectiveness in Complex Organizations. Cross-Disciplinary Perspectives and Approaches (pp. 39- 79). New York: Psychology Press.

Salas, E., Sims, D. E., \& Burke, C. S. (2005). Is there "big five" in teamwork? Small Group Research, 36(5), 555-599. 
Schippers, M. C., Den Hartog, D. N., \& Koopman, P. L. (2007). Reflexivity in teams: A measure and correlates. Applied Psychology-An International Review, 5612), 189-211.

Schippers, M. C., Den Hartog, D. N., Koopman, P. L., \& Wienk, J. A. (2003). Diversity and team outcomes: The moderating effects of outcome interdependence and group longevity and the mediating effect of reflexivity. Journal of Organizational Behavior, 24, 779-802.

Van Der Vegt, G. S., \& Bunderson, J. S. (2005). Learning and performance in multidisciplinary teams: the importance of collective team identification. Academy Of Management Journal, 48(3), 532547.

van Ginkel, W. P., \& van Knippenberg, D. (2009). Knowledge about the distribution of information and group decision making: When and why does it work? Organizational Behavior and Human Decision Processes, 108(2), 218-229.

Volpe, C. E., Cannon-Bowers, J. A., Salas, E., \& Spector, P. (1996). The impact of cross-training on team functioning: An empirical investigation. Human Factors, 38, 87-100.

Waller, M. J. (1999). The timing of adaptive group responses to nonroutine events. Academy of Management Journal, 42, 127-137.

Walter, F., \& Van der Vegt, G. S. (2013). Harnessing members' positive mood for team directed learning behavior and team innovation: The moderating role of perceived team feedback. European Journal of Work and Organizational Psychology, 22, 235-248.

Weaver, J. L., Bowers, C. A., Salas, E., \& Cannon-Bowers, J. A. (1995). Networked simulations: New paradigms for team performance research. Behavior Research Methods, Instruments and Computers, 27, 12-24.

Webb, N. M., Nemer, K. M., \& Chizhik, A. W. (1998). Equity issues in collaborative group assessment: Group composition and performance. American Educational Research Journal, 3514), 607-651.

Wildman, J. L., Thayer, A. L., Pavlas, D., Salas, E., Stewart, J. E., \& Howse. W. (2012). Team knowledge research: Emerging trends and critical needs. Human Factors, 54, 84-111.

Williams, K. D. (2010). Dyads can be groups (and often are). Small Group Research, 41, 268-274.

Yoo, Y., \& Alavi, M. (2001) Media and group cohesion: Relative influences on social presence, task participation, and group consensus, MIS Quarterly, 25(3), 371-390.

Yukawa, J. (2006). Co-reflection in online learning: Collaborative critical thinking as narrative. Journal of Computer-supported Collaborative Learning, 1, 203-228. doi: 10.1007/s11412-0068994-9 


\section{Summary}

Teams have emerged as a widespread unit of accomplishment in educational and professional settings. One of the expected yields of team-based education is stimulation of collaborative learning through peer interactions and shared efforts to solve complex problems (Barron, 2000; Kirschner, 2009). Similarly, whether we are referring to medicine, aviation, software development, or even football, teams are frequently at the center of how work is carried out (Kozlowski \& Ilgen, 2006). Work teams interacting and exchanging ideas are expected to acquire and expand their knowledge and skills, and in turn achieve high coordination and performance. In both professional and educational settings, teams are not static entities but dynamic groups. As such, to perform well, they need to continuously iterate cycles of reflection and action during which they can analyze underlying reasons for success and failure and derive lessons for their future actions accordingly (et al., 2010; Edmondson, 1999). In other words, they need to learn collectively. While the importance of team learning is widely accepted, a current challenge for research and practice is to identify interventions that can facilitate the learning potential of teams, since team learning may simply not occur (Edmondson, 1999; Kozlowski \& Ilgen, 2006). To date, too little attention has been paid to the combined effects of different learning processes on team coordination and team performance and on interventions that could instigate team learning and in turn enhance performance. In this dissertation, we contribute to the literature on teams and team learning by 1) identifying key conditions and learning processes enabling efficient coordination and high performance (chapter 2), 2) empirically investigating two interventions (i.e., feedback and guided team reflexivity) that help establish and reinforce positive team behaviors (chapters 2,3,4,5).

Chapter 2 approaches knowledge coordination (i.e., bringing necessary and unevenly distributed knowledge to bearl through the lens of a learning perspective (Wittenbaum, Vaughan, \& Stasser, 1998). In this chapter, we identify four antecedents of team knowledge coordination. First, shared reflection upon team goals, performance, and strategies and development of improvement 
plans (i.e., team reflexivity) are expected to help teams develop and exploit their synergies efficiently (Schippers, Den Hartog, \& Koopman, 2007). Second, coordination also requires knowledge sharing and building (i.e., team learning behaviors). In fact, sharing ideas and knowledge (i.e., construction), collectively building new understandings and insights (i.e., co-construction) and constructively addressing and discussing disagreements (i.e., constructive conflict) are likely to provide teams with more opportunities to learn about each other's' knowledge more directly and accurately (Van den Bossche, Gijselaers, Segers, \& Kirschner, 2006). Finally, we hypothesize that team members will be more likely to interact and engage in collective learning when they strongly believe in their capacity to complete their task (i.e., group potency) and when they are committed to the team task (e.g., task cohesion). Our results validate the importance of these success factors of team coordination. We show that task cohesion is a significant precondition of team learning processes (team learning behaviors and team reflexivityl, that in turn set the stage for effective team coordination, which is a strong predictor of team performance. Further, team members are more likely to use their expertise effectively when they believe they can be effective than when they do not. All these social, cognitive, and motivational factors combine to determine the team's success or failure in coordination, which is related to team performance. In sum, these results suggest that coordination success requires learning moments during which confident and committed team members can share and build upon ideas and information, gently disagree, and monitor progress by reflecting and planning to build on what's working and repair what isn't working optimally. Although this study sheds light on antecedents of team knowledge, more research is needed on understanding predictors of team learning processes. While initial levels of coordination, task cohesion, and group potency combine to explain $28 \%$ of the variance in team learning behaviors, these antecedents account for only $10 \%$ of the variance in team reflexivity. It remains a matter of concern to identify teamlevel inputs or planned interventions that can develop team learning and extent teams' opportunities to do so. Thus, this gap encourages additional research on how team-level interventions instigating team learning can impact future performance, which is the core question addressed in chapters 3, 4, 5.

Chapter 3 presents a review of the literature on team feedback (i.e., information provided by an external agent about aspects of team performance or processes) and identifies the boundary conditions of its effectiveness. Feedback is widely acknowledged to be central not only to motivation by promoting team efforts, but also to learning due to its informational value (Hattie \& Timperley, 2007). Through feedback, teams receive information about the quality of their 
work and knowledge about the effectiveness of their strategies. As such, it is an error detection device and thus can act as a trigger of problem identification and strategy development. By contrast to the well-known effects of individual-level feedback, the effects of feedback on team processes and performance are not as well understood. The review integrates the findings of fifty-nine studies that provide insights into the conditions under which team-level feedback leads to performance improvement. Following conclusions can be drawn. First, feedback has been shown to enhance important team processes le.g., motivation, team goal, and collaboration) and emergent states (e.g., collective efficacy, cohesion, outcome expectations, and task interest), while not all feedback interventions lead to performance improvement. Second, the review describes several conditions under which feedback has positive effects on performance. Feedback should be (a) of high quality (i.e., specific, well-timed, regular, non-threatening, shared, directed at teams it targets, and fairly distributed amongst team members); (b) more appropriate and profitable in certain optimal situations, with higher effects expected in teams comprising no redundant members, working in projects, setting their own goals and strategies or receiving information about goal attainment, given incentives and rewards, believing they are highperforming, and having no unsolved intragroup conflicts and a flexible workload; (c) attended to, perceived as being relevant and useful and (g) processed. However, very little attention has been paid to how feedback is perceived lonly empirically investigated in Walter \& Van der Vegt, 2013) and processed (not investigated), while it has been recognized as a core boundary condition of feedback effectiveness in theoretical work (e.g., London \& Sessa, 2006). This research gap has fueled the two empirical studies presented in chapters 4 and 5. In chapter 4, we focus on how teams naturally deal with performance feedback they receive over a series of tasks and in chapter 5, we compare performance improvement (and deterioration) of teams only given feedback and no processing instruction with teams given feedback and reflective instructions and teams not given feedback nor instructions.

Chapter 4 zooms into how and when teams process feedback they receive about their performance. We propose that teams process feedback by collectively reflecting on their objectives, strategies, and processes li.e., team reflexivity) (Boud \& Molloy, 2013). The concept of team reflexivity is introduced as a set of relevant indicators of feedback processing, more specifically evaluating performance and strategies, looking for alternatives, and making decisions about new ways to tackle the task. Second, we address the issue of time and timing of team reflexivity. For example, does team reflexivity during action and during feedback increase, decrease, or stay stable over time? Additionally, we 
explore the relation between the timing at which team reflexivity occurs (during action or during feedback and during the early interactions or later interactions of the team) and its relation to performance. In the study presented in chapter 4 , dyads performing a flight simulation, more specifically four landing tasks of increasing complexity, were given time-outs from action during which feedback about their prior performance was made available. We coded reflective communication on the basis of utterances of reflective behaviors and explored phases (or "when", specifically action or feedback, earlier or later interaction) in which some performance events (i.e., crashes and errors) were related to team reflective behaviors. The results show that teams do not spontaneously perform sequences of all three behaviors that altogether form complete reflective cycles. They only complete sequences of two behaviors starting by evaluating and looking for alternatives and ending with a decision (or conclusion). This is an indication of teams' natural tendency to regularly "skip" the analysis of their performance or the inventory of possible alternative ways of performing the task (which is the less frequent behavior overall). Surprisingly, the frequencies of evaluating (the most frequent behavior overall) and making decisions grow over time during action only, suggesting a sub-optimal use of feedback times to stop and reflect and thus missed opportunities to act upon feedback. Additionally, timing of team reflectivity appears to have a key role in its effects on performance. For example, whereas early decision-making impedes subsequent performance (van Ginkel \& van Knippenberg, 2009), evaluating during subsequent feedback is associated with improved subsequent performance. Thus, when in the workflow reflection occurs might have an impact on whether or not it will positively influence future performance. Finally, the study challenges the common assumption that more reflection leads to better performance since we do also find a relation between initial performance and subsequent reflection. This finding suggests that bi-directional relationships exist between team processes and performance. To conclude, since teams seldom reflect in a systematic way, it might be that an intervention instigating reflection during time-outs is beneficial to team performance. This is the focus of chapter 5 that presents and empirically tests a targeted intervention stimulating an iterative three-step reflective cycle that involves evaluating performance and strategies, looking for alternatives, and making decisions le.g., Schippers et al., 2007; Yukawa, 2006).

In Chapter 5, we introduce "Guided reflexivity", which is a structured intervention providing time, space, and guidelines lor steps that teams are expected to follow) explicitly instructing team members to attend to and reflect upon feedback as a team and thus to analyze prior performance, brainstorm 
about alternatives, and derive new goals, strategies, and procedures between performance episodes (Gurtner et al., 2007; van Ginkel \& van Knippenberg, 2009). The chapter describes a study which investigated whether team feedback itself and its combination with guided reflexivity as tool to foster feedback processing have an impact on team performance change compared to a control group in a series of tasks in a PC-based flight simulator. Latent growth curve modeling shows that teams in the feedback and guided reflexivity condition show better performance than the teams in the feedback only condition and in the control condition at the second and third of four measurement points (times 2 and 3). These teams even start with a sharper learning curve (faster rate of change from Time 1 to Time 2) suggesting the combination of these two interventions can speed up the learning of a new task. At time 4, however, the teams of the three conditions differ no more with regard to their performance. Several alternate explanations can be advanced to explain why the effects of both components seem to fade away with time. For example, it might be explained by the more rapid increase in complexity and thus cognitive load from task 3 to task 4 . Performing the very complex task might cognitively overwhelm teams and as a consequence they may abandon the implementation of previously agreed upon strategies that would require additional cognitive resources (Kirschner, Paas, \& Kirschner, 2009). Also, limited expertise increases the amount of cognitive load necessary to obtain and use relevant information to succeed in a task. Another plausible explanation for this outcome is the lack of transfer between tasks due to the team inability to perceive sufficient similarities between the previous tasks and the more complex task. This failure in perception of analogies may have lead teams to drop strategies and remedies identified as being obsolete and inapplicable. To conclude, by investigating reflexivity as a tool to support feedback processing the study contributes to theoretical development in the area of feedback research. The investigation of feedback and reflexivity as interventions to support team performance is of great importance for different application contexts. Moreover, we demonstrate that we cannot consider feedback delivery without considering feedback reception. Teams are at the heart of the feedback process; they have an important role in the impact of feedback on their own behaviors. Since these benefits do not endure over time in our study, more research in applied settings and for longer periods of time seems warranted to identify possible enabling conditions (such as the level of support and guidance). 


\section{REFERENCES}

Barron, B. (2000). Achieving coordination in collaborative problem-solving groups. The Journal of the Learning Sciences, 9, 403-436.

Boud, D., \& E. Molloy. (2013). Rethinking Models of Feedback for Learning: The Challenge of Design. Assessment \& Evaluation in Higher Education, 3816), 698-712.

Decuyper, S., Dochy, F., \& Van den Bossche, P. (2010). Grasping the dynamic complexity of team learning: An integrative model for effective team learning in organizations. Educational Research Review, 5, 111-133.

Edmondson, A. C. (1999). Psychological safety and learning behavior in work teams. Administrative Science Quarterly, 44, 350-383.

Gurtner, A., Tschan, F., Semmer, N. K., \& Nagele, C. (2007). Getting groups to develop good strategies: Effects of reflexivity interventions on team process, team performance, and shared mental models. Organizational Behavior and Human Decision Processes, 102, 127-142.

Hattie, J., \& Timperley, H. (2007). The power of feedback. Review of Educational Research, 771), 81 112.

Kirschner, P. A. (2009). Epistemology or pedagogy, that is the question. In S. Tobias \& T. M. Duffy. Constructivist theory applied to instruction: Success or failure? New York: Routledge.

Kirschner, F., Paas, F., \& Kirschner, P. A. (2009). A cognitive load approach to collaborative learning: United brains for complex tasks. Educational Psychology Review, 21, 31-42.

Kozlowski, S. W. J., \& Ilgen, D. R. (2006). Enhancing the effectiveness of work groups and teams. Psychological Science in the Public Interest, 7, 77-124.

London, M., \& Sessa, V. I. (2006). Group feedback for continuous learning. Human Resource Development Review, 5(3), 1-27.

Schippers, M. C., Den Hartog, D. N., \& Koopman, P. L. (2007). Reflexivity in teams: A measure and correlates. Applied Psychology-An International Review, 56(2), 189-211.

Van den Bossche, P., Gijselaers, W., Segers, M., \& Kirschner, P. A. (2006). Social and Cognitive Factors Driving Teamwork in Collaborative Learning Environments. Team Learning Beliefs \& Behaviors. Small Group Research, 375), 490-521.

van Ginkel, W. P., \& van Knippenberg, D. (2009). Knowledge about the distribution of information and group decision making: When and why does it work? Organizational Behavior and Human Decision Processes, 108(2), 218-229.

Walter, F., \& Van der Vegt, G. S. (2013). Harnessing members' positive mood for team directed learning behavior and team innovation: The moderating role of perceived team feedback. European Journal of Work and Organizational Psychology, 22, 235-248.

Wittenbaum, G. M., Vaughan, S. I., \& Stasser, G. (1998). Coordination in task performing groups. In R. S. Tindale, L. Heath, J. Edwards, E. J. Posevac, F. B. Bryant, J. Myers, et al. (Eds.), Theory and research on small groups (pp. 177-204). New York: Plenum Press.

Yukawa, J. (2006). Co-reflection in online learning: Collaborative critical thinking as narrative. Journal of Computer-supported Collaborative Learning, 1, 203-228. doi: 10.1007/s11412-0068994-9 


\title{
Valorization Addendum
}

\begin{abstract}
"Why is it that bringing more experts does not always bring more expertise?" "Why is it that meetings with team mates can sometimes be so frustrating?" "Why is it that we seem to repeat the same failures?"
\end{abstract}

Anyone who has experienced small group work in higher education assignments or at work can recall an instance in which they have been part of a team that performed exceptionally well, enhanced its processes over time and whose members emerged greater, fulfilled, and more competent. However, teams can be loaded with exceptionally smart individuals or highly-skilled students, but still fail to achieve their objectives, improve performance and come away from the experience more frustrated, as can been seen, for example, in top football teams. More crucially, many examples of air crashes, medical errors and disasters have been caused by breakdowns of team collaboration. These extreme cases as well as situations in which team members fail to engage in effective teamwork and exhibit poor team performance raise questions of interest. For example, what are the properties of effective teams? What are the most powerful factors that allow teams to build up their power as a collective entity? Besides explaining why some teams thrive and others disappoint, it is important to question possible ways to achieve behavioral changes. What can be done to prevent a downward spiral in performance and help team engage in crucial behaviors that will drive them to success? These questions are at the top of the agenda of higher education institutes that increasingly use forms of collaborative-based learning and organizations in which teams are increasingly the main units of work accomplishment.

Chapter 2 answers the "why question". The exceptional team from the first example had critical team dynamics, while losing football teams at the world cup had not. Effective teams that can use their expertise in an optimal way are cohesive, believe in themselves and are thus more likely to engage in learning activities such as sharing knowledge or information, creating together new ideas 
and insights, reflecting on what they do, how they do it, and why things go wrong. Ultimately, all these factors combine to determine the team's success or failure. Our results suggest that members quickly develop beliefs about their teams and that these are necessary for learning behaviors and processes to emerge. Stated differently, if members do not feel everyone puts effort in the team or their team has the capacity to fulfill the task, they are less likely to take time and effort to learn as a team. As a consequence, during the forming phase of a team, educators, managers, or team leaders responsible for enhancing group coordination and performance should pay specific attention to favorable beliefs and appraisals of the task and team (high cohesion and group potency). This would help reduce tension arising from the feeling of anxiety and uncertainty often observed in newly formed teams. Moreover, during later phases of a team, when team members start to challenge each other, constructive conflict and reflexivity may be critical to support and scaffold so that teams increasingly become more team and self-aware of their own processes. However, in situations where people exchange diverse and challenging perspectives, constructive discussions can easily turn into interpersonal conflict and communication breakdowns. Moreover, we know from research and practice that learning moments in teams are difficult and sparse. Turning potential conflict due to divergent thinking and assumptions into learning activities takes some conscious effort and support. This calls for the implementation of panned interventions aiming at facilitating team learning and maintaining high learning opportunities throughout the team tasks. These formal interventions initiated by educators, leaders, and managers can take place during time-outs from task execution. In organizations, typical team-building exercises such as weekend retreats are not sufficient to change behaviors when team members return to the office. Although out-of the office activities seem to have a positive effect on perceptions and attitudes towards training and are nice occasions for getting to know each other, the effects on behavioral changes are generally less prevalent. Building interdependence and trust, improving communication and instigating learning activities should rather be part of the daily corporate (learning) culture in place of a one-year event.

From chapter 3 , we present feedback interventions as daily practices that can give teams benchmarks about how they perform. In fact, success also requires constant reviews and feedback mechanisms. Teams have to be able to monitor their progress to build on what's working and repair what isn't. Our review study in chapter 3 provides organizations and teachers with insights and tools to support their teams. It highlights that feedback is indeed a potent key practice in which organizations should allocate resources: both trainings le.g., 
on how to provide constructive feedbackl and on-the-job interventions should be tailored to the team situations and characteristics to support life-long learning. In educational settings, teachers should continuously observe their students when engaged in a team task so that they can provide them with timely feedback that could help teams optimize their teamwork. Usually, teams receive a team grade at the end of their assignment and are not monitored during the process when they may benefit and learn most from it to make improvements.

Moreover, process feedback interventions could influence important interaction processes and team properties that facilitate learning and performance. In order for a team to function effectively, it is essential for its members to improve their team skills and communication. These team skills necessitate different feedback interventions conveying information about how teams communicate, interact, establish the team atmosphere, define their team objectives, strategies, monitor their performance, come to a common understanding of the task and its requirements, build upon each other's expertise, make team decisions, or coordinate in an efficient way. Process feedback helps team members identify specific areas for improvement and ways to improve. For example, teams displaying problems of communication or irrelevant strategies may lack information about what and how to improve or may not be aware of their behaviors. Since feedback has so many facets and can be augmented in various ways, teachers, managers, and trainers should first pay attention to the team setting, context, and characteristics, observe and monitor their teams on a regular basis to develop relevant team interventions that facilitate and reinforce positive team behaviors and in turn, performance. Moreover, implementing a feedback intervention acts as a prescriptive reference against which teams can evaluate their own behaviors. It helps them understand what is meant by effective (team)work in their specific setting and provide them with an opportunity to learn.

While practitioners agree that team effectiveness depends on accurate and timely feedback, in many professions (such as healthcare, aviation, business), how feedback is provided to teams is usually very much embedded in hierarchical endeavors. Even when the importance of two-way interactions is acknowledged, feedback often remains a superior-driven, one-way process from the expert to the novice. And often, superiors believe that they give feedback regularly but people do not always recognize it. Feedback provision is also frequently not a priority in busy, time-constrained settings. Consequently, there are a lot of missed opportunities to use feedback to improve immediate practice and how the team is going to handle future similar situations. As such, it is important for managers to install a feedback culture by, for example, explicitly 
recognizing the value of feedback, modeling the use of constructive feedback, acknowledging an open-door culture, and implementing regular feedback moments.

Yet, we have learned from chapters 4 and 5 that organizing feedback moments is not sufficient since outcome feedback is purely evaluative in nature. The reflective process that follows this feedback is the most important part of the procedure if one seeks to improve the ability to draw lessons from prior experiences and eventually generate a behavioral change. In the reflection procedure that follows feedback delivery, feedback receivers need to take an active part in the analysis of their performance data and in the generation of reasons why things went right or wrong. Another challenging issue is motivational. Despite the promising effects of systematic reflection, for most individuals and teams reflection is possibly the least preferred activity. As a consequence, teams need support to help them systematically analyze the decisions that produced their performance outcomes.

Chapter 5 shows that teams gain even more when occasions are provided for "guided reflexivity". The latter provides teams guided opportunity to learn from past experiences, and to discuss consequences for future actions. Teams which are capable to reflect on their past experience outperformed teams with performance feedback or no feedback. However, we found as well, that teams that engaged in activities for reflexivity also encountered higher likelihood for conflict. This implies that teams should be trained in how to deal with reflexivity (looking forward) without getting engaged in situational or personal conflict. This requires preparing teams on how to use the results of reflective activities for their own benefits, without getting immersed in conflict situations. Teams need to be supported in their teamwork skills, but leaders also need to be supported in developing strategy-focused approaches. For example, they should learn to anticipate the emotional responses to feedback they give, offer appropriate facilitated support and stimulate the search for practical solutions. They need to be trained and resourced to provide the high-quality facilitative support needed to increase the positive effects of their feedback. The creation of a feedback culture also takes time since feedback needs to get embedded implicitly and explicitly in all activities in which team members can get valuable feedback and in turn ask for feedback and give feedback to each other openly. Early training and repeated experience with feedback delivery and reflection facilitation may improve the feedback culture and overall performance over time. Feedback opportunities must be actively sought and encouraged and data should be constantly collected to discuss future plans for learning and development at the team level. 
To conclude, members of organizations continually face an increasing amount of complex tasks and systems, resulting in multi-professional teamwork, and the necessity to share knowledge and experiences with a high diversity of specialized disciplines. While specialized knowledge has improved organizational performance substantially, it has introduced new challenges such as the necessity to share knowledge, build common understanding, capitalize on one another's resources and skills, coordinate well, and learn as a collective to maintain high performance. Additionally, while people assume they "know" how to turn a team into an effective and efficient entity, the challenge of turning knowledge into action is a key issue in organizations. Teams often know more than they are able to act upon. As a consequence, effective collaboration must be learned and necessitates guidance, instruction, and training. Feedback and guidance can help make concrete action plans to improve task performance and to cause changes in interpersonal behavior. 



\section{About the Author}

Catherine Gabelica (1983) earned her Master degree (Magna Cum Laude) in Educational Sciences from The University of Liège, Belgium (2006). In 2006, she started her academic career as a junior researcher in the Department of Educational Systems and Practices at the Faculty of Psychology and Educational Sciences of the University of Liège. She was in charge of educational research and training such as assessment of school achievement, international comparative studies (Pirls and PISA), external assessment in the Frenchspeaking community of Belgium, and development of mother tongue-based literacy instruments. She also has experience in adult education counseling through her affiliation to a training center, in which she is been helping professionals of diverse disciplines design effective training systems and facilitate trainees' learning. In 2009, her high interest for learning and development of individuals and teams drove her to complete her PhD on the influence of feedback interventions and guided reflection on future team performance. Her current research projects involve the measurement and facilitation of team learning processes in terms of knowledge sharing/building and reflection and the analysis of communication style in innovative work settings. The highlights of 2014 include the winning of the New Investigator Award of the American Educational Research Association (AERA) of the Division "Education In the Professions" and the recent publication of an article on the effects of feedback interventions on team performance change in the journal Learning and Instruction. Additionally, she is in charge of educational advice on innovation in higher education (e.g., e-portfolios, entrepreneurship projects) and curriculum development and teaching in Bachelor and Master programs le.g., Professional Development \& Human Performance; Supporting Learning at the Workplace; Quantitative Research Methods). 


\section{LIST OF PUBLICATIONS}

\section{Journal articles}

Gabelica, C., Van den Bossche, P., Segers, M., \&Gijselaers, W. (2014). The effect of team feedback and guided reflexivity on team performance change. Learning and instruction, 34, 86-96. doi: 10.1016/j.learninstruc.2014.09.001

Gabelica, C., Van den Bossche, P., Segers, M., \& Gijselaers, W. (2014). Dynamics of team reflexivity after feedback. Frontline Learning Research, 212), 64-91. doi:10.14786/flr.v2i2.79

Gabelica, C., Van den Bossche, P., Segers, M., \& Gijselaers, W. (2012). Feedback, a powerful level in teams: A review. Educational Research Review, 7(2), 123-144. doi:10.1016/j.bbr.2011.03.031

Gabelica, C. (2006). Apports possibles des stratégies d'enseignement en immersion dans des classes multiculturelles. Les Cahiers des Sciences de l'Education, 25-26, 29-40.

\section{Resubmitted}

Gabelica, C., Fiore, S. M., Van den Bossche, P., Segers, M., \& Gijselaers, W. (resubmitted). Establishing team coordination from a learning perspective.

\section{Proceedings}

Gabelica, C. \& Fiore, S. M. (2013). PBL, TBL, and SBL: What can training researchers gain from examination of methods for active-learning. Proceedings of 57th Annual Meeting of the Human Factors and Ergonomics Society (pp. 462466). Santa Monica, CA: Human Factors and Ergonomics Society.

\section{Chapter in book}

Gabelica, C., \& Shillings, P. (2010). Involving Students in Texts. In C. Garbe, K. Holle, \& S. Weinhold (Ed.), ADORE-Teaching Struggling Adolescent Readers in European Countries (pp.114-122), Frankfurt am Main, Berlin, Bern, Bruxelles, New York, Oxford, Wien: Peter Lang. 


\section{Conference papers}

Fiore, S. M., Gabelica, C. \&. Hall, K. L. (2014). Education and Training for Team Science. Presented at the 5th Annual Science of Team Science Conference. August 6-8, Austin, TX, USA.

Gabelica, C., Van den Bossche, P., Segers, M., \& Gijselaers, W. (2014). Reflecting on feedback: A dynamic perspective. Paper presented at the EARLI-sig Professional Development and Learning, August 27-30, Oslo, Norway.

Gabelica, C., Van den Bossche, P., Segers, M.,\& Gijselaers, W. (2014). Dynamics of Team Reflexivity. Paper presented at the InGroup conference, July, 17-19 2014, Raleigh, USA.

Gabelica, C., \& Fiore, S. M. (2013). Learning how to be a (team) scientist. Presented at the 4th Annual Science of Team Science Conference, June 24-27, Northwestern University, Evanston, IL.

Gabelica, C., Van den Bossche, P., Segers, M., \& Gijselaers, W. (2013). Looking inside the Box: Cognition as Way to Achieve Team Effectivness in Work Teams. Symposium presented at the European Association of Work and Organizational Psychology Conference (EAWOP), May 22-25 2013, Münster, Germany.

Gabelica, C., Van den Bossche, P., Segers, M., \& Gijselaers, W. (2013). Improving performance in teams through team-level feedback and guided reflexivity: a comparative study. Paper presentred in a Team Learning symposium at the 15th Biennial EARLI Conference for Research on Learning and Instruction (EARLI), August 27-31, Munich, Germany.

Gabelica, C., Van den Bossche, P., Segers, M., \& Gijselaers, W. (2013). Reflection on and for Action: a Powerful Intervention for team Effectiveness. Paper presented at the American Educational Research Association (AERA), April 27May 1 2013, San Franscisco, California, USA.

Gabelica, C., Van den Bossche, P., Segers, M., \& Gijselaers, W. (2013). When do Professional teams learn to Perform: how Coordination Impacts Performance. Paper presented at the American Educational Research Association (AERA), Division-I Winner of the New Investigator Award, April 27-May 1 2013, San Franscisco, California, USA. 
Gabelica, C., Van den Bossche, P., Segers, M., \& Gijselaers, W. (2012). Feedback as a team-level intervention to enhance team performance and team learning. Paper presented at the EARLI-sig Professional Development and Learning, Antwerp, Belgium.

Gabelica, C., Van den Bossche, P., Segers, M., \& Gijselaers, W. (2012). Dynamics of team coordination from a team learning perspective. Paper presented at the InGroup conference, July, 12-14 2012, Chicago, USA.

Gabelica, C., Van den Bossche, P., Segers, M., \& Gijselaers, W. (2011). How Teams Develop Their Collective Power: Team Interpersonal Context and Learning Behaviors as Socio-Cognitive Factors. Paper presented at the Junior researchers' pre-conference (JURE), August 29-30 2011, Exeter, England.

Gabelica, C., Van den Bossche, P., Segers, M., \& Gijselaers, W. (2011). Feedback in Teams: a Review. Paper presented at the 18th Educational Innovation in Economics and Business Conference (EDiNEB), June 7-10 2011, Lyon France.

Gabelica, C., Van den Bossche, P., Segers, M., \& Gijselaers, W. (2011). Enhancing Coordination in Teams: Team Learning Behaviors and Task Cohesion as Powerful Socio-Cognitive Factors. Paper presented at the European Association of Work and Organizational Psychology Conference (EAWOP), May 25-28 2011. Maastricht, The Netherlands.

Gabelica, C., Van den Bossche, P., Segers, M., \& Gijselaers, W. (2011). Feedback as a team-design practice: A Review. Paper presented at the American Educational Research Association (AERA), April 8-April 12 2011, New Orleans, Louisiana, USA.

Gabelica, C., Van den Bossche, P., Segers, M., \& Gijselaers, W. (2010). Feedback as a team-design practice: A Review. Paper presented at the EARLI-sig Professional Development and Learning, Munchen, Germany. 


\section{ICO Dissertation Series}

In the ICO Dissertation Series the dissertations of graduate students from faculties and institutes on educational research within the ICO Partner Universities are published: Eindhoven University of Technology, Leiden University, Maastricht University, Open University of the Netherlands, University of Amsterdam, University of Twente, Utrecht University, VU University Amsterdam, and Wageningen University, and formerly University of Groningen (until 2006), Radboud University Nijmegen (until 2004), and Tilburg University (until 2002). The University of Groningen, University of Antwerp, University of Ghent, and the Erasmus University Rotterdam have been 'ICO 'Network partner' in 2010 and 2011. Below is a list of the most recent dissertations:

240. Lomos, C. (29-03-2012). Professional community and student achievement. Groningen: University of Groningen.

241. Mulder, Y.G. (19-04-2012). Learning science by creating models. Enschede: University of Twente

242. Van Zundert, M.J. (04-05-2012). Optimising the effectiveness and reliability of reciprocal peer assessment in secondary education. Maastricht: Maastricht University.

243. Ketelaar, E. (24-05-2012). Teachers and innovations: on the role of ownership, sense-making, and agency. Eindhoven: Eindhoven University of Technology.

244. Logtenberg, A. (30-5-2012). Questioning the past. Student questioning and historical reasoning. Amsterdam: University of Amsterdam.

245. Jacobse, A.E. (11-06-2012). Can we improve children's thinking? Groningen: University of Groningen.

246. Leppink, J. (20-06-2012). Propositional manipulation for conceptual understanding of statistics. Maastricht: Maastricht University.

247. Andel, J (22-06-2012). Demand-driven Education. An Educationalsociological Investigation. Amsterdam: VU University Amsterdam. 
248. Spanjers, I.A.E. (05-07-2012). Segmentation of Animations: Explaining the Effects on the Learning Process and Learning Outcomes. Maastricht: Maastricht University.

249. Vrijnsen-de Corte, M.C.W. Researching the Teacher-Researcher. Practicebased research in Dutch Professional Development Schools Eindhoven: Eindhoven University of Technology.

250. Van de Pol, J.E. (28-09-2012). Scaffolding in teacher-student interaction. Exploring, measuring promoting and evaluating scaffolding. Amsterdam: University of Amsterdam.

251. Phielix, C. (28-09-2012). Enhancing Collaboration through Assessment \& Reflection [Samenwerking Verbeteren door middel van Beoordeling en Reflectie]. Utrecht: Utrecht University.

252. Peltenburg, M.C. (24-10-2012). Mathematical potential of special education students. Utrecht: Utrecht University.

253. Doppenberg, J.J. (24-10-2012). Collaborative teacher learning: settings, foci and powerful moments. Eindhoven: Eindhoven University of Technology.

254. Kenbeek, W.K. (31-10-2012). Back to the drawing board. Creating drawing or text summaries in support of System Dynamics modeling. Enschede: University of Twente.

255. De Feijter, J.M. (09-11-2012). Learning from error to improve patient safety. Maastricht: Maastricht University.

256. Timmermans, A.C. (27-11-2012). Value added in educational accountability: Possible, fair and useful? Groningen: University of Groningen.

257. Van der Linden, P.W.J. (20-12-2012). A design-based approach to introducing student teachers in conducting and using research. Eindhoven: Eindhoven University of Technology.

258. Noroozi, 0. (11-01-2013). Fostering Argumentation-Based ComputerSupported Collaborative Learning in Higher Education. Wageningen: Wageningen University.

259. Bijker, M.M. (22-03-2013). Understanding the gap between business school and the workplace: Overconfidence, maximizing benefits, and the curriculum. Heerlen: Open University of the Netherlands.

260. Belo, N.A.H. (27-03-2013). Engaging students in the study of physics. Leiden: Leiden University.

261. Jong, R.J. de (11-04-2013). Student teachers' practical knowledge, discipline strategies, and the teacher-class relationship. Leiden: Leiden University. 
262. Verberg, C.P.M. (18-04-2013). The characteristics of a negotiated assessment procedure to promote teacher learning. Leiden: Leiden University.

263. Dekker-Groen, A. (19-04-2013). Teacher competences for supporting students' reflection. Standards, training, and practice. Utrecht: Utrecht University.

264. M.H. Knol (19-04-2013). Improving university lectures with feedback and consultation. Amsterdam: University of Amsterdam.

265. Diggelen, M.R. van (21-05-2013). Effects of a self-assessment procedure on VET teachers' competencies in coaching students' reflection skills. Eindhoven: Eindhoven University of Technology.

266. Azkiyah, S.N. (23-5-2013). The effects of Two Interventions - on Teaching Quality and Student Outcome. Groningen: University of Groningen.

267. Taminiau, E.M.C. (24-05-2013). Advisory Models for On-Demand Learning. Heerlen: Open University of the Netherlands.

268. Milliano, I.I.C.M. de (24-05-2013). Literacy development of low-achieving adolescents. The role of engagement in academic reading and writing. Amsterdam: University of Amsterdam.

269. Vandyck, I.J.J. (17-06-2013). Fostering Community Development in SchoolUniversity Partnerships. Amsterdam: VU Universtiy Amsterdam.

270. Hornstra, T.E. (17-06-2013). Motivational developments in primary school. Group-specific differences in varying learning contexts. Amsterdam: University of Amsterdam.

271. Keuvelaar-Van den Bergh, L. (26-06-2013). Teacher Feedback during Active Learning: The Development and Evaluation of a Professional Development Programme. Eindhoven: Eindhoven University of Technology.

272. Meeuwen, L.W. van (06-09-13). Visual Problem Solving and Self-regulation in Training Air Traffic Control. Heerlen: Open University of the Netherlands.

273. Pillen, M.T. (12-09-2013). Professional identity tensions of beginning teachers. Eindhoven: Eindhoven University of Technology.

274. Kleijn, R.A.M. de, (27-09-2013). Master's thesis supervision. Feedback, interpersonal relationships and adaptivity. Utrecht: Utrecht University.

275. Bezdan, E. ( 04-10-2013). Graphical Overviews in Hypertext Learning Environments: When One Size Does Not Fit All. Heerlen: Open University of the Netherlands.

276. Bronkhorst, L.H. (4-10-2013). Research-based teacher education: Interactions between research and teaching. Utrecht: Utrecht University. 

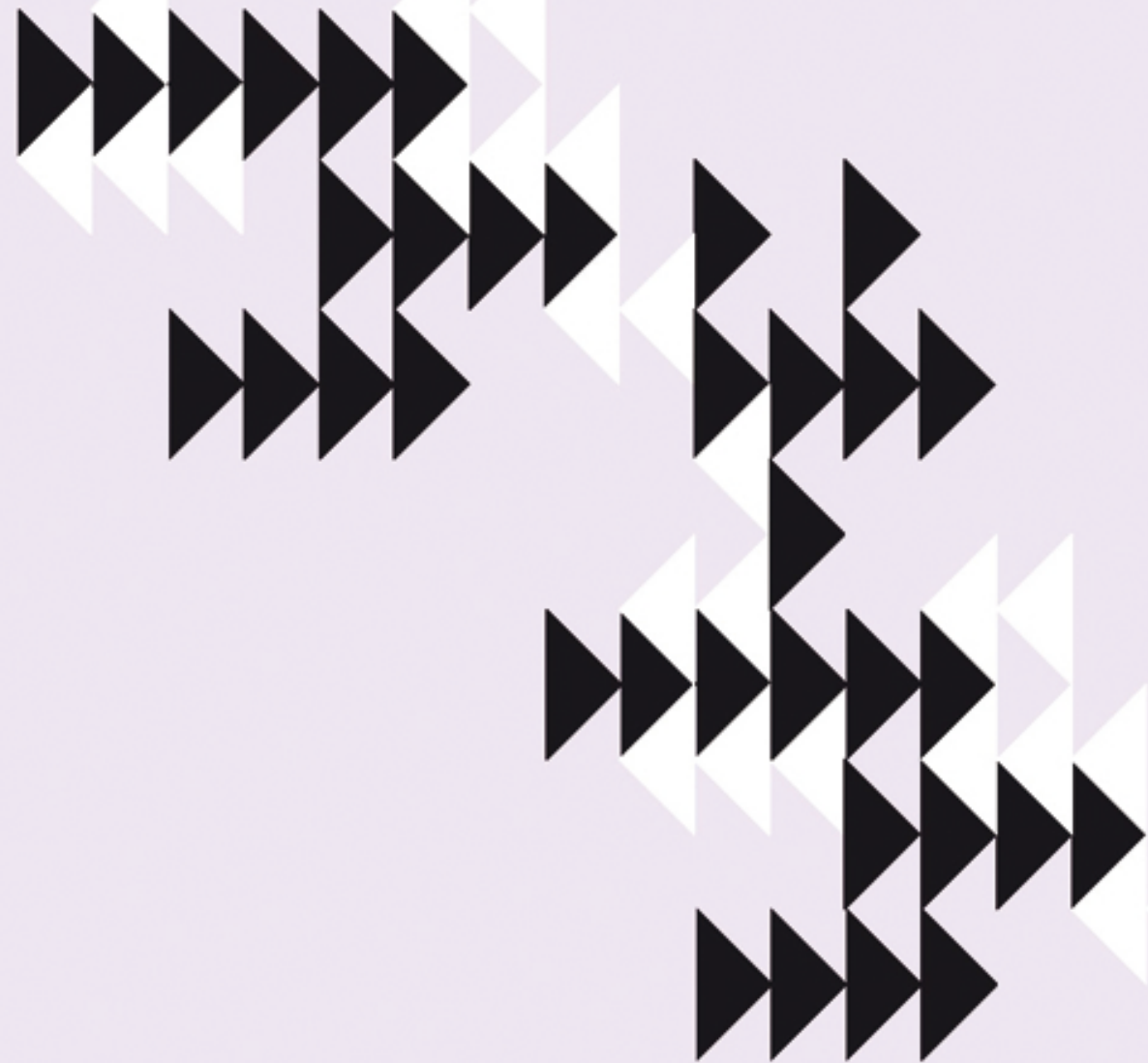

MOVING TEAMS FORWARD

Catherine Gabelica 